$(00-1012)$

Original: English

\title{
CANADA - PATENT PROTECTION OF PHARMACEUTICAL PRODUCTS
}

\author{
Complaint by the European Communities and their member States
}

\section{Report of the panel}

The report of the Panel on Canada - Patent Protection of Pharmaceutical Products is being circulated to all Members, pursuant to the DSU. The report is being circulated as an unrestricted document from 17 March 2000 pursuant to the Procedures for the Circulation and Derestriction of WTO Documents (WT/L/160/Rev.1). Members are reminded that in accordance with the DSU only parties to the dispute may appeal a panel report, an appeal shall be limited to issues of law covered in the panel report and legal interpretations developed by the panel, and that there shall be no ex parte communications with the panel or Appellate Body concerning matters under consideration by the panel or Appellate Body.

Note by the Secretariat: This Panel Report shall be adopted by the Dispute Settlement Body (DSB) within 60 days after the date of its circulation unless a party to the dispute decides to appeal or the DSB decides by consensus not to adopt the report. If the Panel Report is appealed to the Appellate Body, it shall not be considered for adoption by the DSB until after the completion of the appeal. Information on the current status of the Panel Report is available from the WTO Secretariat. 



\section{TABLE OF CONTENTS}

I. INTRODUCTION 1

II. FACTUAL ASPECTS 1

(a) Relevant Provisions of Canadian Patent Law 1

(b) Canada's Regulatory Review System for Drugs 3

III. FINDINGS AND RECOMMENDATIONS REQUESTED BY THE PARTIES 7

IV. ARGUMENTS OF THE PARTIES 9

A. EUROPEAN COMMUNITIES AND THEIR MEMBER STATES 9

(1) SECTION 55.2(2) AND 55.2(3) OF THE PATENT ACT TOGETHER WITH THE MANUFACTURING AND STORAGE OF PATENTED MEDICINES REGULATIONS 9

(a) Article 28.1 and Article 33 of the TRIPS Agreement 9

(b) Article 27.1 of the TRIPS Agreement 10

(2) SECTION 55.2(1) OF THE PATENT ACT 10

(a) Article 28.1 of the TRIPS Agreement 10

(b) Article 27.1 of the TRIPS Agreement 12

(3) HISTORICAL DEVELOPMENTS IN CANADIAN PATENT LEGISLATION AND COMPARISON BETWEEN THE SITUATION IN CANADA BEFORE AND AFTER THE INTRODUCTION OF BILL C-91 AND THE MANUFACTURING AND STORAGE OF PATENTED MEDICINES REGULATIONS IN 1993

(4) ECONOMIC LOSSES SUFFERED BY THE EU PHARMACEUTICAL INDUSTRY 15

(5) ARTICLE 30 OF THE TRIPS AGREEMENT 16

B. CANADA 16

(1) ARTICLE 30 OF THE TRIPS AGREEMENT 16

$\begin{array}{lr}\text { (a) Object, Purpose and Meaning } & 18\end{array}$

(i) Section 55.2(1) and 55.2(2) create limited exceptions 21

(ii) Section 55.2(1) and 55.2(2) do not conflict with a normal
exploitation of the patent

(iii) Section 55.2(1) and 55.2(2) do not prejudice the legitimate

(iv) Section 55.2(1) and 55.2(2) take account of the legitimate
interests of third parties

(b) Travaux Préparatoires and Subsequent Practice 27 
WT/DS114/R

Page ii

(2) ARTICLE 27.1 OF THE TRIPS AGREEMENT

(a) Object, Purpose and Meaning 30

(b) Travaux Préparatoires and Subsequent Practice 31

(c) Section 55.2(1) and 55.2(2) are not Discriminatory 32

(3) ARTICLE 33 OF THE TRIPS AGREEMENT 33

(a) Object, Purpose and Meaning 33

(b) Section 55.2(1) and 55.2(2) do not Reduce the Required Minimum
Term of Protection

(4) THE LEGISLATIVE HISTORY OF THE DISPUTED PROVISIONS, THEIR

FRAMING, THEIR LEGISLATIVE CONTEXT AND THE DEBATE ON

COST CONTAINMENT AND GENERIC DRUGS 34

(a) The Legislative History of the Disputed Provisions 35

(b) The Framing of the Disputed Provisions 37

(c) The Legislative Context 39

(d) Cost Containment and Generic Drugs $\quad 40$

C. EUROPEAN COMMUNITIES AND THEIR MEMBER STATES

(1) ARTICLE 27.1 OF THE TRIPS AGREEMENT 47

(2) ARTICLE 30 OF THE TRIPS AGREEMENT 49

(a) Preliminary Remarks $\quad 50$

(i) The Preamble of the TRIPS Agreement and its Articles 1.1, 7 and $8.1 \quad 51$

(b) Interpretation of the Conditions Enumerated in Article 30 for the Grant of Exceptions to Rights Conferred

(i) The "prior use" exception 54

(ii) The "scientificlexperimental use" exception 55

(c) Section 55.2(2) and 55.2(3) of the Canadian Patent Act together with the Manufacturing and Storage of Patented Medicines Regulations 56

(i) "Limited" 56

(ii) "Do not unreasonably conflict with a normal exploitation
of the patent"

(iii) "Do not unreasonably prejudice the legitimate interests of the patent owner, taking account of the legitimate interests of third parties"

(d) Section 55.2(1) of the Canadian Patent Act 59

(i) "Limited" 59

(ii) "Do not unreasonably conflict with a normal exploitation of
the patent"

(iii) "Do not unreasonably prejudice the legitimate interests of the patent owner, taking account of the legitimate interests of third parties" 
(a) Section 55.2(2) and 55.2(3) of the Canadian Patent Act together with the Manufacturing and Storage of Patented Medicines

Regulations

61

(b) Section 55.2(1) of the Canadian Patent Act

D. CANADA

(1) PRELIMINARY POINTS

(a) Section 55.2(1) and 55.2(2) of the Canadian Patent Act 64

(b) Subsequent Practice

(2) ARTICLE 27.1 OF THE TRIPS AGREEMENT 66

(3) ARTICLE 30 OF THE TRIPS AGREEMENT 70

(a) Articles 7 and 8 of the TRIPS Agreement 71

(b) Interpretation of the Conditions Enumerated in Article 30 for the
Grant of Exceptions to Rights Conferred

(i) The "prior use" exception $\quad 73$

(ii) The "scientific/experimental use" exception 74

(c) Section 55.2(1) and 55.2(2) of the Canadian Patent Act 76

(i) "Limited" 76

(ii) "Do not unreasonably conflict with a normal exploitation
of the patent"

(iii) "Do not unreasonably prejudice the legitimate interests of the patent owner, taking account of the legitimate interests of third parties"

(4) EXCEPTION FOR A REGULATORY SUBMISSION TO A "COUNTRY OTHER THAN CANADA"

(a) The Global Nature of the Pharmaceutical Industry 79

(b) The Global Need for Access to Essential Medicines $\quad 80$

(c) The Context of the TRIPS Agreement 81

(d) Foreign Regulatory Approval and Article 30 of the TRIPS Agreement 82

(e) Creation of a Trade Barrier 83

(5) APPLICATION OF ARTICLE 33 OF THE TRIPS AGREEMENT 83

E. EUROPEAN COMMUNITIES AND THEIR MEMBER STATES 83

(1) ARTICLE 27.1 OF THE TRIPS AGREEMENT 84

(2) ARTICLE 30 OF THE TRIPS AGREEMENT 84 
WT/DS114/R

Page iv

F. CANADA

(a) $\quad$ Principles of treaty interpretation $\quad 87$

(i) Subsequent practice $\quad 89$

(ii) Article 27.1 of the TRIPS Agreement 90

(iii) Article 30 of the TRIPS Agreement 91

(iv) Exception for a regulatory submission to a "country
other than Canada"

V. ARGUMENTS PRESENTED BY THIRD PARTIES 94

$\begin{array}{lr}\text { AUSTRALIA } & 94\end{array}$

$\begin{array}{lr}\text { BRAZIL } & 106\end{array}$

$\begin{array}{lr}\text { COLOMBIA } & 108\end{array}$

$\begin{array}{ll}\text { CUBA } & 111\end{array}$

$\begin{array}{ll}\text { INDIA } & 119\end{array}$

$\begin{array}{lr}\text { ISRAEL } & 121\end{array}$

JAPAN

POLAND $\quad 125$

$\begin{array}{lr}\text { SWITZERLAND } & 127\end{array}$

$\begin{array}{ll}\text { THAILAND } & 134\end{array}$

$\begin{array}{ll}\text { UNITED STATES } & 137\end{array}$

VI. INTERIM REVIEW 145

$\begin{array}{lll}\text { VII. FINDINGS } & 146\end{array}$

A. MEASURES AT ISSUE 146

(1) SECTION 5.2(1): THE REGULATORY REVIEW EXCEPTION 146

(2) SECTION 55.2(2): THE STOCKPILING EXCEPTION 148

B. CLAIMS OF THE PARTIES 149

$\begin{array}{ll}\text { C. PRINCIPLES OF INTERPRETATION } & 149\end{array}$

D. BURDEN OF PROOF 150

E. SECTION 55.2(2) (THE STOCKPILING EXCEPTION) 151

(1) APPLICATION OF ARTICLE 28.1 AND ARTICLE 30 OF THE TRIPS AGREEMENT 151

(a) Introduction 151

(b) Object and Purpose 153

$\begin{array}{lr}\text { (c) "Limited Exceptions" } & 154\end{array}$

F. $\quad$ SECTION 55.2(1) (THE REGULATORY REVIEW EXCEPTION) 157

(1) APPLICATION OF ARTICLE 28.1 AND ARTICLE 30 OF THE TRIPS AGREEMENT 157

(a) "Limited Exceptions" 157

(b) "Normal Exploitation" 160

(c) "Legitimate Interests" 162 
(i) Primary EC claim of legitimate interest 162

(ii) Definition of "legitimate interests" 164

(iii) Second claim of legitimate interest 166

(iv) Conclusion with Regard to Compliance of Section 55.2(1)
with Article 30

(2) APPLICATION OF ARTICLE 27.1 OF THE TRIPS AGREEMENT 169

(a) Applicability of Article 27.1 to Article 30 Exceptions 169

(b) Discrimination as to the Field of Technology 171

VIII. CONCLUSIONS 174

$\begin{array}{lll}\text { ANNEX 1: } & \text { DOCUMENT WT/DS114/5 } & 175\end{array}$

ANNEX 2: $\quad$ THE CANADIAN FOOD AND DRUG REGULATIONS -

PART C.08 177

ANNEX 3: $\quad$ LETTER FROM JIM KEON, CANADIAN DRUG

MANUFACTURERS ASSOCIATION TO REAGAN WALKER 190

ANNEX 4: $\quad$ PATENTED MEDICINES (NOTICE OF COMPLIANCE)

REGULATIONS

191

ANNEX 5: $\quad$ QUESTIONS POSED BY THE PANEL AND REPLIES

RECEIVED FROM THE PARTIES AND THIRD PARTIES

ON THE PRACTICE IN COUNTRIES OTHER THAN

CANADA AS REGARDS REGULATORY REVIEW

EXCEPTIONS AND PATENT TERM EXTENSION

OR SUPPLEMENTARY PROTECTION CERTIFICATE

SYSTEMS

199

ANNEX 6: $\quad$ EXCEPTIONS TO RIGHTS CONFERRED BY A

PATENT: SUCCESSIVE URUGUAY ROUND

NEGOTIATING DRAFTS 



\section{INTRODUCTION}

1.1 On 19 December 1997, the European Communities and their member States requested Canada to hold consultations pursuant to Article 4 of the Understanding on Rules and Procedures Governing the Settlement of Disputes (DSU) and Article 64 of the Agreement on Trade-Related Aspects of Intellectual Property Rights (TRIPS) regarding the protection of inventions in the area of pharmaceuticals under the relevant provisions of the Canadian implementing legislation (in particular the Patent Act) in relation to its obligations under the TRIPS Agreement (WT/DS114/1). No mutually satisfactory solution was reached in these consultations, held on 13 February 1998 and 12 June 1998. The European Communities and their member States requested the Dispute Settlement Body (DSB), in a communication dated 11 November 1998, to establish a panel to examine the matter (WT/DS114/5). ${ }^{1}$ At its meeting of 1 February 1999, the DSB agreed to establish a panel with standard terms of reference in accordance with Article 6 of the DSU. Australia, Brazil, Columbia, Cuba, India, Israel, Japan, Poland, Switzerland, Thailand and the United States reserved third party rights.

1.2 In document WT/DS114/6 of 29 March 1999, the DSB was informed of the terms of reference and the composition of the Panel. Due to the absence of agreement between the parties to the dispute on the composition of the Panel, the composition of the Panel was determined by the Director-General pursuant to Article 8.7 of the DSU.

\section{$\underline{\text { Terms of reference }}$}

"To examine, in the light of the relevant provisions of the covered agreements cited by the European Communities and their member States in document WT/DS114/5, the matter referred to the DSB by the European Communities and their member States in that document and to make such findings as will assist the DSB in making the recommendations or in giving the rulings provided for in those agreements."

\section{$\underline{\text { Composition }}$}

Chairman: Mr. Robert Hudec

Members: Mr. Mihály Ficsor

Mr. Jaime Sepúlveda

1.3 The Panel heard the parties to the dispute on 9-10 June and 15 July 1999 . The interim report was issued to the parties on 21 January 2000. Both parties requested the Panel to review parts of the interim report. While neither party requested in its comments on the interim report a further meeting with the Panel, Canada did request that it be granted an opportunity to comment on the submission of the European Communities. The Panel considered this request and decided to grant both parties the opportunity to comment upon the other's submission, informing them that these further comments should raise no issues not contained in the initial comments on the interim report.

\section{FACTUAL ASPECTS}

(a) Relevant Provisions of Canadian Patent Law

2.1 For the purposes of the case in hand, the main provisions of Canadian patent law which are of relevance to the case in hand stipulate the following:

Patent Act, Section 42. "Every patent granted under this Act shall contain the title or name of the invention, with reference to the specification, and shall, subject to this Act, grant

\footnotetext{
${ }^{1}$ See Annex 1 to this Report.
} 
to the patentee and the patentee's legal representatives for the term of the patent, from the granting of the patent, the exclusive right, privilege and liberty of making, constructing and using the invention and selling it to others to be used, subject to adjudication in respect thereof before any court of competent jurisdiction."

Patent Act, Section $44 . \quad$ "Subject to section 46, where an application for a patent is filed under this Act on or after October 1, 1989, the term limited for the duration of the patent is twenty years from the filing date." ${ }^{2}$

Patent Act, Section 55(1). $\quad$ "A person who infringes a patent is liable to the patentee and to all persons claiming under the patentee for all damages sustained by the patentee or by any such person, after the grant of the patent, by reason of the infringement."

Patent Act, Section 55.2(1). "It is not an infringement of a patent for any person to make, construct, use or sell the patented invention solely for uses reasonably related to the development and submission of information required under any law of Canada, a province or a country other than Canada that regulates the manufacture, construction, use or sale of any product."

Patent Act, Section 55.2(2). "It is not an infringement of a patent for any person who makes, constructs, uses or sells a patented invention in accordance with subsection (1) to make, construct or use the invention, during the applicable period provided for by the regulations, for the manufacture and storage of articles intended for sale after the date on which the term of the patent expires."

Patent Act, Section 55.2(3). "The Governor in Council may make regulations for the purposes of subsection (2), but any period provided for by the regulations must terminate immediately preceding the date on which the term of the patent expires."

Patent Act, Section 55.2(4). "The Governor in Council may make such regulations as the Governor in Council considers necessary for preventing the infringement of a patent by any person who makes, constructs, uses or sells a patented invention in accordance with subsection (1) or (2) including, without limiting the generality of the foregoing, regulations

(a) respecting the conditions that must be fulfilled before a notice, certificate, permit or other document concerning any product to which a patent may relate may be issued to a patentee or other person under any Act of Parliament that regulates the manufacture, construction, use or sale of that product, in addition to any conditions provided for by or under that Act;

(b) respecting the earliest date on which a notice, certificate, permit or other document referred to in paragraph $(a)$ that is issued or to be issued to a person other than the patentee may take effect and respecting the manner in which that date is to be determined;

(c) governing the resolution of disputes between a patentee or former patentee and any person who applies for a notice, certificate, permit or other document referred to in paragraph $(a)$ as to the date on which that notice, certificate, permit or other document may be issued or take effect;

(d) conferring rights of action in any court of competent jurisdiction with respect to any disputes referred to in paragraph $(c)$ and respecting the remedies that may be

\footnotetext{
${ }^{2}$ Section 46 requires the payment of maintenance fees.
} 
sought in the court, the procedure of the court in the matter and the decisions and orders it may make; and

(e) generally governing the issue of a notice, certificate, permit or other document referred to in paragraph $(a)$ in circumstances where the issue of that notice, certificate, permit or other document might result directly or indirectly in the infringement of a patent."

Patent Act, Section 55.2(5). "In the event of any inconsistency or conflict between

(a) this section or any regulations made under this section, and

(b) any Act of Parliament or any regulations made thereunder,

this section or the regulations made under this section shall prevail to the extent of the inconsistency or conflict."

Patent Act, Section 55.2(6). "For greater certainty, subsection (1) does not affect any exception to the exclusive property or privilege granted by a patent that exists at law in respect of acts done privately and on a non-commercial scale or for a non-commercial purpose or in respect of any use, manufacture, construction or sale of the patented invention solely for the purpose of experiments that relate to the subject-matter of the patent."

Manufacturing and Storage of Patented Medicines Regulations. By virtue of these Regulations, "the applicable period referred to in subsection 55.2(2) of the Patent Act is the six month period immediately preceding the date on which the term of the patent expires."

Patented Medicines (Notice of Compliance) Regulations. See under paragraph 2.7 below.

\section{(b) Canada's Regulatory Review System for Drugs}

2.2 Under Canada's Food and Drugs Act, the Therapeutic Products Programme (TPP) of the Federal Department of Health (Health Canada) is responsible, on behalf of the Minister of Health, to ensure that "new drugs" meet health and safety requirements.

2.3 A "new drug" is defined in Section C.08.001 of the Food and Drug Regulations ${ }^{3}$ as a drug which contains a substance which has not been sold in Canada for a sufficient time and in sufficient quantity to establish its safety and efficacy. ${ }^{4}$ Thus, "newness" is not tied to novelty, and the category of "new drugs" includes both novel products (such as a drug that has had its novelty and utility recognized by the grant of a patent) as well as drugs that are not novel but are "new" in the sense that the particular version of the drug has not been previously marketed (as in the case of a competing or generic version of a drug that has the same properties as another version, whether patent-protected or not, that has been previously marketed).

\footnotetext{
${ }^{3}$ The full text of Part C.08 of the Regulations is reproduced in Annex 2 to this Report.

${ }^{4}$ According to the Federal Court of Appeal, in Apotex Inc. v. Canada, [1994] 1 F.C. 742 (appeal dismissed [1994] 3 S.C.R. 1100 (S.C.C.), at p. 753, the process by which a "new drug" is approved for manufacture and sale in Canada can be summarized as follows:
}

\footnotetext{
"A "new drug" must undergo rigorous testing before it may be sold. The manufacturer of the drug must file a New Drug Submission ("NDS") with the [TPP] setting out, inter alia, the drug's qualities, ingredients and methods of manufacture and purification. The NDS also includes the results of the manufacturer's clinical studies supporting the drug's safety and effectiveness. All aspects of the NDS are examined by multidisciplinary teams of the Drugs Directorate of the [TPP]. A NOC [Notice of Compliance, i.e. marketing approval] will only issue if the drug is found to be both effective and safe for human use..."
} 
2.4 Subject to the distinctions described below, the same requirements of the Food and Drug Regulations apply to the manufacture and control of the active ingredient and the dosage form of a drug regardless of whether the application for regulatory review relates to a patented or generic product. Both products are treated as a "new drug" because a generic is equivalent, not identical, to the patented drug it replicates. It contains the same active ingredient as the patented drug but its dosage formulation (including the filler, binding agent and coating) usually differs.

The application contains details on the facilities, method of manufacture and controls to be used in the manufacture, preparation and packaging of the new drug, details of the tests applied to control the purity, stability and safety of the new drug, and evidence that all test batches of the new drug used in any studies included in the submission were manufactured and controlled in a manner that is representative of market production.

- The major difference between a submission for a new active substance (patented product) and a generic product is the data required to establish the safety of the new drug and its clinical effectiveness for the purpose and under the conditions of use recommended.

- For a new active substance, extensive pre-clinical testing is conducted, including pharmacological evaluation and toxicity testing (acute, subchronic, chronic toxicity, carcinogenicity and reproductive studies) in animals. Clinical studies range from early tolerability studies and pharmacokinetic studies to extensive trials in patients to establish clinical safety and efficacy.

- For a generic drug, evidence of clinical safety and effectiveness may be established by comparative studies with another, usually an innovator's (patented) product, i.e. the "Canadian Reference Product" identified in section C.08.001.1 of the Food and Drug Regulations. Pharmaceutical equivalence (identical amounts of active ingredients, in comparable dosage forms) and bioequivalence (therapeutic equivalence) based on pharmaceutical and, if necessary, bioavailability (rate of absorption of the active ingredient in the human body) characteristics, must be demonstrated.

Comparative bioavailability studies are normally conducted by measuring the level of the drug in the blood of healthy human volunteers with each "study subject" (i.e. volunteer) receiving both the original brand and the new generic brand on two separate occasions. The generic drug must be demonstrated to deliver the same amount of active ingredient at the same rate as the original brand. The number of volunteers required for a study depends on the characteristics of the drug product under study. On this basis the therapeutic effects of the two products should be the same since the effect of a drug depends on the levels of the medicinal ingredient(s) in the body.

- $\quad$ Some products may not be suitable for comparative bioavailability testing. In these cases, other methods, such as comparing the clinical or pharmacodynamic effects of the generic drug with the original brand, may be used. Generic drugs that are solutions and are administered by direct injection into the blood stream are not suitable for a comparative bioavailability study, because the rate and extent at which the medicinal ingredients enter the body are not dependent upon the formulation. Products applied topically to the skin may likewise not be suitable for comparative bioavailability testing.

- Additional information respecting safety and effectiveness of the generic drug may be required depending on the results of the evaluation of the above information.

2.5 The regulatory review procedure is time consuming. It may take from one to two-and-a-half years to complete. However, prior to this period, a generic manufacturer will have spent from two to 
four years in the development of its regulatory submission. ${ }^{5}$ Thus, the overall time required for a generic manufacturer to develop its submission and to complete the regulatory review process ranges from three to six-and-a-half years. After the development of its regulatory submission, the generic manufacturer will file an Abbreviated New Drug Submission ("ANDS") with Health Canada. The generic manufacturer files an ANDS because, typically, it is relying on comparative studies to a drug product that has proven to be safe and effective. An innovator, on the other hand, would file a New Drug Submission, since it must provide full pre-clinical and clinical data to establish the safety and efficacy of the drug in question. For an innovator, it takes approximately eight to 12 years to develop a drug and receive regulatory approval, which takes place during the 20 -year patent term. The resulting period of market exclusivity under the current Canadian Patent Act varies from drug to drug. Estimated averages, at the time that the Act came into force, range from eight to ten years, according to the Pharmaceutical Manufacturers Association of Canada (PMAC), or 12 to 14 years, according to the Canadian Drug Manufacturers Association (CDMA). ${ }^{6}$

2.6 The delay involved in pre-market activities for a generic drug arises because, after first perceiving a market for a particular product, a generic manufacturer will then ordinarily seek an outside fine chemical producer to supply the active ingredient for the product, although sometimes manufacturing of the raw material is done internally or through a subsidiary. The technology involved in manufacturing fine chemicals requires different expertise and equipment from the manufacture of dosage forms (e.g., tablets).

- The fine chemical producer must attempt to develop a means to manufacture the active ingredient to the required degree of purity. Sometimes more than one producer will be asked by the generic manufacturer to develop a manufacturing process for the active ingredient, because not all will succeed in achieving the necessary purity. The generic manufacturer will do its own testing of the raw material samples sent by the fine chemical producer to satisfy itself that the purity is acceptable. On average, all this takes about one year, although it has, in some instances, taken much longer.

- Once a generic manufacturer has established a satisfactory source for the raw material, it will buy it as required from the fine chemical manufacturer. The generic manufacturer will then develop the formulation of the final dosage form.

- This involves mixing the raw material with the excipients (i.e., the inactive ingredients), typically consisting of inert filler, a binding agent and a coating of some kind. A testing model will be developed for establishing bioequivalence with the Canadian reference product to the satisfaction of Health Canada.

- The nature of this testing will vary depending on the new drug. Variables will include how many subjects (i.e., healthy volunteers) are to be used, how much of the drug is to be administered, whether a fed or a fasting study or both need to be done, how many samples will be taken of blood, urine, etc., and how they will be measured, and whether a comparative clinical trial (i.e., a trial comparing effectiveness in treating the condition with the Canadian Reference Product) must be done.

- Candidate formulations will be developed, manufactured in small batches, and then tested on subjects. This will be repeated if necessary until test results show that pharmaceutical equivalence can be established using a testing model satisfactory to Health Canada. The generic manufacturer must also include six months of stability data in its

\footnotetext{
${ }^{5}$ See Annex 3 to this Report.

${ }^{6}$ Information package prepared jointly by Industry Canada and Health Canada to provide factual background information for the review of the Patent Act Amendment Act, 1992 (Bill C-91) by the House of Commons Committee on Industry, Government of Canada, February 1997.
} 
submission, showing the formulation will not deteriorate prematurely. All this might take one to three years, in addition to the one year (approximately) needed for development of the raw material. Thus, the total pre-submission time necessary to develop a generic drug is two to four years.

2.7 Bill C-91, which resulted in the current Canadian Patent Act, led to a number of changes in the marketing and sale of patented drugs in Canada as well as the regulatory review process:

(i) ANDS reviews will lead to the grant of a Notice of Compliance in between 12 to 30 months, subject to litigation under the Patented Medicines (Notice of Compliance) Regulations enacted pursuant to section 55.2(4) of the Patent Act. The full text of these regulations can be found in Annex 4 to this Report. They "prohibit the issuance of Notices of Compliance in respect of 'patent-linked' drugs. A 'patent-linked' drug is one in respect of which both a Notice of Compliance and an unexpired patent have been issued. The patent may relate to either the medicine itself or the method of using the drug to treat an illness". ${ }^{7}$ This prohibition against the issuance of Notices of Compliance in respect of "patent-linked" drugs means that the Minister of Health may not issue a Notice of Compliance to a party who is not the patent holder (i.e. to a generic drug manufacturer) where the patent holder alleges that marketing the medicine would infringe its patent. The procedure envisaged by the regulations is as follows:

a patentee may submit a patent list to the Minister in respect of any drug that contains a "medicine", as defined in section 2 of the Regulations ${ }^{8}$;

- $\quad$ where a generic manufacturer files a submission for a Notice of Compliance in respect of a drug, and the submission compares the drug or refers to the drug of another manufacturer (the innovator) that has already been marketed in Canada pursuant to a Notice of Compliance, and concerning which the innovator has filed a patent list with the Minister, the generic manufacturer's ANDS must contain one or the other of two prescribed statements: (i) a statement that the generic manufacturer accepts that the Notice of Compliance will not issue until the patent expires, or (ii) an allegation that the innovator is not the owner or the exclusive licensee of the patent, that the patent has expired, that the patent is not valid, or that the generic manufacturer's marketing of the drug would not infringe any claim for the patented medicine itself or any claim for the use of the patented medicine ${ }^{9}$;

if the generic manufacturer makes an allegation of the kind just described, it is obliged to serve a notice of the allegation on the innovator ${ }^{10}$;

the innovator may then, within 45 days after being served with the notice of allegation, apply to a court for an order prohibiting the Minister from issuing the Notice of Compliance until the patent that is the subject of the allegation has expired $^{11}$;

${ }^{7}$ Federal Court of Appeal, in Apotex Inc. v. Canada, [1994] 1 F.C. 742 (appeal dismissed [1994] 3 S.C.R. 1100 (S.C.C.)),.at p. 756 .

${ }^{8}$ Section 4(1) of the Regulations

${ }^{9}$ Section 5(1) of the Regulations

${ }^{10}$ Section 5(3) of the Regulations

${ }^{11}$ Section 6(1) of the Regulations 
- $\quad$ the Minister may not issue the Notice of Compliance during the 24-month period following receipt of the innovator's notice of application ${ }^{12}$, unless the application is finally dismissed by the court within that period. ${ }^{13}$

The normal practice is for Notices of Compliance to issue for generic drugs immediately upon patent expiry, at which time the drugs are available on the open market, except for provincial public assistance plans, which have their own acceptance processes (which range from one to 16 months).

(ii) Prior to the Patent Act Amendment Act, 1992 (Bill C-91), nothing prevented Notices of Compliance from being issued once all the safety and efficacy requirements were satisfied. "Prior to the proclamation of Bill C-91, a generic drug company could obtain a compulsory licence from the Commissioner of Patents authorizing it to advertise, manufacture and sell any drug in respect of which a Notice of Compliance had been issued. Although the generic drug company was required to pay royalties to the drug's innovator, it could sell the drug notwithstanding the innovator's patent rights. This arrangement was governed by subsection 39(4) of the Patent Act, R.S.C. 1985 [...]. Bill C-91 was drafted in order to protect innovator pharmaceutical companies' distribution and sales rights to patented drugs and represents a reversal of government policy adopted by Parliament in 1923 [...]. The immediate effects of Bill C-91 are well known. Section 3 of the Bill repealed the compulsory licensing provisions of the Patent Act, while section 12(1) extinguished all compulsory licences issued on or after December 20, 1991 [...]."14

\section{FINDINGS AND RECOMMENDATIONS REQUESTED BY THE PARTIES}

3.1 The European Communities and their member States requested the Panel to make the following rulings, findings and recommendations:

I. Section 55.2(2) and 55.2(3) of the Patent Act together with the Manufacturing and Storage of Patented Medicines Regulations

\section{Article 28.1 together with Article 33 of the TRIPS Agreement}

(a) That Canada, by allowing manufacturing and stockpiling of pharmaceutical products without the consent of the patent holder during the six months immediately prior to the expiration of the 20-year patent term by virtue of the provisions of Section 55.2(2) and 55.2(3) of the Patent Act together with the Manufacturing and Storage of Patented Medicines Regulations, violated its obligations under Article 28.1 together with Article 33 of the TRIPS Agreement.

\section{Article 27.1 of the TRIPS Agreement}

(b) That Canada, by treating patent holders in the field of pharmaceutical inventions by virtue of these provisions less favourably than inventions in all other fields of technology, violated its obligations under Article 27.1 of the TRIPS Agreement requiring patents to be available and patent rights enjoyable without discrimination as to the field of technology.

\footnotetext{
${ }^{12}$ As originally promulgated, the Regulations prohibited the Minister from issuing the Notice of Compliance for a period of 30 months, but that period was reduced to 24 months by amendment in 1998 (SOR/98-166).

${ }^{13}$ Section 7(1)(e) and 7(4) of the Regulations

${ }^{14}$ Federal Court of Appeal, in Apotex Inc. v. Canada, [1994] 1 F.C. 742 (appeal dismissed [1994] 3 S.C.R. 1100 (S.C.C.)), at pp. 754-55.
} 
WT/DS114/R

Page 8

\section{Section 55.2(1) of the Patent Act}

\section{Article 28.1 of the TRIPS Agreement}

(c) That the provisions of Section 55.2(1) concerning activities related to the development and submission of information required to obtain marketing approval for pharmaceutical products carried out without the consent of the patent holder violated the provisions of Article 28.1 of the TRIPS Agreement.

\section{Article 27.1 of the TRIPS Agreement}

(d) That Canada, by treating patent holders in the field of pharmaceutical inventions by virtue of these provisions less favourably than inventions in all other fields of technology, violated its obligations under Article 27.1 of the TRIPS Agreement requiring patents to be available and patent rights enjoyable without discrimination as to the field of technology.

III. Article 64.1 of the TRIPS Agreement, Article XXIII of GATT 1994 and Article 3.8 of the DSU

(e) That the violations referred to under I. and II. above constituted prima facie nullification or impairment under Article 64.1 of the TRIPS Agreement, Article XXIII of GATT 1994 and Article 3.8 of the DSU.

(f) That the DSB request Canada to bring its domestic legislation into conformity with its obligations under the TRIPS Agreement.

3.2 Canada requested the Panel to reject the complaints of the European Communities and their member States on the basis of the following findings:

\section{Section 55.2(1) and 55.2(2) of the Patent Act}

Section 55.2(1) and 55.2(2) of the Patent Act conform with Canada's obligations under the TRIPS Agreement, because:

(a) Each of these provisions is a "limited exception" to the exclusive rights conferred by a patent within the meaning of Article 30 of the TRIPS Agreement;

(b) Neither of these provisions discriminates, within the meaning of Article 27 of the TRIPS Agreement, as to the field of technology in which any relevant invention occurs or has occurred, because:

the prohibition in Article 27.1 against discrimination on the basis of field of technology does not apply to allowable limited exceptions;

or, if the Panel were to find Article 27.1 applicable, because:

the limited exceptions of Section 55.2(1) and 55.2(2) are not expressly related to any particular field of technology;

(c) Neither of these provisions reduces the minimum term of protection referred to in Article 33 of the TRIPS Agreement to a term that is less than that minimum. 


\section{ARGUMENTS OF THE PARTIES}

4.1 The sections numbered $\mathrm{A}$ to $\mathrm{F}$ below have a consecutive character, reflecting the development of the arguments as presented by the parties, thus allowing to reflect also the discrepancies in approach by the two parties to the issues at hand.

A. EUROPEAN COMMUNITIES AND THEIR MEMBER STATES

(1) SECTION 55.2(2) AND 55.2(3) OF THE PATENT ACT TOGETHER WITH THE MANUFACTURING AND STORAGE OF PATENTED MEDICINES REGULATIONS

(a) $\quad$ Article 28.1 and Article 33 of the TRIPS Agreement

4.2 The European Communities and their member States argued that, by allowing manufacturing and stockpiling of pharmaceutical products under Sections 55.2(2) and (3) of the Patent Act together with the Manufacturing and Storage of Patented Medicines Regulations ${ }^{15}$ during the six months immediately prior to the expiration of the 20-year patent term, Canada breached its obligations under Articles 28.1 and 33 of the TRIPS Agreement. ${ }^{16}$ The following points were advanced in support of this argument:

- Canadian law allowed all the acts referred to in Article 28.1(a) of the TRIPS Agreement, if a product patent was concerned, and Article 28.1(b) of the Agreement, if a process patent was concerned, with the sole exception of the act of selling to a distributor or consumer without the consent of the patent owner from six months before the expiry of the 20-year patent term. In other words Canada only provided for 19 years and six months of the minimum patent protection as mandated by Articles 28.1 and 33 of the TRIPS Agreement.

- In practical terms this meant that anybody in Canada was allowed to perform the acts of making, constructing and using of the invention during the last six months of the patent term without the authorization of the patent holder. This possibility was automatic for anybody in Canada, i.e. no particular authorization had to be applied for and eventually granted by a Canadian authority. The faculty was entirely unqualified in terms of the extent and volume of the use and no royalty fees whatsoever had to be paid to the patent holder nor did the latter have any right to be informed of such unauthorized use of his invention. Both product and process patents were subject to this denial of protection.

- To the best of the knowledge of the European Communities and their member States, Canada was the only country in the world - industrialized or developing - which allowed manufacturing and stockpiling of products covered by a patent during the term of such a

\footnotetext{
${ }^{15}$ See above under paragraph 2.1 .

${ }^{16}$ Article 28.1 of the TRIPS Agreement reads (footnote omitted):

"1. A patent shall confer on its owner the following exclusive rights:
}

(a) where the subject matter of a patent is a product, to prevent third parties not having the owner's consent from the acts of: making, using, offering for sale, selling, or importing for these purposes that product;

(b) where the subject matter of a patent is a process, to prevent third parties not having the owner's consent from the act of using the process, and from the acts of: using, offering for sale, selling, or importing for these purposes at least the product obtained directly by that process."

Article 33 of the TRIPS Agreement reads (footnote omitted): "The term of protection available shall not end before the expiration of a period of twenty years counted
from the filing date". 
patent. Canada itself recognized that, at least in the United States and the member States of the European Communities, such a possibility did not exist. ${ }^{17}$

(b)

\section{Article 27.1 of the TRIPS Agreement}

4.3 The European Communities and their member States argued that, by treating patent holders in the field of pharmaceutical inventions less favourably than inventions in all other fields of technology, Canada infringed its obligations contained in Article 27.1 of the TRIPS Agreement. ${ }^{18}$ The following points were advanced in support of this argument:

- The Canadian patent legislation, which under Section 55.2(2) and 55.2(3) together with the Manufacturing and Storage of Patented Medicines Regulations practically speaking provided only for a 191/2-year term of patent protection, applied exclusively to product and process patents for inventions in the field of pharmaceutical products. During the legislative process, other fields of technology were not even considered and no draft legislation to extend the scope of these provisions to other or all fields of technology was, according to the information available to the European Communities and their Member States, presently pending in the Canadian legislature. In this context, it was also noteworthy that Section 55.2(2) of the Canadian Patent Act was, taken in isolation, an inoperative provision and created only legal effects through the promulgation of the Manufacturing and Storage of Patented Medicines Regulations. This Regulation was expressly limited to "patented medicines" and could not apply to any other product.

- Thus, the Canadian legislation discriminated against pharmaceutical inventions by treating them less favourably than inventions in all other fields of technology and therefore Canada violated its obligations under Article 27.1 of the TRIPS Agreement.

\section{SECTION 55.2(1) OF THE PATENT ACT}

\section{(a) Article 28.1 of the TRIPS Agreement}

4.4 The European Communities and their member States argued that Section 55.2(1) of the Canadian Patent Act allowed all activities related to the development and submission of information required to obtain marketing approval for pharmaceutical products carried out by a third party without the consent of the patent holder at any time during the patent term, notwithstanding the exclusive rights stipulated in Article 28.1 of the TRIPS Agreement. ${ }^{19}$ These activities were completely unlimited in quantity and extent and included the acts of offering for sale and selling, at least insofar as any manufacturer of the patented product or process could invoke this right, if only the final purchaser of the product had the intention to use the product for "[...] uses reasonably related to the development and submission of information required under the law of Canada, a province or a country other than Canada that regulates the manufacture, construction, use or sale of any product". ${ }^{20}$ Therefore, Section 55.2(1) of the Canadian Patent Act had to be considered to be incompatible with the provisions of Article 28.1(a) and (b) of the TRIPS Agreement. The following points were advanced in support of this argument:

The permissible activities under Section 55.2(1) of the Canadian Patent Act were not limited in time. In other words, they might be performed without the consent of the right holder at any point in time during the 20 -year patent term.

\footnotetext{
${ }^{17}$ Reference was made to the information package referred to in footnote 6 above.

${ }^{18}$ Article 27.1 of the TRIPS Agreement reads in pertinent part: "... patents shall be available and patent rights enjoyable without discrimination as to the field of technology...".

${ }^{19}$ For the text of Article 28.1, see footnote 16 above.

${ }^{20}$ For the text of Section 55.2(1), see paragraph 2.1 above.
} 
- $\quad$ Section 55.2(1) of the Patent Act took away all the rights a patent granted its owner, i.e. making, constructing, using (this included importing) ${ }^{21}$ and selling, and did not stipulate any quantitative limits for these activities. The only limitation set out by the law consisted in the objective of these activities, i.e. they must be "... reasonably related to the development and submission of information" required for obtaining marketing approval anywhere in the world.

- The requirements for obtaining marketing approval for pharmaceutical products in industrialized countries were similar and broadly focused on three criteria: safety, quality and efficacy of the product. Thus, the documentation required by the national drug administrations contained information on the composition, manufacture, quality control and stability of the product. This included also in Canada proof that a full production line was viable and could involve full batch testing ${ }^{22}$, which in turn required the production of significant quantities of the product protected by a patent. The non-clinical testing information that was required related to the pharmacological effects of the product in relation to the proposed use in humans and to the toxicological effects of the product on the organism and in different organs. The clinical test data which had to be compiled constituted by far the most important part of the marketing approval activities as far as time, resources and costs were concerned. It was typically subdivided into three phases starting out from tests in small doses administered to a small number of patients (phase I) to the use of the product in wideranging comparative studies involving large numbers of patients which could go into tens of thousands for some indications (phases II and III).

- It was also noteworthy that Section 55.2(1) of the Canadian Patent Act did not only allow all the activities mentioned in the text to be carried out by somebody who had himself the intention to use the substances for preparing his application for marketing approval, but allowed such activities as manufacturing, importing and selling for anybody, if only the results of these activities were eventually intended to be used by somebody else for his application to a marketing approval authority in any country of the world. Here it was important to understand that, while research-based pharmaceutical companies did generally produce the active pharmaceutical ingredients in-house, many - in particular small and medium-sized - copy (generic) producers sourced the active ingredients from independent manufacturers domestically or from abroad. The reason for this was linked to the fact that the production of the active ingredients was often highly capital intensive and once the equipment was in place and running, huge quantities could be manufactured by a very small staff in a short period of time.

- The interplay and cumulation of all these possibilities led to a situation that very significant quantities of the products protected by a patent could be manufactured, imported and sold without the consent of the patent holder at any time during the patent term.

- $\quad$ There existed no provisions under the laws of the EC member States which would allow a party to carry out the activities referred to in Section 55.2(1) of the Canadian Patent Act without the consent of the patent owner. ${ }^{23}$

${ }^{21}$ According to the EC, while the text of the Patent Act did not expressly grant an importation right, such a right was recognized by Canadian jurisprudence (see Wellcome Foundation LTD v. Apotex Inc. (1990) 32 C.P.R.(3d), at p. 352.

${ }^{22}$ According to the EC, this was expressly confirmed by Canada on a question by the European Communities and their member States during the first round of consultations on 13 February 1998.

${ }^{23}$ Reference was made to the information package referred to in footnote 6 above, in which this was expressly recognized by Canada at page 9 . 


\section{(b) $\quad$ Article 27.1 of the TRIPS Agreement}

4.5 The European Communities and their member States argued that, by allowing all the activities referred to in paragraph 4.3 above related to the development and submission of information required to obtain marketing approval for pharmaceutical products and carried out by a third party without the consent of the patent holder at any time during the patent term, Canada treated holders of pharmaceutical patents less favourably than holders of patents in all other fields of technology and thus violated its obligations under Article 27.1 of the TRIPS Agreement. The following points were advanced in support of this argument:

- It was true that Section 55.2(1) of the Canadian Patent Act did not mention expressly pharmaceuticals or medicines, but referred to cases where "... Canada, a province or a country other than Canada [...] regulates the manufacture, construction, use or sale of any product"; it was in effect only applied to pharmaceutical products. This was not astonishing because the considerations in relation to the formulation and adoption of Bill C-91, of which Section 55.2(1) of the Patent Act formed a pivotal part, were exclusively concerned with the treatment of pharmaceutical products. ${ }^{24,25}$

While the text of the law read as if this provision would apply to all fields of technology, it did in practice only apply to pharmaceuticals. This became apparent from the legislative history of this provision, where in the discussions - to the extent that reports were available to the European Communities and their member States - other areas of technology were not even mentioned. The Canadian authorities had confirmed in the formal consultations under the DSU that this provision was applied only to pharmaceuticals. This was particularly interesting in a situation where for many other categories of products "... the development and submission of information [is] required under any law of Canada, a province or a country other than Canada that regulates the manufacture, construction, use or sale of (such) products". The product categories meeting this condition included agricultural chemical products, certain foodstuffs, motor vehicles, aircraft, ships and many more.

- While the manufacture, construction, use or sale of a great plethora of products were, under the laws of Canada, its provinces or any other country, subject to regulations, Section 55.2(1) of the Patent Act did not apply to these other fields of products; in none of these areas did Section 55.2(1) of the Patent Act apply. This was confirmed by Canada in the formal consultations under the DSU.

4.6 The European Communities and their member States advanced the following information about the historical developments in Canada as well as a comparison between the situation in Canada before and after the introduction of Bill C-91 and the Manufacturing and Storage of Patented Medicines Regulations in 1993, taking the view that the curtailment of patent rights for pharmaceuticals as pursued by Canada was incompatible with the patent provisions of the TRIPS Agreement independently of whether it was presented as a compulsory licence, as under the pre-C-91 system or as "exceptions" under the C-91 system itself:

\footnotetext{
${ }^{24}$ Reference was made to the historical developments in Canadian patent legislation as presented by the EC and their comparison between the situation in Canada before and after the introduction of Bill C-91 and the Manufacturing and Storage of Patented Medicines Regulations in 1993 (see the relevant section under paragraph 4.6 below).

${ }^{25}$ See paragraph 2.7 above.
} 
- Patent protection in Canada had been in place for many decades and also inventions in the field of pharmaceuticals had been patentable under the ordinary conditions. As early as 1923, Canada modified the patent protection for pharmaceuticals by introducing a regime of compulsory licences for pharmaceuticals. Compulsory licences allowed a third party without the authorization of the owner of the patent to make, use or sell patented pharmaceuticals. The compulsory licence could be granted at any time during the patent term. The patentee was entitled to the payment of royalties by the beneficiary of the compulsory licence.

- Because the granting of the compulsory licences was subject to the requirement that the active ingredients used in the pharmaceutical product be produced in Canada, few compulsory licences were effectively granted at the time, since it was difficult to obtain Canadian-made active ingredients.

- In 1969, the requirement to produce the active in gredient in Canada was dropped having as a consequence that numerous compulsory licences were granted thereafter. The licensing fee amounted generally to 4 per cent of the sales price of the products produced under the compulsory licence, which often covered several patents.

In 1987, the Canadian Patent Act was further amended by replacing the previous term of protection of 17 years from the time the patent was granted by one of 20 years from the time the patent application was filed. This amendment entered into force in 1989. Under this new regime, compulsory licences continued to be available but were limited in time. Such compulsory licences could be obtained after the patented product had been on the Canadian market for seven years, if the licensee intended to produce in Canada, or ten years if he intended to import the active ingredient. These amendments had as practical effect that the patent holder was guaranteed at least seven years (ten years if the holder of the compulsory licence did not intend to produce or source locally) of patent protection.

- Canada further modified its patent laws by the Patent Act Amendment Act, 1992 (Bill C91), which entered into force in February 1993. While inventions in the area of pharmaceuticals were under the pre-C-91 patent regime only patentable as process patents (or so-called 'product-by-process patents'), product patents for pharmaceutical inventions were only introduced by C-91 in $1993 .^{26}$ The major modification consisted of the elimination of the existing compulsory licensing system for pharmaceuticals and the introduction of exceptions to the patent rights of the holder of a patent in the area of pharmaceuticals which were at issue in the present case. In order to understand the motivation of the Canadian authorities one had to look at the historic situation in 1991 and 1992 as far as international rulemaking on intellectual property issues to which Canada was a party was concerned.

- In December 1991, the then Director-General of the General Agreement on Tariffs and Trade, Arthur Dunkel, had compiled a Draft Final Act for the conclusion of the Uruguay Round negotiations, which also contained a text of the draft Agreement on Trade-Related Aspects of Intellectual Property Rights (TRIPS). ${ }^{27}$ The text of the TRIPS Agreement as

${ }^{26}$ Mac Kay J. in Apotex Inc. v. Attorney General of Canada et al., 71 C.P.R.(3d), at p. 170.

${ }^{27}$ The EC provided the following short negotiating history of the TRIPS Agreement:

"At the Ministerial Conference which launched the Uruguay Round of Multilateral Trade Negotiations at Punta del Este, Uruguay in September 1986, TRIPs was included into the negotiation agenda as one of the so-called new topics. Multilateral rulemaking in the IPR area was so far dominated by the World Intellectual Property Organisation (WIPO) which administers or co-administers practically all important conventions in this area. There existed at the outset fundamental divergencies between industrialized countries, who wished to achieve a comprehensive coverage of all intellectual property rights and developing countries (LDCs) who wanted to limit work to a Code against trade in counterfeit goods. During the negotiating process the view of those who pursued a comprehensive approach prevailed. This had as a consequence that practically all existing IPRs were included in TRIPs. To start with the principles of national treatment and most favoured nation treatment (the latter being a novelty in the area of IPRs) were stipulated. The most important WIPO conventions (the Paris Convention covering industrial property rights and the Berne Convention covering copyright as well as the Washington 
contained in the so-called Dunkel text was informally agreed by all parties to the negotiations and became practically verbatim part of the Agreement finally adopted in 1994 in Marrakesh. The TRIPS Agreement contained in Article 31 detailed provisions on "Use Without the Authorization of the Right Holder". It was certain that the Canadian regime on compulsory licences for pharmaceutical products existing in the pre-C-91 system would have been incompatible with Article 31 of the TRIPS Agreement. This had been expressly admitted by the Canadian Government. ${ }^{28}$

- While the Uruguay Round negotiations were somewhat in limbo in 1991/1992, the negotiations on a North American Free Trade Agreement (NAFTA) between Canada, Mexico and the United States of America were concluded in 1992 and the agreement was signed at the end of 1992. NAFTA contained in Chapter Seventeen extensive disciplines on the protection of intellectual property rights. The provisions of Chapter Seventeen were largely based on, and in many instances were a verbatim reproduction of, the provisions of the then draft TRIPS Agreement. ${ }^{29}$ Article 31 of the TRIPS Agreement was reproduced almost identically in Article 1709(10) of NAFTA. Thus, the Canadian compulsory licensing system for pharmaceuticals in the pre-C-91 system would also have been incompatible with Canada's obligations under NAFTA, in particular its Article 1709(10). This conclusion had been expressly stated by the Canadian Government. ${ }^{30}$

In order to fully appreciate the Canadian 'philosophy' for patent protection in the area of pharmaceutical products, it was important to understand the interplay between pharmaceutical research, patenting of inventions and granting of marketing approval for medicinal products. From the moment an application for a pharmaceutical product or process patent was filed until the resulting pharmaceutical product could be effectively marketed it took on average

\footnotetext{
Treaty for the protection of semiconductor topographies) were included by reference, also to make these conventions subject to an efficient dispute settlement system. Over and above the level provided for under the provisions of these conventions the substantive levels of protection were set at the level prevailing in the mid 1980s in the industrialized countries. Furthermore extensive rules for the enforcement of the substantive IPR standards were sought for, which constituted an absolute novelty for international IPR rulemaking. The Dunkel text on TRIPS of December 1991 to which reference was made under point 19 above, became almost verbatim part of the Final Act adopted at the Marrakech Ministerial Conference in April 1994 which successfully concluded the Uruguay Round Negotiations. The substantive provisions for the protection of patents are contained in Section 5 of Part II, i.e. Articles 27 to 34 of the TRIPS Agreement. Article 27.1 TRIPS sets out the principle that patents have to be available in all fields of technology if the general conditions for the grant of a patent are met. This is of fundamental importance because many countries, in particular developing countries, had not made - and some still today do not make - available patents for specific areas of technology, notably pharmaceuticals, agrochemicals or foodstuffs. Article 27.2 and 27.3 TRIPS give the option to exclude a number of well defined subject matter from patentability, which is largely derived from modern pieces of IPR legislation as the European Patent Convention (EPC) (compare in particular Article 53 EPC). Article 28 TRIPS describes in detail the rights, which are conferred on a patent owner once the patent has been granted. Article 29 TRIPS stipulates the duties which a patent applicant has to meet and Article 30 TRIPS addresses exceptions to rights conferred which WTO members may provide. Article 31 TRIPS deals primarily with what is generally termed as compulsory licences and sets out detailed rules for the grant of such licences. Article 32 TRIPS addresses revocation and forfeiture and Article 33 TRIPS mandates a minimum term of protection for patents of 20 years from filing. Finally, Article 34 TRIPS establishes rules for process patents and provides in particular for a reversal of the burden of proof in an infringement procedure. While transitional periods for the benefit of LDCs (including - under certain conditions - so-called economies in transition) and least developed countries (LLDCs) are still running, all industrialized country members of the WTO had to comply fully with all the obligations flowing from the TRIPS Agreement as of 1 January 1996 (see Articles 65 and 66 TRIPS). Thus Canada's obligations vis-à-vis the EC and their Member States had to be met fully as of 1 January 1996." The EC also referred to Gervais, "The TRIPS Agreement: Drafting History and Analysis", London 1998, pages 3 to 28.

${ }^{28}$ Reference was made to page 2 of the information package referred to in footnote 6 above.

${ }^{29}$ Reference was made to Dr Herz, who was part of the Canadian TRIPS and NAFTA negotiating team, who had written: "[...] With respect to IPRs, NAFTA closely tracks the language of the 1991 Dunkel draft of the TRIPs negotiating text. Therefore NAFTA's Chapter 17: Intellectual Property and TRIPs generally are textually close enough to ensure that interpretations of the meaning of the one would be directly relevant to the elucidation of the other. IP-related findings of eventual NAFTA panels may, therefore, powerfully influence TRIPs interpretation and vice versa." (Canada-United States Law Journal, Vol.23 (1997), at p. 281)

${ }^{30}$ Reference was made to page 2 of the information package referred to in footnote 6 above.
} 
between eight and 12 years. ${ }^{31}$ This period of eight to 12 years was necessary for product development which included important periods for pre-clinical and clinical testing. Subsequent to the testing activities, the submissions for the marketing approval authority had to be prepared and the latter had to process the submitted information. ${ }^{32}$ This meant in practical terms that, under the present patent law provisions of Canada, a holder of a pharmaceutical patent enjoyed an effective patent term of eight to 12 years in which he could claim exclusivity on the market and it was during this period that all R\&D costs had to be depreciated on sales. Under the pre-C-91 system, compulsory licences were automatically granted to all Canadian operators who wanted to copy the invention after the patented pharmaceutical product had been on the Canadian market for at least seven years (or ten years if the active ingredients for the generic product were imported). Furthermore, a period of at least two-and-a-half years for obtaining marketing approval in Canada for the copy product ${ }^{33}$ had to be taken into consideration because, under the previous Canadian patent law, producers of copy products could only start to generate pre-marketing approval testing activities once the compulsory licence had been granted ${ }^{34}$. For the holder of the patent for the original product this system provided for a period of effective market exclusivity from nine-and-a-half years $^{35}$ to $12 \frac{1}{2}$ years. ${ }^{36}$ This also had as a consequence that the effective market exclusivity for the patent holder went in certain cases beyond the end of the 20 -year patent term. ${ }^{37}$ To put it in a nutshell, the economic situation in terms of effective market exclusivity for the holder of the patent under the old 1989 to 1993 system, which granted on average 11 years $^{38}$, was indeed very similar to the C-91 system from 1994, which granted on average a market exclusivity for the patent holder of ten years.

4.7 The European Communities and their member States, in support of their claims, also advanced information of the economic losses suffered by their pharmaceutical industry from the effects of Sections 55.2(1) and 55.2(2) of the Patent Act together with the Manufacturing and Storage of Patented Medicines Regulations. The European research-based pharmaceutical industry (EFPIA) had made an analysis of its alleged losses suffered in Canada, which exceeded the amount of C\$ 100 million per year. This analysis was based on the conservative assumption that, while the operation of the provisions referred to above would allow copy manufacturers to market the product immediately upon patent expiry, in the absence of these provisions effective marketing would only be possible at the earliest two years after patent term expiry. The extrapolation was based on sales of the top 100 original pharmaceutical products sold in Canada between 1995 and 1997.

\footnotetext{
${ }^{31}$ Reference was made to page 2 of the information package referred to in footnote 6 above.

${ }^{32}$ See also paragraph $4.4,3^{\text {rd }}$ indent above. Reference was also made to page 18 of the information package referred to in footnote 6 above.

${ }^{33}$ According to the EC, this information was given by Canada on a specific question by the EC during the first round of consultations held on 13 February 1998.

${ }^{34}$ Reference was made to Muldoon J. in Wellcome Foundation v. Apotex Inc. (1990) 32 C.P.R.(3d) at p. 356: "The sequence envisaged in the statutory scheme is that first, one obtains the compulsory licence; then one may import for experimentation in order to make appropriate submissions to the Health Protection Branch for a notice of compliance."

35 i.e. seven years counted from the introduction of the patented product on the Canadian market plus two-and-ahalf years for obtaining marketing approval for the generic version under compulsory licence, when the active ingredient is produced in Canada

${ }^{36}$ i.e. ten years counted from the introduction of the patented product on the Canadian market when the active ingredient was imported plus two-and-a-half years for obtaining marketing approval for the copy product under compulsory licence

${ }^{37}$ These were cases in which the original marketing approval was obtained later than ten-and-a-half years after the filing of the patent application. If the active ingredient for the copy product was produced in Canada the maximum postpatent term exclusivity could reach one-and-a-half years and in all cases in which the active ingredient for the copy was imported into Canada the effective post-patent exclusivity lasted for up to two-and-a-half years.

${ }^{38}$ Nine-and-a-half years if the active ingredient was produced in Canada and $12 \frac{1}{2}$ years if it was imported
} 
WT/DS114/R

Page 16

\section{ARTICLE 30 OF THE TRIPS AGREEMENT}

4.8 In respect of Article 30 of the TRIPS Agreement, the European Communities and their member States initially took the position that, while Canada, during the formal consultations under the DSU, had invoked Article 30 of the TRIPS Agreement to justify the measures at issue, it had done so in a rather summary and rudimentary manner. Therefore, the EC limited itself in its first written submission in this regard to stating that their view was that the Canadian measures could not be justified under Article 30, because the conditions set out in this provision were not met: the curtailment of patent rights under Canadian legislation did not constitute "limited exceptions to the exclusive rights conferred by a patent". Furthermore, the exceptions unreasonably conflicted with a normal exploitation of a patent and unreasonably prejudiced the legitimate interests of the patent owner, taking account of the legitimate interests of third parties. In any event, a violation of Article 27.1 of the TRIPS Agreement could not be justified under Article 30.

\section{B. CANADA}

4.9 Canada, in response, requested the Panel to dismiss the complaint of the European Communities and their member States, submitting that:

(1) Canada's exceptions to the exclusive rights conferred by a patent were "limited exceptions" within the meaning of Article 30 of the TRIPS Agreement, because they:

did not conflict in any mode or manner with the "normal exploitation" of a patent;

they did not prejudice, or if they did, they did not "unreasonably prejudice" the "legitimate interests" of a patentee taking account of the "legitimate interests" of third parties; and

the third party interests that the exceptions took account of were "legitimate interests" of relevant third parties.

(2)(a) the prohibition in Article 27.1 of the TRIPS Agreement against discrimination on the basis of field of technology did not apply to allowable limited exceptions;

(2)(b) in any event, Canada's limited exceptions to the exclusive rights conferred by a patent did not discriminate as to the field of technology in which an invention occurred, because they related to products that were subject to laws regulating the manufacture, construction, use or sale of a product and were not expressly related to any particular field of technology; and

(3) as regards Article 33 of the TRIPS Agreement, Canada's limited exceptions to the exclusive rights conferred by a patent did not reduce the term of protection accorded to a patent, because they did nothing to impair a patentee's right to exploit its patent for the full term of protection by working the patent for its private commercial advantage.

4.10 Canada argued that the essential question in these proceedings was whether the provisions of Section 55.2(1) and 55.2(2) were "limited exceptions to the exclusive rights conferred by a patent", within the meaning of Article 30 of the TRIPS Agreement. According to Canada, these two measures:

(a) were "limited exceptions" within the meaning of Article 30, since they allowed patent owners complete freedom to exploit their rights throughout the full term of patent 
protection, leaving the monopoly of commercial exploitation and the exclusivity of economic benefits unimpaired for the life of the patent;

(b) did not conflict with a normal exploitation of a patent or prejudice the legitimate interests of the patent owner, since they only affected the patent owner's commercial exploitation after the patent had expired;

(c) in any event, took into account Canada's national interest in measures conducive to social welfare and the achievement of a balance between rights and obligations, both of which were recognized objectives in Article 7 of the TRIPS Agreement; and

(d) in particular, as required by Article 30, took account of the legitimate interests of third parties, in that:

- $\quad$ they allowed potential competitors to compete freely with the patentee after the patent expired, consistent with the policy of full competition underlying the requirement of Article 29 that, in return for the grant of patent protection, patentees must disclose their inventions to the public; the provision of Article 33 that the exclusive rights be conferred for a specified term only; and the authorization in Article 40 of national measures to prevent abuse of intellectual property rights having an adverse effect on competition; and

- $\quad$ they sought to protect public health - a value recognized in Article 8.1 of the TRIPS Agreement - through promoting access to cost-effective generic medicines following patent expiry and, in this connection, they took into account the legitimate interests of individuals, private insurers and public sector entities that financed health care in maintaining access to affordable medicines.

4.11 According to Canada, Article 30 allowed uses that did not unreasonably conflict with a normal exploitation of the patent or unreasonably prejudice the legitimate interests of the patent owner, taking account of the legitimate interests of third parties. Canada submitted that Article 30 therefore authorized measures that limited exclusive rights, provided that no commercial exploitation - i.e. sales - took place during the patent term. Any other interpretation would:

ignore the existence of the word "unreasonably" in Article 30 and, thereby, the fact that conflicts with normal exploitation and prejudice to the patent owner's interests were allowed;

- disregard the public policy principles inherent in Articles 29 and 33, which encouraged free and open competition with the patent owner immediately upon expiry of the patent; and

as a consequence, where regulatory review delayed the entry of competing products on the market, promote the practice of enforcing patent rights within the patent term so as to extend the monopoly of the patent owner beyond the term, a policy which the European Communities and their member States had sought to have included in the Agreement, but which had not been so included, i.e. as the European Communities and their member States made plain in their first written submission, they sought to win through litigation the windfall period of protection that they could not secure by negotiation.

4.12 Canada further referred to the interpretative rule set out in Article 31 of the Vienna Convention on the Law of Treaties and argued that the terms of any international treaty, including the 
WT/DS114/R

Page 18

TRIPS Agreement, were to be interpreted in good faith in accordance with their ordinary meaning in their context and in light of the object and purpose of the treaty. When the exception provisions in Part II of the TRIPS Agreement were interpreted in accordance with this rule, it became apparent that Article 30 provided a general and flexible authority for Members to adopt measures that balanced the interests of patent owners with the interests of others, as Article 7 of the Agreement expressly stated was an objective of the TRIPS Agreement.

The language of Article 30 was markedly different from other provisions, which allowed exceptions to treaty rights. For example, GATT 1994, Article XX, required - as in paragraph (b) - that the exception measures be necessary to protect human health, and it contained additional restrictions in its chapeau portion. No similar restrictions were required under Article 30. Similarly, Article 13 of the TRIPS Agreement (and Article 9(2) of the Berne Convention for the Protection of Literary and Artistic Works (1971), upon which Article 13 was modelled), did not allow conflict with a normal exploitation of the work.

- $\quad$ Thus, the TRIPS Agreement contemplated that Members might, in implementing their obligations within their legal systems, adopt measures which, like those in issue here, introduced limited exceptions to the exclusive rights conferred by a patent and confined the patent monopoly to the specific term for which it was granted, in the interests of promoting full competition in regulated-product markets after the expiry of that term and of realizing the cost-saving benefits that competition in those markets (particularly the health care products market) conferred on society. The TRIPS Agreement did not contemplate that these important societal interests should be overridden by an alleged right of patentees to exploit time-consuming regulatory review systems - which were neither designed nor intended to protect intellectual property rights - in order to extend the term of patent protection and to gain a windfall monopoly.

- $\quad$ Equally, the TRIPS Agreement did not contemplate that these important societal interests should be overridden by the anti-discrimination requirement of its Article 27.1. This provision was not intended to require "across-the-board" derogations from patent rights. That would only defeat the purpose of Article 30 of permitting exceptions that were "limited", and would compel the application of exceptions where they were not needed. Instead, since Article 27.1 did not purport to define the "patent rights" that it required to be made available and enjoyable without discrimination, those rights were the ones enumerated in Article 28.1 of the Agreement, subject to any exception that might be made under Article 30. This interpretation gave effect to the language of Article 27.1 in its context rather than in isolation, and achieved the balance contemplated by Article 7 as an objective of the TRIPS Agreement.

\section{(a) Object, Purpose and Meaning}

4.13 In order to answer the essential question in these proceedings, i.e. whether the challenged measures were "limited exceptions" within the meaning of Article $30^{39}$, Canada argued that the language of Article 30 must be interpreted according to the rules of interpretation contained in the Vienna Convention on the Law of Treaties. Article 31, paragraph 1, of that Convention set out the basic principle that "[a] treaty shall be interpreted in good faith in accordance with the ordinary meaning to be given to the terms of the treaty in their context and in the light of its object and purpose". ${ }^{40}$ Article 31, paragraph 2, of the Vienna Convention went on to specify that the context in which treaty terms were to be read included, among other things, the preamble to the treaty. Canada

\footnotetext{
${ }^{39}$ See the chapeau of paragraph 4.10 above.

${ }^{40}$ Article 31.1 forms part of the "customary rules of interpretation of public international law" within the meaning of Article 3(2) of the WTO Understanding on Rules and Procedures Governing the Settlement of Disputes (1994), and thus applies to the interpretation of the TRIPS Agreement pursuant to Article 64.1 thereof: United States - Standards for Reformulated and Conventional Gasoline, WT/DS2/AB/R, at p. 17.
} 
advanced the following points as being important to bear in mind in seeking to ascertain the scope of Article 30:

- The first recital in the Preamble of the TRIPS Agreement stated that Members were "[d]esiring to reduce distortions and impediments to international trade, and taking into account the need to promote effective and adequate protection of intellectual property rights, and to ensure that measures and procedures to enforce intellectual property rights do not themselves become barriers to legitimate trade" (emphasis added by Canada). The Preamble thus evidenced Members' understanding that protection for intellectual property rights should not go beyond what was "effective and adequate", since any greater level of security would imperil other important interests.

- That basic understanding was expanded upon in Article 7 of the Agreement, where its objectives were stated. Article 7 made it clear that intellectual property rights were not conferred in a vacuum, and that the TRIPS Agreement therefore did not aim to achieve a degree of protection for those rights which would unduly prejudice the vital public interest in social and economic welfare or the rights of others. Article 7 provided that "[t]he protection and enforcement of intellectual property rights should contribute to the promotion of technological innovation and to the transfer and dissemination of technology, to the mutual advantage of producers and users of technological knowledge and in a manner conducive to social and economic welfare, and to a balance of rights and obligations" (emphasis added by Canada).

- When Article 30 was read in context, it could be seen that it reflected the recognition and agreement of Members that the full application of all Article 28 rights at all times and in all circumstances would be inconsistent with the "balanced" objectives of the TRIPS Agreement. Unlike provisions such as Articles 31 and 40, which permitted measures that curtailed the rights of patent holders only where specified conditions were met, Article 30 granted Members the discretion to limit the full application of patent rights in light of the particular circumstances that prevailed in their respective jurisdictions, when balance was required and when social and economic welfare had to be considered. The existence of such a discretion was consistent with the provision of Article 1.1 that Members should be free to determine the appropriate method of implementing the provisions of the TRIPS Agreement, which provisions of course included Articles 7 and 30 as well as Articles 27, 28 and 33.

- The provision of this discretion, in the interests of achieving an appropriate balance in each of the national legal systems, reflected Members' desire to ensure that the limitations on the scope of patent rights that existed within - or were contemplated for - their own intellectual property laws at the time the Agreement was being negotiated would be taken into account.

During the Uruguay Round, an adequate exception provision had been an integral part of the negotiations. Proposals, particularly for exceptions to patent rights, had been made by many Members. ${ }^{41}$

41 Reference was made to: Statement by Thailand at the Meeting of 12-14 September 1988; MTN.GNG/NG11/W/27, p. 2; Guidelines and Objectives Proposed by the European Community for the Negotiation on Trade-Related Aspects of Substantive Standards of Intellectual Property Rights, 7 July 1988, MTN.GNG/NG11/W/26, pages 5-6; Existence, Scope and Form of Generally Internationally Accepted and Applied Standards/Norms for the Protection of Intellectual Property, Note prepared by the International Bureau of the World Intellectual Property Organization, 15 September 1988, MTN.GNG/NG11/W/24/Rev.1, p. 7; Compilation of Written Submissions and Oral Statements Prepared by the Secretariat, 5 February 1988, MTN.GNG/NG11/W/12/Rev.1, p. 14; Proposal by the Nordic Countries for the Negotiations on Standards and Principles for Trade-Related Aspects of Intellectual Property Rights, 10 July 1989, MTN.GNG/NG11/W/36, p. 2; Standards and Principles Concerning the Availability, Scope and Use of Trade-Related Intellectual Property Rights: Communication From India, 10 July 1989, MTN.GNG/NG11/W/37, p. 7 and 
- Although agreeing on the need for safeguard provisions, the negotiators could not agree on the specific circumstances that would merit protection, and had chosen the broad criteriabased text that now appeared as Article 30. Article 30 was not limited to any particular circumstance. It was not limited by reference to any particular purpose or policy objective. It was not limited to any particular type of exception. It was not limited by reference to an exhaustive list of eligible exceptions. Nor was it limited by reference to an illustrative, but non-exhaustive list of special cases justifying an exception.

- More particularly, Article 30 did not require a Member invoking its application to prove that its measure was not a disguised restriction on international trade, unlike the chapeau of GATT 1994, Article XX. ${ }^{42}$ Similarly, Article 30 did not require a Member to prove that its measure was the least trade-restrictive possible, unlike Article $2.2^{43}$ of the Agreement on Technical Barriers to Trade and Article $5.6^{44}$ of the Agreement on the Application of Sanitary and Phytosanitary Measures. Neither did it require a Member to prove that its measure was necessary for any particular purpose, such as "to protect human, animal or plant life or health", as in paragraph (b) of GATT 1994, Article XX. In addition, unlike Article 2.2 of the Agreement on Technical Barriers to Trade, there was nothing in Article 30 even requiring that a Member's measure fulfil a particular objective or take account of the risks that nonfulfilment would create.

- Article 30 also differed significantly from the other exceptions of the TRIPS Agreement itself. ${ }^{45}$ Article 13 (copyright) ${ }^{46}$ stipulated that "Members shall confine limitations or exceptions to exclusive rights to certain special cases which do not conflict with a normal exploitation of the work and do not unreasonably prejudice the legitimate interests of the right holder". Article 17 (trademarks) provided that "Members may provide limited exceptions to the rights conferred by a trademark, such as fair use of descriptive terms, provided that such exceptions take account of the legitimate interests of the owner of the trademark and of third parties" (emphases added).

- By way of contrast, Article 30 was not confined to certain special cases or fair use, and it did allow conflict with a normal exploitation of the patent, provided that the conflict was not

p. 18; Trade-Related Aspects of Intellectual Property Rights: Submission from the European Communities, 14 November 1989, MTN.GNG/NG11/W/49, p. 7; Standards for Trade-Related Aspects of Intellectual Property Rights: Submission from Hong Kong, 29 November 1989, MTN.GNG/NG11/W/51, p. 6; Draft Agreement on Trade-Related Aspects of Intellectual Property Rights (from the EC delegation), 29 March 1990, MTN.GNG/NG11/W/68, p. 10; Communication from Argentina, Brazil, Chile, China, Colombia, Cuba, Egypt, India, Nigeria, Peru, Tanzania and Uruguay, 14 May 1990, MTN.GNG/NG11/W/71, p. 9; Submission from Brazil, 31 October 1988, MTN.GNG/NG11/W/30.

42 "Subject to the requirement that such measures are not applied in a manner which would constitute a means of arbitrary or unjustifiable discrimination between countries where the same conditions prevail, or a disguised restriction on international trade, nothing in this Agreement shall be construed to prevent the adoption or enforcement by any contracting party of measures:" (emphasis added by Canada)

43 "Members shall ensure that technical regulations are not prepared, adopted or applied with a view to or with the effect of creating unnecessary obstacles to international trade. For this purpose, technical regulations shall not be more traderestrictive than necessary to fulfil a legitimate objective, taking account of the risks non-fulfilment would create. Such legitimate objectives are, inter alia: national security requirements; the prevention of deceptive practices; protection of human health or safety, animal or plant life or health, or the environment. In assessing such risks, relevant elements of consideration are, inter alia: available scientific and technical information, related processing technology or intended enduses of products." (emphasis added by Canada)

44 "Without prejudice to paragraph 2 of Article 3, when establishing or maintaining sanitary or phytosanitary measures to achieve the appropriate level of sanitary or phytosanitary protection, Members shall ensure that such measures are not more trade-restrictive than required to achieve their appropriate level of sanitary or phytosanitary protection, taking into account technical and economic feasibility." (emphasis added by Canada)

${ }_{45}$ Other than Article 26.2, which provides for similar limited exceptions with respect to industrial designs

${ }^{46}$ Article 13 was based on Article 9(2) of the Berne Convention for the Protection of Literary and Artistic Works (1971), which was referred in TRIPS Article 2.2. Article 9(2) of the Berne Convention provides: "It shall be a matter for legislation in the countries of the Union to permit the reproduction of such works in certain special cases, provided that such reproduction does not conflict with a normal exploitation of the work and does not unreasonably prejudice the legitimate interests of the author." 
unreasonable. In other words, unlike the other provisions referred to above, there was nothing in Article 30 indicating a limited or special application.

- The extent or scope of the exceptions authorized by Article 30 were only restricted by the requirements that:

(a) they must be "limited";

(b) they must not "unreasonably conflict with a normal exploitation of the patent [...] taking account of the legitimate interests of third parties"; and

(c) they must not "[...] unreasonably prejudice the legitimate interests of the patent owner, taking account of the legitimate interests of third parties".

4.14 Canada argued that the exceptions created by subsections 55.2(1) and (2) of its Patent Act met each of the above requirements, for the following reasons.

\section{Section 55.2(1) and 55.2(2) created limited exceptio ns}

- $\quad$ Canada's measures were "limited" within the ordinary meaning of that word. ${ }^{47}$ The early working exception was restricted to the narrow circumstance where a third party made, constructed, used or sold a patented invention solely for purposes reasonably related to regulatory review. The stockpiling exception could only be used by the person who had relied on the first exception, and was limited to the last six months of the relevant patent. Neither measure affected commercial sales by the patent holder during the term or any other economic benefit of a patent, such as the profit that could be earned through licensing royalties or the sale of the right. ${ }^{48}$

Subsection 55.2(1) permitted a third party to use a patented invention without infringement liability only where the third party made, constructed, used or sold a patented invention solely for uses of the invention that were reasonably related to the development and submission of information required under any law that regulated the manufacture, construction, use or sale of a product to which the invention related. (The reference to selling the invention was necessitated by the fact that a generic drug manufacturer had to usually purchase the active ingredient for its product from a fine chemical producer. Other technical "transfers" made in the course of a regulatory review submission would include administration of the drug to test subjects and use of an outside laboratory for priority testing. $)^{49}$

${ }^{47}$ i.e., according to The New Shorter Oxford English Dictionary, p. 1592, confined within definite limits; restricted in scope, extent, amount.

${ }^{48}$ In response to a question from the Panel, Canada added that Section 55.2(1) was a "limited" measure, because it displayed certain characteristics that restricted or confined its scope of application. In so saying, Canada did not say that these limiting characteristics were necessary characteristics for the purposes of qualifying an exception for the protection of Article 30. What it did say was that these restrictions on the scope of the application of the subsection were sufficient in this particular case to qualify the measure as a "limited exception" within the meaning of Article 30. In Canada's view, the "sufficiency" of the limitations used to restrict the scope of an excepting measure was a question of fact to be determined on a case-by-case basis and would depend on the nature of the exception. Thus, depending on their nature, other exceptions from the exclusive rights conferred by a patent might require different, further or fewer limiting characteristics than were present in this case in order to be sufficient to qualify for the protection of Article 30.

${ }^{49}$ In response to a question from the Panel, Canada explained that, if the patentee claimed that a fine chemical manufacturer was infringing the patent, i.e. was manufacturing fine chemicals for purposes which were outside the exception, the patentee would commence infringement litigation against the manufacturer under Sections 54 and 55 of the Patent Act. The manufacturer would then be obliged to prove that it would have been reasonable, objectively, for a party in its position to believe that the use made of its manufactured active ingredients related to the development and submission of information required by law. It would be common commercial practice for the supply contract with the manufacturer to 
- The contention by the European Communities and their member States that the activities excepted from infringement liability were unlimited in time, quantity and extent, could not be reconciled with the unequivocal wording that Canada's Parliament had used. In particular, the allegations that "very significant quantities of the products protected by a patent" could be manufactured, imported and sold, and that "only the final purchaser of the product" need have the intention to use it for the purposes of a regulatory submission, were at complete variance with the clear requirement that "any person" who engaged in the activities must do so "solely" for uses connected with the development of a regulatory submission. Every other use of a patented invention would be exposed to infringement liability. Significantly, the EC did not explain how this plain language could be misconstrued in the manner for which it contended, and did not refer to any rule of statutory interpretation in support of its position.

- $\quad$ Subsection 55.2(2) permitted only the third party who made, constructed, used or sold a patented invention, in the manner contemplated by subsection 55.2(1), to make, construct or use the invention without infringement liability during the last six months of the patent term only for the purposes of the manufacture and storage of articles intended for sale after the date on which the term of the patent expired.

The attack of the European Communities and their member States on this exception again adopted an interpretation of the language which was not supported by the plain meaning of the words used. The EU alleged that the stockpiling provision could be relied upon by "anybody in Canada". Manifestly, that was not so. Subsection 55.2(2) was expressly limited in its application to a person who had engaged in the activities specified in subsection 55.2(1), i.e. a person who had developed information for the purposes of a regulatory submission. Nothing in the language of subsection 55.2(2) lent any support to the allegation that it had a broader application, and the EC offered no explanation at all for interpreting it that way.

While limiting the right to bring infringement proceedings in the narrow circumstances described in subsections 55.2(1) and 55.2(2), the excepting measures did not otherwise curtail any of the exclusive rights enjoyed by the patent owner. The right holder continued, throughout the full term of protection, to possess the right to bring infringement proceedings to restrain others from any acts of making, using, offering for sale, selling or importing the patented subject-matter outside the restricted scope of the exceptions under Section 55.2. The unsubstantiated allegation that widespread infringing activities could occur during the patent term did not respect the ordinary meaning of the words actually used in the exceptions. $^{50}$

specify the purposes for which the chemicals were being manufactured and to provide an appropriate indemnity against infringement liability. While the matter had not been decided in the courts, the effect of the exception of Section 55.2(2) for the fine chemical producer would appear to be that a third party could acquire intermediate products, or "inputs", such as the bulk fine chemical constituting the active ingredient of a generic drug, for manufacture and storage during the last six months of the patent term. In other words, both the third party and manufacturer would appear to be covered by the exception.

${ }^{50}$ In response to questions from the EC, Canada explained that Section 55.2(2) only relieved against infringement liability in Canada during the prescribed period prior to the expiry date of the Canadian patent where the invention was manufactured, constructed or used to manufacture and store articles for sale after the expiry of the term of protection. It was clear from the express language of the subsection that it did not curtail the patentee's right to prevent sales of articles protected by a Canadian patent during the term of protection accorded to the patentee in respect of the patent. It was equally clear from the language of the provision that it did not impose any restriction on the freedom of persons availing themselves of the protection of the exception, to sell, whether domestically or internationally, such articles as might have been manufactured and stored under the protection of the subsection, in the post-expiry market. Any international sales would, of course, be subject to infringement liability in any importing jurisdiction where the product at issue continued to be subject to the protection of a valid subsisting patent or some analogous instrument conferring supplementary protection on the product. Since a patentee's right during the term of the patent to prevent the unauthorized sale, whether domestic or international, of infringing products ceased with the expiry of the patent, any restriction on the post-expiry sale, including the post-expiry 
- In fact, all of the effects which the European Communities and their member States complained about occurred after the term of protection had expired. The extension of market exclusivity which was lost because generic manufacturers were permitted to make regulatory submissions during the term was of course a post-expiry phenomenon. So too were the lost profits that a patent owner would otherwise have realized during that extended period. These effects were simply the practical consequences of legislation designed to ensure that lowercost competitive products, particularly drug products, reached the market as soon as possible after patent expiry. They were purely commercial concepts, not violations of intellectual property law rights which the TRIPS Agreement either recognized or sought to counteract.

The attempt of the European Communities and their member States to equate Canada's present regime with its previous compulsory licensing system failed to acknowledge that all of the principal effects of compulsory licensing were felt during the term of patent protection. A compulsory licensee was permitted to work a patented invention in full competition with the patent owner. That was plainly not the case under the challenged measures, since they prohibited all commercial sales until after patent expiry.

Additionally, the suggestion of the European Communities and their member States that the period of market exclusivity for the patent holder was about the same under the limited exceptions regime as it was under the former compulsory licensing system was based on a wrong assumption. The pre-Bill C-91 law permitted a compulsory licence to be issued at any time. ${ }^{51}$ However, that law went on to provide that such licences would only become effective to permit otherwise infringing activities linked to "sale for consumption in Canada" after the patented product had been on the Canadian market for seven to ten years. The EC was wrong in thinking that this law prevented holders of compulsory licences from undertaking the kinds of activities now envisaged by subsections 55.2(1) and 55.2(2) before the period of suspension had expired, and that the patentee's period of exclusivity was effectively extended. The Supreme Court of Canada had earlier held that such activities were covered by the experimental use defence. ${ }^{52}$

In any event, even if the respective periods of market exclusivity were about the same, that result would be of no significance in these proceedings. Compulsory licensing was an approach to cost containment adopted by Canada which was fully consistent with the thenexisting international rules respecting intellectual property law. When it appeared that those rules would be adjusted by the TRIPS Agreement, Canada moved to amend its domestic

export sale, of articles manufactured and stored under the protection of the subsection would be tantamount to a de facto extension of the patent term and as such would be antithetical to the underlying motivation of the TRIPS Agreement "to reduce [...] impediments to international trade [...] and to ensure that measures and procedures to enforce intellectual property rights do not themselves become barriers to legitimate trade" (Preamble of the Agreement). As regards Section 55.2(1), its express language allowed "any person to make, construct, use or sell [a] patented invention solely for uses reasonably related to the development and submission of information required under any law of Canada, a province or a country other than Canada that regulates the manufacture, construction, use or sale of any product" (emphasis added). Assuming that the referenced regulatory laws required the preparation of a product in order to develop and submit relevant information relating to that product to the regulatory authorities, the restricted exception would allow any person relying on its authority to prepare the product sufficiently in order to develop that information and make such submissions as the regulatory authorities in Canada, a province of Canada or a country other than Canada required and to do so without exposure to infringement liability in Canada. The excepting provision set out the circumstances in which an otherwise unauthorized use would not attract infringement liability in Canada. The circumstances were focused on the presence of a valid Canadian patent and the potentially infringing uses of the invention that might be required in order to make a viable submission to a competent regulatory authority. The excepting provision was not therefore concerned with the frequency with which the circumstances might arise; they would arise whenever a person wished to make a submission to a regulatory authority and where to do so might require making an infringing use of an invention patented in Canada. Similarly, since the focus of the provision was on infringement in Canada, it referenced the requirements of the laws of other jurisdictions only in order to circumscribe the scope of the exception by linking the relief from infringement liability in Canada to the requirements of any regulatory laws which, if complied with, might involve the infringement of a Canadian patent.

${ }^{51}$ Patent Act, R.S.C. 1985, chap. P-4, subsection 39(4).

${ }^{52}$ Micro Chemicals Limited v. Smith Kline \& French Inter-American Corporation, [1972] 2 S.C.R. 506, at p.520. 
legislation, in order to be consistent with the new obligations. Even if conformity with the new obligations resulted in about the same period of market exclusivity as was produced by conformity with the previous rules, that would simply be a coincidence, not a matter of any consequence under the TRIPS Agreement. Again, the effective period of market exclusivity cited by the EU was a purely commercial concept, not an intellectual property law right or concept which the TRIPS Agreement recognized.

\section{Section 55.2(1) and 55.2(2) did not conflict with a normal exploitation of the patent}

The exclusive rights conferred by a patent were normally exploited by "working" the patent for commercial gain. Typically, this would involve the patentee engaging in any combination of the following activities: using the patent to manufacture and sell the product as a monopolist; licensing the right to use the invention to others in return for the payment of royalty or other compensation; and selling either a part or the whole of its property right in the invention and its patent. ${ }^{53}$ None of these activities was impaired or prevented by the limited exceptions created by subsections 55.2(1) and 55.2(2). The patentee retained the full, unfettered and exclusive right to work the patent for commercial reward during the full term of protection whether by exercising: the unimpaired exclusive right to manufacture and sell the product; the unimpaired exclusive right to license the right to use the invention to others in return for the payment of valuable consideration; and the unimpaired exclusive right to sell, in whole or in part, its property right in the invention and patent. Therefore, at no time during the term of protection, did either exception conflict in any mode or manner with a normal exploitation of the patent.

Where there was no conflict, "unreasonableness" was not at issue.

(iii) Section 55.2(1) and 55.2(2) did not prejudice the legitimate interests of the patent owner

The legitimate interests of a patent owner must, by definition ${ }^{54}$, be interests that related to the rights and duties that the patent laws conferred or imposed, as the case might be, on persons who had developed or subsequently acquired a patentable invention. In other words, legitimate interests arose from the status of being a patent holder, not from the more general status of being a business person or a manufacturer. Thus, in return for disclosing an invention to the public and obtaining the grant of a patent, a patent holder had a legitimate interest in exploiting and enforcing for the duration of the term of protection the exclusive right to "work" the patent as a monopolist and to earn the economic returns that rewarded inventive activity and investment. After the term of protection expired, however, the interest in exploiting the invention could no longer be that of a monopolist. Instead, the interest was reduced to: (a) the right to compete on the open market; (b) any trademark interest in the brand name, which subsisted after patent expiry; (c) any right to prevent "passing off" at common law; and (d) any copyright interest in materials describing the product. None of these interests pertained to patent protection and none was affected by Canada's limited exceptions.

Since the exceptions created by subsections 55.2(1) and 55.2(2) did not conflict with the normal exploitation of the patent during the term of protection, they did nothing to prejudice the legitimate interest of the patent owner in respect of the right to exploit the patent for the full duration of its term of protection. Similarly, since they did not impair a patentee's

${ }^{53}$ Staniforth Ricketson, The Law of Intellectual Property, The Law Book Co. Ltd., Sydney, Australia (1984), at pp. 1012-19; $C f$. TRIPS, Art. 28.2: "Patent owners shall also have the right to assign, or transfer by succession, the patent and to conclude licensing contracts."

54 "Legitimate: ... Conformable to law or rule; lawful, proper" (New Shorter Oxford English Dictionary, p. 1563) 
right to bring infringement proceedings at any time during the term of protection to restrain others from making any commercial sale of the patented invention, they did nothing to prejudice the patent owner's legitimate interest in prohibiting commercial exploitation during the term of protection.

The interest that a patentee could have in restraining, during the term of protection, the activities that were sheltered from infringement liability by subsections 55.2(1) and 55.2(2) involved exploiting regulatory review laws which delayed the market entry of competitor products subject to those laws, in order to extend the patentee's monopoly beyond the term of protection specified by the patent law. As was apparent from their submission, it was that windfall period of protection that the European Communities and their member States asserted here. Such gratuitous distortion of the competitive market could not be said to be a legitimate interest. That interest could not be said to be legitimate, because by treaty and domestic law prescription, patents only conferred exclusive rights for a specified term. When the prescribed term expired, so did the exclusive rights. Accordingly, and notwithstanding the private economic advantage that would be obtained by doing so, a patentee could have no legitimate interest deriving from patent law in exercising its exclusive use and enforcement rights within the term of protection to achieve, through exploitation of regulatory review laws, a de facto extension of that term of protection beyond the prescribed period, thereby unilaterally altering the bargain between the patentee and society. In this respect, the interests of a patentee of a pharmaceutical invention could be no different from those of patentees in other fields of technology.

(iv) Section 55.2(1) and 55.2(2) took account of the legitimate interests of third parties

If, however, a patentee's "normal exploitation" involved more than working the patent for commercial gain, or if the patentee's "legitimate interest" included exercising its exclusive rights during the term so as to extend the term unilaterally beyond the period specified by statute, neither the exploitation nor the interest was affected unreasonably by the disputed measures, "taking account of the legitimate interests of third parties".

In this context, "third parties" had to be a reference to those who were adverse in interest to the patent owner. Persons not adverse in interest, such as licensees, were already covered by the protection that was extended to the patent owner. Consequently, "third parties" had to mean all those who, not having a property interest in the patent, had an interest in the availability, consumption, cost or production of regulated products that were subject to the protection of a patent. Thus "third parties" included society at large, individual and institutional consumers of such regulated products and would-be competitor producers of those products. In the particular case of pharmaceutical products, the "third parties" included the individual users of Canada's health care system and the public and private sector entities that paid for it.

This reading of Article 30 was the one that gave proper effect to its terms in the context in which they were found. The TRIPS Agreement as a whole was framed so as to achieve balance between competing interests, and to ensure that the assertion of patent rights did not prevent the realization of other important societal objectives. As stated in the first recital of its Preamble and in the objectives endorsed by its Article 7, the TRIPS Agreement was not intended to promote patent rights at the expense of legitimate trade, social and economic welfare, and the rights of others. In order to achieve the desired balance, these latter interests had been recognized in the reference in Article 30 to "third parties".

The interests of these third parties were that the exclusive rights granted to patentees for a specified term of protection would be extinguished on the expiry of that term and that 
competitive conditions would thereafter govern the operation of the previously monopolized market for the regulated products at issue. The interest in the reinstatement of competition was not merely a "legitimate interest", it was a right which derived from the first principles of patent law. As stated in a report to Congress by the United States House of Representatives Committee on Energy and Commerce: "[T]he Constitution empowers Congress to grant exclusive rights to an inventor for a limited time. That limited time should be a definite time and, thereafter, immediate competition should be encouraged. ${ }^{155}$

Third parties therefore had an undeniably legitimate interest in measures which ensured that patent rights were not exercisable in a manner that effectively extended the term of protection sanctioned by statute, thereby giving the former patentee a gratuitous monopoly and restraining trade unreasonably in the post-expiry market.

In this regard, it was significant that Articles 8.2 and 40 acknowledged that Members could invoke measures to control the abuse of patent rights by curtailing, whether by compulsory licence or revocation, the patent right for some or all of the remainder of its term of protection. Where such measures could be taken consistently with the Agreement to control the exercise of intellectual property rights that had an abusive or anti-competitive effect during the term specified for their protection, then a fortiori similar measures, which did not conflict with a normal exploitation of the patent, could also be taken consistently with the Agreement to prevent the anti-competitive effects of the patent after its term of protection had expired.

- $\quad$ The legitimacy of the third party interest in the adoption of measures like those enacted by Section 55.2 to counteract the post-expiry monopoly for regulated products was particularly pronounced in the cases of both users and payers of health care products. Public health was a value whose importance was recognized as a matter of principle in Article 8.1 of the TRIPS Agreement. Accordingly, the exercise of exclusive rights in respect of regulated health care products during the term of protection to extend the patentee's monopoly into the post-expiry market was of particular concern in the pharmaceutical products sector: "It is generally accepted that the scope and duration of the patent monopoly must be limited, because monopolies are inherently economically inefficient. A monopolist profits by reducing output below competitive levels and correspondingly raising the price, causing a "deadweight loss" to society. In the pharmaceutical context, outside the patent term, a monopoly would mean that the quantity of drugs available to society would be less than optimal, due to sales at prices considerably higher than marginal cost. ${ }^{156}$

- The cost of health care was a major concern for all WTO Member countries. A significant component of health care costs was the expense of drug therapies. Most Members, including both parties to this dispute, had taken positive measures to contain those costs, including direct price controls and incentives to encourage the use of generic drugs. The latter were particularly relevant here, since the creation of sophisticated and technical review requirements had meant that the only way to ensure a supply of generic drugs in the market as soon after patent expiry as possible was through an exception to the patent monopoly for purposes related solely to the development of information required to obtain marketing authorization for competitive versions of a patented product.

- $\quad$ The use of generic medicines resulted in important economies for the public health care system, and so contributed to its viability and the protection of public health. In view of

${ }^{55}$ Harold C. Wegner. Patent Law in Biotechnology, Chemicals \& Pharmaceuticals (2nd ed.), Stockton Press (N.Y.:1994), p. 475.

${ }^{56}$ Ben Hattenbach. "GATT, TRIPS and the Small American Inventor: an Evaluation of the Effort to Preserve Domestic Technological Innovation" (1995), 10 Intellectual Property Journal 61 at p. 95 
this, it was not surprising that Members had pursued a wide variety of measures to promote the use of generic drug products: "The actual level of growth of the generic market is becoming increasingly influenced by regulatory measures being introduced by governments and other payers for health care aimed either at forcing or encouraging the increased use of generic products. These measures have been introduced in response to the rising costs of health care in the major markets. ${ }^{157}$

Measures that sought to control the costs of the health care system and to ensure access to needed drug therapies were obviously conducive to social welfare. As such, they could properly be adopted by Members pursuant to Article 30, as a means of achieving the balance contemplated by Article 7. In the post-expiry market, the interests of consumers and payers in ensuring access to less costly generic drugs were legitimate and important, while a patentee's interest in extending the period of monopoly was not one that was recognized in the TRIPS Agreement, let alone sanctioned as legitimate.

The legitimacy of measures to promote the use of generic drug products as means of protecting public health was endorsed by the World Health Organization (WHO). In its resolution scheduled for adoption in May 1999, in connection with its Revised Drug Strategy, the WHO encouraged its members "to explore and review their options under relevant international agreements, including trade agreements, to safeguard access to essential drugs". ${ }^{58}$ The WHO's Revised Drug Strategy also called for the use of generic drugs as a necessary means for ensuring a supply of essential drugs for individuals in all member states: "Drug supply is certainly one component of an essential drug policy whose economic advantages have been most studied. Generic drug programmes are today probably the most relevant economic strategy for drug supply. The most important economic feature of generic drugs is that, unlike the situation with named brands, they allow for competition among producers of a given drug." ${ }^{59}$ (emphasis added by Canada)

Thus, society at large and individual and institutional consumers of the health care system had an undeniably legitimate, indeed essential, interest in assuring the availability of competitively priced generic medicines as soon after patent expiry as possible. Canada's measures served that interest, and in doing so complied with the fundamental objectives, referred to in the TRIPS Agreement, of promoting social welfare and achieving balance between rights and obligations, while protecting the legitimate interests of intellectual property rights holders.

\section{(b) Travaux Préparatoires and Subsequent Practice}

4.15 Canada further argued that recourse to the additional interpretative aids of treaty interpretation as referred to in Article 32 of the Vienna Convention, namely the "preparatory work of the treaty and the circumstances of its conclusion" and "any subsequent practice in the application of the treaty" confirmed the conclusion that its measures fell squarely within the ordinary meaning of the text of Article 30. Canada advanced the following arguments in support:

- $\quad$ During the Uruguay Round, the EU had sought to restrict exceptions to non-commercial purposes, as evidenced by its proposal for a Draft TRIPS Agreement of 29 March 1990, which contained a provision reading: "Limited exceptions to the exclusive rights conferred by a patent may be made for certain acts, such as rights based on prior use, acts done privately

\footnotetext{
${ }^{57}$ Amanda Southworth, Generic Pharmaceuticals (1996 ed.), a Financial Times Management Report, p. 9

${ }^{58}$ World Health Organization Executive Board Resolution EB103.R1, January 26, 1999, scheduled to be tabled by the World Health Assembly in its 52nd session, May 17-25, 1999, Articles 1.3 and 2.7

${ }^{59}$ Fernando S. Antezana and Germàn Velàsquez. Health Economics: Drugs and Health Sector Reform. WHO Task Force on Health Economics, December 1996, p. 13
} 
and for non-commercial purposes and acts done for experimental purposes, provided that they take account of the legitimate interests of the proprietor of the patent and of third parties." ${ }^{60}$

- However, many developing countries had argued for a much broader approach to excepting measures, including measures which would permit compulsory licensing of food and medicines: "Nothing in this Agreement shall be construed to prevent any Party from taking any action necessary:

i) for the working or use of a patent for government purposes; or

ii) where a patent has been granted for an invention capable of being used for the preparation or production of food or medicine, for granting to any person applying for the same a licence limited to the use of the invention for the purposes of the preparation or production and distribution of food and medicines." ${ }^{61}$

- In the end, a compromise was reached, which now appeared as Article 30. It was significant that its language not only was not confined to "acts done for non-commercial purposes", but also expressly allowed some degree of conflict with a normal exploitation of the patent and some degree of prejudice to the legitimate interests of the patent owner.

- This was in part due to the fact that the United States, the major demandeur with respect to patent protection, was intent on securing an exception that allowed its pre-existing Bolar exemption" to be preserved. This was confirmed by the United States Trade Representative (and subsequently reiterated by his successor): "[O]ur negotiators ensured that the TRIPS Agreement permits the Bolar exemption to be maintained."62

- The Bolar exemption" had been in existence for several years before the TRIPS Agreement was negotiated, and negotiators must have known of its existence. They apparently did not take issue with the proposition that it was a limited exception. Accordingly, the "Bolar exemption" must be an example of the type of exception that was intended to come within Article 30.

- In addition, at the time the TRIPS Agreement was being negotiated, guidelines issued by the United States Food and Drug Administration contained a provision requiring that, as a precondition to regulatory approval, a generic manufacturer had to make at least three full production runs on a commercial scale.

- It was inconceivable that an agreement on pharmaceuticals could have been reached without the support of the United States, since agreement in this area was pivotal to concluding the whole Uruguay Round: "The question of the protection of pharmaceutical patents was one of the key issues in the negotiations as a whole and perhaps the key issue in the North-South axis of the negotiations. It was the last issue to be resolved in the negotiations prior to the tabling of the draft Agreement at the end of 1991. At that time, it was clear that there would be no TRIPS Agreement without a commitment to make available patent protection for 20 years in virtually all areas of technology, including pharmaceuticals,

\footnotetext{
${ }^{60}$ GATT document MTN.GNG/NG11/W/68, p. 10, Art. 24(2)

${ }^{61}$ Communication from Argentina, Brazil, Chile, China, Colombia, Cuba, Egypt, India, Nigeria, Peru, Tanzania and Uruguay, 14 May 1990, p. 9, Art. 6

${ }_{62}$ Letter from Michael Kantor to Alfred B. Engelberg, 1 February 1996. Confirmed in a letter from Charlene Barshefsky to Greg Perry, 1 January 1997
} 
and that without a TRIPS Agreement it was doubtful that the Uruguay Round could be concluded."163

Moreover, the subsequent practices of many Members since the Dunkel text - whether through the judicial interpretation of the experimental use defence or their own legislation had allowed an exception to exclusive use rights for generic drug and other regulated product applications for marketing authorizations. ${ }^{64}$ For example:

In Germany, the Federal Court of Justice had recently confirmed that clinical tests to establish the efficacy and human tolerance of a drug containing a patent-protected chemical ingredient would not infringe the patent, regardless of the commercial nature of the tests, by virtue of the experimental use exception in German patent law, provided that such tests also advanced the state of the art in some way. ${ }^{65}$

In Italy, the Court of Milan had held that a patent holder could not prevent a generic manufacturer from experimental activity in connection with an application for regulatory review during the term of the patent. ${ }^{66}$

In Japan, the courts had also concluded that use for regulatory review purposes was sheltered from infringement liability by the experimental use defence in Japanese law. The Japanese Supreme Court had unanimously affirmed the judgment of the Tokyo High Court that the use of a patented invention for purposes of obtaining a licence to market a generic version of a patented medicine was not an infringement of the patent. ${ }^{67}$

These decisions had all been rendered after the conclusion of the Uruguay Round. Accordingly, had those Members considered that the decisions rendered their laws noncompliant with their TRIPS obligations, they would have introduced legislation to overturn the decisions, since the TRIPS Agreement was now in force in all those jurisdictions. None had done so.

Similarly, Portugals national industrial property office interpreted the experimental use provision in Portugal's patent law as allowing the necessary development work for a competitor product to obtain marketing authorization immediately upon patent expiry - to take place during the patent term. ${ }^{8}$

As a legislative solution to the monopoly extension problem, $\underline{\text { Hungary }}$ had amended its patent law, in 1995, expressly allowing for tests of generic drugs in connection with an application for marketing authorization: "The exclusive right of exploitation shall not extend to: [...] b) acts done for experimental purposes relating to the subject matter of the invention, including experiments and tests necessary for the registration of medicines." ${ }^{69}$

\footnotetext{
${ }^{63}$ Adrian Otten, "The implications of the TRIPS Agreement for the protection of pharmaceutical inventions", WHO Drug Information, Vol. 11, No. 1, 1997, pp. 12-16, in particular p. 13

${ }^{64}$ In interpreting the terms of a treaty, subsequent practice is to be considered together with the context in which the terms are found: Vienna Convention, Article 31(3)(b).

${ }^{65}$ Klinische Versuche (Clinical Trials) II, [1998] R.P.C. 423

${ }^{66}$ E.R. Squibb \& Sons Inc. v. Giovannia Aguggini, 12 June 1995, T. Milano

67 Otsuka Pharmaceutical Co., Ltd. v. Towa Yakuhin K.K., Tokyo High Court, Civil 6th Division, Case No. 3498(ne), 31 March 1998; affirmed by Second Petty Bench of the Supreme Court, Case No. 1998 ju) 153 , April 16, 1999.

${ }^{68}$ Letter from Madalene Abreu, Information Services Director, Instituto Nacional de Propriedade Industrial, to Nadene McClay, European Generic Medicines Association, 29 April 1998

${ }^{69}$ Law No. XXXIII of 1995 on the Protection of Inventions by Patents, Art. 19(6).
} 
Similarly, Argentina $(1996)^{70}$, Australia $(1997)^{71}$ and Israel $(1998)^{72}$ had amended their respective patent laws to allow expressly for experimentation and testing relating to generic drugs solely for the purposes of review of regulated products that were subject to patent protection. Again, all these legislative amendments had taken place after the conclusion of the Uruguay Round.

- In summary, both the circumstances surrounding the negotiation of the Agreement and subsequent state practice confirmed that exceptions to the exclusive rights conferred by a patent which permitted experimentation and testing in connection with marketing authorizations were within the ambit of Article 30.

\section{ARTICLE 27.1 OF THE TRIPS AGREEMENT}

(a)

\section{Object, Purpose and Meaning}

4.16 Canada argued that the scope of the Article 27.1 obligation to make patent rights available and enjoyable without discrimination hinged on the meaning of the term "patent rights". It gave rise to the question whether:

(a) the term referred to the patent rights listed in Article 28.1 of the Agreement, without regard for Article 30 thereof, or any measure preserved by that Article; or

(b) the term referred to the rights enumerated in Article 28.1, subject to any exception that might be made under Article 30.

However, following the applicable rules of treaty interpretation led to the conclusion that the meaning reflected under (b) above was the correct one. Canada advanced the following points in support:

- As Article 32(b) of the Vienna Convention on the Law of Treaties indicated, the interpretation of treaty terms should not produce manifestly absurd or unreasonable results. The adoption of the meaning of Article 27.1 reflected under (a) above would clearly violate

${ }^{70}$ Argentine Law 24.766 of December 1996, Article 8: "When a product or process is protected by a patent, any third party shall be able to use the invention before the expiration of the patent, with experimental aims and to gather the information required for the approval of a product or process by the competent authority, for its commercialization after the expiration of the patent."

${ }^{71}$ Patent Act, 1990, subsection 78(2), as added by Intellectual Property Laws Amendment Bill 1997: If the Commissioner grants an extension of the term of a standard patent, the exclusive rights of the patentee after the grant of the extension are not infringed by a person exploiting:

(a) a pharmaceutical substance per se that is in substance disclosed in the complete specification of the patent and in substance falls within the scope of the claim or claims of that specification; or

(b) a pharmaceutical substance when produced by a process that involves the use of recombinant DNA technology, that is in substance disclosed in the complete specification in substance falls within the scope of the claim or claims of that specification;

solely for purposes in connection with

(c) having goods included in the Australian Register of Therapeutic Goods, where the goods are intended for therapeutic use; or

(d) obtaining similar regulatory approval under the law of a foreign country or part of a foreign country.

72 Patents (Amendment No. 3) Law, 5758-1998, section 54A: An experimental activity within the process of obtaining a licence for the marketing of a product after the expiry of a patent shall not be regarded as 'exploitation of an invention' if the following two conditions are fulfilled:

(1) the process of obtaining the licence was carried out for the purpose of obtaining such licence in Israel or in a State which permits experimental activity in respect of a patented invention for the purpose of obtaining a licence prior to the expiry of the patent;

(2) the whole of the product produced within the scope of the provisions of this section shall not serve for any purpose except for obtaining the said licence, either during the term of the patent or thereafter.

For the purposes of this section, 'licence' means an authorization, permit or any other document required by law for marketing a product. 
that rule of construction. It would lead to a requirement for "across-the-board" derogations from patent rights, thus compelling exceptions where there was no practical need and reducing patent protection more than was required in all areas save those in which a balancing measure was actually required. Such an incongruous result would not be consistent with the objectives of the TRIPS Agreement.

- $\quad$ Article 31.1 of the Vienna Convention required that treaty terms be read in their context and in light of the objects and purposes of the treaty. Flowing from this was the principle of effectiveness, a fundamental tenet of treaty interpretation which, as the Appellate Body had recognized, meant that "[w] hen a treaty is open to two interpretations one of which does and the other does not enable the treaty to have appropriate effects, good faith and the objects and purposes of the treaty demand that the former interpretation should be adopted" ${ }^{173}$ (emphasis added by Canada).

- The application of that principle underscored the correctness of the meaning of Article 27.1 as reflected under (b) above. Reading Article 27.1 in the context of other provisions which permitted exceptions to be made to the exclusive rights, and in light of the overall balance that the TRIPS Agreement sought to achieve (particularly in connection with social and economic welfare), the "patent rights" it referred to were those enumerated in Article 28.1 of the Agreement, subject to any exceptions made under its Article 30.

- Thus, after the allowable limited exceptions had been made, the remaining minimum patent rights had to be enjoyable across all fields of technology. This was the interpretation of Article 27.1 that was consistent with the intent of Article 30, i.e. allowing exceptions that were "limited" because they were not spread across all sectors of technology, and which respected the objective, as reflected in the TRIPS Agreement, of ensuring balance, by avoiding an anti-discrimination rule which would overwhelm other important societal interests if it had to be applied "across the board", without regard for particular circumstances.

- The European Communities and their member States did not seek to read Article 27.1 in its context and in light of the TRIPS objectives but, instead, asserted that Article 27.1 was absolute in nature, such that "violations" of its provisions could not be justified under Article 30. This approach, in failing to give effect to the applicable rules of interpretation, simply led to the undesirable and absurd results referred to above. It deprived Members of the ability to create appropriate solutions for specific problems on a case-by-case (or product group by product group) basis, and instead obliged them to impose universally applicable measures which could be entirely inappropriate in most contexts. It required "limited exceptions" to be unlimited.

(b) Travaux Préparatoires and Subsequent Practice

4.17 Canada further argued that the correctness of the meaning reflected in the chapeau of paragraph 4.16 above under (b) was confirmed through recourse to the additional interpretative aids set out in Article 32 of the Vienna Convention ("preparatory work of the treaty and the circumstances of its conclusion" and "any subsequent practice in the application of the treaty"). Canada advanced the following points in support:

A reference to the drafting history of Article 27.1 was instructive. Its structure and wording reflected two separate negotiating thrusts: (a) a desire to ensure that subject to certain listed exceptions, patents would be available for inventions in all fields of

${ }^{73}$ Japan - Taxes on Alcoholic Beverages, WT/DS8/AB/R, WT/DS10/AB/R, WT/DS11/AB/R, p. 12 and note 21 (quoting (1966) Yearbook of the International Law Commission, Vol. II, p. 219) 
technology ${ }^{74}$; and (b) a desire to eliminate compulsory licence provisions respecting food and drug products in national patent laws. ${ }^{75}$

- There was nothing in the drafting history to suggest that the prohibition against discrimination on the basis of field of technology was ever meant to override limited exceptions.

- Thus, Canada's interpretative approach was consistent with the circumstances of negotiation. The United States had, at that time, in its legislation, a 'Bolar exemption" that applied to the pharmaceuticals (and later medical devices) industry.

- Canada's approach was also consistent with subsequent practice. Similar exemptions had been introduced into a number of Members' laws, following the conclusion of the Uruguay Round, on the basis - for the most part, in contrast to Canada - of their application to the pharmaceutical industry only. If this analysis and conclusion were not correct, then the national laws of all those Members which contain an exemption for the use, by a pharmacist, of a patented pharmaceutical invention in the course of preparing and dispensing a medicinal compound would discriminate as to the field of technology in which the invention occurred, and would therefore also not be consistent with the TRIPS obligations of those states. ${ }^{76}$

- Consequently, Canada's measures did not contravene Article 27.1, because the term "patent rights", as used in that provision, meant the exclusive rights set out in Article 28.1 as they might be modified pursuant to Article 30 .

\section{(c) Section 55.2(1) and 55.2(2) are not Discriminatory}

4.18 Canada further argued that, in any event, the limited exception measures as set out in subsections 55.2(1) and 55.2(2) were not discriminatory in respect of the field of technology in which an affected invention occurred, because the exceptions were not expressly related to any particular field of technology in which a patented invention occurred. In this regard, Canada advanced the following points:

- $\quad$ The limited exceptions created by the impugned measures of the Patent Act were related to patents of invention which concerned products that were subject to laws regulating the manufacture, construction, use or sale of the products at issue, whether patented or not. ${ }^{77}$

- The allegation that, during the formal consultations under the DSU, the Canadian authorities had confirmed that the disputed measures only applied to pharmaceuticals, was incorrect. Canada had consistently maintained that its limited statutory exceptions did not discriminate on the basis of field of technology, and that subordinate regulations had been introduced only where a need for them had arisen.

\footnotetext{
(unpublished).

${ }^{74}$ Reference was made to the TRIPS $10+10$ meeting, 16 December 1991, Speaking Note for the Chairman

${ }^{75}$ Op Cit, at p. 8

${ }^{76}$ Provision for the dispensing pharmacist's exception is made in ten of the 15 EU member States (Belgium, Denmark, France, Germany, Greece, Ireland, Luxembourg, Netherlands, Sweden and the United Kingdom) as well as the Czech Republic, Hungary, Iceland, Norway, the Slovak Republic and Slovenia.

${ }^{77}$ In response to a question from the EC, Canada explained that Canadian courts had held that the unauthorized importation of a substance manufactured abroad in accordance with a process claimed in a subsisting Canadian patent infringed a patentee's exclusive right to make, use and sell to others to use (American Cyanamid Co. v. Charles E. Frosst \& Co. [1965] 2 Ex. C.R. 355 and Wellcome Foundation Ltd. et al. v. Apotex Inc. (1991), 39 C.P.R. (3 ${ }^{\text {rd }}$ ) 361). Since Section 55.2(2) exempted the third party manufacture, construction or use of a patented invention for the manufacture and storage of articles intended for sale after the expiry of the patent, the exemption could be interpreted to apply to both domestic manufacture and importation of the regulated product. However, this specific issue respecting the scope of the Section 55.2(2) exception had not yet been heard or determined by the Canadian courts.
} 
- The issue concerning the application of Canada's limited exceptions was not, therefore, that they were most noticeably operative in respect of one particular industry, i.e. pharmaceuticals. Instead, it was whether or not those exceptions were available to all fields of technology that involved the development of products whose manufacture, construction, use or sale was subject to pre-marketing regulation.

- $\quad$ By their express language, the measures were available for any industry that required pre-marketing authorization for its products. Indeed, the regulatory review exception had been raised as a defence in an action for patent infringement arising out of the use of a medical apparatus. ${ }^{78}$

- The field of application of the stockpiling exception - which was coterminous with that of the regulatory review measure - was similarly uncircumscribed by any reference to field of technology. The difference was that the stockpiling exception was restricted temporally and had so far only been made operative, by means of subordinate regulations, for the pharmaceutical industry.

- To this point, the pharmaceutical industry was the only one where the need for the application of the stockpiling measure had been made apparent. This ensured that the measure was limited in nature. However, the fact that subordinate regulations had so far only been promulgated for one industry did not deprive the executive branch of the Canadian Government of its express statutory authority to adopt regulations for other industries as and when required. ${ }^{79}$

\section{Object, Purpose and Meaning}

4.19 Canada argued that, firstly, Article 33, read in its context, was clearly limited to defining the longevity of a patent right and did not define the right itself, advancing the following points:

- $\quad$ Patent rights were defined by Article 28, subject of course to any exceptions that might be authorized by Article 30. Thus, to the extent that Article 33 had any bearing on the existence or content of a right, it was subject to the provisions of Articles 28 and 30 of the Agreement.

Accordingly if, pursuant to the authority of Article 30, the scope of a right under Article 28 was restricted in a manner that could be said to reduce the minimum term of protection, Article 33 could not operate to negate the restriction and restore the right to its 289 (Fed. C.A.)

${ }^{78}$ Visx, Inc. v. Nidek Co. et al. (1997), 77 C.P.R.(3d) 286 (Fed. Ct. T.D.), appeal allowed (1998), 82 C.P.R.(3d)

${ }^{79}$ In response to a question from the EC, Canada elaborated as follows. By virtue of its restrictive reference back to the person and use referred to in Section 55.2(1), the limited exemption from infringement liability established by Section 55.2(2) would be applicable to the manufacture and storage of any product covered by a patent whose manufacture, construction, use or sale was subject to regulation. The restricted excepting measure was, therefore, available in law to shield otherwise unauthorized uses of patented inventions in other sectors where regulatory review or approval was required for products that were the subject-matter of patent protection. However, by virtue of the fact that it was only applicable during a prescribed period immediately preceding the expiry of a patent, the restricted exception was inoperative unless and until the Governor in Council (Canada's executive branch of government) exercised the authority delegated by Section 55.2(3) to make regulations prescribing whatever period of application might be appropriate in the circumstances surrounding the manufacture, construction, use or sale of the regulated product in question. To date, the Governor in Council had only exercised this authority to make the Manufacturing and Storage of Patented Medicines Regulations, to define the period during which the exception would operate in respect of regulated medicinal products. However, the Governor in Council's authority to regulate was not thereby spent. Accordingly, the executive government remained empowered to promulgate at any time further regulations respecting any other regulated product sector where the need for similar regulations might arise. 
original or ordinary scope. It could not operate in that fashion, because the result produced would plainly be absurd.

If Article 33 could negate an exception under Article 30, then the national laws of all Members which contained exceptions that curtailed, in whole or in part, the scope of a right under Article 28 and thereby limited its enjoyment for the whole or a part of the term of protection, would reduce the term by the degree of curtailment and so contravene or not be consistent with the obligation imposed by Article 33 .

(b) Section 55.2(1) and 55.2(2) do not Reduce the Required Minimum Term of Protection

4.20 Canada then argued that, in any event, neither subsection 55.2(1) nor subsection 55.2(2) of the Patent Act reduced the minimum term of protection referred to in Article 33 of the TRIPS Agreement to a term that was less than that minimum. According to Canada, subsections 55.2(1) and 55.2(2) created limited exceptions which did not conflict with the normal exploitation of a patent so as to reduce the term of protection accorded to the patent. Referring to its arguments as to why the provisions in question created "limited exceptions" within the meaning of Article 30 of the TRIPS Agreement ${ }^{80}$, it drew attention to the following points:

- A patentee whose rights might be affected by the application of the limited exceptions retained the full, unfettered and exclusive right to work the patent for commercial reward during the full term of protection, whether the "working" involved the monopolistic manufacture and sale of the product; the licensing of the right of use to others for valuable consideration; or the sale, in whole or part, of the property right in the patent.

- Similarly, a patentee affected by the limited exceptions continued, throughout the full term of protection, to possess the right to bring infringement proceedings to restrain others from any commercial sale of the patented invention.

- Furthermore, in addition to retaining the rights to work and to restrain, where a person who had used an invention in the manner contemplated by the exceptions sought marketing authorization for a pharmaceutical product during the term of protection on the basis of an allegation that the person would not infringe the product or product-by-process patent, the patentee could bring a summary proceeding under the Patented Medicines (Notice of Compliance) Regulations to challenge that allegation and, where successful, prohibit the issuance of the marketing authorization until the expiry of the patent. ${ }^{81}$

- Where a patentee could bring such proceedings to prevent the issuance of a marketing approval certificate until the expiry, at the conclusion of the full term of protection, of its patent, it could not be tenably argued that the limited exceptions created by subsections 55.2(1) and 55.2(2) of the Patent Act reduced the term of protection to a term shorter than the term prescribed by Article 33.

(4) THE LEGISLATIVE HISTORY OF THE DISPUTED PROVISIONS, THEIR FRAMING, THEIR LEGISLATIVE CONTEXT AND THE DEBATE ON COST CONTAINMENT AND GENERIC DRUGS

4.21 Canada advanced the following information concerning the legislative history of the provisions at issue in order to explain the various public policy objectives that their introduction had sought to take into account:

\footnotetext{
${ }^{80}$ See paragraph 4.14 above

${ }^{81}$ See paragraph 2.7 above.
} 


\section{The Legislative History of the Disputed Provisions}

Before the TRIPS Agreement, Canada had been bound only by the Paris Convention on the Protection of Industrial Property (London Act, 1934). ${ }^{82}$ Under that Convention (and its predecessors), member states had created a Union in which each member was to accord national treatment, including filing date priority, to citizens of other member states with respect to patent applications. ${ }^{83}$

- $\quad$ However, minimum standards for substantive patent protection were not addressed to any significant extent under the Convention. In contrast to the TRIPS Agreement, it allowed for the compulsory licensing of patented technology, with only minimal, self-judging constraints. ${ }^{84}$

Canada had introduced provisions into its Patent Act for compulsory licensing for the domestic manufacture of patented food and medicine products in $1923{ }^{85}$ In 1969 , the original compulsory licensing provisions had been expanded to allow the importation of the active ingredients for licensed patented drug products. ${ }^{86}$ The Act had again been amended in 1987 to suspend the operation of a compulsory licence to prohibit the importation or the manufacture of the medicine for sale consumption in Canada for periods ranging from seven to ten years, measured from the date of the Notice of Compliance (marketing authorization) first issued in Canada on the medicine. ${ }^{87}$ This compulsory licensing system was consistent with the international rules respecting intellectual property rights established by the Paris Convention.

By providing competition for patented medicines during the term of protection, the compulsory licensing system had become an important policy tool for cost containment in Canada's public health care system during this period. It had been estimated that, during its currency, compulsory licensing saved Canadian consumers of prescription medicines and the third parties who might have paid for them many millions of dollars each year in health care costs by opening the market to competitively priced medicines during the period of patent protection. $^{88}$

During the Uruguay Round, a major objective of many participants had been the elimination of the compulsory licensing provisions respecting patented foods and medicines in national intellectual property laws.

In December 1991, the Dunkel text ${ }^{89}$ of the TRIPS Agreement had been released in connection with the Uruguay Round. Canada, the United States and Mexico, who were negotiating the North American Free Trade Agreement (NAFTA) at the time, all anticipated that the Dunkel text would become the new international standard for patent protection. Consequently, they had incorporated its substance, particularly as regards patents, into Chapter 17 of NAFTA.

${ }^{82}$ In force in Canada as of 30 July 1950. Under Article 2.1 of the TRIPS Agreement, Canada is now bound by the Stockholm Act, 1967 of the Paris Convention.

${ }^{83}$ Articles 1, 2 and 4 of the Convention

${ }^{84}$ Article $5 \mathrm{~A}$ of the Convention

${ }^{85}$ S.C. 1923 , Chap. 23 , s. 17

${ }^{86}$ S.C. $1968-69$, Chap. 49

${ }^{87}$ S.C. 1987, Chap. 41, adding sections 41.11 and 41.14. These amendments also established the Patented Medicines Price Review Board.

${ }^{88}$ A Royal Commission estimated that the annual total savings to Canadians from compulsory licensing was \$211 million in 1983 (Report of the Commission of Inquiry on the Pharmaceutical Industry, H.C. Eastman, 1985, at p. 315).

${ }^{89}$ MTN.TNC/W/FA, dated 20 December 1991. 
- $\quad$ The Dunkel text restricted the ability of states to adopt compulsory licensing measures. Specifically, Article 31 confined their grant to particular individual circumstances or as a remedy for anti-competitive practices. $^{90}$

It had been anticipated that the TRIPS Agreement would come into force before NAFTA $^{91}$, which was scheduled to take effect on 1 January $1994 .{ }^{92}$ Accordingly, the Government of Canada had, in June 1992, introduced the Patent Act Amendment Act, 1992 (Bill C-91) in Parliament in order to ensure that Canada's patent law would conform with its international obligations when they came into force.

- $\quad$ As described by Canada's Federal Court of Appeal, Bill C-91 "[...] was drafted in order to protect innovator pharmaceutical companies' distribution and sales rights to patented drugs and represents a reversal of government policy adopted by Parliament in 1923. [...] The immediate effects of Bill C-91 are well known. Section 3 of the Bill repealed the compulsory licensing provisions of the Patent Act, while subsection 12(1) extinguished all compulsory licences issued on or after December 20, 1991. [...] $]^{193}$

However, Bill C-91 also pursued other public policy objectives. One such objective was to find another policy tool to address cost containment in the health care system, to the extent permitted under Canada's new obligations. This objective had arisen out of the concern that expenditures on therapeutic drugs had been rising steadily for several years, and had been becoming very significant. In 1975, the annual cost had been $\$ 1.1$ billion, but by 1992-93 it had risen to $\$ 8.6$ billion. $^{94}$ Consequently, the Government had determined that, while providing the level of patent protection contemplated by the international treaties, it should also enact measures to provide balance in the post-expiry market, as contemplated by Articles 7 and 30 of the TRIPS Agreement, to address the concern about the costs to the health care system that such enhanced protection would entail.

Bill C-91 and other related legislation therefore included measures providing the full protection required under both NAFTA and the Dunkel text for patentees' drugs, and ensuring that less expensive generic products would be able to enter the regulated health care products market as soon after the period of protection had expired as possible. Notwithstanding this balancing, the Bill became the subject of public debate, as some Canadians believed that the provision of increased protection for innovators' patent rights would inevitably lead to higher drug costs. "The bill generated considerable controversy. Proponents argued that it would make the Canadian pharmaceutical industry more profitable and thereby generate further research, development and jobs. The bill's opponents contended that it would destroy Canada's $\$ 400$ million-a-year generic drug industry and force Canadians to pay billions of dollars more for drugs in the years to come."195

\footnotetext{
${ }^{90}$ In conjunction with Article 5A of the Stockholm Act, 1967 of the Paris Convention, which was incorporated by reference in Article 2.1 of the Dunkel text

${ }^{91}$ However, the Uruguay Round was not concluded until the Marrakesh Agreement was signed, on 15 April 1994. The TRIPS Agreement did not come into effect (for developed countries) until 1 January 1996.

92 NAFTA was concluded on 17 December 1992, but under Article 2203 would not come into effect until 1 January 1994: "This Agreement shall enter into force on January 1, 1994, on an exchange of notifications certifying the completion of necessary legal procedures."

${ }_{93}^{93}$ Apotex Inc. v. Canada, [1994] 1 F.C. 742 at p. 754; appeal dismissed [1994] 3 S.C.R. 1100 (S.C.C.)

94 "Total Drug Expenditures (prescribed and non-prescribed and personal health supplies) Canada, 1975-1996." Source: Health Canada. The full report of Drug Costs in Canada is available at http://www.hcsc.gc.ca/datapcb/datahesa/drugs/drugs97.htm.

${ }_{95}$ George Francis Takach. Patents: A Canadian compendium of law and practice. (Juriliber: Edmonton, Alberta), at p. 115
} 
- The controversy had continued throughout the time Bill C-91 had been before Parliament, until it had become law on 15 February 1993. ${ }^{96}$ Stakeholders on both sides of the debate had made many representations to government officials and Members of Parliament, and had appeared before Parliamentary committees studying the Bill in order to make submissions. ${ }^{97}$ As a consequence, certain amendments had been made to the proposed law, but the Government's commitment to fulfil Canada's international obligations while at the same time ensuring access to generic products following patent expiry had remained unchanged.

\section{The Framing of the Disputed Provisions}

The measures in issue had been enacted in light of the requirements of NAFTA and the Dunkel text, both of which recognized the right of parties to provide limited exceptions to the exclusive rights conferred by a patent. NAFTA, Article 1709(6), stipulated that "[a] Party may provide limited exceptions to the exclusive rights conferred by a patent, provided that such exceptions do not unreasonably conflict with a normal exploitation of the patent and do not unreasonably prejudice the legitimate interests of the patent owner, taking account of the legitimate interests of other persons". The wording of Article 30 of the Dunkel text was almost identical: "PARTIES may provide limited exceptions to the exclusive rights conferred by a patent, provided that such exceptions do not unreasonably conflict with a normal exploitation of the patent and do not unreasonably prejudice the legitimate interests of the patent owner, taking account of the legitimate interests of third parties."

Relying upon these provisions, Canada had adopted two exceptions in Bill C-91. Subsection 55.2(1) of the Patent Act, colloquially referred to as the "regulatory review exception", the "early working exception", or the 'Bolar exemption" and subsection 55.2(2) of the Patent Act, which was usually called the "stockpiling" exception.

Canada's reliance on Article 30 of the TRIPS Agreement to enact its provisions paralleled the similar reliance by the United States to maintain and not repeal its Bolar exemption", which provided, in part, that "[I]t shall not be an act of infringement to make, use, offer to sell, or sell within the United States or import into the United States a patented invention [...] solely for uses reasonably related to the development and submission of information under a Federal law which regulates the manufacture, use, or sale of drugs or veterinary biological products." ${ }^{18}$

The "Bolar exemption" had been added to the United States patent statute in 1984, following the ruling of the Court of Appeals for the Federal Circuit in Roche Products Inc. v. Bolar Pharmaceuticals Co. Inc. ${ }^{99}$ In that case, a generic manufacturer had used a patented invention to test and apply for marketing authorization of its version of a patented medicine. The Court had determined that the common law "experimental use" defence only covered experimentation for scientific, not commercial, purposes, and that the generic manufacturer's activities therefore amounted to an infringement of the relevant patents.

- $\quad$ Subsequently, the United States Congress had predicated its acceptance of the TRIPS Agreement on the understanding that its "Bolar exemption" would be fully compliant with the Agreement. As indicated in the Statement of Administrative Action for the Uruguay Round Agreements Act, "Article 28 specifies that a patent must include the right to exclude others from making, using, offering for sale, selling, or importing the product. The Agreement

\footnotetext{
${ }^{96}$ S.C. 1993 c. 2 (with the exception of s. 55.2, which came into force on March 12, 1993)

${ }^{97}$ Some of the events in Bill C-91's progress through Parliament are recounted in Apotex Inc. v. Canada, [1997] 1 F.C. 518 (Fed. Ct. T.D.) at pp. 528-30.

9835 U.S.C. Section $271(\mathrm{e})$

99733 F.2d 858; cert denied 221 USPQ 937; 469 US 856 (1984)
} 
permits limited exceptions to the exclusive rights conferred by a patent if certain conditions are met. United States law contains some such exceptions, such as those set out in Section 271(e) of the Patent Act (35 U.S.C. s.271(e)). ${ }^{100}$

While the European Communities and their member States were contending in the present proceeding that Canada was the only country with a stockpiling provision, subsection 55.2(2) of the Patent Act essentially paralleled a practice followed in the United States, where an FDA guideline required a generic manufacturer, as a precondition to marketing authorization, to make at least three full production runs on a full commercial scale: "The FDA will not approve an application if the manufacturing facility has not yet been 'scaled up' from the product development phase, during which only limited manufacturing capacity is required, to the commercial phase, where the company is ready to produce large quantities of product for immediate commercial distribution."101

Canada understood that, while this FDA guideline involved full production runs, its purpose was health-oriented, to demonstrate the safety and efficacy of the drug product, and not to allow the manufacturer to prepare to enter the market as soon as possible after patent expiry. Nevertheless, it appeared that fulfilment of this guideline's requirement would, as a practical matter, facilitate the early entry of a generic drug product into the United States post-expiry market: "[Congress'] primary concern was to create a legal environment that would enable new, medically beneficial, cost-competitive products to reach the general market place in meaningful volume just as soon as the undistorted operation of the patent laws would permit. [...] We believe that in enacting this exemption Congress clearly decided that it wanted potential competition to be able to ready themselves, fully, during the life of the patent, to enter the commercial marketplace in a large scale way as soon as the relevant patents expired." 102 (emphasis in original)

Notwithstanding the similarity of Canada's exceptions to existing parallel measures in United States law, the transition from the compulsory licensing system to the enhanced patent protection regime had been marked by controversy and public debate. The framers of the TRIPS Agreement had anticipated that Members' domestic political processes would involve debates respecting the balancing of the competing interests at issue, and that such debates would necessarily result in variations between the national measures taken to implement the TRIPS Agreement, since they had stipulated, in the last sentence of Article 1.1 of the Agreement, that "Members shall be free to determine the appropriate method of implementing the provisions of this Agreement within their own legal system and practice".

\footnotetext{
${ }^{100} 103$ d Congress, 2d Session, House Document 103-316, Vol. 1, p. 986
}

${ }^{101}$ NeoRX Corp. v. Immunomedics, Inc., 877 F. Supp 202 at p. 206 (U.S. Dist. Ct., Dist. N.J., 1994). In that case, four commercial-scale production runs were held to be reasonably related to the FDA approval process, but Canada understands that the FDA guideline calls for three full production runs. In response to a question from the Panel, Canada said that the Canadian new drug approval process did not require that an applicant make at least three full, commercial scale production runs as a condition precedent to the issuance of a Notice of Compliance. Consequently, the applicants for new drug approvals for the sale of a drug in Canada did not exit the process with a commercial-scale inventory of product that had been approved for manufacture, use or sale. However, if a firm in Canada were to use a patented invention in Canada solely for uses reasonably related to the development and submission of information required under the law of the United States that regulated the manufacture, construction, use or sale of drug products and in doing so were to make the three full, commercial-scale production runs required under the Food and Drug Administration (FDA)'s guideline in Canadian facilities, its resulting stock of product would have to be held by the firm in inventory since any other use would infringe the Canadian patent. That was to say that the product could not be sold either domestically or internationally to others because any such sale would not be a "use reasonably related to the development or submission of information" required by a regulatory authority. Once the term of the Canadian patent expired, the product in inventory could, if approved for sale in the United States, be sold for export to the United States provided that its product expiry date had not passed and provided that any relevant patent term (or patent term extension) in the United States had also expired. (The FDA guideline was completely silent in respect of what if any use could be made of the material that was produced as a result of the three fullscale production runs required to fulfil the process (production) validation requirements of the FDA.)

${ }^{102}$ Ibid., at p. 205, quoting Intermedics, Inc. v. Ventritex, 775 F. Supp. 1269 at p. 1273 (N.D. Cal. 1991) 
In order to understand the operation of the Canadian measures, it was necessary to understand the relationship between Canadian patent legislation and legislation regulating the manufacture, construction, use and sale of products that may be subject to patent protection.

- $\quad$ Exclusive rights under patents were stipulated in Sections 42, 44, 49 and 50 of Canada's Patent $\mathrm{Act}^{103}$ and, without subsections 55.2(1) and 55.2(2), it would likely be an infringement of these patent rights for anyone to make, construct, use or sell a patented invention in connection with a submission for regulatory review of a product or to manufacture and stockpile for purposes of commercial exploitation in the post-expiry market. $^{104}$

The exceptions had been enacted because of the potential delaying effect of regulatory review systems on the ability of would-be competitors to enter the market as soon after patent expiry as possible, as was particularly the case in the regulatory regime for pharmaceutical products. That regime involved long delays before new drugs - both innovator and generic - could be placed on the market. ${ }^{105}$

- The delays arose because, independent of the time it might take to invent, or to discover a method to replicate, a new drug, the time required to develop the information needed to demonstrate the safety and effectiveness of a new drug, whether innovative or replicative, was considerable and variable. ${ }^{106}$

Similarly, the time that the regulatory authorities took to review and assess the adequacy of the materials submitted in support of an application for marketing authorization was also considerable and variable. ${ }^{107}$

- It was not uncommon for the product development, application preparation and regulatory review process to take, in the case of an innovative drug, eight to 12 years and, in the case of a generic drug, three to six-and-a-half years.

Section 55.2(1) and Section 55.2(2) of the Patent Act had been enacted in order to address the economic distortion that would be caused by the delays inherent in the regulatory review process. ${ }^{108}$ There was nothing in these limited exceptions that would permit a

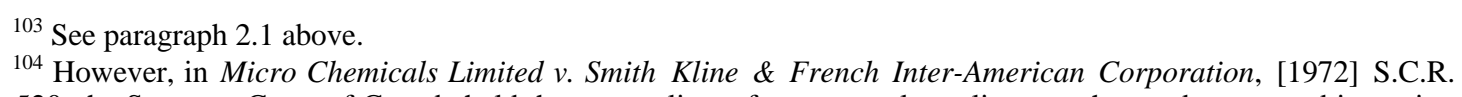
506, at p. 520, the Supreme Court of Canada held that an applicant for a compulsory licence who used a patented invention in order to establish that it could manufacture the invention was protected from infringement liability by the experimental use defence.

${ }^{105}$ See paragraphs 2.2 and following above.

${ }^{106}$ See paragraphs 2.2 and following above.

${ }^{107}$ See paragraphs 2.2 and following above.

${ }^{108}$ In response to a question from the Panel, Canada explained that the circumstances facing innovators were different from those facing generic drug manufacturers. The difference was that the only factor which delayed an innovator's market entry was society's requirement that it establish, to the satisfaction of the regulatory authorities, that its product was safe and effective for the use claimed. Given the potential harm that chemical substances might cause, it was difficult to characterize the delay associated with this process as being a "distortion". In contrast to the innovator's position, there were two factors that delayed a generic manufacturer's market entry. The first was its parallel need to demonstrate the safety and efficacy of its product to the satisfaction of the regulatory authorities. As in the case of the innovator, this delay factor was not by itself fairly described as a "distortion". The second factor which delayed generic entry was the presence of an innovator's patent. In order to obtain regulatory approval, a generic manufacturer must make and use a product that would, during its term of protection, infringe an innovator's patent. Absent provisions such as those here in issue, patent owners could exercise their exclusive rights to prevent the commencement of a generic manufacturer's application for regulatory review until the relevant patent had expired. The capacity to prevent such use gave rise to distortions in the legal system which both granted those rights and imposed the relevant regulatory review requirements. The distortion arose because the rights accorded by the patent laws, which were by law supposed to expire on the conclusion of a specified term, could be 
competing regulated product to come to market before the patents relating to the patented product expired. Nor was there anything that allowed commercial exploitation by a person using an invention within the scope of the exceptions during the period of protection required by the TRIPS Agreement. Indeed, whereas regulated patented drug products had formerly been subject to compulsory licensing, the current legislation decisively strengthened patent protection by not only eliminating compulsory licensing but also providing a summary procedure for preventing patent infringement, under which the Minister of Health might be prohibited from issuing marketing approval for a new generic drug during the term of any applicable patent. ${ }^{109,110}$

- Without the limited exceptions (particularly the regulatory review exception), patentees would benefit from an additional gratuitous and often lengthy period of de facto protection - equal to the time required for a competitor manufacturer to prosecute its application for regulatory approval - which was neither contemplated by domestic law nor required by the TRIPS Agreement.

\section{$\underline{\text { Cost Containment and Generic Drugs }}$}

Intellectual property rights did not exist in a vacuum. They were granted taking into account other social and economic welfare policy interests and values. This reality was clearly recognized in Article 7 of the TRIPS Agreement and had been expressed by Canada in its Statement on Implementation of the TRIPS Agreement: "The rapid increase in technology has made the protection of innovation a key determinant of economic success. How governments approach that protection, however, requires a compromise between two conflicting goals. The owners of intellectual property - the tangible results of innovation, including patents, trademarks and copyright - have a natural interest in enjoying exclusive rights to their innovation as long as possible. A reasonably long period of exclusive rights, therefore, can act as a powerful incentive to innovation. Consumers and competitors, on the other hand, would prefer that the fruits of innovation be made generally available as quickly as possible, so that competition will both reduce prices and lead to further innovation. Most national intellectual property regimes reflect compromises between these two objectives." ${ }^{111}$

- In enacting Bill C-91, Canada had been particularly concerned that the increased patent protection available for, among other things, pharmaceutical inventions, not create any unintended hardship for consumers, public drug plans and other third party payers. It had therefore been essential that, consistent with Articles 29 and 33 of the TRIPS Agreement, competitors had the ability to be on the market as soon after the expiry of patents relating to regulated products as possible.

exercised during their currency before their expiry to convert the requirements of the regulatory review laws, which were designed to protect public health, not private commercial interests, into a de facto extension of patent rights which, under the patent law, had ceased to have any de jure existence. For obvious reasons relating to this prolongation of private commercial rights, the "economic distortion" referred to followed from the distortion of the legal framework defining patent rights and regulatory review requirements. Where, as explained in the foregoing, the distortion referred to only affected one side of the market, there was no distinction in policy approach that invited specific justification.

${ }^{109}$ Pursuant to the Patented Medicines (Notice of Compliance) Regulations (see paragraph 2.7 above).

${ }^{110}$ In response to a question from the EC, Canada explained that, as a practical matter and depending on the medicine involved and the amount of time a generic manufacturer estimated it would take to obtain marketing approval, it might start its product and submission development activities at any time, such that the "start" time could be - before the patent issued in Canada - where the generic manufacturer had non-infringing material; after the patent issued in Canada but before the medicine received its first "notice of compliance", where the safety and efficacy of the medicine appears to be assured; or, at any time after the patent and the first "notice of compliance" had been issued in Canada, where the generic manufacturer had a specific business plan in respect of when it expected to enter the post-expiry market. Since the date when a generic manufacturer began its development work was a matter of commercial confidentiality, it was not possible for the Government of Canada to determine how long on average before patent expiry generic manufacturers began their development work.

${ }^{111}$ Canada Gazette, Part I, 31 December 1994, pages 4934-35 
- $\quad$ Patented medicines were expensive in large part because of the high development costs which patentees sought to recoup through the exclusive marketing rights conferred by a patent during the period of patent protection. The expense adversely affected the health care system. Where individuals must pay for their drugs directly, some people would not be able to afford them and would thereby be deprived of appropriate drug therapies.

If drug costs were funded through a public system, affordability for the individual might not be an issue, but the health care system as a whole would suffer as the funds spent on paying monopoly prices for prescription drugs resulted in deprivation to other areas of the health care system. ${ }^{112}$

\section{Rising drug costs were a concern for most countries. ${ }^{113}$}

Without some form of government intervention during the period of patent protection, patent owners would be able to charge monopoly prices for their drugs and so impose the full weight of their monopoly on national health care budgets. Such costs would result in hardship by unduly restricting access to needed medicines. Moreover, that hardship would be further extended into the post-expiry market, unless similar interventions promoting the use of lower-cost generic substitutes were widely adopted.

Accordingly, many Members, including both parties to this dispute, had implemented a number of measures to address these concerns. Although there were others ${ }^{114}$, those measures could be broken down into two main categories: (a) measures aimed at prices that related to patented medicines, and (b) various measures to encourage the use of generic substitutes.

${ }^{112}$ In response to a question from the EC, Canada said that it did not have an estimate of the total savings of pharmaceutical-related expenses that could be attributed to the limited exceptions of Section 55.2. That said, Canada did have reasonably reliable information to demonstrate that generic versions of innovative medicines traded at a significant discount to the innovative version of the medicine. In this respect, it could be shown that on average: the first and second generic versions of a previously patented product came on the market at just less than 75 per cent of the innovator's price; when a third and a fourth generic entered, the average price dropped about 20 percentage points to about 54 per cent of the innovator price; and when a fifth entered, the average fell another ten percentage points to just under 46 per cent of the innovator's price for the same medicine (Savings to Canada's Health Care System, Canadian Drug Manufacturers Association, January 1997). While such discounts suggested substantial savings, the quantum of the savings realized would, of course, depend on the degree of market penetration that the generic products achieved. The quantum of the savings would also vary if the innovator adjusted its prices downward in an effort to retain market share. (Health Canada, together with some of its provincial counterparts, expected to release a study in the fall of 1999 which would provide a more detailed picture of the savings generally attributable to the use of generic versions of previously patented medicines.)

113 As calculated by the OECD, using purchasing power parity dollars, and illustrated by the following table, which lists per capita drug spending. Purchasing power parities are the rates of currency conversion that equalize the purchasing power of different currencies across the full range of goods and services contained in medical services and pharmaceutical goods respectively (OECD Health Data, 1998: a comparative analysis of 29 countries (ISBN 92-6405122 8), an interactive CD-ROM product not reproducible as an exhibit).

$\begin{array}{llll}\text { Country } & \underline{1990} & \underline{1997} & \\ \text { Canada } & & & \text { Chang } \\ \text { France } & 191 & 264 & 38.2 \% \\ \text { Germany } & 256 & 351 & 37.1 \% \\ \text { Italy } & 182 & 294 & 61.5 \% \\ \text { Sweden } & 242 & 308 & 27.3 \% \\ \text { Switzerland } & 120 & 219 & 82.5 \% \\ \text { United Kingdom } & 144 & \text { N.A. } & \text { N.A. } \\ \text { United States } & 132 & 233 & 76.5 \% \\ & 240 & 319 & 32.9 \%\end{array}$

\footnotetext{
${ }^{114}$ For example, volume-supply agreements and controls on profits
} 


\begin{abstract}
- $\quad$ Canada had adopted a mational price review mechanism for patented medicines to help prevent any excesses in monopoly pricing during the term of patent protection. At the Federal level, the Patented Medicines Price Review Board (the "Board") influenced the price of patented drugs. The Board had been created in 1987 as a quasi-judicial agency. Because Canada's Constitution limited the jurisdiction of the Federal Parliament to "Patents of Invention and Discovery"115, the Board's authority was limited to the review of the prices of patented medicines. In 1997, sales of patented drugs represented just over half of all drug sales in Canada. ${ }^{116}$ Accordingly, the Board only had authority over about one half of all the medicines sold. The Board, rather than setting prices, intervened to ensure prices did not reach excessive levels. Maximum non-excessive prices were determined using Price Guidelines that had been developed in consultation with representatives of Provincial ministries of health, the drug industry and consumer groups. ${ }^{117}$ These Guidelines contained the following principles. The prices of most new drugs should not exceed the prices of drugs currently on the market that treated the same disease; on average, prices in Canada should not exceed the median of prices in other industrialized countries (France, Germany, Italy, Sweden, Switzerland, the United Kingdom and the USA $)^{118}$; and prices should not rise faster than the Consumer Price Index. ${ }^{119}$ In this manner, the Board exercised a more limited form of price control than the member States of the European Union with their State drug plans ${ }^{120}$ and such control as it did exert was only exercisable during the term of patent protection.
\end{abstract}

- $\quad$ However, Canada's Constitution limited Federal jurisdiction to "Patents of Invention and Discovery"121, and therefore this strategy was not available to assist in the control of drug costs after a patent had expired. In the post-patent expiry market, the authority to regulate

\footnotetext{
${ }^{115}$ Constitution Act, 1867, s. 91(22)

${ }^{116}$ 10th Annual Report of the Patented Medicines Price Review Board, 29 May 1998, p. 13

${ }^{117}$ Patent Act, subs. 96(4)

${ }^{118}$ Patented Medicines Regulations, 1994, SOR/94-688, Schedule 1

${ }^{119}$ R. Elgie. "Regulating Prices of Patented Pharmaceuticals in Canada: the Patented Medicines Price Review
} Board", Food, Drug \& Cosmetic Law Digest, Vol. 13, No. 2 (May 1996), p. 80

${ }_{120}$ According to Canada, the member States of the EU administer national pharmacare programmes where the majority of citizens are eligible for coverage under a publicly funded plan. Within this scheme, the market power of the monopoly seller (the patent owner) is partly counterbalanced by the presence of a "monopoly" buyer (the public drug plan). More specifically, in some states, prices are controlled directly. In other states, prices are controlled through reimbursement policies. EU members determine which drugs are listed on their State drug plans, at what price, and the levels at which they will be reimbursed. In this manner, they are able to effectively influence the price of drugs.

${ }^{121}$ Constitution Act, 1867, subsection 91(22). In response to a question from the Panel, Canada said that the purpose of the point made was to explain that the limits that were imposed on the constitutional jurisdiction of the national (federal) governmental authority in a confederate state could deny it the freedom to pursue policies that were freely available to the national governmental authorities of unitary states. Thus, the constitutional provision that limited the federal government's authority to make laws in respect of patents of invention did not allow the federal authority to make laws respecting the prices and other contractual arrangements that might be developed or agreed to between seller and purchaser entities once the patent jurisdiction was spent. This was because the constitutional authority respecting property and civil i.e., inter alia, contractual - rights resided in the provincial governmental authorities. The consequence of this constitutional arrangement was that the Federal Government of Canada was not capable of pursuing the long-term strategies of price and profit control respecting medicinal products that was clearly available to a number of the member States of the EU. Canada recognized that such constitutional restraints on a federal government's authority to adopt measures or to pursue strategies to implement treaty obligations that it had undertaken to implement were an issue of domestic, not international, law. However, the issue before the Panel did not involve Canada's authority, as a federal sovereign entity, to implement its international obligations. In contrast, the issue was whether the measures that the federal authority had, within the ambit of its constitutional authority, taken were in conformity with its obligations under the TRIPS Agreement. Canada said that the measures it had taken were within its federal authority and were, by virtue of meeting the criteria set out in Article 30, in conformity with its TRIPS obligations. It was within the context of this assertion that the reference to the constitutional limitations on its federal sovereign authority had relevance to the legal issues before the Panel. The legal relevance of the constitutional consideration was therefore Canada's or, for that matter, any other Member's right, under Article 1.1 of the TRIPS Agreement, to exercise the freedom guaranteed by that paragraph "to determine the appropriate method of implementing the provisions of [TRIPS] within [the Member's] own legal system" [...] so as to promote "the mutual advantage", within its own legal environment "of producers and users of technological knowledge [...] in a manner conducive to social and economic welfare, and to a balance of rights and obligations" between those producers and users of technological knowledge that was subject to the protection of intellectual property right laws. 
prices of medicines resided in the ten Provinces and three Territories, not the Federal Parliament.

In the European Union, all member States, except Belgium, Greece and Luxembourg, had established national policies promoting the use of generic drugs. ${ }^{122}$ Canada's Provinces and Territories, each of which had its own public drug plan, had done the same. ${ }^{123}$ Many WTO Members, including both parties to this dispute, had sought to favour the use of generic drugs because such drugs were significantly less expensive than patented ones. In Canada, for example, generic drugs accounted for about 40 per cent of all prescriptions filled in $1997^{124}$, but only amounted to about 15 per cent of the total cost of such drugs. ${ }^{125}$ As between Canada and the EU, the overall market share of generics was about the same: 15 per cent of total dollar sales of prescribed drugs. ${ }^{126}$

Pursuant to Article 1.1 of the TRIPS Agreement, Canada and EU member States had each adopted their own methods to achieve this level of market penetration by generics. The EU member States had used extensive price controls, profit controls and other mitigating strategies (such as monopsony buyers) as their instruments of choice. ${ }^{127}$ Canada, due to its different constitutional structure, its division of responsibility for public health management among ten Provinces and three Territories, and its inability to establish a monopsony buyer had been unable to use the same measures. As a result, it had adopted measures such as those challenged here to reinvigorate competition in the post-expiry markets for regulated products.

- $\quad$ Absent an exception like that contained in Canada's patent legislation allowing the non-infringing uses of patented inventions for regulatory review purposes during patent protection, competitive products, particularly generic drug products, would not be able to enter the regulated product markets for prolonged periods following patent expiry.

Even the European Union recognized the salutary effect of such exceptions. In a report dated 2 April 1996, the European Parliament had considered that it would be necessary in order for the EU to compete in international non-proprietary, i.e. generics, markets for measures to be introduced to exempt experiments and regulatory preparations required for the registration of generic pharmaceuticals, so that they could be marketed immediately after patent expiry. ${ }^{128}$ Consequently, on 16 April 1996, the EU Parliament had adopted the following Resolution:

"17. Considers that in order for the EU to be competitive in the growing European and international non-proprietary markets, measures should be introduced which enable pharmaceutical companies to begin, in advance of patent or supplementary protection certificate expiry, such laboratory experiments and regulatory preparations as may be required only for the registration of generic pharmaceuticals developed in

\footnotetext{
${ }^{122}$ National Economic Research Associates (NERA), Policy Relating to Generic Medicines in the OECD: Final Report for the European Commission, 20 December 1998, p. 27

${ }^{123}$ R. Bakovsky, Federal, Provincial and Territorial Government-Sponsored Drug Plans and Drug Databases. Background information prepared for the Conference on National Approaches to Pharmacare, 2 December 1997

${ }^{124}$ Intercontinental Medical Statistics (IMS) Canada, Pharmacy Practice, Vol. 12, No. 12

${ }^{125}$ NERA Report (see footnote 122 above), p. 23; cf 10th Annual Report of the Patented Medicines Prices Review Board, May 1998, which estimates market share at 11 per cent and IMS Canada, Canadian Pharmaceutical Industry Review, 1996, which estimates market share at 17 per cent.

${ }^{126}$ NERA Report (see footnote 122 above), p. 23.

${ }^{127}$ Konrad R.B. Wallerstein, Pharmaceutical Pricing and Reimbursement in Europe, SCRIP Reports (PJB Publications, August 1995), pp. 31-32. See also NERA Report (footnote 122 above), p. 27.

${ }^{128}$ NERA (see footnote 122 above), p. 169
} 
the EU to be available on the market immediately, but only after the expiry of a patent or supplementary protection certificate for a proprietary product."129

As to the background and consequences of this Resolution, Canada drew attention to the fact that, in its resolution of 19 November 1993 on public health policy after the Maastricht Treaty ${ }^{130}$, the European Parliament had asked the European Commission to look into whether it would be possible to encourage greater use of generic medicinal products. Partly in response to this request, the European Commission had provided its Communication From the Commission to the Council and the European Parliament on the Outlines of an Industrial Policy for the Pharmaceutical Sector in the European Community. ${ }^{131}$ In the Communication the Commission had addressed the problem created by the competition between two important interests. On the one hand, there was an economic need to maintain and strengthen the international competitiveness of the European pharmaceutical industry. On the other hand, however, there was a social welfare need to obtain the best value from social security and health services which are paid for out of the public purse. At page 19 of the Communication, the Commission stated: "Obviously, generic competition only arises when intellectual property protection conferred by the patent and, as the case may be, by the supplementary protection certificate, is exhausted. Whenever doctors and pharmacists are better informed about the cost of the various treatments which are available, they can select the treatment offering the required therapeutic benefit which is less expensive for society. Thus, prescribing doctors, if better informed about the cost/efficacy ratio of medicinal products will tend to prescribe generically. Pharmacists will tend to deliver the product offering the best value, if the prescription allows it." On 20 December 1995, the Council of the European Union, taking account of the Communication, among other things, had adopted a resolution which "[calls] on the Commission, in close cooperation with the Member States, to draw up, in the light of the guidelines in the Annex, a report concerning policy on generic medicinal products in the Member States of the European Union and in the other OECD countries, in particular the USA, Canada and Japan". The report referred to in this Resolution had been issued on 20 December 1998 by National Economic Research Associates. ${ }^{132}$ In the meantime, on 2 April 1996, the European Parliament's Committee on Economic and Monetary Affairs and Industrial Policy had addressed the following demand to the Commission: "[...] 4. We demand that the Commission devote more attention to promoting competition in the medicine market, particularly by: [...] - promoting generic medicines with respect for the responsibility of the prescribing physician and for the life-span of the patent." ${ }^{133}$ This had soon been followed by the Resolution of the European Parliament, on 16 April 1996, which called for measures to be introduced to enable pharmaceutical companies to begin, in advance of patent expiry, the necessary laboratory and regulatory preparations to obtain market authorization. On 18 May 1998, the Council of the European Union had adopted the following conclusion regarding the single market in pharmaceuticals: "[...] 9. The Council therefore believes it necessary: [...] (ii) to consider, in respect of patentexpired medicines, how a more competitive European generic market could be developed."134 The European Commission had issued its "Communication on the Single Market in Pharmaceuticals" on 25 November 1998. In that document, the Commission had noted that the Frankfurt Round Tables (a tripartite dialogue between EU member States, industrial interests and the Commission) had "identified that a more competitive generic market had an

\footnotetext{
${ }^{129}$ No. A4-1014/96; Official Journal No. C 141, 13/05/96, p. 0063

${ }^{130}$ The Maastricht Treaty increased the European Community's role in public health and gave it a particular role in promoting health protection and disease prevention.

${ }_{131}$ COM(93) 718, dated 2 March 1994

132 The NERA Report referred to in footnote 122 above

${ }^{133}$ Report on the Communication from the Commission to the Council and the European Parliament on the outlines of an industrial policy for the pharmaceutical sector in the European Community (COM(93) 0718 final - C30121/94); Committee on Economic and Monetary Affairs and Industrial Policy; A4-0104/96/PART, p. 16

${ }^{134} 2094^{\text {th }}$ Council meeting (Internal Market), Brussels, 18 May 1998, 8528/98, Presse 148, C/98/148
} 
important contribution to overall competition in the pharmaceutical sector", and that the matters of particular importance to the generic sector were: encouraging the prescribing by doctors and the dispensing of generics by pharmacists so as to stimulate consumer choice; increasing consumer awareness of the availability of generic medicines; ensuring that the licensing process for generic products operated speedily to ensure that consumers had access to lower-priced generics as soon as possible after patent protection of the original product expired; developing financial mechanisms within the health care systems in ways that favoured price competition between generic products and originator brands (emphasis by Canada). ${ }^{135}$ The European Parliament had responded to the Commission's Communication with a Resolution dated 5 April 1999, which called upon the Commission to bring forward a proposal to complete the internal market in pharmaceuticals. The Resolution cautioned that, while the proposal should "provide an incentive to continue development of in-patent products", the provisions put forward by the Commission "should not restrict or prejudice generic medicines from entering the market". ${ }^{136}$

Canada had previously reached the same conclusion, and through its limited measures balanced the legitimate interests of the patent owners against the legitimate interests of third parties. This was particularly so in the case of pharmaceutical products, where the chemistry of drugs was such that they must be subject to a careful, time-consuming process in order to ensure their safety and efficacy. In the absence of the measures complained of, consumers would be required to pay considerably more for previously patented drugs during a windfall period of protection following expiry. That period was, of course, wholly outside the period of protection required by the TRIPS Agreement.

\section{EUROPEAN COMMUNITIES AND THEIR MEMBER STATES}

4.22 The European Communities and their member States maintained that the provisions of Section 55.2(1) of the Canadian Patent Act as well as Section 55.2(2) together with the Manufacturing and Storage of Patented Medicines Regulations violated Canada's obligations under the TRIPS Agreement, namely Article 28.1 thereof together with 33, and Article 27.1. While Canada had presented the manufacturing and stockpiling facility and the permissible activities related to the development and submission of information required for obtaining marketing approval as a single entity, the European Communities and their member States were of the view that both issues had to be kept separate, both from a factual point of view and as far as the legal analysis was concerned. Before going into the legal issues, the following factual points were addressed:

Section 55.2(2) and 55.2(3) of the Patent Act together with the Manufacture and Storage of Patented Medicines Regulations

- Canada had insisted that the benefits of the manufacturing and stockpiling authorization were only available to operators who performed the activities related to the development and submission of information required to obtain marketing approval under Section 55.2(1) of the Canadian Patent Act. While the language of these provisions was not entirely clear on this point, even if one were to accept this interpretation, this did not mean that the number of potential beneficiaries was limited in a meaningful manner. Section 55.2(1) only referred to "[...] uses reasonably related to the development and submission of information required under any law of Canada, a province or a country other than Canada that regulates the manufacture [...] of any product". This provision did not require any actual application for marketing approval in Canada or any third country, but only an intention to make such an application. To base legal consequences only on intentions created an inherent source of

\footnotetext{
${ }^{135} \mathrm{COM}(98) 588$, at p. 15

${ }^{136}$ No. A4-0205/99, Provisional Edition, at p. 2
} 
uncertainty which was further aggravated by the fact that such intentions could change over time.

- Canada had referred to a practice in the United States under Food and Drug Administration (FDA) regulations on which its manufacturing and stockpiling provision was allegedly based. First of all, this remark was in open contradiction with the unequivocal statement contained in the information package of the Government of Canada concerning the review of the Patent Act Amendment Act, 1992 (Bill C-91), issued in February $1997^{137}$ that manufacturing and stockpiling was not allowed in the United States. The United States had also contradicted Canada's assertion in an unequivocal way as a third party in the present dispute.

\section{Section 55.2(1) of the Patent Act}

- The conclusion to be drawn from the information provided by Canada in its first written submission on the time necessary to prepare the submission for marketing approval of a generic drug in Canada including the administrative process itself, which was between three and six-and-a-half years, taken together with the eight to 12 years necessary for the obtaining of marketing approval for the original product, counted from patent application, was that the term of effective patent protection in Canada amounted to a maximum of nine years to a minimum of one-and-a-half years. This was to be compared with the minimum of 20 years foreseen in Article 33 of the TRIPS Agreement. This was the more significant because the most sophisticated and investment-intensive pharmaceutical drugs were likely to be the ones, both as original products but also as generics, to require the longer rather than the shorter periods for the preparation and obtaining of marketing approval in Canada, thus reducing the term during which the originator could fully enforce his rights to a few years, with an extreme of only one-and-a-half years. ${ }^{138}$

- By allowing the activities referred to in Section 55.2(1) of the Canadian Patent Act with a view to obtaining marketing approval in any country in the world, the extent of such activities and their duration during the patent term were totally open-ended and completely outside the control of the Canadian authorities. While it was generally unlikely that there would be a great number of would-be generic producers for one specific product for the sole Canadian market, allowing these activities for obtaining marketing approval in any country of the entire world was likely to significantly increase the number of beneficiaries for the very same product and as a consequence significantly increase the extent of infringing activities. Consequently, very significant quantities of the products protected by the patent could be used, manufactured, imported and sold without the consent of the patent holder at any time during the patent term.

4.23 The European Communities and their member States understood from Canada's reply that Canada, at least implicitly, accepted the claim of the EC that the manufacturing and stockpiling provisions contained in Art. 55.2(2) Canadian Patent Act together with the Manufacturing and Storage of Patented Medicines Regulations violated Article 28.1 together with Article 33 of the TRIPS Agreement, and that the pre-marketing approval activities provisions contained in Section 55.2(1) of

${ }^{137}$ The document referred to in footnote 6 above, in particular the table at p. 9 of the document

${ }^{138}$ In response to a question from the Panel, the EC explained that obtaining marketing approval for a newly invented drug, economically speaking, reduced the effective period of patent protection by some eight to 12 years. Since Canadian law provided patent protection for a period of 20 years counted from the filing date, this effective period of protection would therefore be 12 years at a maximum and eight years at a minimum. Generic producers needed three to sixand-a-half years of pre-marketing activities in Canada to obtain marketing approval for their generic copies of a patented drug. The shortest period that the generic producers would need ( 3 years) combined with the longest effective period of protection for the patented drug (12 years) left a period of 9 years of fully effective protection. The longest period needed by the generic producers $\left(6 \frac{1}{2}\right.$ years) combined with the shortest effective period of protection for the patented drug ( 8 years) left a period of $1 \frac{1 / 2}{2}$ year of fully effective protection. 
the Canadian Patent Act were at variance with Article 28.1 of the TRIPS Agreement, but was of the view that the provisions in question were justifiable under Article 30 of the Agreement.

\section{ARTICLE 27.1 OF THE TRIPS AGREEMENT}

4.24 The European Communities and their member States understood from Canada's reply that it could confirm, at least implicitly, that the possibility of manufacturing and stockpiling unlimited quantities of a protected product without the authorization of the patent holder during the last six months of the patent term, under Section 55.2(2) and 55.2(3) of the Canadian Patent Act together with the Manufacturing and Storage of Patented Medicines Regulations, was only available for pharmaceutical products and was not available for any other product category.

4.25 As regards Section 55.2(1) of the Patent Act, the European Communities and their member States noted that Canada, at least implicitly, had confirmed that this provision only applied to pharmaceutical products and had not rebutted the assertion of the EC that a significant number of categories of products required, in Canada and in other countries, the development and submission of information to obtain marketing approval.

4.26 While Canada asserted that the contested provisions could in the future also apply to other fields of technology, the fact remained that ever since their enactment the provisions had only applied to patents for pharmaceuticals. There could be no doubt that this situation constituted a violation of the non-discrimination obligation as to fields of technology contained in Article 27.1 of the TRIPS Agreement, by treating owners of patents in the area of pharmaceuticals less favourably than owners of patents in all other product areas. ${ }^{139}$ The drafting history of Section 55.2(1) made it utterly clear that the legislator's intent had been to limit the effects of the provisions to pharmaceutical products. ${ }^{140}$ Elaborating on this, in response to a question from the Panel, the European Communities and their member States expressed the view that, while they considered Section 55.2(1) of the Canadian Patent Act to constitute a de jure violation of Article 27.1 of the TRIPS Agreement, Section 55.2(1) would also violate Article 27.1 if one were to consider that it only constituted de facto discrimination. ${ }^{141}$

4.27 While Canada took the view that this violation was justifiable under Article 30 of the Agreement, the European Communities and their member States continued to be of the view that a violation of Article 27.1 of the TRIPS Agreement could not be justified by Article 30, because Article 30 was not applicable to Article 27.1. The EC advanced the following points to support its view in this regard:

- $\quad$ Article 30 of the TRIPS Agreement constituted, as its title expressly stated, an exception clause. The text of Article 30 referred expressly to its "limited" character, which underlined that it had to be interpreted in a narrow manner. Furthermore, the exception character of Article 30 shifted the burden of proof that all its conditions were met on Canada, which

\footnotetext{
${ }^{139}$ In response to a question from the Panel, the EC said that the "practising pharmacist" exception, which existed in a number of countries, concerned a unique, in the meantime mostly historic situation, in which a pharmacist could produce on the prescription of a doctor a small quantity of a pharmaceutical product for an individual patient without the consent of the patent holder. There existed no comparable situation in other fields of technology; no car mechanic would give a "prescription" to the car owner to have a single piece of patent-protected car component or accessory manufactured by a mechanical or electronic manufacturer. Therefore, it lacked comparability and thus discriminatory character. See also footnote 146 below.

${ }^{140}$ Reference was also made to the information package referred to in footnote 6 above.

${ }^{141}$ As to the term "discrimination", the EC indicated, in response to a question from the Panel, that one could find definitions as "a failure to treat all persons equally where no reasonable distinction could be found between those favoured and those not favoured" (Black's Law Dictionary, p.420); and that Canada had not invoked any reason which would justify treating patent holders in the field of pharmaceutical products less favourably than patent holders in all other areas of technology.
} 
invoked this provision. In this context, the EC fully shared the views expressed by the United States as a third party in the present dispute. ${ }^{142}$

A plain reading of Article 30 militated in favour of its interpretation insofar as already the title of Article 30 spoke of 'Exceptions to Rights Conferred' and the text itself referred to '... exceptions to the exclusive rights conferred by a patent ...'. The term "rights conferred" only occurred in Article 28 of the Agreement, but did not appear in any way in Article 27.1.

- Canada had argued that this textual interpretation would produce an "incongruous" result, because it would make it necessary to apply exceptions across the board to all fields of technology. This result was, however, by no means "incongruous"; it was clearly the intended result under Article 27.1. This could be explained by using the example of compulsory licences, which had also been mentioned by Canada. In the past, a great number of countries, many of them Members of the WTO, had provided for systems of compulsory licences where it was much less burdensome to obtain compulsory licences in certain areas of technology than in others. The areas where compulsory licences had been granted more generously included pharmaceutical products, agrochemical products and foodstuffs. The Canadian provisions for compulsory licences for pharmaceutical products in the pre-C-91 system were a good illustration of this phenomenon, because they had also applied exclusively to pharmaceutical products. While attempts had been made to define the cases in which compulsory licences could be granted in Article 31 of the TRIPS Agreement, this provision stipulated only the procedures for the grant of compulsory licences. However, Article 27.1 became relevant when it came to the choice of the situations which were made subject to compulsory licences. While Article 27.1 did not exclude any field of technology from the scope of areas to be made subject to compulsory licences, Article 27.1 required that, if they were made available for one field of technology, they had to be made available to all fields of technology under the same conditions, the underlying consideration being that it was generally politically easier for a country to adopt provisions for making compulsory licences easily available for technologies where it had little or no industry and maintaining a more stringent level for the grant of compulsory licences or not allowing such licences at all in areas of technology where its industry was more competitive. It was indeed the aim of the non-discrimination provision contained in Article 27.1 of the TRIPS Agreement to avoid this tendency and to exclude an "a la carte" approach. The reasoning developed in relation to compulsory licences applied equally to exceptions.

- If one were to follow the Canadian interpretation that Article 30 overrode the nondiscrimination provision in Article 27.1, this would necessarily lead to the result that exceptions could also be made as to the place of the invention or whether products were imported or locally produced. In other words, exceptions could be made if the place of invention was outside Canada, without making the same exception if the invention had been made in Canada. Equally, one could confine the exception to imported products and not apply it to locally produced products. Clearly, these consequences were not intended by the TRIPS negotiating parties. ${ }^{143}$

- The United States and Switzerland, third parties in the present dispute ${ }^{144}$, shared the view that Article 27.1 could not be overridden by Article 30. The point made by the United States and Australia ${ }^{145}$, that not each and every differential treatment amounted to a violation of

\footnotetext{
${ }^{142}$ See under section V. below.

${ }^{143}$ Reference was made to Gervais, The TRIPS Agreement, at pp. 144-148.

${ }^{144}$ See under section V. below.

${ }^{145}$ See under section V. below.
} 
Article 27.1, was a distinct matter ${ }^{146}$, because if Article 27.1 was not violated, the issue of the relationship between Articles 27.1 and 30 became redundant.

4.28 According to the EC, if the Panel should follow this chain of reasoning, the legal argumentation in relation to Article 27.1 could stop at this point. Should the Panel, however, take the view that there existed no violation of Article 27.1, or that such a violation could be excusable under Article 30, the analysis had to proceed to Article $30 .{ }^{147}$

\section{ARTICLE 30 OF THE TRIPS AGREEMENT}

4.29 As reflected under section IV.C(1) above, the European Communities and their member States remained of the opinion that a violation of Article 27.1 of the TRIPS Agreement could not be justified by Article 30, because Article 30 was not applicable to Article 27.1. However, should the Panel take the view that such a violation could be excusable under Article 30, the EC noted that the provisions of Canadian law in dispute were not excusable under Article 30 in any event. ${ }^{148}$ Section 55.2(2) and 55.2(3) of the Patent Act together with the Manufacturing and Storage of Patented Medicines Regulations constituted a violation of Article 28.1 together with Article 33 of the TRIPS Agreement and Section 55.2(1) of the Patent Act constituted a violation of Article 28.1 of the TRIPS Agreement, while the provisions in question could not qualify as an exception justified by Article 30 of the TRIPS Agreement.

4.30 The European Communities and their member States advanced the following arguments in support of their view that the incompatibilities with the TRIPS Agreement constituted by the provisions of Canadian law in dispute could not be excused on the basis of Article 30.

${ }^{146}$ In response to a question from the Panel, the EC said that they shared the views expressed by Australia and the United States that patent term extension for pharmaceutical products (see paragraph 4.31 below, under (b)) did not constitute a discrimination prohibited by Article 27.1 of the TRIPS Agreement, and that one could even argue that, under certain circumstances, patent term extension might be mandated by Article 27.1. The fact that eight to 12 years of the patent term were "lost" because of marketing approval requirements constituted the "good reason" to treat pharmaceutical patents more favourably than other patents, where marketing approval, if at all required, could be obtained in a much shorter period of time. Such a situation could be compared to an example taken from everyday life. If a public transport authority mandated that in its vehicles the handicapped and the elderly had priority seating rights, this clearly treated the non-handicapped and non-elderly less favourably. However, everybody was likely to agree that this differential treatment did not constitute a discrimination, the "good reason" for it being that the handicapped and elderly tended to be physically more frail than others. See also footnote 139 above.

${ }^{147}$ In response to questions from the Panel, the EC said that the existence of provisions allowing for patent term extension or the grant of a special protection certificate (see paragraph 4.31 below, under (b)) could be of significance when considering, and influence the finding of discrimination as to, whether "Bolar-style" exceptions amounted to "discrimination" under Article 27.1. However, since Canada did not have a system of patent term extension or the like, such considerations were hypothetical for the resolution of the present dispute, not only in connection with Article 27.1, but also in relation to Article 30. Of course, the possible interplay between patent term extension on the one hand and "Bolarstyle" exceptions on the other hand was also relevant when balancing, under Article 30, the interests of the patent owner with the interests of the would-be copy producer. The existence of a patent term extension or special protection certificate system might influence the balance of interests to be struck between the patent holder and the would-be copy producer under Article 30. Depending on the way in which protection after the expiry of the original patent was granted and how the "Bolar-style" exception operated, one could imagine a case where Article 30 might be redundant, because there would be no violation of Article 28.1 of the TRIPS Agreement in the first place. However, again, since Canada did not have a system of patent term extension or the like, there was no need to go into such a balancing exercise. Under no circumstances could Article 27.1 of the TRIPS Agreement allow a differential treatment below TRIPS minimum standards.

${ }^{148}$ See the footnotes to paragraphs 4.28 and 4.27 , last indent, above. 


\section{$\underline{\text { Preliminary Remarks }}$}

The European Communities and their member States failed to understand the relevance for the case of the extensive arguments put forward by Canada on "Cost Containment and Generic Drugs". ${ }^{149}$ While issues of health care and costs of drugs played an important role in the domestic policy discussion in many if not all societies, including of course the European Communities and their member States, these considerations appeared to be of little, if any, relevance for the purposes of interpreting the TRIPS Agreement.

- $\quad$ It was one of the major features of the TRIPS Agreement that its implementation was in principle neutral vis-à-vis societal values. This principle was most clearly expressed in Article 8.1 of the Agreement: "Members may, in formulating or amending their laws and regulations, adopt measures necessary to protect public health and nutrition, and to promote the public interest in sectors of vital importance to their socio-economic and technological development, provided that such measures are consistent with the provisions of this Agreement" (emphasis added by the EC). This provision made it utterly clear that none of the public policy considerations, referred to in the first half sentence, could be invoked to justify measures which were inconsistent with provisions of the TRIPS Agreement. This principle of neutrality vis-à-vis societal values was also confirmed if one compared the exception provision in Article 30 with the exception provisions contained in Article XX of the GATT. While exceptions under the latter were only permissible if they were necessary to achieve certain well-defined societal values (public morals, protection of human, animal or plant life or health, etc.), Article 30 of the TRIPS Agreement did not refer to any such societal values to justify an exception.

To put it differently, the TRIPS negotiating parties had taken societal interests into consideration when agreeing on the balance of interests which were enshrined in the TRIPS Agreement. Consequently, individual WTO Members could not now rebalance these interests unilaterally by modifying the level of protection provided for in the Agreement. ${ }^{150}$

A practical illustration of the consequences of this principle was that many countries, including the European Communities and their member States which were very much concerned with the containment of the costs of health care including the cost of pharmaceuticals, took measures to control the resale prices or the refund amounts for pharmaceuticals without curtailing the intellectual property rights which were attached to these products. ${ }^{151}$

The European Communities and their member States also failed to understand the relevance of the repeated reference by Canada in its submission to Article 40 of the TRIPS Agreement in relation to anti-competitive practices, because at no time during the legislative

\footnotetext{
${ }^{149}$ See paragraph 4.21 under (d) above.

${ }^{150}$ Reference was also made to the arguments reflected under IV.C(2)(b) below relating to the Preamble of the TRIPS Agreement as well as its Articles 1.1, 7 and 8.1.

${ }^{151}$ In response to a question from the Panel on the relevance of constitutional limitations for the introduction of price controls, as advanced by Canada (see paragraph 4.21 under (d) above), the European Communities and their member States advanced that they understood Canada's statement to mean that, while the Federal Government had, under Canada's Constitution, the right to control prices for pharmaceutical products during the patent term and indeed had adopted such price control measures, it was prevented from taking such measures after patent expiry. After patent expiry, the authority to take such measures vested with the Canadian Provinces and Territories. In the view of the EC, the internal distribution of powers in Canada between the Federal level and the sub-federal levels were completely irrelevant for the legal questions before the Panel. In any event, if the competent authorities in Canada at the various competent levels considered that the containment of costs for public health required price control measures for pharmaceutical products, such measures could be taken during the patent term and thereafter. It was a totally different question whether all sub-federal authorities shared the public policy objective advocated by the Federal Government and eventually adopted measures accordingly. To argue otherwise would mean that the level of minimum protection of intellectual property rights, which had to be granted by WTO Members, would depend on the niceties of their internal constitutions, which were subject to change at any moment.
} 
history of the incriminating provisions (Bill C-91) had there been any mention that either individual holders of pharmaceutical patents or all holders of pharmaceutical patents collectively had engaged in anti-competitive practices.

\section{(i) The Preamble of the TRIPS Agreement and its Articles 1.1, 7 and $8.1^{152}$}

- Article 3.2 of the DSU directed panels to interpret the covered agreements in accordance with customary rules of interpretation of public international law. It was now wellestablished that this was a reference to the rules of interpretation contained in the Vienna Convention on the Law of Treaties. ${ }^{153}$ Article 31(1) of that Convention provided that "[a] treaty shall be interpreted in good faith in accordance with the ordinary meaning to be given to the terms of the treaty in their context and in the light of its object and purpose". Canada adopted a rather different approach to applying this principle than the EC. Leaving aside the "ordinary meaning", which would be discussed in connection with the provisions invoked in the present dispute, the EC wished to comment on the erroneous use made by Canada and others of the context and object and purpose of the TRIPS Agreement.

It was first instructive to recall the teaching of the Appellate Body in Shrimps ${ }^{154}$ where the Appellate Body reproached a panel for engaging in creative interpretation based on its own "overly broad" view of the object and purpose of the relevant agreements, stating:

"The Panel did not follow all of the steps of applying the 'customary rules of interpretation of public international law' as required by Article 3.2 of the DSU. As we have emphasized numerous times, these rules call for an examination of the ordinary meaning of the words of a treaty, read in their context, and in the light of the object and purpose of the treaty involved. A treaty interpreter must begin with, and focus upon, the text of the particular provision to be interpreted. It is in the words constituting that provision, read in their context, that the object and purpose of the states parties to the treaty must first be sought. Where the meaning imparted by the text itself is equivocal or inconclusive, or where confirmation of the correctness of the reading of the text itself is desired, light from the object and purpose of the treaty as a whole may usefully be sought". ${ }^{155}$

Thus, the correct approach was to focus first on the text of the provisions to be interpreted read in its context and to discern from this the intention of the parties to an agreement. It was only if this left a doubt that it was appropriate to seek enlightenment from the object and purpose of the agreement.

Canada claimed to be interpreting Article 30 of the TRIPS Agreement in context when it invoked the first recital to the Preamble and Articles 1.1 and 7 of the TRIPS Agreement. It was clear that the whole text of an agreement, including the preamble, formed part of the context of a provision of that agreement. However, the above provisions were not in reality being invoked by Canada as context to discern the ordinary meaning of the terms

152 These points were put forward by the EC in response to a question from the Panel.

${ }^{153}$ See United States - Gasoline (WT/DS2/AB/R, p. 17); Japan - Taxes on Alcoholic Beverages (WT/DS8/AB/R, WT/DS10/AB/R, WT/DS11/AB/R, pp. 10-12); India - Patent Protection for Pharmaceutical and Agricultural Chemical Products (WT/DS50/AB/R, paragraphs 45-46); Argentina - Measures Affecting Imports of Footwear, Textiles, Apparel and Other Items (WT/DS56/AB/R, paragraph 47); European Communities - Customs Classification of Certain Computer Equipment (WT/DS62/AB/R, WT/DS67/AB/R, WT/DS68/AB/R, paragraph 85); United States - Import Prohibition of Certain Shrimp and Shrimp Products (WT/DS58/AB/R, paragraphs 114-117); and Guatemala - Anti-Dumping Investigation Regarding Portland Cement from Mexico (WT/DS60/AB/R, paragraph 70).

${ }^{154}$ United States - Import Prohibition of Certain Shrimp and Shrimp Products (WT/DS58/AB/R), paragraphs 114117.

${ }^{155}$ In a footnote, the Appellate Body had referred to the first four authorities cited by the EC as reflected in footnote 153 above. 
used in Article 30, but as expressions of object and purpose. The arguments drawn from these provisions by Canada all related to the supposed object and purpose of the TRIPS Agreement and not to contextual guidance as to the meaning of the terms of Article 30 thereof.

The first recital of the Preamble of the TRIPS Agreement started with the word "Desiring" and was thus a clear expression of object and purpose. Article 1.1 set out, as its title indicated, the "nature and scope of obligations" which the TRIPS Agreement was intended to create and was therefore also an expression of object and purpose. Article 7 was entitled "Objectives" and set out objectives for the protection of intellectual property rights.

- $\quad$ The first recital of the Preamble to the TRIPS Agreement ${ }^{156}$ expressed three purposes, namely: to reduce distortions and impediments to international trade, i.e. to secure a more uniform protection of intellectual property rights throughout the world; to promote effective and adequate protection of intellectual property rights, i.e. to reinforce the protection of these rights; and to ensure that measures and procedures to enforce intellectual property rights did not themselves become barriers to legitimate trade. Canada emphasized only the last of these purposes in order to argue that the protection of intellectual property rights should be limited. This was of course misleading. The third element of the first recital was not referring to the rights themselves at all. It was referring to the "measures and procedures" to enforce those rights regulated in Part III of the TRIPS Agreement. On the contrary, the TRIPS Agreement clearly provided in Article 1.1 that it was in general only laying down minimum rights, not limited rights.

- $\quad$ As regards Article 7 of the TRIPS Agreement ${ }^{157}$, Canada only emphasized the last elements of the objectives referred to, namely the "manner conducive to social and economic welfare" and the "balance of rights and obligations". However, Canada's main error was to consider that this required the patent rights set out in Article 28 of the TRIPS Agreement to be limited in some circumstances so as to provide "balance". Article 7 was not dealing with the scope of the intellectual property rights defined in Article 28, but only with their "protection and enforcement".

Article 1.1 of the TRIPS Agreement ${ }^{158}$ was invoked by Canada in order to establish that it had a broad discretion as to how to implement its obligations under the Agreement. However, Canada was wrong to consider that this provision provided a general discretion for Members to adjust obligations under the Agreement. It clearly stated that the protection of intellectual property under the TRIPS Agreement was to be considered a minimum level of protection. The flexibility which was allowed related to the means by which this minimum level of protection was secured in each Member's legal system.

156 "Desiring to reduce distortions and impediments to international trade, and taking into account the need to promote effective and adequate protection of intellectual property rights, and to ensure that measures and procedures to enforce intellectual property rights do not themselves become barriers to legitimate trade;"

157 "The protection and enforcement of intellectual property rights should contribute to the promotion of technological innovation and to the transfer and dissemination of technology, to the mutual advantage of producers and users of technological knowledge and in a manner conducive to social and economic welfare, and to a balance of rights and obligations."

158 "Members shall give effect to the provisions of this Agreement. Members may, but shall not be obliged to, implement in their law more extensive protection than is required by this Agreement, provided that such protection does not contravene the provisions of this Agreement. Members shall be free to determine the appropriate method of implementing the provisions of this Agreement within their own legal system and practice." 
- $\quad$ Canada was careful not to invoke Article 8.1 of the TRIPS Agreement ${ }^{159}$ as context or object and purpose for the purpose of supporting its interpretation. It merely referred to it as demonstrating that public health was a relevant consideration under the TRIPS Agreement. Certain third parties had, however, referred to it in connection with their consideration of the context or object and purpose of the Agreement. ${ }^{160}$ According to the EC, however, the key phrase to the understanding of this provision was "provided that such measures are consistent with the provisions of this Agreement". This demonstrated that the public health, nutrition and other public interests were to be considered subordinate to the protection of the intellectual property rights insofar as the minimum rights guaranteed by the TRIPS Agreement were concerned. In fact, this provision was merely providing that Members should not be subject to claims for non-violation nullification and impairment when taking measures consistent with the TRIPS Agreement in pursuit of these interests, even where these measures could nullify and impair TRIPS rights in some way.

(b) Interpretation of the Conditions Enumerated in Article 30 for the Grant of Exceptions to Rights Conferred

The conditions enumerated in Article 30 of the TRIPS Agreement for the grant of exceptions to rights conferred were threefold:

- $\quad$ only "limited" exceptions were permissible;

- $\quad$ the exceptions must not unreasonably conflict with a normal exploitation of the patent; and

the exceptions must not unreasonably prejudice the legitimate interests of the patent owner, taking account of the legitimate interests of third parties.

- $\quad$ The European Communities and their member States disagreed with Canada that the interests of third parties would also be of relevance for the second condition. The language of Article 30 was clear on this point, because it compared two interests. Another reading would require that the normal exploitation had to be compared with an interest, which appeared nonsensical. In other words, under a textual interpretation of Article 30, the third party interests could only be logically considered vis-à-vis the interests of the right holder. One could only reasonably compare one interest with another interest, not on the one hand the normal exploitation of the patent and on the other hand an interest of a third party.

While Canada had referred to a number of submissions by parties to the TRIPS negotiations and GATT Secretariat documents ${ }^{161}$, Canada interestingly enough had not referred to its own submission of 25 October 1989 to the TRIPS Negotiating Group ${ }^{162}$, in which it had proposed, inter alia, the following under the title "Rights Conferred":

"National laws, however, may provide that the owner of a patent has no right to prevent third parties from performing the following acts :

(i) acts done privately and on a non-commercial scale provided that they do not significantly prejudice the economic interests of the owner of the patents; and

159 "Members may, in formulating or amending their laws and regulations, adopt measures necessary to protect public health and nutrition, and to promote the public interest in sectors of vital importance to their socio-economic and technological development, provided that such measures are consistent with the provisions of this Agreement."

160 The EC referred specifically to Brazil, India, Israel and Poland (see section V. of this Report below).

161 See footnote 41 above.

162 Document MTN.GNG/NG11/W/47 
(ii) making or using for solely experimental purposes or scientific research in relation to the technology in respect of which the patent was granted, or a competing technology."

While no complete synopsis of all views expressed had been prepared by the EC, it was instructive to see what some "opinion leaders", both from developing countries and industrialized countries, had had in mind. Hong Kong, as one of the opinion leaders for certain developing countries, had proposed the following ${ }^{163}$ :

"Limited exceptions to the exclusive rights conferred by a patent, which take account of the legitimate interests of the proprietor of the patent and of third parties, may be made for certain acts, such as acts done privately and for non-commercial purposes and acts done for experimental purposes".

The United States, in its submission of 11 May $1990^{164}$, which was also not mentioned in the submission by Canada among the negotiating documents, had proposed:

"Contracting parties may limit the patent owner's exclusive rights solely through compulsory licenses and only to remedy an adjudicated violation of competition laws or to address, only during its existence, a declared emergency...".

In response to a question from the Panel, the European Communities and their member States explained why the "prior use" exception and the "scientific/experimental use (excluding activities relating to providing information for regulatory approval)" exception would satisfy each of the criteria of Article 30 and therefore would qualify as permissible exceptions under Article 30. The following arguments were advanced:

\section{(i) The "prior use" exception}

There existed no internationally accepted definition of what constituted "prior use". While many countries provided for a "prior use exception", albeit with greatly diverging approaches, others did not provide for such an exception at all, the United States being the most prominent example. The "prior use" exception occurred in practice only extremely rarely and in many jurisdictions, which foresaw such an exception, there existed no reported case law in relation to it. The reason for this very scarce occurrence resided in the fact that in an "ideal world" the case of "prior use" of an invention could not arise. In order for an invention to be patentable, it had to be "new" (see Article 27.1 of the TRIPS Agreement). Therefore, "prior use" could only occur in a secret and thus extremely limited manner. As soon as products being based on such an invention were offered for sale to the public, advertised or described in a catalogue, this product would become state of the art and defeat the novelty requirement as far as the patent applicant was concerned. No extensive discussion on "prior use" had taken place in the context of the TRIPS negotiations. However, some work on the issue had been carried out in WIPO in the late ' 80 s and early '90s, although no treaty had emerged from these efforts to date. "Prior use" had been defined in that context in the following way ${ }^{165}$ : "... any person who, in good faith, before the filing date [...] and within the territory where the patent produces its effect, was using the invention or was making effective and serious preparations for such use; any such person shall have the right, for the purposes of his enterprise or business, to continue such use or to use the invention as envisaged in such preparations". The EC used this definition for its further analysis and

\footnotetext{
${ }^{163}$ Document MTN.GNG/NG11/W/51

${ }^{164}$ Document MTN.GNG/NG11/W/70

${ }^{165}$ As reproduced by Wegner, Patent Harmonization, London, Sweet \& Maxwell, p. 115
} 
assumed, for the sake of argument, that such "prior use" might be excepted from patent protection under Article 30 of the TRIPS Agreement.

The exception was strictly limited to the person who had been in possession of the invention prior to filing of the patent application by the future patentee. Given that the "prior use" was only protected as far as his actual activities had gone prior to patent filing and given that these activities must have been "secret activities", as pointed out above, the scope of the excepted activities must be very small. Also as far as the intended activities were concerned, it was also important to note that the more "effective and serious" the preparations might be, the more this would bring the invention to the knowledge of the interested public and thus defeat the later patent application. In other words, the fact that knowledge of the interested public (e.g. by advertisement, catalogue, etc.) would defeat the novelty of the patent application, the scope of permissible activities by the "prior user" would necessarily be very restricted. Therefore, this exception met the requirement under Article 30 that it must be "limited".

The normal exploitation of the patent consisted of the full enjoyment of all patent rights which had a direct or indirect commercial significance. Given that the prior use right, as defined above, did indeed allow, albeit seriously restricted, commercial acts carried out by the prior user in competition with the patentee, there existed indeed a conflict with the normal exploitation of the patent. The remaining question was whether this conflict was not unreasonable. In the light of the situation in relation to novelty and prior use, as described above, the fact that the patentee had indeed not been the first to make the invention, but that someone else had made the invention objectively before him, created a certain degree of relative "weakness" of his patent vis-à-vis this prior inventor and justified that this prior inventor/user could continue to perform the very restricted acts allowed by the exception. It was also noteworthy that this relative weakness of his patent was largely preferable for the patentee to the situation where the prior inventor/user would have gone public, thus defeating the patent application in the first place. Therefore, the "prior use" exception did not unreasonably conflict with the normal exploitation of the patent.

Again, the legitimate interests of a patent owner could only be the full enjoyment of all his patent rights. By applying this yardstick, the "prior use" right did prejudice the legitimate interests of the patent holder. It remained to be established whether this prejudice was not unreasonable, taking account of the legitimate interests of third parties. The obvious third party where legitimate interests had to be taken into account was the prior inventor/user, who had obtained justified expectations through the "prior use" or making effective and serious preparations of such use, thus making investments with a view to continue such use. The extent of the permissible subsequent use was strictly limited by the extent of such "prior use" and investment which created the justified expectations. On the other hand, the argument that the patentee was objectively not the first to make the invention justified the weak spot of his rights vis-à-vis the previous inventor/user within the limits of the latter's justified expectations. Therefore the "prior use" exception did not unreasonably prejudice the legitimate interests of the patent owner, taking account of the legitimate interests of third parties.

\section{The "scientificlexperimental use" exception}

There was no internationally accepted definition of "scientific/experimental use". It could, however, be said that practically all Members of the WTO had such an exception albeit drafted in a great variety of ways. The practically universal existence of this exception was closely linked to the basic underlying deal between society and the patentee. The patentee agreed to disclose his invention and thus share with society the fruits of his inventive activities and investment at an early stage in order to avoid investment in multiple research 
and to make the invention available as the basis for further, more advanced research. On the other hand, the patentee obtained the exclusive patent rights for a fixed patent term (a minimum of 20 years according to Article 33 of the TRIPS Agreement). In a sense, this exception was the corollary to the disclosure requirement, because otherwise researchers would only be allowed to read the description of the patented invention, without being able to experiment with the invention (e.g. to see if and how it worked). The EC relied on the text of Article 27(b) of the Community Patent Convention which excepted from liability for patent infringement "acts done for experimental purposes relating to the subject matter of the patented invention". As to further details and interpretations given by courts in the European Communities and their member States, reference was made to an overview provided in a publication by Cornish. ${ }^{166}$ As a more general remark, it could be said that, while courts used to limit this exception to academic research, it was today largely accepted that it could also cover industrial research.

The exception was limited in character. It only applied to typically one out of five patent rights referred to in Article 28.1 of the TRIPS Agreement, since only use was permissible, while offering for sale, selling and importing were not permissible. The scope of the exception was narrowly defined. For a good example of such a definition, reference was again made to the publication by Cornish ${ }^{167}$ : "[...] experimental activities are excepted from patent protection only when they are solely for the purpose of determining whether the patented invention is feasible, useful or technically operable, that is whether or not the invention works. Furthermore, experimental activities are considered permissible to the extent that they serve the purpose of technically perfecting and further developing the patented subject-matter."

- Given that the basic patent deal consisted of the making public of the invention against the grant by the state of a bundle of exclusive rights for a defined period of time, it could reasonably be argued that the exclusive rights granted to the patentee were designed to control all commercially relevant activities related to his patent. However, this did not give him an exclusivity for the use of his invention for experimental purposes. It was a consequence of this "basic patent deal" that others could use the patentee's invention in order to develop the state of the art further. Thus, there existed no conflict with the normal exploitation of the patent.

Given that the "basic patent deal" required the patentee to disclose his invention to the public and to accept that it served as the basis for further research, it could be reasonably argued that a "research monopoly" was not included in his legitimate interests and, therefore, the interests of third parties and their balancing with the patentee's interests appeared to be redundant for the research exception.

(c) Section 55.2(2) and 55.2(3) of the Canadian Patent Act together with the Manufacturing and Storage of Patented Medicines Regulations

\section{"Limited"}

The term "limited" in Article 30 confirmed that exceptions allowed under that provision had to be narrowly interpreted. In other words, the exceptions had to be restricted, bounded, prescribed, confined within positive bounds, restricted in duration, extent or scope. ${ }^{168}$ The manufacturing and stockpiling possibility under Canadian law did not qualify as a limited exception under Article 30 of the TRIPS Agreement.

\footnotetext{
${ }^{166}$ See the publication referred to in footnote 188 below, pp. $735-753$.

${ }^{167}$ See the publication referred to in footnote 188 below, p. 742 .

${ }^{168}$ Reference was made to Black's Law Dictionary, p. 836.
} 
While Article 28.1(a) of the TRIPS Agreement granted a patent holder a minimum of five fundamental individual rights, i.e. making, using, offering for sale, selling and importing, the manufacturing and stockpiling possibility under Canadian law took away at least three of these rights, i.e. the right to prevent others from making and using - which included importation - of the invention. The curtailment of three out of five rights could not be considered "limited". In any event, there was no limitation as to the quantity of material that could be manufactured and stockpiled. ${ }^{169}$

Also, if one used the timing aspect, one could not say that the six-month period stipulated in the Manufacturing and Storage of Patented Medicines Regulations could be considered as being "limited", if compared to the 20-year patent term. This conclusion applied a fortiori if one compared the six-month period to the effective term of protection for inventions in the pharmaceutical field, which was limited to eight to 12 years.

\section{(ii) "Do not unreasonably conflict with a normal exploitation of the patent"}

The manufacturing and stockpiling possibility under Canadian law conflicted unreasonably with a normal exploitation of a patent. The right to prevent others from making and using a patent were among the fundamental patent rights. These purely commercial activities being carried out by any person in Canada without the consent of the right holder and without the payment of any licence fee created an unreasonable conflict with the normal exploitation of the patents concerned.

In response to a question from the Panel, the European Communities and their member States expressed the view that the term "not unreasonably", which qualified the notion of "conflict with a normal exploitation of the patent", was intended to further narrow the scope of the exception. While it was true that neither Article 13 of the TRIPS Agreement nor Article 9(2) of the Berne Convention used the notion of "not unreasonably" to qualify the "conflict with a normal exploitation", it was difficult to judge if this difference of wording did indeed lead necessarily to a different interpretation of Article 30 of the TRIPS Agreement, which had been negotiated after its Article 13. The EC continued to believe that the examples which the TRIPS negotiating parties had had in mind to be covered by Article 30 were the most appropriate yardstick with which to compare the Canadian exceptions which were before this Panel.

- $\quad$ Canada had argued that "only" the rights of making and using were curtailed, the selling right remaining untouched. This argument was based on a misconception of the character of a patent. All the patent rights referred to in Article 28.1 of the TRIPS Agreement were important in themselves and could not be reduced to a single selling right. This misconception became perfectly obvious when one compared Article 70.9 of the TRIPS Agreement with Article 28.1. Article 70.9 related to a situation where a country did not provide patents, but had to provide "exclusive marketing rights" for a transitional period. The latter clearly constituted a significantly lesser right than a full patent.

Canada's argumentation that the patent owner continued to be free to carry out all acts referred to in Article 28.1 of the TRIPS Agreement was equally based on a misconception of a patent. A patent did not grant a positive right to the patent holder to perform certain acts, but was concerned with giving the patent owner the legal means to exclude others from performing certain acts.

- $\quad$ The conflict with the normal exploitation of patents constituted by the manufacturing and stockpiling possibility under Canadian law was unreasonable given the importance of the

${ }^{169}$ With respect to Article 28.1(b), the same applied mutatis mutandis. 
patent rights curtailed and given the unlimited extent and the relatively long duration of the permissible activities under Canadian Patent Law.

(iii) "Do not unreasonably prejudice the legitimate interests of the patent owner, taking account of the legitimate interests of third parties"

The manufacturing and stockpiling possibility under Canadian law unreasonably prejudiced the legitimate interests of the patent owner, taking account of the legitimate interests of third parties.

- $\quad$ The legitimate interests of a patent owner could only be the full enjoyment of all his patent rights during the entire patent term.

- $\quad$ As to the legitimate interests of third parties, the EC dsagreed with Canada that consumers or society at large could be considered as third parties in the context of Article 30. The purchase or consumption of a medicine by a patient was no act which was of any relevance in patent terms. This meant in turn that there could be no adverse interests between the consumer and the patent holder. In general, there could exist adverse economic interests between a seller and a buyer, but this was no different whether or not the products in question were covered by a patent. This argument also applied to the providers of public health or health insurance enterprises. It could only be the would-be producer of the generic product, who could reasonably qualify as a third party with adverse interest vis-à-vis the patent holder.

- When it came to the "legitimacy" of the interests of the patent owner on the one hand and the third parties referred to under Article 30 on the other hand, Canada displayed a curiously biased approach. While the "legitimacy" of the patent owner's interests was in Canada's view strictly confined to the legal rights flowing from the patent, the "legitimacy" of third parties' interests could be based on any kind of economic, moral or other consideration.

If one followed the strict approach, by allowing only patent law arguments both for the patent owner and the third party, then a situation where a third party could have a legitimate interest would be very rare indeed. One could think of a scientist as having such a legitimate interest to carry out experiments. Obviously, the Patent Section of the TRIPS Agreement did not stipulate any legal right for a counterfeit generic producer to effectively have a share of the market on day one after patent expiry. ${ }^{170}$

${ }^{170}$ In response to a question from the Panel, the EC said that they had consulted the European research-based pharmaceutical industry regarding the practice under pharmaceutical patent licensing contracts in regard to the payment of royalties for products made during the patent term but sold after expiry thereof. The following information had been received: "Licenses within the pharmaceutical industry may relate to patented processes or products. Patented products include process intermediates, active ingredients and formulations. The rights granted under a patent license may be limited to any one or more of the acts of "making, using, offering for sale, selling or importing". Each of the licensed acts may be further limited, e.g. to a field of use. In theory, the consideration for each of the licensed acts may be separately accountable. In practice, the terms of license agreements commonly include one or more of the following financial considerations: execution fee; maintenance fees, e.g. annual payments; milestone payments, e.g. lump sums payable upon initiation and/or completion of pre-clinical or clinical trials, submission and/or approval of regulatory dossiers and/or launch; royalties. Royalties, if payable, may be based on any measurable aspect of product development, manufacture or sales. Thus, a fee per unit may be levied based on e.g. the weight, volume, profit margin or value/cost/price of the product or process concerned. The fee may be expressed as a fixed amount, e.g. amount of money x per kg active ingredient/finished product or as a percentage, e.g. of price. This means that in cases in which the royalties are based entirely or largely on manufacture, royalties will be payable for products produced during the patent term but sold afterwards. Pharmaceutical product manufacture, development and sale is a lengthy and complex procedure involving a large number of steps including primary and secondary manufacture, the preparation of substantial quantities of material for clinical trials and regulatory purposes, and potentially the storage, distribution and sale of intermediates, active ingredients, formulated and packaged products. Absent a license, each of these steps may represent individual acts of patent infringement." The Canadian response to the same Panel question is reflected in footnote 263. 
- If one were to follow an approach which would allow to also take into account on both sides commercial and economic considerations and expectations, it appeared first of all necessary to point to the fact that both research-based and generic pharmaceutical producers were enterprises which operated for economic profit and investors in both kinds of enterprises sought exactly the same objectives, albeit through different business practices. As both research-based and generic producers were on an equal footing, nobody could claim any priority of the legitimate interest by one over the interests of the other. It also had to be mentioned that it was a normal commercial requirement, for new competitors who wanted to come on the market, that the introduction of a new product would take some time, not only in terms of marketing efforts, but also in terms of manufacturing and distribution efforts. Given the significant length of time during which manufacturing and stockpiling could occur and given the fundamental importance of the manufacturing and use rights, the prejudice could clearly be characterized as unreasonable.

(d) Section 55.2(1) of the Canadian Patent Act

(i) "Limited"

Section 55.2(1) of the Canadian Patent Act did not qualify as a limited exception under Article 30 of the TRIPS Agreement. ${ }^{171}$

The activities related to the development and submission of information required for obtaining marketing approval permissible under Canadian law curtailed all patent rights, even the rights to prevent selling and offering for sale.

- $\quad$ As to the element of timing, the denial of patent protection under Article 55.2(1) of the Canadian Patent Act could occur at any time during the 20-year patent term.

While it was true that the purpose for which all the patent rights were disregarded under Canadian law were circumscribed by "[...] uses reasonably related to the development and submission of information required under any law of Canada, a province or a country other than Canada that regulates the manufacture, construction, use or sale of any product", this nevertheless allowed wide-ranging activities by a wide range of operators. Beneficiaries of this exception included not only the would-be generic producers, but also their completely independent suppliers of active ingredients, i.e. fine chemical manufacturers.

- Moreover, given that the objective was marketing approval anywhere in the world, the exception provision allowed infringing acts of a significant extent, including the manufacture, sale and importation of industrial quantities of active ingredients when this was required by the marketing approval authorities.

Furthermore, the extent of permissible activities was out of the control of the Canadian authorities insofar as they could not influence, and in many instances would not even know, the conditions for obtaining marketing approval in all countries other than Canada.

- $\quad$ Section 55.2(1) of the Canadian Patent Act conflicted unreasonably with a normal exploitation of patents. It disregarded all patent rights stipulated by Article 28.1 of the TRIPS Agreement. ${ }^{172}$

${ }^{171}$ As to the definition of the limited character of the exceptions under Article 30, reference was made to what is reflected under IV.C(2)(c)(i), first indent, above. 
- $\quad$ The points made in this regard in relation to the manufacturing and stockpiling possibility under Canadian law equally applied in relation to Section 55.2(1). ${ }^{173}$

(iii) "Do not unreasonably prejudice the legitimate interests of the patent owner, taking account of the legitimate interests of third parties"

Section 55.2(1) of the Canadian Patent Act unreasonably prejudiced the legitimate interests of the patent owner, taking account of the legitimate interests of third parties. The points made in this regard in relation to the manufacturing and stockpiling possibility under Canadian law equally applied in relation to Section 55.2(1). ${ }^{174}$

- $\quad$ It had to be emphasized, as to the eligible third party interests under Article 30, that only would-be generic manufacturers qualified. Both research-based and generic enterprises operated for commercial gain and none could claim any priority interest over the other. This meant that, from the perspective of Article 30, the legitimate interest of both could be nothing else but a full respect of the existing intellectual property rights. In particular, there could be no legitimate interest of the generic producers to be able to sell on the Canadian market, and even less so to sell outside Canada, on the day the Canadian patent lapsed. ${ }^{175}$

Canada's argument ${ }^{176}$ that a full respect of the patent rights until the end of the patent term would give the patent holder a "windfall" period of protection beyond the legal patent term mixed up two separate matters. As far as the patentee was concerned, he could expect a legal patent right of at least 20 years counted from filing, to prevent activities which used his patented product. For the holder of a patent in the pharmaceutical field, this meant in practical terms that he would not be able to exercise the exclusive rights during eight to 12 years, because the requirements for obtaining marketing approval for his product would take eight to 12 years from patent filing. On the other hand, the patent holder had also an economic expectation that, when the laws provided for marketing approval requirements, these applied equally to his competitors and that activities coming within the scope of his patent could only start after the patent had lapsed. In other words, there existed no reason why the research-based pharmaceutical enterprise was obliged to accept the economic consequences of marketing approval requirements which reduced its effective term of protection to eight to 12 years, while the copy producer could completely ignore the economic consequences of the need for marketing approval for his generic products, and this at the expense of inventors and patent holders.

The legitimate expectations of the generic producer could from a legal point of view only be that he could start infringing activities after the patent had expired and that he had to bear the burden of limited marketing approval requirements just as the patent holder had to bear much greater consequences before he put the product on the market. Already the fact that the marketing approval requirements for generic products only required a fraction of effort as compared to the original product, which also led to much shorter periods of time for obtaining marketing approval, gave the generic product a competitive advantage at the expense of the producer of the original product. For a generic producer, the delay was only a matter of timing of when he came to the market. He lost no rights. However, for the originator patentee, every day of delay in marketing meant a day less patent protection.

\footnotetext{
${ }^{172}$ Reference was made to the points reflected under IV.C(2)(d)(i) above.

${ }^{173}$ See under IV.C(2)(c)(ii) above.

${ }^{174}$ See under IV.C(2)(c)(iii) above.

175 See footnote 170 above.

${ }^{176}$ See paragraph 4.21 above, under (c), indents 4-6.
} 
4.31 The European Communities and their member States could not see the relevance of the description provided by Canada of the legal situation in a number of countries, and in particular in the United States, to the appreciation of the Canadian legislation. Only provisions of Canadian legislation were the subject of the present dispute settlement procedure. In response to a question from the Panel concerning "subsequent practice" within the meaning of Article 31.3 of the Vienna Convention on the Law of Treaties ${ }^{177}$, the EC advanced the following points:

The first point to note about "subsequent practice" was that it was to be taken into account "together with the context". In the case of the WTO agreements this included, in particular, the general rules in the Marrakesh Agreement Establishing the WTO itself relating to the interpretation and development of WTO law. Article IX:2 of the Marrakesh Agreement granted exclusive authority for the making of authoritative interpretations to the Ministerial Conference and Article X provided for special procedures for amendments. This, taken together with the principle in Article 3.2 of the DSU that dispute settlement panels could not add to or diminish the rights and obligations of Members, demonstrated that the Members of the WTO wanted to retain strict control over the modification of the rules that they had agreed and that they did not wish the meaning of what they had agreed to be changed in any other way. This already suggested a very limited role for "subsequent practice" in the interpretation of WTO agreements.

- $\quad$ It must also be remembered that the requirements for establishing "subsequent practice" would be difficult to satisfy in practice and that it would rarely be relevant. It was clear from the wording of Article 31.3(b) of the Vienna Convention that a "subsequent practice" must be such as to establish a tacit agreement between the parties. It had been expressed by learned commentators as requiring a subsequent practice which was "concordant, common and consistent". ${ }^{178}$ The practice must also be common to all the parties and so would be particularly difficult to establish in the case of a multilateral agreement.

In the present case, it would seem that existence of a subsequent practice establishing agreement regarding the interpretation of the relevant provisions of the TRIPS Agreement could be excluded because of the short period of time the Agreement had been in force.

- $\quad$ The answers to the questions posed by the Panel to the third parties in the present dispute showed that any practice which existed was by no means consistent and concordant. ${ }^{179}$ Most importantly, however, the European Communities and their member States had contested Canada's practice which was the subject of the present dispute ever since the legislation on which it was based had been notified to the Council for TRIPS in 1996. It was therefore impossible to claim that there had been anything approaching agreement on the matter.

(a) Section 55.2(2) and 55.2(3) of the Canadian Patent Act together with the Manufacturing and Storage of Patented Medicines Regulations

- $\quad$ None of the eleven third parties to the present dispute allowed pre-patent expiry manufacturing and stockpiling, not even those which supported some of the Canadian arguments. Moreover, a comparison between the Canadian manufacturing and stockpiling

\footnotetext{
177 "There shall be taken into account together with the context: [... (b) and subsequent practice in the application of the treaty which establishes the agreement of the parties regarding its interpretation; [...]."

${ }^{178}$ See Yasseen, "L'interprétation des traités d'après la Convention de Vienne sur le Droit des Traités", 151 Recueil des Cours (1976-III), p. 48. See also I. Sinclair, The Vienna Convention on the Law of Treaties, 2nd ed. (Manchester University Press, 1984), p. 137.

${ }^{179}$ See Annex 5 to this Report.
} 
exception and the exceptions put forward by the negotiating parties of the Uruguay Round as referred to above ${ }^{180}$ showed that not even remotely comparable exceptions had been proposed in those negotiations.

\section{$\underline{\text { Section 55.2(1) of the Canadian Patent Act }}$}

It was interesting to note that a certain number of third parties, albeit supporting the compatibility of the Canadian Law with the TRIPS Agreement, did not allow such premarketing approval activities in their own laws (Brazil, Colombia, Cuba, India, Poland). This situation was the more revealing because these countries still benefited from a transitional period under Article 65 of the TRIPS Agreement and thus did not have yet to comply with the Agreement (as was the case for Argentina, Hungary and Israel, to which Canada had made reference in support of its arguments ${ }^{181}$ ).

The United States, Japan and Australia (to which Canada had also made reference in support of its arguments ${ }^{182}$ ) operated a system of patent term extension or special protection certificates, which extended the patent term or provided some specific exclusive rights for pharmaceutical products for typically up to five years beyond the 20 -year patent term. The individual period of additional protection was generally a period which compensated to some extent for the duration of the process to obtain marketing approval. ${ }^{183}$ Therefore the question of which activities to obtain marketing approval were permissible focused on the post 20-year patent term period.

As far as Switzerland was concerned, there existed a special protection certificate system to extend patent rights for a maximum of five years and no pre-marketing activities were permissible before the expiry of the patent term including the term provided by the special protection certificate. ${ }^{184}$

Canada had also made reference to the practice in a number of EC member States in support of its arguments. ${ }^{185}$ However, in none of these member States did a situation exist which would even remotely be comparable to the situation prevailing in Canada under Section 55.2(1) of the Canadian Patent Act. At Community level, a supplementary protection certificate for medicinal products had been created by Council Regulation (EEC) $\mathrm{N}^{\circ}$ 1768/92. ${ }^{186}$ By this Regulation, the patent rights for an active ingredient for which a marketing approval had been granted could be extended for a period of maximum five years after the basic patent had lapsed. As to the activities which were permissible without the authorization of the patent holder, this had to be assessed under the patent law of the member States. There existed no exception for activities in relation to regulatory approval in the member States of the $\mathrm{EC}^{187}$. While there existed no jurisprudence in a number of member States on this issue, where such a jurisprudence did exist, exceptions for experimental activities to advance the knowledge of science were permissible, while activities which only

\footnotetext{
${ }^{180}$ See under IV.C(2)(b) above.

${ }^{181}$ See paragraph 4.15 above, $8^{\text {th }}$ indent.

${ }^{182}$ See paragraph 4.15 above.

${ }^{183}$ See the information provided by the United States, Japan and Australia in the proceedings as reflected in section V. below.

${ }^{184}$ See section V. below.

${ }^{185}$ See paragraph 4.15 above.

${ }^{186}$ There exists a similar system for plant protection products under Regulation (EC) $N^{\circ} 1610 / 96$.

${ }^{187}$ A good example of how the refusal to allow regulatory approval activities under the law of the Netherlands interacted with Articles 30 and 36 of the EC Treaty could be found in the Judgement of the EC Court of Justice in Generics v. Smith Kline of 9 July 1997.
} 
concerned the obtaining of marketing approval for an identical generic product were not permissible. $^{188}$

\section{CANADA}

4.32 In response, Canada maintained that neither Section 55.2(1) nor 55.2(2) of its Patent Act violated the provisions of the TRIPS Agreement.

4.33 According to Canada, the non-discrimination requirement of Article 27.1 of the TRIPS Agreement did not apply "across the board" in the manner contended for by the European Communities and their member States and the only issue in this case was whether Canada's measures were "limited exceptions" within the meaning of Article 30. The answer to that question had to take into account "the legitimate interests of third parties", which necessarily involved a consideration of the societal values referred to elsewhere in the TRIPS Agreement, in particular Article 7. To contend that the Agreement was "neutral vis-à-vis societal values", as the EC did, rendered Articles 7, 8 and 30 meaningless. That was why all the third parties to the dispute, with the exception of Switzerland, had agreed with Canada that Article 30 could only be understood as the provision which enabled Members to achieve a balance between important public policy concerns and the rights of patent holders. The achievement of a proper balance was a central objective of the TRIPS Agreement, and Canada's measures contributed to a proper balance by promoting the legitimate interests of third parties without affecting the commercial interests of patent holders during the period of protection. All of the third parties, apart from Switzerland, were in agreement with Canada that the EC's theory about the "economic expectation" of a patent holder ${ }^{189}$ had nothing to do with intellectual property rights, but was rather a purely commercial concept, and that the effective extension of the patent term sought by the EC in these proceedings was neither a right recognized, nor an obligation imposed, by the TRIPS Agreement.

4.34 Canada further emphasized that the third parties to the dispute, with the sole exception of Switzerland, had overwhelmingly endorsed Canada's position that a "regulatory review exception" similar to the provision of Section 55.2(1) of the Patent Act was a limited exception of the kind permitted by Article 30 of the TRIPS Agreement. In reaching that conclusion, the third parties had disagreed with the EC's contention that the TRIPS Agreement "is in principle neutral vis-à-vis societal values"190, and had instead confirmed Canada's view that Article 30 was the mechanism by which the objectives outlined in Article 7 of the Agreement, including social and economic welfare, and a balance of rights and obligations, were to be achieved. Further, a majority of the third parties had agreed that a "stockpiling" exception like Section 55.2(2) of the Patent Act was also consistent with the requirements of Article 30, and was therefore sustainable as a limited exception to the exclusive rights conferred by a patent.

\section{PRELIMINARY POINTS}

4.35 Canada responded as follows to the points of fact addressed by the $\mathrm{EC}^{191}$ as well as to the arguments put forward by the EC as to the legal relevance of "subsequent practice" in other countries $^{192}$ :

${ }^{188}$ An excellent overview of the development in the Community can be found in Cornish, Experimental Use of Patented Inventions in European Community States, (29) IIC (7/1998), pp. 735 et seq.

${ }^{189}$ See paragraph 4.30 above, under (d)(iii), $3^{\text {rd }}$ indent.

${ }^{190}$ See paragraph 4.30 above, under (a), $2^{\text {nd }}$ indent.

${ }^{191}$ See paragraph 4.22 above.

${ }^{192}$ See paragraph 4.31 above. 
The EC had contended that the regulatory review exception "does not require any actual application for marketing approval in Canada or any third country, but only an intention to make such an application". While it was true that the protection of Section 55.2(1) might be engaged prior to the actual submission of an application for regulatory review (since the generic manufacturer must necessarily do developmental work in order to generate the information required by the regulatory authorities), the test for determining whether or not the exemption applied was not a subjective one. In other words, the question was not whether the generic manufacturer intended to file an application, but rather whether, on an objective assessment of all the facts, the use of a patented invention was reasonably related to the submission of an application for regulatory review. The challenged provision expressly spoke of "uses", not "purposes", and the difference in meaning was significant. ${ }^{193}$

The information package of the Government of Canada to which the EC had referred contained a chart which indicated, in a box entitled "Exceptions to Infringement", that the United States did not have an exception for "Stockpiling". This statement was accurate. The United States had no legislative provision similar to Section 55.2(2) of the Canadian Patent Act. However, contrary to the EC's contention, Canada had not alleged that the United States had a legislated stockpiling exception. Instead, Canada had merely stated that there was an FDA guideline which "appears [...] as a practical matter, [to] facilitate the early entry of a generic drug product into the U.S. post-expiry market" (emphasis added). The EC was well aware of the distinction between legislated requirements and practical results, having built its whole case on a theory of what a patent holder should expect "in practical terms"194, as opposed to what the language of the TRIPS Agreement explicitly required. With further reference to the FDA practice, it must be acknowledged that the United States had indicated that Canada's statements were "factually inaccurate". ${ }^{195}$ Significantly, however, the United States had not specified how Canada's statements were inaccurate, and made no attempt to correct the alleged inaccuracy. In particular, the United States had not indicated in what respect Canada's understanding failed to reflect the practice under the relevant FDA guideline, which provided as follows: "It is important that the manufacturer prepare a written validation

${ }^{193}$ Compare Intermedics, Inc. v. Ventritex, Inc., 775 F.Supp. 1269 (N.D.Cal. 1991), at p. 1278; affirmed 991 F.2d 808 (Fed.Cir. 1993). In response to questions from the EC, Canada explained that the exception of Section 55.2(1) did not focus on and was not triggered by "the subjective intention to apply for a marketing authorization". Rather, the test for determining the application of the excepting measures was an objective test that focused on the "use" of a patented invention "solely for uses reasonably related" to developing and submitting the information required to apply for regulatory review, and ultimately to obtain regulatory approval to manufacture, construct, use or sell the product in question. The language and meaning of the exempting provision had not been interpreted by the Canadian courts. However, exactly the same language as was used in the Canadian provision was also used to set out the test for exemption from infringement liability under the "Bolar" exemption in United States patent legislation. The United States courts had, in Intermedics, Inc. v. Ventritex, Inc., closely analysed and lucidly explained the legal substance of the language used to circumscribe the test for the application of the exception. Canada referred to 1274,1277 and 1279 as being the more telling passages of the Intermedics court decision. Given the cogency of these judicial views there was no basis for the implicit allegation or suggestion of the EC that Section 55.2(1) of the Canadian Patent Act operated or might operate as an open-ended licence to abuse the exception or to infringe patents on the basis of some objectively indiscernible and unknowable "subjective intention". If intention had any relevance in the present context, it would be revealed by "use". Of course, there would be moments of pure "subjective intention" in the "mind" of a would-be competitive entity when it "considered" whether or not it wished to seek to compete with a patentee in the future production of some particular patented subject-matter. However, at those or any other moments of "subjective intention", there would be no executive "use" or act that would attract infringement liability or that could benefit from the limited exception from infringement liability that had been created by Section 55.2(1). When, however, such an intention was acted upon in Canada and an unauthorized "use" occurred, then the full panoply of the enforcement rights and mechanisms referred to in Part III of the TRIPS Agreement would, subject to the application of Section 55.2(1), be available to the patentee to enforce its patent exclusivity and to "control" a generic manufacturer's "uses" of the relevant invention.

\footnotetext{
${ }^{194}$ See paragraph 4.30 above, under (d)(iii), $3^{\text {rd }}$ indent.

195 See under section V. below.
} 
protocol which specifies the procedures (and tests) to be conducted and the data to be collected. The purpose for which data are collected must be clear, the data must reflect facts and be collected carefully and accurately. The protocol should specify a sufficient number of replicate process runs to demonstrate reproducibility and provide an accurate measure of variability among successive runs"196 (emphasis added by Canada). The decision of the US District Court containing a quotation of the evidence given by the patentee in that case as to what the FDA guideline entailed should be stressed. ${ }^{197}$ Obviously, the patentee had no interest in overstating the extent of the guideline, since to do so would only have expanded the defendant's exemption from infringement liability. Given that consideration, and in the absence of any contradictory evidence, it could only be concluded that the situation was as the patentee had described it.

- $\quad$ The explanation by the EC that the term of full patent protection in Canada was a maximum nine to a minimum of one-and-a-half years compared to a maximum of 20 years foreseen in Article 33 of the TRIPS Agreement ${ }^{198}$ misstated the effect of the right conferred by a patent. A patent was not a guarantee that an invention would be on the market, earning a return, for the full period of the term. Many factors affected the length of market exclusivity under a patent, particularly the very real likelihood that a competitor might introduce a better product, thus capturing the market for itself. Marketing, political, legal or business issues might delay or prevent the patented product from being effectively commercialized, or from enjoying a dominant position for long once it got to market, or at all. ${ }^{199}$ Many, perhaps even most, patented inventions never reached the market. In addition, in some industries (particularly the electronics and computer industry), the period of actual market exclusivity might be very short - as little as a few months - because technology developed so quickly that the patented product might soon be obsolete. A patent was not a government-backed guarantee of monopoly revenues for a full 20 years. Further, there was no basis for the assertion that the "term of full patent protection" had been eroded in Canada. During the entire time that a generic manufacturer developed and submitted its regulatory review submission, the patentee could fully exploit its patent. ${ }^{200}$ Its commercial exploitation was unaffected by the generic manufacturer's activities. Where a patentee could bring infringement proceedings, or summary proceedings to prevent the issuance of a marketing authorization for a generic product, it could not tenably be argued that Canada's limited exceptions reduced the term of patent protection.

The EC had asserted that, since Section 55.2(1) of the Patent Act contemplated actions taken with a view to obtaining marketing approval in another country, it permitted activities completely outside the control of the Canadian authorities. The implicit notion that patent rights must be enforced by public authorities found no support in any provision of the TRIPS Agreement. The Preamble expressly recognized that "intellectual property rights are private rights", and Part III made it clear that enforcement was a matter for private remedy. The language of Article 42 was unequivocal in this regard: "Members shall make available to right holders civil judicial procedures concerning the enforcement of any intellectual property right covered by this Agreement." A right holder who observed a use being made of its

${ }^{196}$ US Food and Drug Administration, Guideline on General Principles of Process Validation, May 1987 (Internet: http://www.fda.gov/cder/guidance/pv.htm)

${ }^{197}$ See paragraph 4.21 above, under (b), $6^{\text {th }}$ indent.

${ }^{198}$ See footnote 138 above.

199 "Tagamet was the first drug of its class to reach the market but its market share was far exceeded by that of Glaxo Wellcome's Zantac long before Tagamet's patent expired. This was due in no small part to the formidable size and expertise of Glaxo Wellcome's marketing capability": Amanda Southworth, Generic Pharmaceuticals (1996 ed.), at p. 41.

${ }^{200}$ In response to a question from the EC, Canada said that it neither agreed nor disagreed with the estimate of the cost to the EU innovative pharmaceutical industry that the EC and the EU-based industry had attributed to the limited exceptions at issue in this proceeding. The alleged costs were irrelevant to the issues before the Panel, because the costs alleged by the EU industry were incurred or were experienced in the post-expiry market and were therefore attributable to legitimate competition rather than to infringement of a patent right or any limited exception to a patent right. 
patented invention in Canada without its consent was fully entitled to initiate legal proceedings for all of the remedies contemplated by the TRIPS Agreement. National authorities had no role to play in such a process.

\section{$\underline{\text { Subsequent Practice }}$}

As to the relevance of the situations in other countries to the appreciation of the challenged Canadian legislation, Articles 31 and 32 of the Vienna Convention on the Law of Treaties made plain that information of this nature was highly relevant to treaty interpretation, since it revealed the circumstances of a treaty's conclusion (here, the provisions of their own national laws which Members, in negotiating the treaty, had presumably been seeking to preserve), and the subsequent practice of Members in applying the treaty (their adoption of laws and practices which they believed complied with the treaty's requirements). Reference was made to what is reflected under section B. above in this regard and to the points made by Australia as a third party to the dispute ${ }^{201}$.

That which "establishes the agreement of the parties regarding the interpretation" of an agreement would depend on the circumstances and the context. In the case of an important global agreement like the WTO Agreement, which was the subject of constant scrutiny and debate by WTO Members, within an institutional framework, there was a strong presumption that legislation passed by important Members in the immediate aftermath of an agreement and not challenged or protested by other parties was, in fact, accepted or acquiesced in by the other contracting parties. As such, a pattern of unprotested legislative practice enacted at a critical time by key parties did establish the "agreement of the parties regarding its interpretation". The same comment would apply to judicial rulings that were not overturned by the legislature. An exchange between the Chairman and Special Rapporteur of the International Law Commission (both later Presidents of the International Court of Justice) when the draft articles leading to the Vienna Convention were being developed shed light on this issue. ${ }^{202}$ In order to be relevant, the subsequent practice must be "concordant", which excluded - in the words of the Chairman - "any unilateral practice which was disputed by the other parties". The Special Rapporteur explained that the practice of only some of the parties "was not automatically excluded as a means of interpretation", and even if it did not cover a broad group of parties it could serve as an "indication", while requiring further evidence in support of the alleged interpretation. As suggested above, an absence of protest or challenge by other WTO Members in the face of a significant pattern of legislation (and judicial decision) might well supply such additional evidence. ${ }^{203}$

\section{ARTICLE 27.1 OF THE TRIPS AGREEMENT}

4.36 Canada advanced the following further points in support of its view that the nondiscrimination requirement of Article 27.1 of the TRIPS Agreement did not apply "across the board" in the manner contended for by the EC. If it did so apply, Article 30 of the Agreement would be reduced to inutility, contrary to the first principles of treaty interpretation. Those principles recognized that different treaty provisions could interact in different ways. Hence, it was appropriate to conclude that the "patent rights" referred to in Article 27.1 were the rights enumerated in Article 28.1 subject to limited exceptions imposed under Article 30, but not subject to "other use" under Article 31. The EC's opinion that the non-discrimination requirement of Article 27.1 of the TRIPS Agreement applied "across the board", and did not allow any scope for the recognition of

\footnotetext{
${ }^{201}$ See under section V. below.

${ }^{202}$ Yearbook of the International Law Commission 1964, Volume I: Summary records of the sixteenth session, 11 May to 24 July 1964, United Nations, New York, 1965, pp. 275-291

${ }^{203}$ This was put forward by Canada in response to a question from the Panel.
} 
limited exceptions under Article 30, was not shared by any of the third parties to the dispute other than Switzerland. ${ }^{204}$

The EC had contended that it would not lead to "incongruous" results if Article 27.1 were to be interpreted as requiring that any exception to patent rights must apply "across the board" to all fields of technology. ${ }^{205}$ However, as India had succinctly observed as a third party in the dispute, this approach produced the strange consequence that Canada's legislation, which under Article 30 must be limited in scope, was being criticized for being too limited in scope. ${ }^{206}$

- The EC's proposed interpretation of Article 27.1 would render Article 30 of the Agreement nugatory, since no exception could be both broad enough to satisfy the antidiscrimination requirement of Article 27.1 and, at the same time, narrow enough to meet the test of "limited exception" in Article 30. Similarly, the "absolute" construction advocated by Switzerland as a third party in the dispute would reduce Article 30 to meaninglessness. ${ }^{207}$ While Switzerland suggested that Canada's interpretation could only arise if the words "Subject to the provisions of this Section (or Article 30) [...]" were added at the opening of the second sentence of Article 27.1, such additional language would mean that Article 30 could be used to deny patent availability. An exception of this nature would hardly be "limited", and would not be consistent with the other requirements of Article 30.

- The principle of effectiveness ${ }^{208}$ required that Article 30 be given real meaning and that it not be sterilized in the manner contended for by the EC and Switzerland. In Canada's view, a proper construction of Article 30 would, as Colombia had stated as a third party in the dispute, recognize that, by definition, Article 30 required that the benefit not be granted horizontally but exclusively, where there was justification for it, because Article 30 created a derogation of the principle of non-discrimination. ${ }^{209}$

The example of compulsory licensing referred to by the $\mathrm{EC}^{210}$, to which the United States had also referred as a third party in the dispute ${ }^{211}$, appeared to have been invoked as a basis for the argument that Article 27.1 should interact with Article 30 in precisely the same way as it did with Article 31. However, a consideration of the language of Articles 30 and 31, and of the TRIPS negotiating history, made it clear that these provisions had been adopted for very different purposes, and that their respective relationships with the anti-discrimination provision of Article 27.1 were therefore not identical. In this regard, the fact that one treaty provision might inform other provisions in different ways was unremarkable, and was entirely consistent with the principle of effectiveness. ${ }^{212}$

Article 30 was of course framed in general terms and set out a broad, criteria-based approach to the creation of exceptions. The wording of Article 31, on the other hand, was narrow and explicit, and permitted compulsory licensing only where specified conditions were fulfilled. As stated before, the language of Article 30 could be interpreted as evincing an intention to provide Members with the discretion to achieve a proper balance of rights and obligations within their national systems. If the term "patent rights" in Article 27.1 were to be interpreted without taking Article 30 "limited exceptions" into account, Members would be

${ }^{204}$ See under section V. below.

${ }^{205}$ See paragraph 4.27 above.

${ }^{206}$ See section V. below.

${ }^{207}$ See section V. below.

${ }^{208}$ See paragraph 4.16 above, $2^{\text {nd }}$ indent.

${ }^{209}$ See under section V. below.

${ }^{210}$ See paragraph 4.27 above.

${ }^{211}$ See under section V. below.

212 Reference was made to Japan - Taxes on Alcoholic Beverages (WT/DS8/AB/R, WT/DS10/AB/R, WT/DS11/AB/R), at p. 18. 
prevented from achieving that balance, and a major objective of the TRIPS Agreement would be incapable of attainment. Such a result would not accord with the most basic principles of treaty interpretation, and therefore "patent rights" in Article 27.1 should be understood as meaning the rights enumerated in Article 28.1, subject to limited exceptions imposed under Article $30 .{ }^{213}$

Unlike Article 30, the language of Article 31 was not permissive. It prescribed precise requirements that must be satisfied ("[...] the following provisions shall be respected [...]") if use without authorization (i.e. compulsory licensing) was to be allowed. The United States had raised, as a third party in the dispute, the question why, if Article 27.1 applied to the rights in Article 28 as modified by Article 30, it would not also apply to the rights in Article 28 as modified by Article $31 .{ }^{214}$ The EC, after stating that Article 27.1 should apply to compulsory licences (i.e. to Article 31), asserted that the logic which had been described for compulsory licences applied equally to exceptions. ${ }^{215}$ The answer to the United States question and the assertion by the EC was that Article 31 was mandatory and clearly (when read together with Article 27.1) must apply to all fields of technology. On the other hand, Article 30 was permissive and had a clear nexus to the objectives of the TRIPS Agreement articulated in Article 7. There was no reason why the relationship with Article 27.1 of the permissive Article 30 should be the same as that of the mandatory Article 31. Had the drafters of the TRIPS Agreement intended that Articles 30 and 31 had the same relationship with Article 27.1, both provisions would have been permissive or both mandatory. Their different wording clearly indicated an intention that they should operate differently within the Agreement.

- This conclusion was reinforced by a consideration of the negotiating history of Article 27.1. As stated before, one of the underlying aims of Article 27.1 was the elimination of compulsory licensing provisions respecting food and drug products in national patent laws. If "patent rights" in this provision simply meant the rights remaining after compulsory licensing had been imposed - i.e. if Article 27.1 had been intended to interact with Article 31 in the same way as with Article 30 - there would be no mechanism for ensuring that a particular field of technology could not be subjected to compulsory licensing, contrary to the intention of the framers of the TRIPS Agreement. The purpose of the Article 27.1 anti-

${ }^{213}$ In response to a question from the EC as to the implications of Canada's view for the application of the nondiscrimination clause of Article 27.1 in respect of provisions of national law allegedly discriminating as to "the place of invention" or as to "whether products are imported or locally produced", Canada said that it was a consequence of Canada's position that, where an exception met these criteria in limiting the exclusive rights conferred by a patent, the excepting measure must be taken as being consistent with all other TRIPS obligations. Accordingly, if hypothetical measures as posited by the EC could be shown to meet the criteria set out in Article 30 and if the limitation of an exclusive Article 28.1 right were also to have a limiting impact on any of the non-discrimination elements of Article 27.1, those elements could not be taken to operate to negate the permissible exception. Were it to be otherwise, then Article 30 would need to be read as including a fourth restriction on its application to the effect that the exception would also be consistent with Article 27.1. Such an additional restriction was, manifestly, nowhere to be found in the express language of Article 30. If Article 27.1 did not, as Canada argued, make reference to the patent rights available under the domestic law of a Member subject to any limited exceptions to those rights enacted pursuant to the authority of Article 30, then its application might lead to repugnancy between Article 27.1 and Article 30. Other participants in these proceedings had suggested that this need not be the case, because differential treatment between fields of technology was not necessarily discriminatory where it might be justified by reference to the presence of exogenous legal requirements which distorted the even-handed application of domestic law. While this might indeed be the case, the alternative interpretative theory would not appear to be sufficient to protect the "dispensing pharmacist" exception that continued to exist in the national laws of many EC member States. This appeared to be so since, in eroding the patent owner's commercial right to exploit its invention at any time within the term of protection, the exception discriminated on the basis of field of technology and it did so without reference to any exogenous legal requirements of domestic law that might justify the differential treatment extended to a qualifying pharmacist's use of the invention. With respect to the specific example put by the EC question, there would not appear to be enough hypothetical "facts" available - for instance, there were no assumptions respecting third party interests - to make a reasoned judgement about whether or not the hypothetical exception would meet the criteria of Article 30.

${ }^{214}$ See under section V. below.

${ }^{215}$ See paragraph 4.27 above, $3^{\text {rd }}$ indent. 
discrimination requirement would be substantially defeated. Consequently, "patent rights" in Article 27.1 must mean the rights in Article 28.1, subject to "limited exceptions" under Article 30 but not to "other use" under Article 31.

The United States had taken the position as a third party in the dispute that exceptions under Article 30 could not be applied in a discriminatory fashion because that would contravene Article 27.1. ${ }^{216}$ However, the United States had its own Bolar" provision to consider which - unlike Section 55.2(1) of the Canadian Patent Act, which was neutral as to field of technology - made specific reference to "drugs or veterinary biological products". The United States must reconcile its position that Article 30 limited exceptions could not be applied in a discriminatory fashion with its own technology-specific "Bolar" provision. The means it had chosen to reconcile its own position was that differential treatment did not necessarily mean discriminatory treatment because different technologies might require different treatment to restore "parity of enjoyment". This argumentation was based on GATT jurisprudence suggesting that differential treatment was not necessarily discriminatory. Australia's argumentation as a third party in the dispute seemed to be an attempt to justify patent term extension. ${ }^{217}$ Unlike the United States, Australia had not taken specific issue with Canada's position on the relationship between Article 30 and Article 27. Rather, Australia took the position that the discrimination that Article 27 was directed against was denial of patent rights altogether. This position was not wholly unreasonable, given that all exceptions cited in Article 27.1 - Articles 65.4, 70.8, 27.2 and 27.3 - covered situations in which patent rights were denied. ${ }^{218}$ Australia had stated that differential treatment did not necessarily amount to discrimination, and then cited patent term extension as a means of "restoring the balance of interests". While it might be that in some cases differential treatment did not amount to discrimination, Canada respectfully disagreed with both the United States and Australian positions on this point. As regards the United States argument that the consequence of Canada's interpretation would, with respect to exceptions to exclusive rights, make Article 27.1 redundant of Articles 28 and 30 because no exception would violate Article 27.1 without also violating Article 28 and not being justified by Article 30, it is difficult to see how finding that Article 30 could be applied on a selective basis would make Article 27.1 redundant. The exceptions permitted by Article 30 were limited and, therefore, could have only limited impact on Article 27. The real redundancy problem arose if exceptions under Article 30 were required to conform to Article 27. If Article 30 was required to conform to Article 27.1, Article 30 would be reduced to redundancy or inutility. As expressed by Colombia as a third party in the dispute ${ }^{219}$, it was precisely Article 30 that required exceptions to be limited: in other words, by definition, Article 30 required that the benefit not be granted horizontally but exclusively, where there was justification for it. Otherwise, to grant this exception to all technology sectors would be contrary to the first requirement of Article 30. Accordingly, the condition contained in Article 30 created a derogation of the principle of non-discrimination set forth in Article 27.1 of the TRIPS Agreement. The Colombian position seemed a much more sensible reconciliation of the relationship between Articles 27 and 30 than importing jurisprudence from GATT 1994 that was being applied in very different circumstances. The case cited by the United States related to Article III of GATT 1947, which required that no less favourable treatment be applied to imports than to domestic "like products". Article 27.1 of the TRIPS Agreement referred to different fields of technology and, therefore, to unlike products. In summary, the distinction

\footnotetext{
${ }^{216}$ See under section V. below.

${ }^{217}$ See under section V. below.

${ }^{218}$ Switzerland had emphasized as a third party in the dispute (see under section V. below) that these were the only exceptions identified in Article 27.1, and contended that if it were intended that Article 27.1 be subject to Article 30, Article 27.1 would have included Article 30 in the list of exceptions. However, since the exceptions listed in Article 27.1 covered situations in which patent rights were denied altogether, it would have been wholly inappropriate to include Article 30 among those listed exceptions.

${ }^{219}$ See under section V. below.
} 
referred to by the United States and Australia between differential treatment and discrimination seemed less of a means of reconciling Articles 27.1 and 30 and more of a means of justifying their own facially discriminatory legislation including, in Australia's submission, its patent term extension scheme. ${ }^{220,221}$

The "practising pharmacist's" exception was not inconsistent with Article 27.1, because it was a "limited exception" within the meaning of Article 30 and, as Canada had submitted throughout these proceedings, the "patent rights" referred to in Article 27.1 were the Article 28.1 rights subject to any limited exceptions imposed under Article 30. However, the "practising pharmacist's" exception would be inconsistent with Article 27.1 if either of the alternative interpretations of that Article put forward in these proceedings were to be adopted. Clearly, the EC's "across-the-board" interpretation of the non-discrimination requirement left no room for the survival of the exception, since in the EC approach any differentiation at all amounted to prohibited discrimination. Equally, the theory of some other participants, reflected under the previous indent of this paragraph, that differential treatment between fields of technology was not necessarily discriminatory where it could be justified by reference to exogenous distorting circumstances, would not save this exception. It would still run foul of Article 27.1 because it discriminated on the basis of field of technology, eroded the patent owner's commercial right to exploit its invention at any time within the term of protection and did so without reference to any exogenous circumstance that might justify the differential treatment extended to qualifying pharmacist uses of the invention. ${ }^{222}$

ARTICLE 30 OF THE TRIPS AGREEMENT

4.37 Consequently, Canada maintained that the only issue in this case was whether Canada's measures under Section 55.2(1) and 55.2(2) of the Patent Act were "limited exceptions" within the meaning of Article 30. The answer to that question had to take into account "the legitimate interests of third parties" referred to in Article 30 and this necessarily involved a consideration of Articles 7 and 8 of the Agreement, in particular the societal values referred to. Canada advanced the following further points in support of its view that the measures in dispute were limited exceptions permitted by Article $30^{223}$ :

${ }^{220}$ In response to questions from the Panel, Canada said that, although it was technically correct, it was misleading to say that all countries other than Canada with regulatory review/approval-type exceptions also had patent term extension or supplementary protection certificate (SPC) systems in place for the benefit of innovative drug producers or were countries benefiting from a transitional period under the TRIPS Agreement. Countries that currently enjoyed a transitional period other than least-developed countries - were nearing the end of that period, which terminated on 1 January 2000 (see Article 65.2 and 65.3 of the TRIPS Agreement). Thus, these countries would shortly be obligated to the full level of protection required by the TRIPS Agreement. The purpose of recent legislation in such countries, such as Argentina, must be taken to implement, not ignore, TRIPS obligations. Moreover, Thailand had confirmed as a third party in the dispute that legislation that was due to be enacted in September 1999 would not alter Section 36(5) of its Patent Act, which - like Argentina's recent legislation - contained a regulatory approval exception, but did not require patent term extension. Similarly, according to Poland as a third party in the dispute, its draft law would also contain a regulatory approval exception with no patent term extension, similar to Hungary's current law. These developing countries and transition economies, that were on the eve of being bound by the TRIPS Agreement, must be taken as having enacted their patent legislation in this respect in contemplation of their obligations. Moreover, none of the third parties that had intervened in this dispute had argued that a regulatory approval exception had to be accompanied by patent term extension. See also what is reflected in footnote 223 below.

${ }^{221}$ What is reflected under this indent was put forward by Canada in response to a question from the Panel.

${ }^{222}$ What is reflected under this indent was put forward by Canada in response to a question from the Panel.

${ }^{223}$ In response to a question from the Panel, Canada said that there was no nexus between Article 30 and patent term extension. Article 30 permitted limited exceptions from the exclusive rights granted under Article 28. A patent term extension was an augmentation of the enjoyment of a right and not an exception, and for this reason had no relevance to the application of Article 30. Article 7 required a balance of rights and obligations, and Article 30 provided the substantive means of providing that balance in the case of patents. However, Article 30 permitted exceptions only, not amplification of rights. As there was no counterpart to Article 30 dealing with amplification of rights, it must be concluded that the balance required by Article 7 was to be achieved through limited exceptions only. It had been open to the TRIPS negotiators to make special provision for augmenting the enjoyment of patent rights in the case of products requiring time-consuming regulatory approval. By way of comparison, Article 1709(12) of the North American Free Trade Agreement, which was 


\section{Articles 7 and 8 of the TRIPS Agreement}

The EC had contended ${ }^{224}$ that the TRIPS Agreement as a whole was neutral vis-à-vis societal values and that the wording of Article 8.1 of the Agreement supported this view, because none of the public policy considerations referred to in the first half sentence could be invoked to justify measures which were inconsistent with the TRIPS provisions. Canada agreed that policy considerations could not justify measures that were inconsistent with the provisions of the TRIPS Agreement. However, the provisions of this Agreement included Article 30. Measures which were consistent with this provision would be so either because they did not conflict, inter alia, with a normal exploitation of the patent or, if they did so conflict, because the conflict was not unreasonable, "taking account of the legitimate interests of third parties". As extensively argued earlier ${ }^{225}$, the legitimate interests of third parties were ascertained, inter alia, by reference to the societal interests mentioned in the TRIPS Agreement itself, including the first recital of the Preamble and Article 7, as well as Article 8. Thus, public policy considerations were highly relevant to the determination of what was "consistent with the provisions of this Agreement".

The EC's suggested interpretation of Article 8 simply robbed that provision of any meaning or effect, since it suggested that the only operative words were those which required consistency with the provisions of the Agreement other than Article 8 itself. Even Switzerland, the only third party which entirely supported the EC, did not go that far. Switzerland accepted the rule of treaty interpretation recognized by the Appellate Body in the Gasoline Case $^{226}$, that "[a]n interpreter is not free to adopt a reading that would result in reducing whole clauses or paragraphs of a treaty to redundancy or inutility". ${ }^{227}$ While it was unnecessary for the purposes of the present case to determine the precise scope of Article 8, it was essential that it not be rendered meaningless. Canada's approach, which appeared to be shared by Brazil, Cuba, India, Israel, Poland, Thailand and the United States as third parties in the present dispute ${ }^{228}$, recognized that the societal interests identified in Article 8 could be protected by measures that met the standards of Article 30. Since it gave meaning to Article 8, this approach was to be preferred to the "inutility" that would result from acceptance of the EC's argument.

The third parties just mentioned, together with Australia, Colombia and Japan indeed, all of the third parties with the exception of Switzerland - also agreed that Article 30 was the vehicle by which Members were able to give effect to the societal values referred to

similarly based on the Dunkel text, expressly did so: "Each Party shall provide a term of protection for patents of at least 20 years from the date of filing or 17 years from the date of grant. A party may extend the term of patent protection, in appropriate cases, to compensate for delays caused by regulatory approval" (emphasis added). Had the drafters of the TRIPS Agreement wished to provide for increased protection, they would have done so by including a provision similar to the above NAFTA provision. However, under the final wording of the Agreement, term limits were as prescribed in Article 33, which did not contemplate patent term extension. Moreover, providing patent term extension for some products but not others would be contrary to Article 27.1. In addition, patent term extension was squarely before the parties during the negotiations. Both Switzerland and Austria had made proposals for it (see GATT documents MTN.GNG/NG11/W/38, p.3, and MTN.GNG/NG11/W/55, paragraph 5.3). The fact that it had clearly been raised during negotiations, but not agreed to, also indicated that the intent of the TRIPS Agreement was that such a level of protection was not required. It was significant that four WTO Members had implemented their imminent obligations in such a way that a regulatory approval exception was not coupled with patent term extension. This indicated that, in the opinion of those Members, such an extension of patent rights was not required. Rather, in balancing private and public rights under Articles 7 and 8 - through an exception under Article 30 - there was no requirement to exceed the minimum patent term required by Article 33 . See also what is reflected in footnotes 220 and 108 above.

${ }^{224}$ See paragraph 4.30 above, under (a), $2^{\text {nd }}$ indent.

${ }^{225}$ Reference was made, in particular, to what is reflected in paragraphs 4.13, indents 1-3, and 4.14(iv) above.

${ }^{226}$ See Japan - Taxes on Alcoholic Beverages, at p. 12.

${ }^{227}$ See under section V. below.

${ }^{228}$ See under section V. below. 
in Article 7.229 Neither the EC nor Switzerland had made any mention at all of Article 7. Instead, they had sought to interpret Article 30 in isolation, without regard for the objectives of the TRIPS Agreement. Such an approach was contrary to the first principles of treaty interpretation. As indicated in Article 31 of the Vienna Convention on the Law of Treaties, treaty terms are to be interpreted "in light of [the treaty's] object and purpose". As applied to the present case, this meant (as Brazil had put it as a third party in the present dispute ${ }^{230}$ ) that each Article of the TRIPS Agreement was part of a whole that guaranteed the balance of rights and obligations.

As to the wording of Article 30 - which, unlike Article XX of the GATT, did not mention particular values - rather than confirming that the TRIPS Agreement was neutral vis$\grave{a}$-vis societal values ${ }^{231}$, in Canada's view, it more likely indicated that the significant feature of Article 30's language was that it did not limit Members to particular purposes or policy objectives, but instead provided broad criteria to guide Members' exercise of discretion. Far from supporting the view that the TRIPS Agreement took no account of societal interests, the broad wording of Article 30 "echoed" the objectives set out in Article 7, as the United States had observed as a third party in the dispute. ${ }^{232}$

The EC had misapprehended the basis for Canada's position that the two provisions of its Patent Act which were challenged in these proceedings were "limited exceptions" within the meaning of Article 30 of the TRIPS Agreement. Canada did not say that its measures were justified merely by reason of "public health considerations". Rather, Canada submitted that the provisions were consistent with Article 30 because they allowed patent owners complete freedom to exploit their rights throughout the full term of patent protection, and only affected patentees' commercial exploitation after patent expiry. Their purpose was to promote competition in regulated-product markets, in particular the prescription drug market, in the post-expiry period, in the interests of cost containment and of facilitating access to needed medicines.

(b) Interpretation of the Conditions Enumerated in Article 30 for the Grant of Exceptions to Rights Conferred

The EC did not accept that "the legitimate interests of third parties" had to be taken into account when considering whether or not limited exceptions "unreasonably conflict with a normal exploitation of the patent". ${ }^{233}$ However, it was to be noted that the punctuation of Article 30 placed both the "unreasonably conflict" and "unreasonably prejudice" considerations in a single clause (set off between two commas), while the "legitimate interests" consideration sat outside that clause. ${ }^{234}$ This construction clearly suggested that "legitimate interests" was intended to apply to both of the considerations within the single

${ }^{229}$ See under section V. below.

${ }^{230}$ See under section V. below.

${ }^{231}$ See paragraph 4.30 above, under (a), $2^{\text {nd }}$ indent.

${ }^{232}$ See under section V. below.

${ }^{233}$ See paragraph 4.30 above, under (b), $2^{\text {nd }}$ indent.

${ }^{234}$ In response to a question from the Panel, Canada added that, if the drafters had intended that the phrase respecting third parties should apply only to the third condition, Article 30 would have provided as follows: "Members may provide limited exceptions to the exclusive rights conferred by a patent, provided that such exceptions do not unreasonably conflict with a normal exploitation of the patent, and provided that such exceptions do not unreasonably prejudice the legitimate interests of the patent owner taking into account the legitimate interests of third parties" (emphasis added). There was nothing about the context of Article 30 in the TRIPS Agreement, or the object and purpose of it, that suggested that Article 30 should be read otherwise than in accordance with its ordinary meaning. In fact, the application of the term respecting third parties to both the second and third conditions was consistent with the objectives of the TRIPS Agreement as articulated by its Article 7 . 
clause, a view that appeared to be shared by Australia, Cuba, Poland and the United States as third parties in the dispute. ${ }^{235,236}$

The EC had summarized the views advanced by three "opinion leaders", including Canada, during the Uruguay Round negotiations, presumably in an effort to imply that Article 30 was narrow in its scope. ${ }^{237}$ However, as the language of Article 30 made clear, the views of these "opinion leaders" had not been adopted. Instead, Members had agreed upon a broad criteria-based approach. The EC made no effort to relate the views of the "opinion leaders" to the wording that now appeared in Article 30, thus confirming the irrelevance of those views to the interpretative task facing the Panel.

In response to a question from the Panel, Canada explained why the "prior use" exception and the "scientific/experimental use" exception would satisfy each of the criteria of Article 30 and therefore would qualify as permissible exceptions under Article 30. While both the "prior use" and the "experimental use" exceptions were common to the patent laws of many nations, there was also considerable variation in the specifics of how either of the exceptions was expressed in or applied pursuant to those national laws. Since no particular laws creating such exceptions were in issue in these proceedings, Canada's response to the Panel's question must therefore be general in nature. The following arguments were advanced:

\section{The "prior use" exception}

Broadly speaking, the exception usually provided that any person who, before the issuance of a patent or, in some jurisdictions, before the filing or priority date of the application for the patent, had purchased, constructed, or acquired an invention for which a patent was subsequently obtained, was permitted to use and to sell to others the specific article, machine, manufacture or composition of matter so purchased, constructed or acquired without being liable to the patentee for so doing.

The exception was "limited" within the meaning of Article 30 because: (a) it applied only to persons who had purchased, constructed or acquired the invention or the subjectmatter which subsequently became patented subject-matter prior to the date of issue, application or priority, as the case might be; and (b) it only protected the specific article, machine, manufacture or composition of matter acquired prior to the relevant date, and since in most cases the specific articles, etc. would be finite in number, they would be unlikely to be put into the channels of commerce for any lengthy period of time. In the latter respect, it was important to note that, while the exception did not accord any right to continue to manufacture the invention after the grant of the patent, the specific article, machine, manufacture or composition of matter previously acquired might continue to be used or disposed of after the patent issued. In the result, the exception might erode the patentee's exclusive rights of use and sale for an indeterminate amount of time within the term of protection accorded to the invention. In certain instances, the erosion of the patentee's exclusive rights might endure for the entire term of the patent. This would be the case, for instance, where, in the case of a machine, it continued in working order for the entire term of protection. It would also be the case where, in the case of articles, a large enough inventory was acquired to continue to sell the articles in question throughout the full duration of the term of protection. Similarly, if the exception extended to a pure process invention (an issue

${ }^{235}$ See under section V. below.

${ }^{236}$ Reference was also made to a comment made by one of the panelists at the first substantive meeting of the Panel with the parties. In Canada's view, the observation that prior use could be recognized as a reasonable conflict with normal exploitation once the interest of the third party who had made the prior use was taken into account supported the correctness of its interpretation.

${ }^{237}$ See paragraph 4.30 above, under (b), indents 3 and 4. 
that remained unresolved in Canadian law), it would create the potential for the "prior user" to practise the process under the immunity of the exception for the full duration of the term. Thus, while the exception was clearly "limited", the scope of its impact on the patentee's commercial interests and exclusivity rights might vary considerably between being entirely trivial to being consistently significant, depending on the degree of use that could be made of the protected subject-matter during the patent term.

If, as appeared from the foregoing, the "prior use" exception could be said to conflict with the normal exploitation of the patent, it did not unreasonably conflict with the normal exploitation of the patent taking account of the legitimate third party interest of the "prior user" and its successor or assigns. The conflict permitted by the exception was not unreasonable because, while it respected the "vested right" of the "prior user" to the exploitation of its non-infringing subject-matter, the patentee remained entitled throughout the term of protection to exercise its exclusive rights to exploit the patent for its own commercial benefit and to exercise its exclusive rights against: (a) all other would-be users or vendors of the invention or the product of the invention; and (b) the "prior user" who exhausted its noninfringing machine or its supply of non-infringing articles. Moreover, given that the exception did not protect the "prior user" against the further manufacture of the patented subject-matter, it was extremely unlikely that the "prior user" would, without a licence to engage in further manufacture, be able to compete effectively against the patentee solely on the basis of its possession of non-infringing subject-matter, and thus erode the patentee's capacity to act as a monopolist in respect of the patented subject-matter.

The "prior use" exception could not be said to unreasonably prejudice the le gitimate interests of the patentee, taking into account the legitimate interests of third parties - here, the "prior user" and its successors and assigns - because the patentee did not have any exclusive rights to assert at the time when the principal third party (the "prior user") had acquired or learned how to construct by himself the subject-matter at issue, before the publication of the invention. Whatever his economic interests might be, a patentee could not, in the absence of explicit authority in the patent laws, be said to have a legitimate interest flowing from its patent to deny or usurp a third party's property right that had arisen prior to the patentee acquiring the right to exclude others from the use of its invention. Without the exception, patentees would be able to exercise the remedies provided for in the patent laws essentially to expropriate, without compensation, property that was non-infringing at the time of its manufacture or acquisition. Such a result would violate equitable principles and offend the common law respecting interference with vested rights as well as the common law respecting expropriation without either clear authority or adequate compensation. Society had a transcendent interest in the fairness of its rules. This legitimate policy interest in the protection of the "prior user" rights was an additional third party interest which must also be taken into account in the balancing of the reasonableness of the subsequent patentee's interest in asserting its after-acquired patent rights to restrain the exploitation of the acquired or vested pre-patent property interests of a "prior user".

\section{The "scientific/experimental use" exception}

It was well accepted that the patent bargain required disclosure of the invention during the term of protection so completely and accurately that it could be made and used by persons skilled in the art. ${ }^{238}$ The fact that disclosure was required suggested that there were limits to the patent holder's exclusive rights even during the patent term, including a limitation for scientific or experimental uses. As stated by Professor Eisenberg: "If the public had absolutely no right to use the disclosure without the patent holder's consent until after the patent expired, it would make little sense to require that the disclosure be made freely

${ }^{238}$ Reference was made to Article 29 of the TRIPS Agreement. 
available to the public at the outset of the patent term. The fact that the patent statute so plainly facilitates unauthorized uses of the invention while the patent is in effect suggests that some such uses are to be permitted. This inference is fortified by cases recognizing, at least in principle, that certain experimental uses of patent inventions should not give rise to infringement liability."239

The existence of an experimental use exception was common among WTO Members.

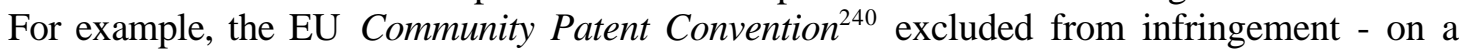
State-by-State basis, if implemented by domestic law - the making or using of patented inventions purely for experimental purposes or for scientific research. Similarly, judicial decisions in common law countries such as the United States ${ }^{241}$ and Canada ${ }^{242}$ had also recognized such an exception. The scope of the exception varied from country to country, but would ordinarily include one or more of the following: (a) testing an invention to determine its sufficiency or to compare it to prior art; (b) tests to determine how the patented invention worked; (c) experimentation on a patented invention for the purpose of improving on it or developing a further patentable invention; (d) experimentation for the purpose of "designing around" a patented invention; (e) testing to determine whether the invention met the tester's purposes in anticipation of requesting a licence; and (f) academic instructional experimentation with the invention. ${ }^{243}$

The experimental use exception was grounded in the theory that the experimentation was either a de minimis use of the invention or a form of scientific experimentation ${ }^{244}$, i.e. a "fair use". ${ }^{245}$ As such, the exception was well within the four corners of Article 30 of the TRIPS Agreement. It was "limited" in that it only applied to non-commercial experimentation, i.e. testing for academic or scientific purposes, or to commercial experimentation when a licence was anticipated. It would not be worth the trouble to sue a researcher or university for patent infringement, particularly if the research did not threaten the commercial interests of the patent holder. ${ }^{246}$

It did not conflict with a normal exploitation of the patent, mr did it unreasonably prejudice the legitimate interests of the patent owner, in that the latter retained the right, as a monopolist, to prevent the marketing or sale of any infringing subject-matter during the patent term. In this connection, in Canada, the Supreme Court had adopted the reasoning of the courts of the United Kingdom to the effect that experimental use involved "neither using nor vending of the invention for profit"247, i.e. the same reason that justified the limited exceptions in Section 55.2 of the Patent Act under Article 30.

- The experimental use exception took account of the legitimate interests of third parties in that non-commercial experimentation would aid the advance of scientific and technical knowledge, to the benefit of society at large. Researchers would face an unreasonable administrative burden if they had to conduct patent searches and either negotiate

\footnotetext{
${ }^{239}$ Rebecca S. Eisenberg, "Patents and the Progress of Science: Exclusive Rights and Experimental Use". The University of Chicago Law Review, Vol. 56 (1989), p. 1017 at 1022.

240 Article 31: "The rights conferred by a Community patent shall not extend to: [...] (b) acts done for experimental purposes relating to the subject-matter of the patented invention."

${ }^{241}$ Harold C. Wegner, Patent Law in Biotechnology, Chemicals \& Pharmaceuticals (2 ${ }^{\text {nd }}$ ed.), Stockton Press, 1994 (New York), pp. 451 et seq.

${ }^{242}$ Micro Chemicals Ltd. v. Smith Kline \& French Inter-American Corp., (1971) 2 C.P.R. (2d) 193

${ }^{243}$ Harold C. Wegner, Patent Law in Biotechnology, Chemicals \& Pharmaceuticals (2 ${ }^{\text {nd }}$ ed.), Stockton Press, 1994 (New York), p. 465

${ }^{244}$ Ibid., p. 453

${ }^{245}$ Frearson v. Loe, (1878) 9 Ch.D. 48 at pp. 66-7, cited in Micro Chemicals, supra note 5, at p. 203

${ }^{246}$ Harold C. Wegner, Patent Law in Biotechnology, Chemicals \& Pharmaceuticals (2 ${ }^{\text {nd }}$ ed.), Stockton Press, 1994

(New York), p. 455

${ }^{247}$ Frearson v. Loe (1878), 9 Ch. D. 48 at pp. 66-7, cited in Micro Chemicals, supra note 220, at p. 203
} 
licences (even for nominal royalties) or be subject to patent litigation when designing or conducting experiments. It would be unthinkable to shut the door to further research for 20 years in this way by granting a patent. The research community proceeded on the assumption that science would advance most rapidly if the community enjoyed free access to prior discoveries. ${ }^{248}$

The EC had pointed out that Hong Kong, the United States and Canada had all, at one time, proffered negotiating proposals containing narrower language than now found in Article 30, that had specifically referred to experimental use. ${ }^{249}$ The EC also accepted that a scientist had a legitimate interest in carrying out experiments. ${ }^{250}$ The EC clearly accepted that experimental use for non-commercial uses was covered by Article 30. Yet, the EC had stated that the only third parties referred to in Article 30 that could have legitimate interests were would-be producers. ${ }^{251}$ As noted above, the rationale for the non-commercial experimentation exception was that society at large would benefit from the advance in scientific and technical knowledge. The necessity of preventing a "research chill" when granting patents was not a narrow interest for an immediate competitor, but a long-term one that was widely shared by the whole of society, which benefited from the use of scientific information to create new and better inventions. ${ }^{252}$ The legitimate interest to carry out experiments referred to by the EC was not the narrow interest of the scientist but, rather, the broader interest of those who would benefit from the results of the scientist's experiments. By agreeing that Article 30 covered the non-commercial experimental exception, the EC had conceded that the term "third parties" referred to in Article 30 was not confined to would-be producers, but also included other interested parties and society at large. The broader nature of the interests served by the experimental use/scientific research exception was suggested in the rationale for its recognition, which had been summarized by Professor Straus as follows: "By taking the information and the incentive function of patent protection into account, this limitation guarantees the freedom to all skilled in the art to test and examine patented inventions, without the consent of the patent owner even during the term of protection, to establish the invention's utility, working advantages and disadvantages, and above all to develop, on the basis of the knowledge so acquired, improved (patent-dependent) or new (patent-independent) solutions." ${ }^{1253}$

(c) Section 55.2(1) and 55.2(2) of the Canadian Patent Act

"Limited"

In interpreting the word "limited" in Article 30, the EC had offered a list of proposed meanings, all of which, with the exception of "restricted", were aimed at confining permissible limitations to measures that had little or no impact (e.g., "insignificant"). ${ }^{254}$ However, the plain meaning of the word was not so narrowly confined. For example, Black's Law Dictionary defined "limited" as meaning "[r]estricted; bounded; prescribed. Confined within positive bounds; restricted in duration, extent, or scope". 255 Thus, a "limited" exception would not necessarily be minor or insignificant. It could have very important consequences, but still qualify as "limited" because it was restricted in duration.

\footnotetext{
${ }^{248}$ Wegner, supra note 241, pp. 453 and 455

${ }^{249}$ See paragraph 4.30 above, under (b).

${ }^{250}$ See paragraph 4.30 above, under (c), $5^{\text {th }}$ indent.

${ }^{251}$ See paragraph 4.30 above, $3^{\text {rd }}$ indent.

${ }^{252}$ Wegner, supra note 241, p. 460

${ }^{253}$ Quoted in Wegner, supra note 241, pp. 458-9

${ }^{254}$ See paragraph 4.30 above, under (c)(i).

${ }^{255}$ Sixth edition, p. 927
} 
- $\quad$ The other factors listed in Article 30 would of course exert an influence on what would be judged a "limited exception" in any given case, and for that reason it was not correct to fasten on the word "limited" in isolation in order to ascertain the scope of Article 30 as a whole. However, even on the EC's "isolationist" approach, its proposed interpretation of the word "limited" was problematic. If Article 30 had in fact been intended to permit exceptions that were merely "minor" or "insignificant", it was difficult to see how any of the objectives of the TRIPS Agreement could be realized. The overall balance contemplated by Article 7 could not be achieved, if the only measures permitted on one side of the equation were those of little consequence. In such circumstances, Articles 7 and 30, at least, would be reduced to "inutility". The principles of treaty interpretation did not permit such a result.

- $\quad$ Similarly, the principles of interpretation did not support Switzerland's argument that the word "limited" could be taken as corresponding to the wording "in certain special cases" in Article 13 of the TRIPS Agreement (and Article 9(2) of the Berne Convention). ${ }^{256}$ The Appellate Body, in Japan - Taxes on Alcoholic Beverages, had made it clear that due meaning had to be given to the distinction between different words and expressions. Obviously, if the framers of the TRIPS Agreement had intended Article 30 to bear the same meaning as Article 13, they would have used the same words in each provision. The fact that they did use the same language in Article 26.2, but not in Article 13 (or Article 17), was highly significant.

\section{"Do not unreasonably conflict with a normal exploitation of the patent"}

The EC appeared to take the position that Canada's measures did not come within Article 30, because they provided limited defences to patent infringement actions, and the right to prevent others from making and using a patent were among the fundamental patent rights. ${ }^{257}$ While the right to prevent third parties from using a patented invention was indeed an exclusive right recognized by Article 28, it was not itself an "exploitation" of the patent within the meaning of Article 30. The purpose of the exclusive rights conferred by a patent could be the "spurring on" of "the actual exploitation of the invention in the marketplace", i.e. to "offer a basket for the collection of [the marketplace] reward"258, but the exclusive rights themselves should not be mistaken for the actual exploitation of the invention. Canada's measures did not conflict at all with the actual exploitation of the invention in the marketplace; hence there was no conflict, let alone an unreasonable conflict, with a normal exploitation of a patent. ${ }^{259}$

\footnotetext{
${ }^{256}$ See under section $\mathrm{V}$. below.

${ }^{257}$ See paragraph 4.30 above, under (c)(i) and (ii).

${ }^{258}$ H. Ullrich, "The Importance of Industrial Property Law and Other Legal Measures in the Promotion of Technological Innovation", Industrial Property (March 1989), pp. 102 and 103

${ }^{259}$ In response to a question from the Panel, Canada said that the Vienna Convention required that the term "unreasonably" be given its ordinary meaning in light of the purpose and context of the Agreement. That meaning was "in an unreasonable manner" or "to an unreasonable extent". The word "unreasonable" meant "going beyond what is reasonable or equitable; excessive" (The New Shorter Oxford English Dictionary, p.3503). What amount of conflict or prejudice that would not be considered to be unreasonable, or excessive, must be determined by the context of the Agreement, including Article 7, which contemplated a balancing between the rights of patent holders and other competing public interests "[...] in a manner conducive to social and economic welfare". As regards the difference between Article 30 and Article 13, reference was made to what is reflected above in paragraph 4.36, under (c)(i), $3^{\text {rd }}$ indent. In addition, the following comments from Daniel Gervais (The TRIPS Agreement: Drafting History and Analysis, Sweet \& Maxwell, London, 1998, pp. 143-144 and 159) might be helpful: "In referring to material concerning the Berne Convention, however, it is necessary to take into account the different nature of copyright and other intellectual property rights and thus to import only relevant historical or other concepts. Moreover, the addition of the phrase "taking account of the legitimate interests of third parties" introduces a balance that is not found in the Berne Convention. [...] As already explained, however, given the different nature of industrial property, the reference to copyright-related principles here should be limited to terminology and carried out with utmost caution." It was clear, from a comparison of the two provisions, that Article 13 was a far narrower exception than Article 30, the latter not only allowing conflict with a reasonable exploitation and legitimate interests of the right holder, but also taking account of the legitimate interests of third parties, such as consumers and health care providers. Reference was also made to what is reflected above in paragraph 4.36 , under (c)(i), $1^{\text {st }}$ and $2^{\text {nd }}$ indents.
} 
- $\quad$ According to the EC, Canada's arguments were based on misconceptions about patent rights. ${ }^{260}$ It seemed apparent though that the EC's argumentation flowed from the misconception that Article 30 was an "inutility". In other words, the EC did not accept that patent rights could be limited in any way, as was evident from its assertion that Canada's measures unreasonably prejudiced the legitimate interests of the patent owner because the legitimate interests of a patent owner could only be the full enjoyment of all his patent rights during the entire patent term. ${ }^{261}$ This left no room for any prejudice at all to a patent holder's interests, and equated "normal exploitation" with "unfettered exploitation", notwithstanding Article 30's unequivocal acceptance of reasonable prejudice. Again, the failure to accord any meaning to plain words was a fundamental error of treaty interpretation.

(iii) "Do not unreasonably prejudice the legitimate interests of the patent owner, taking account of the legitimate interests of third parties"

The EC's contention that the only relevant third party interests to be considered in this case were those of would-be generic manufacturers ${ }^{262}$ depended on what Canada had argued were the incorrect propositions that the TRIPS Agreement was neutral with respect to societal values, and that Article 30 should be interpreted in isolation from the other provisions, including in particular Article 7. Further, even if the EC was correct in its view that the consumption of a medicine by a patient was no act which was of any relevance in patent terms, the issues in this case related to the acquisition, not the consumption, of a medicine, and the competitive circumstances in which that act occurred. These were issues intimately connected with the offering for sale and selling of a medicine - two of the fundamental rights of a patent holder identified by the EC - and involved the ultimate question of whether the TRIPS Agreement was capable of extending a patentee's exclusive economic benefits into the post-expiry period, to the economic detriment of consumers, public drug plans and other third party payers. ${ }^{263}$

With reference to the activities contemplated by Section 55.2(1) of the Patent Act, the EC had said that, since a submission to a regulatory authority in a country other than Canada was included, the extent of permissible activities was completely out of the control of the Canadian authorities. ${ }^{264}$ For the reasons given above, it was not apparent what relevance this allegation had to the present proceeding, given that the TRIPS Agreement contemplated the private enforcement of the private rights with which it was concerned. Equally, it was unclear what the relevance was of the EC's further allegation that the conditions for obtaining marketing approval in other countries would be unknown in Canada. In order to enforce their rights in Canada, patentees did not need to know the regulatory requirements of other countries. They only needed to know that their invention was being exploited without their consent, since the onus of establishing a defence under either Section 55.2(1) or 55.2(2) would clearly be on the defendant. ${ }^{265}$

Although the EC had contended that Canada had mixed up two separate matters in pointing out the "windfall" benefits which would accrue to patentees in the post-expiry period under a system in line with the position taken by the EC in the present dispute ${ }^{266}$, it was

${ }^{260}$ See paragraph 4.30 above, under (c)(ii).

${ }^{261}$ See paragraph 4.30 above, under (c)(iii).

${ }^{262}$ See paragraph 4.30 above, under (c)(iii) and (d)(iii).

${ }^{263}$ In response to a question from the Panel, Canada said that, where a patentee licensed a related generic unit, in order to "tool up" and compete as a branded generic product immediately after expiry, it involved a private contractual arrangement, the terms of which would be commercial confidences and therefore not available to the government. The EC response to the same Panel question is reflected in footnote 170

${ }^{264}$ See paragraphs $4.22,4^{\text {th }}$ indent, and 4.30 , under (d)(iii), above.

${ }^{265}$ See further under section IV.D(4) below.

${ }^{266}$ See paragraph 4.30 above, under (d)(iii). 
apparent that the EC's theory blurred the distinction between two very different concepts. As the EC had explained it, a patentee had a "legal patent right" during the period of protection, and also an "economic expectation" for the post-expiry period, both of which allegedly gave rise to a TRIPS-based entitlement. However, while the TRIPS Agreement was certainly concerned with the right, it did not recognize or in any way seek to protect the expectation. The whole of the EC's case was about the effective extension of patent rights beyond the minimum period of protection required by the TRIPS Agreement, and involved the assertion of commercial interests rather than intellectual property rights. ${ }^{267}$

\section{EXCEPTION FOR A REGULATORY SUBMISSION TO A "COUNTRY OTHER THAN CANADA"}

4.38 Expanding its arguments ${ }^{268}$ in response to the EC's allegation that, since a submission to a regulatory authority in a country other than Canada was included in the exception stipulated in Section 55.2(1) of the Canadian Patent Act, the extent of permissible activities under that provision was completely out of the control of the Canadian authorities, Canada submitted that the "other country" aspect of Section 55.2(1) met the requirements of Article 30 of the TRIPS Agreement. According to the EC, this aspect unreasonably conflicted with a normal exploitation of a patent, because it excepted from infringement liability uses of a patented invention reasonably related to the development and submission of information required under a law of a country other than Canada. Similarly, the United States had expressed the view as a third party in the present dispute ${ }^{269}$ that, while a "pre-expiration testing" exception addressed the legitimate interests of consumers, only the interests of domestic consumers could be taken into account, as testing for "foreign regulatory approval" was not within a "properly crafted" exception. Canada was of the view that this element of the regulatory use exception was the same as the other elements, in that it did not affect the core rights of a patent holder during the term of protection and only impacted upon a patentee's economic exploitation after the term had expired. It differed from the other elements only in that it served the legitimate interests of third parties in other countries around the world, by enabling them to obtain needed medicines as soon as possible after patent expiry. The achievement of that goal was consistent with the objectives of the TRIPS Agreement, because it sought to protect public health and because it reduced distortions and impediments to international trade. The following points were advanced in support of this view.

\section{The Global Nature of the Pharmaceutical Industry}

- $\quad$ Both the brand name and generic pharmaceutical industries were global in nature. Very few countries had fully integrated brand name or generic drug industries within their borders. Even in large countries, generic producers frequently had to obtain ingredients such as fine chemicals from producers in other countries. Many countries had no generic industries at all and had to obtain generic (as well as brand name) products from other countries. Smaller countries that did have generic industries did not have domestic markets sufficiently large to enable those industries to operate on an economic scale. Those industries had to export in order to be able to manufacture in sufficient quantities to achieve economies of scale, so that domestic consumers could receive the benefits of cost-effective generic products.

The United States agreed that a "pre-expiration testing" exception was a reasonable exception to the exclusive rights conferred under the TRIPS Agreement. ${ }^{270}$ However, the market in the United States was large enough for generic producers to manufacture on an

\footnotetext{
${ }^{267}$ Reference was made to the similar views expressed by Australia, Brazil, Colombia, Cuba, India, Israel, Japan, Poland, Thailand and the United States as third parties in the dispute (see section V. below).

${ }^{268}$ See paragraph 4.37 above, under (c)(iii).

${ }^{269}$ See under section V. below.

${ }^{270}$ See under section V. below.
} 
economic scale. Very few countries were in that position. "Pre-expiration testing" exceptions that had the effect of confining all activities to a single country were of little use to countries that, unlike the United States, depended on international trade to obtain generic products.

In fact, the "Bolar exemption" under United States law recognized one side of the international trade equation by expressly permitting imports. By including this provision, the United States Congress had clearly contemplated that some aspects of the "pre-expiration testing" process would take place in countries other than the United States. ${ }^{271}$ The Statement of Administrative Action by the United States Government in respect of the Uruguay Round Agreements Act expressly referred to the United States exemption as an example of a limited exception permitted under Article 30 of the TRIPS Agreement. ${ }^{272}$ Since the TRIPS Agreement required patent protection in all 134 WTO Members by the year 2005 at the latest, the drafters of the Statement of Administrative Action must have contemplated that other countries would have "pre-expiration testing" exceptions that would permit activities to be carried on for the purposes of obtaining regulatory approval in the United States. Canada's limited exception was one such case.

\section{The Global Need for Access to Essential Medicines}

Although not manufactured in all countries of the world, generic medicines of course had a role to play in promoting public health in all countries. According to the World Health Organization, more than one third of the world's population lacked regular access to essential drugs. Every year, millions of children and adults in developing countries around the world still died from diseases that could be readily treated by drug therapies, and more economically treated with generic drugs. ${ }^{273}$

- Many countries still lacked the facilities and expertise needed to review the safety, efficacy and quality of drugs destined for their national markets, and remained dependent on reliable foreign authorities to set the necessary standards and on foreign generic companies to do the necessary testing to those standards. For example, a 1993 study of 36 African countries conducted by the World Health Organization had found that only three had a "limited drug regulatory capacity". Not one African nation had what the WHO called a "comprehensive drug regulatory capacity". ${ }^{274}$

A refusal to allow testing of generic medicines for the purposes of foreign regulatory submissions during the term of patent protection, while permitting it for domestic submissions, would needlessly delay the regulatory review process in many countries. As a result, generic drugs would not be readily available, and many treatable diseases would remain untreated, in the period following patent expiry. Moreover, such a refusal would require that tests be repeated in their entirety in foreign countries. The World Health

${ }^{271}$ Foreign testing is accepted by the Food and Drug Administration: "The FDA permits the submission of foreign-generated clinical data so long as the procedures used in compiling the data comply with FDA requirements." Intermedics, Inc. v. Ventritex, Inc. (see footnote 185 above), p. 1284.

${ }^{272}$ Reference was made to what is reflected above in paragraph 4.21 , under (b), $5^{\text {th }}$ indent.

273 The Worldwide Role of Generic Pharmaceuticals, Presentation to International Generic Pharmaceuticals Association by Dr. Jonathon D. Quick, Director of Essential Drugs and Other Medicines, World Health Organization, June 1999. The diseases and death rates are: respiratory infections (4 million); diarrhoeal disease (3 million); tuberculosis ( 2 million); measles ( 1 million); malaria ( 1 million); tetanus ( $1 \frac{2}{2}$ million); heart attack and strokes (5 $1 / 2$ million); and cancer ( $3 \frac{1 / 2}{2}$ million).

${ }^{274}$ Status of Drug Regulation and Drug Quality Assurance in WHO African Region and Selected Countries, World Health Organization, March 1999. 
Organization opposed multiple human testing because of its resource implications for developing countries. ${ }^{275}$

Consequently, if permissible "pre-expiration testing" were to be confined to activities related to domestic regulatory review only, the protection of public health would unquestionably suffer. An important value expressly recognized in Article 8.1 of the TRIPS Agreement would be impaired.

\section{$\underline{\text { The Context of the TRIPS Agreement }}$}

The TRIPS Agreement was not a free-standing intellectual property convention like the Paris Convention for the Protection of Industrial Property and the Berne Convention for the Protection of Literary and Artistic Works. Rather, it was a part of a much larger system, the overarching purpose of which was to reduce barriers to trade. The full title of the TRIPS Agreement was the Agreement on Trade-Related Aspects of Intellectual Property Rights, and the very first line of its Preamble recited the desire of Members "to reduce distortions and impediments to international trade [...]". The TRIPS Agreement was one of 15 agreements listed in Annex I of the Marrakesh Agreement Establishing the World Trade Organization (the "WTO Agreement"). One of the objectives of that Agreement was set out in its Preamble as follows: "[...] being desirous of contributing to these objectives by entering into reciprocal and mutually advantageous arrangements directed to the substantial reduction of tariffs and other barriers to trade and to the elimination of discriminatory treatment in international trade relations". As noted in Article XVI:3 of the WTO Agreement, provisions of the WTO Agreement prevailed over provisions of the Multilateral Trade Agreements, of which the TRIPS Agreement was one.

- Protection of intellectual property rights was necessary to the integrity of the international trading system, because countries that did not respect intellectual property rights could gain unfair advantages over countries that did respect and protect such rights. A principal objective of the TRIPS Agreement, as one of the agreements comprising the international trading system, was to eliminate "free-riding" distortions resulting from the failure of some countries to respect intellectual property rights by establishing standards to be applied by all Members.

However, intellectual property rights, in conferring exclusive rights on those entitled to them, were themselves trade-inhibiting if interpreted in an absolute fashion. The first paragraph of the Preamble to the TRIPS Agreement recognized this. The paragraph in its entirety provided as follows: "Desiring to reduce distortions and impediments to international trade, and taking into account the need to promote effective and adequate protection of intellectual property rights, and to ensure that measures and procedures to enforce intellectual property rights do not themselves become barriers to legitimate trade; [...]". The emphasis of the paragraph was on the reduction of "distortions and impediments to international trade". The protection of intellectual property rights was referred to as a factor that must be taken into account in achieving this overall objective. As was evident from the Preambles to both the TRIPS Agreement and the WTO Agreement, the protection of intellectual property rights provided for in the TRIPS Agreement had to be considered in the broader context of achieving the reduction of "barriers to trade" (WTO Agreement), as well as to ensuring that the existence and enforcement of intellectual property rights did not result in "distortions and impediments to international trade" (TRIPS Agreement). Accordingly, while the protection

${ }^{275}$ Developing International Standards for the Generic Pharmaceutical Industry, Presentation to International Generic Pharmaceuticals Association by Dr. Juhana E. Idanpaan-Heikkila, Special Advisor, Quality Assurance and Safety, World Health Organization, June 1999. 
of intellectual property rights under the TRIPS Agreement had to be adequate for achieving these purposes, it clearly must not be allowed to frustrate these broader objectives.

A "pre-expiry testing" exception that did not permit activities in respect of foreign regulatory approval was useful only to those countries with markets large enough to sustain domestic generic industries on an economic scale. It failed to recognize that most countries depended on international trade for their supply of generic drugs. In order to be consistent with the first paragraph of the Preamble to the TRIPS Agreement and with the overarching objective of the WTO Agreement set out in its Preamble quoted above, a properly crafted "pre-expiry testing" exception ${ }^{276}$ had to take foreign regulatory approvals into account in order that the objective of removing impediments to international trade could be sustained.

\section{(d) Foreign Regulatory Approval and Article 30 of the TRIPS Agreement}

- $\quad$ The inclusion of "foreign regulatory approval" in a "pre-expiry testing" exception was consistent with the requirements of Article 30. As the purpose of the TRIPS Agreement was to "reduce distortions and impediments to international trade", the TRIPS system extended across borders. As stated by Australia as a third party in the dispute, the TRIPS Agreement recognized that the need for this balance extended across borders, acknowledging the tradedistorting effects of insufficient or inappropriate protection of intellectual property rights, and the impact of uneven or inconsistent forms of protection. ${ }^{277}$

- $\quad$ As the TRIPS system was designed to be international and so to extend across borders, there was no reason why the legitimate interests of third parties in other countries could not be taken into account when applying a limited exception under Article 30. As indicated above, unlike the United States, very few countries had markets large enough to support domestic generic drug industries, and many countries had no generic industries at all. The effect of limiting the scope of a "pre-expiry testing" exception to domestic regulatory approval was to delay the benefits of generic drugs to consumers in, and governments of, other countries.

Alternatively, if the legitimate interests of third parties in other countries were not to be taken into account, the interests of the patent owner in those countries also should not be taken into account. If the country in question was a Member, the interests of the patent owner in that country would be protected in accordance with that country's intellectual property laws, which had to conform to the TRIPS Agreement as it applied to that country. If the country in question was not a Member and did not protect intellectual property rights, the patent owner had no interests in that country to protect.

As regards the EC's observation that, by allowing the activities referred to in Section 55.2(1) of the Canadian Patent Act with a view to obtaining marketing approval in any country in the world, the extent of such activities and their duration during the patent term was totally open-ended and completely outside the control of the Canadian authorities ${ }^{278}$, it should be noted that the whole point of the TRIPS Agreement was to establish standards for intellectual property protection in all WTO Members. Accordingly, while the conduct of foreign regulatory approvals was not within the control of Canadian authorities, the use of patented inventions in foreign countries was within the control of the patent laws of those countries, most of which were, or would soon be, subject to the requirements of the TRIPS Agreement.

${ }^{276}$ The term "properly crafted pre-expiration testing exception" was used by the United States as a third party in the dispute (see under section V. below).

${ }^{277}$ See under section V. below.

${ }^{278}$ See paragraph 4.37 above, under (c)(iii), $2^{\text {nd }}$ indent. 


\section{Creation of a Trade Barrier}

As noted above, the "Bolar exemption" under United States law expressly excepted from infringement liability the "import into the United States" of a patented invention "solely for uses reasonably related to the development and submission of information under a Federal law" (and the Food and Drug Administration permitted the submission of foreign-generated clinical data). The import exemption assumed third party activity in other countries that would otherwise constitute an infringement of TRIPS requirements.

- $\quad$ An indirect ban (through foreign patent systems) on foreign "pre-expiration testing", in the face of allowable domestic testing, would thus be inconsistent with the apparent United States policy of accepting foreign testing and samples for FDA purposes and would constitute a shift towards protectionism. Generic manufacturers in the United States would thenceforth be protected against competition from countries which, like Canada, allowed foreign "preexpiration testing". This would defeat the objective of the TRIPS Agreement, as set out in the first paragraph of the Preamble, "to ensure that measures and procedures to enforce intellectual property rights do not themselves become barriers to legitimate trade". Moreover, such a requirement would be contrary to the spirit of the Agreement on Technical Barriers to Trade which, in Articles 2.2 and 6.1 respectively, required that "Members shall ensure that technical regulations are not prepared, adopted or applied with a view to or with the effect of creating unnecessary obstacles to international trade [...]" and "[...] Members shall ensure, whenever possible, that results of conformity assessment procedures in other Members are accepted, even when those procedures differ from their own, provided they are satisfied that those procedures offer an assurance of conformity with applicable technical regulations or standards equivalent to their own procedures $[\ldots] "$.

Such a restriction on the interpretation of Article 30 of the TRIPS Agreement would, thus, be contrary to the principle in Article 31.3 of the Vienna Convention on the Law of Treaties, which required that account be taken not only of the context of the treaty in question, but also "any relevant rules of international law applicable in the relations between the parties". Further, the TRIPS Agreement and the Agreement on Technical Barriers to Trade both formed part of an integrated treaty framework created by Article II:2 of the WTO Agreement, all of whose provisions should be construed together so as to create a coherent system. The Agreement on Technical Barriers to Trade was part of the context in which the TRIPS Agreement was to be interpreted pursuant to Article 31.2 of the Vienna Convention.

\section{APPLICATION OF ARTICLE 33 OF THE TRIPS AGREEMENT}

4.39 Canada also maintained that the EC's contention that Section 55.2(1) and 55.2(2) reduced the term of protection to less than the minimum required by Article 33 of the TRIPS Agreement was unfounded. As the United States had pointed out as a third party in the dispute ${ }^{279}$, Canada's Patent Act clearly provided the requisite term of protection, and the only issue was whether the rights conferred within the term met the standards of the TRIPS Agreement.

\section{E. EUROPEAN COMMUNITIES AND THEIR MEMBER STATES}

4.40 The European Communities and their member States maintained that Section 55.2(2) and 55.2(3) of the Canadian Patent Act together with the Manufacturing and Storage of Patented Medicines Regulations violated Article 28.1 together with Article 33 of the TRIPS Agreement; that Section 55.2(1) of the Canadian Patent Act violated Article 28.1 of the TRIPS Agreement; and that

\footnotetext{
${ }^{279}$ See under section V. below.
} 
both these measures violated Article 27.1 of the TRIPS Agreement. The following additional comments were made in response to Canada's arguments:

While Canada agreed that Article 27.1 of the TRIPS Agreement applied to Article 31 thereof, it tried to distinguish the latter from Article 30 of the Agreement on systemic grounds by qualifying Article 31 as mandatory and Article 30 as permissive. The EC disagreed not only with the conclusion drawn by Canada, but also with the argument itself. Both Articles 30 and 31 were permissive provisions. Under Article 30, a Member could, under certain conditions, stipulate exceptions to patent rights and under Article 31 a member is given the possibility to grant compulsory licences. Only if a Member decided to grant compulsory licences, the conditions referred to in Article 31 had to be applied. In other words, no Member was obliged under the Agreement to provide for exceptions under Article 30, nor was any Member obliged to grant compulsory licences under Article 31.

As far as the purposes of Articles 30 and 31 were concerned, the EC were, contrary to Canada, of the view that both provisions had a common objective. This common objective consisted of giving WTO Members the possibility to curtail patent rights under well-defined conditions. While Article 30 constituted the fine-tuning mechanism, Article 31 allowed more important interferences with patent rights. A military person might refer to Article 30 of the TRIPS Agreement as the air rifle and to Article 31 as artillery.

\section{ARTICLE 30 OF THE TRIPS AGREEMENT}

- $\quad$ As far as Article 30 of the TRIPS Agreement was concerned, the divergence of views between the parties concentrated on the scope of permissible exceptions. While the EC considered that Article 30 was a provision which only allowed minor exceptions for finetuning purposes - to the exclusive rights conferred under a patent in conformity with Article 28.1 of the TRIPS Agreement and not measures inconsistent with the nondiscrimination clause in Article 27.1 of the Agreement - Canada considered Article 30 to be the corner provision of the Patents Section of the TRIPS Agreement, which allowed WTO Members to freely overwrite the obligations contained in the TRIPS Patents Section in the light of their individual societal values. The EC maintained that Article 30 only allowed minor exceptions and submitted that this resulted from the text, the context and the negotiating history of the provision. Article 30 resembled other minor exceptions provisions in the Agreement, such as Articles 13,17 and 26.2. All of these provisions were based on the rule-exception principle and circumscribed - not necessarily with identical language exceptions to the rule. ${ }^{280}$

As to the term "limited" in Article 30, Canada seemed to suggest that all exceptions to the rule which were not unlimited would meet the requirement of "limited". If this interpretation were the right one, Article 30 could be invoked to reduce the patent term to one day or to reduce the patent rights to an exclusive marketing right, thus reversing the ruleexception principle. The EC therefore disagreed with Canada's statement that limited exceptions could have very important consequences, but still qualify as limited because they were restricted in duration.

280 The EC wished to note that, while Canada attached some importance to the lack of uniform drafting of Article 13 of the TRIPS Agreement and Article 9(2) of the Berne Convention on the one hand and Articles 26.2 and 30 of the TRIPS Agreement on the other, it did not offer any evidence for its view nor did it explain in what respect this difference might be "highly significant" (see paragraph 4.37 above, under (c)(i), $3^{\text {rd }}$ indent). 
- Canada attributed to a member of the Panel the view that a "prior use" exception could constitute an unreasonable conflict with normal exploitation, if one did not take the third party interests into consideration. ${ }^{281}$ The European Communities and their member States were of the view that a classical "prior use" exception would be covered by Article 30, in order to sell off the stock manufactured prior to patent protection as long as the quantities concerned could be considered as reasonable and would not constitute unreasonable conflict. However, if a "prior use" exception should allow continued manufacture after patent protection had started, then one clearly left the scope of Article 30. This became patently clear when one looked at Article 70.4 of the TRIPS Agreement, which required, as a minimum, that continued manufacturing was only permissible against payment of equitable remuneration to the right holder. This, indeed, was nothing other than a compulsory licence solution.

As to the systematic arguments on the relationship between Article 30 and Article 31, reference was made to what is reflected above in this paragraph in relation to Article 27.1. ${ }^{282}$ Article 30 covered minor curtailments of patent rights without the need to compensate the right holder for that minor curtailment, while Article 31 allowed more serious curtailments of patent rights, but necessitated in turn, among others, a remuneration to be paid to the right holder. ${ }^{283}$

As far as the negotiating history was concerned, Canada put forward the view that the submission to the Uruguay Round TRIPS Negotiating Group to which the EC had referred would be irrelevant for the interpretation of Article 30. While Canada might in retrospect have doubts about the relevance of its own submission, it constituted together with all the other submissions part of the negotiating history of the Agreement. Starting out from the draft text of Article 30 as reflected in GATT document MTN.GNG/NG11/W/76 ${ }^{284}$, it appeared safe to say that, in July 1990, the coverage of the first four elements had largely been agreed by the negotiators and had constituted the background on which the modified text for the Brussels Ministerial Conference in December 1990 had been drafted, which in turn was essentially identical to the actual text of Article 30 in the TRIPS Agreement. The reason for the redrafting from an illustrative list in July 1990 to an abstract generic text had not been to extend the scope of the exceptions, but to express the same value judgement in other words, inspired by the existence of abstractly formulated exception clauses in the field of copyright. Canada seemed to implicitly suggest that, between the July 1990 text and the Brussels text of December 1990, the negotiating parties had had a major change of mind with a view to extending the scope of exceptions allowed under Article 30. Canada had not submitted any evidence to support this assertion. The EC was not aware of any new submission by a negotiating party in relation to Article 30 after the July 1990 text, which would have suggested extending the scope of the exception clause. Indeed the opposite happened when the government use exception was moved from Article 30 to Article 31, thus

\footnotetext{
${ }^{281}$ See footnote 236 above.

${ }^{282}$ See this paragraph above, under (1).

${ }^{283}$ See Article 31(h) of the TRIPS Agreement.

284 "[Provided that legitimate interests of the proprietor of the patent and of third parties are taken into account,] limited exceptions to the exclusive rights conferred by a patent may be made for certain acts, such as:
}

1. Rights based on prior use.

2. Acts done privately and for non-commercial purposes.

3. Acts done for experimental purposes.

4. Preparation in a pharmacy in individual cases of a medicine in accordance with a prescription, or acts carried out with medicine so prepared.

5A. Acts done in reliance upon them not being prohibited by a valid claim present in a patent as initially granted, but subsequently becoming prohibited by a valid claim of that patent changed in accordance with procedures for effecting changes to patents after grant.

5B. $\quad$ Acts done by government for purposes merely of its own use." 
making government use subject to remuneration to be paid to the patent holder. If anything could be said in relation to the developments between July and December 1990, it was that the negotiators had intended to reduce the scope of the exceptions contained in the July text of Article 30.

The EC wished to reiterate that Canada bore the burden of proof that its measures qualified as permissible exceptions under Article $30 .{ }^{285}$

As to the term "normal exploitation of the patent", it should be emphasized that the argument that the patent owner was not prevented from making, using and selling the patented products was not the point. A patent was not a right to do something, but a right to prevent others from doing some well-defined acts.

Moreover, a patent was a bundle of equally important rights. This became plainly apparent when comparing Articles 28.1 and 70.9 of the TRIPS Agreement. Therefore, the argument that the patent owner could exclude others from selling on the marketplace while others carried out the activities permitted under Section 55.2(1) of the Canadian Patent Act was irrelevant.

The EC maintained that, under Article 30, the third party interests could, in the case at hand, only be the interests of the would-be generic producer.

- $\quad$ As to the interests to be compared, they had to be either legal and patent-related on both sides or take into consideration factual economic expectations on both sides. It was inadmissible to limit the relevant interests on the patentee side to legal patent rights, while invoking any kind of economic consideration on the third party side.

\section{Exception for a regulatory submission to a "country other than Canada"}

By pointing out that the extent of permissible activities was completely out of the control of the Canadian authorities, the EC had intended to demonstrate the far-reaching character of the exception. This argument had nothing to do with questions of enforcement and burden of proof, as Canada had suggested. Because any country could set its regulatory standards freely without Canada even knowing about this, Canada was not in a position to control the scope of its exception.

- $\quad$ As regards the argument that the measures at issue served the legitimate interests of third parties in other countries around the world consistent with the objectives of the TRIPS Agreement to protect public health and to reduce distortions and impediments to international trade, the EC wished to emphasize that it was perfectly well possible to protect public health with numerous measures without violating international obligations. The European Communities and their member States were able to do so for their citizens and did not need any unsolicited interference in these matters by Canada or any other country. On the contrary, the objective of this dispute settlement case was to prevent patent rights of European right holders from being eroded in Canada, thus depriving them of obtaining a just return on the investment they had to make for the development of new drugs with a view to enhancing public health. Article 30 of the TRIPS Agreement was not a clause aimed at solving the public health problems of the entire world.

- The generic pharmaceutical industry was not of a global nature. While a small number operated on a truly international level, generic companies predominantly operated on

${ }^{285}$ See Appellate Body reports in US - Standards for Reformulated and Conventional Gasoline, and US - Measure Affecting Woven Woolshirts and Blouses from India. 
their domestic market and many developing countries had flourishing generic pharmaceutical companies. For example, the Canadian generic industry itself only exported 16 per cent of its production and held only a de minimis market share on the EC generic market. ${ }^{286}$

As to essential medicines, the WHO had issued a list of such essential medicines which, at present, contained 306 products. Only 15 of these were protected by patents (Model List of Essential Drugs, Tenth Revision 1997).

The "trade-related" character of the TRIPS Agreement could not be invoked to create exceptions from TRIPS minimum standards, with the argument that such measures would allegedly facilitate trade. While the facilitation of trade flows had indeed constituted a major objective for the TRIPS Agreement, the TRIPS Agreement did not eliminate all IPR-related trade obstacles, because it was based on the pre-existing principle of territoriality of intellectual property rights and created only minimum standards. As far as this was concerned, it was not different from the Paris or Berne Conventions under the auspices of WIPO.

\section{F. CANADA}

4.41 Canada maintained that a consideration of Article 30 of the TRIPS Agreement in context and in light of the object and purpose of the TRIPS Agreement made it evident that Article 30 was the vehicle by which the societal values recognized in Article 7 of the Agreement were to be given effect. As all parties to this proceeding except the EC and Switzerland agreed, the TRIPS Agreement was not neutral vis-à-vis societal values. The following additional comments were made in response to the arguments put forward by the European Communities and their member States:

- Canada wished to emphasize that its challenged measures were "limited exceptions" within the meaning of Article 30 of the TRIPS Agreement, because they promoted competition in regulated-product markets, particularly the prescription drug market, in the period following patent expiry, in the interests of cost containment and of facilitating access to needed medicines.

- The EC's interpretative approach sought to elevate the exclusive rights of a patent holder to a position of primacy over every other interest in society, thereby depriving not only Article 30, but also Articles 7 and 8.1, of any significance or practical effect.

\section{(a) Principles of treaty interpretation}

The EC's effort to apply Article 31 of the Vienna Convention involved an attempt to subdivide the single, indivisible principle of Article 31.1 into discrete compartments. The EC tried to draw a distinction between a treaty's "context", on the one hand, and its "object and purpose" on the other, in an effort to argue that the "ordinary meaning" of terms could not be overridden by considerations of "object and purpose". However, Article 31.1 required that the terms of a treaty be given their "ordinary meaning [...] in their context and in light of [the treaty's] object and purpose". The EC appeared to argue that "context" could not include provisions of a treaty which addressed "object and purpose", as if provisions of a purposive nature - such as those usually found in a preamble - were to be entirely disregarded when interpreting a particular provision in "context". The EC seemed to be contending that "ordinary meaning", "context" and "object and purpose" were separate concepts which were in opposition to each other in Article 31. Manifestly, however, the plain wording of the provision did not support the attempt to compartmentalize it in this way. Moreover, Article 31.2 made it clear that the context of a treaty was its whole text, including the

${ }^{286}$ Reference was made to the NERA Report referred to in footnote 122 above, p. 105. 
preamble and annexes. Consequently, all of the TRIPS Agreement, as well as the Marrakesh Agreement Establishing the World Trade Organization, of which the TRIPS Agreement was a part, must be considered when interpreting one of its provisions, not for the purpose of overriding the "ordinary meaning" of the provision but rather in order to establish what the ordinary meaning was.

The EC had not indicated how its proposed interpretation of Article 30 of the TRIPS Agreement took any account of "context". They had continued to rely on a reading of the words of Article 30 in isolation, and to avoid any discussion of why Article 7 of the Agreement had been included in the Agreement. With respect to the first recital of the Preamble of the TRIPS Agreement, the EC had contended that it merely referred to "measures and procedures to enforce intellectual property rights", and that Article 1.1 made clear that the TRIPS Agreement was laying down "minimum rights" rather than "limited rights". Given that "minimum rights" might nevertheless be subject to some form of limitation pursuant to Article 30, it was not clear how the EC's argument answered Canada's point that the first recital clearly contemplated limitations, by providing that "measures and procedures" to enforce rights should not "themselves become barriers to legitimate trade". According to the EC, Article 7 provided no context for Article 30 because it did not deal with the scope of the intellectual property rights defined in Article 28 but only with their protection and enforcement. This simply begged the question. What scope would there be for the Article 28 rights if they were not protected and enforced? The scope of the intellectual property rights defined in Article 28 could not be divorced from their protection, because the scope, duration and enforcement of the right determined what the actual protection would be. Further, in addressing protection and enforcement, Article 7 was dealing with the means by which the objectives of the TRIPS Agreement it described were to be achieved, i.e. it applied to both Parts II (standards) and III (enforcement) of the TRIPS Agreement. Even on the EC's compartmentalized approach to the application of the Vienna Convention, this aspect of Article 7, as well as Article 1.1 as explained by the EC for that matter, provided "context" for Article 30, because it was not solely concerned with "object and purpose".

Canada wished to reiterate that the relevance it saw in the provisions of Article 8.1 was that Article 8.1 informed the inquiry into the meaning of "the legitimate interests of third parties" in Article 30. That was plainly a contextual consideration. The EC's interpretation of Article 8 was one which robbed it of any meaning, since the EC suggested that the only operative words were those which required consistency with provisions of the Agreement other than Article 8 itself. While it was unnecessary for the purposes of the present case to determine the precise scope of Article 8, it was essential that it not be rendered meaningless. Canada's approach, which appeared to be shared by Brazil, Cuba, India, Israel, Poland, Thailand and the United States as third parties to the dispute ${ }^{287}$, recognized that the societal interests identified in Article 8 might be protected by measures that met the standards of Article 30, and that they were not always subordinate to the protection of the intellectual property rights, as the EC argued. Consequently, Article 8 was relevant to a contextual interpretation of Article 30. Canada agreed with the EC that Article 8.1 provided that Members should not be subject to non-violation nullification and impairment when taking measures for the purposes set out in Article 8.1. This interpretation was consistent with Canada's view, and that of a number of other Members, that Article 8.1 signalled that the societal interests it identified were to be taken into account in interpreting the scope of TRIPS obligations.

\footnotetext{
${ }^{287}$ See under section V. below.
} 
- $\quad$ Further, the EC had sought to extract a general approach to treaty interpretation from the Shrimps case ${ }^{288}$ which was not consistent with the very specific circumstances of that case, and which disregarded the contextual approach to treaty analysis that the Appellate Body had in fact adopted in that case. The EC had cited the decision of the Appellate Body in the Shrimps case as authority for its view that the wording of Article 30 should be interpreted in isolation, without regard for any contextual provision or for the object and purpose of the TRIPS Agreement as a whole. What distinguished the Shrimps case from this proceeding, however, was the fact that, as the Appellate Body had determined, the panel in Shrimps had not grounded its interpretation of Article XX of GATT 1994 in the text of that provision. Instead, it had substituted its own generalized and subjective assessment of the object and purpose, without regard for the words actually used. That was not at all similar to the approach Canada advocated in this case. On the contrary, Canada urged that each element of Article 30 of the TRIPS Agreement be analysed on the basis of its particular language, and in the specific context in which it appeared. That was what the Appellate Body had done in the Shrimps case and - contrary to the EC's theory - it had taken the objective of the WTO Agreement, as stated in its Preamble, into account in establishing the "ordinary meaning" of Article XX. ${ }^{289}$ Importantly, the Appellate Body in Shrimps had based its decision on the finding that the panel's interpretation would render "most, if not all, of the specific exceptions of Article XX inutile, a result abhorrent to the principles of interpretation we are bound to apply". ${ }^{290}$ This was an application of the principle of effectiveness which, as the Appellate Body had held in Alcoholic Beverages, meant that "[a]n interpreter is not free to adopt a reading that would result in reducing whole clauses or paragraphs of a treaty to redundancy or inutility". ${ }^{291}$ It was the principle of effectiveness which ultimately stood in the way of the EC's effort to have the Panel construe the provisions of the TRIPS Agreement in isolation. The principle of effectiveness required that account be taken of both the contextual provisions, which indicated that intellectual property rights were not intended to be unlimited, and the objectives provision, which made it clear that the TRIPS Agreement sought a balance of rights and obligations. To fail to take those provisions into account, and to read Article 30 as if it were intended that the TRIPS Agreement should be "neutral vis-à-vis societal values", as the EC contended, would be to render Articles 7, 8.1 and 30 inutile. Such a result was not possible, as all parties to this proceeding, except for the EC and Switzerland, agreed. ${ }^{292}$

\section{(i)}

\section{Subsequent practice}

The exclusive authority, to which the EC had referred, that the Ministerial Conference had to adopt interpretations of the Agreement related to formal interpretations that were binding in the same way as the TRIPS Agreement itself. The use of subsequent practice related to a quite different matter: the use of extrinsic aids to interpretation that had not been addressed by the Ministerial Conference under Article IX of the WTO Agreement. Thus, subsequent practice, in the form of patterns of conduct, were relevant to attempts to ascertain the meaning of disputed provisions.

The EC had noted that learned commentators had said that subsequent practice must be "concordant, common and consistent". The EC took this as meaning that practice must be "common to all the parties". In the case of a multilateral agreement, such a standard would be extremely difficult, if not impossible, to satisfy. However, the standard was not as exacting as the EC contended. In Alcoholic Beverages, the Appellate Body had held that "concordant, common and consistent" meant a "sequence of acts or pronouncements which is sufficient to

${ }^{288}$ United States - Import Prohibition of Certain Shrimp and Shrimp Products (WT/DS58/AB/R), paragraphs 115

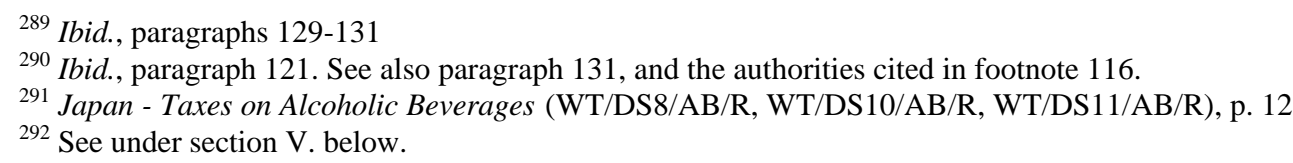


establish a discernible pattern implying the agreement of the parties" regarding the interpretation of the treaty. The emergence of a discernible pattern did not depend on the universal adoption of a practice. On the contrary, the discernible pattern standard was only intended to require the identification of something more than an "isolated act". ${ }^{293}$

The EC had argued that there could be no discernible practice, because the TRIPS Agreement had only been in force for a short period of time. This contention ignored the fact that not all periods of time were of equal significance. The immediate aftermath of the conclusion of a treaty like the TRIPS Agreement was, in reality, more important than the longer term, because Members were obliged, within a relatively short period of time, to ensure that their domestic legislation met their new obligations. It was in the immediate aftermath that a treaty like this generated both legislative activity and documents like the US Statement of Administrative Action ${ }^{294}$, when the parties were actively engaged in the exercise of interpreting the new agreement and putting it in their own words, and closely reviewing the legislative activity of other Members. Far from being irrelevant, the implementation period had a vital importance far exceeding what might transpire later on.

The EC had said that, since it had contested Canada's practice, there was no agreement on the matter. However, the reference in Article 31.3 of the Vienna Convention did not deal with the specific subject-matter of a dispute, but with patterns of conduct from which assumptions about the meaning of a provision could be inferred. In every dispute taken to an international tribunal, there was a difference of opinion about the specific subject of the litigation, but that did not mean that there could be no relevant subsequent practice. If it did, Article 31.3 would be ruled out of consideration in every contentious matter, precisely in those circumstances in which it was intended to be of assistance. Consequently, all that the fact of the EC's disagreement meant was that the EC's position was inconsistent with a pattern of conduct on the part of other Members - including member States of the EC for that matter $^{295}$ - which established implicit agreement about the meaning of the relevant TRIPS provisions.

\section{Article 27.1 of the TRIPS Agreement}

The EC's theory on the interplay of Articles 27.1, 30 and 31 was not based on any analysis of the language actually used. Articles 30 and 31 were not framed in similar terms and, as the Appellate Body had made clear in Alcoholic Beverages, due effect must be given to the distinction between different words and expressions. ${ }^{296}$

- It was interesting to note that the EC had been obliged $b$ modify its "across-theboard" interpretation of Article 27.1 in an effort to justify its own "practising pharmacist's exception". In response to the relevant question from the Panel, the EC had contended that, because the exception responded to an "unique" situation, it therefore lacked comparability and thus discriminatory character. If that was indeed a test for determining consistency with Article 27.1, Canada's measures met that test. They addressed a situation that was "unique" to regulated products, where - but for measures like Canada's limited exceptions - a patentee could exploit regulatory review requirements in order to achieve a de facto extension of the period of patent protection. In the case of patented medicines, the de facto extension would delay competition in the post-expiry prescription drug market.

\footnotetext{
${ }^{293}$ Japan - Taxes on Alcoholic Beverages (WT/DS8/AB/R, WT/DS10/AB/R, WT/DS11/AB/R), pp. 12-13

${ }^{294}$ See footnote 100 above.

${ }^{295}$ Reference was made to Germany, Italy and Portugal (see paragraph 4.15 above, $8^{\text {th }}$ indent).

${ }^{296}$ Japan - Taxes on Alcoholic Beverages (WT/DS8/AB/R, WT/DS10/AB/R, WT/DS11/AB/R), p. 26
} 
- $\quad$ The EC had said that patent term extension for pharmaceutical products was not discriminatory because there was "good reason" for it, and had given the example of a measure which advantaged disadvantaged persons, such as the handicapped and the elderly. This rationale applied equally to Canada's measures. There was good reason for the limited exceptions in Section 55.2(1) and 55.2(2) of the Canadian Patent Act, because they were clearly aimed at ensuring that necessary medicines were made available at competitive prices to those in need - the sick, the elderly, the physically and mentally disadvantaged - as soon as possible after patent expiry. On the EC's own approach, then, the challenged provisions were not discriminatory.

- $\quad$ According to the EC, Canada's approach would necessarily lead to the result that exceptions could also be made as to the place of the invention or whether products are imported or locally produced. However, the examples cited would clearly be prohibited by the national treatment requirement of Article 3 of the TRIPS Agreement, to which Article 30 was clearly subject. The concerns expressed by the EC were therefore unfounded, and simply illustrated the EC's lack of understanding of Article 30 and its relationship to the rest of the TRIPS Agreement.

The EC had acknowledged that Section 55.2(1) of the Canadian Patent Act was formulated in a way that could apply to various fields of technology. However, the EC had made reference to the information package of February 1997 prepared jointly by Industry Canada and Health Canada to provide factual background information for the review of the Patent Act Amendment Act, 1992 (Bill C-91) by the House of Commons Committee on Industry $^{297}$, in particular because this document would show that the Canadian Government itself considered that the measures in question were exclusively concerned with pharmaceutical products, and therefore would constitute proof of a legislative intent to limit the provision's effects to pharmaceutical products. Canada wished to emphasize that, from the time of the introduction of Bill C-91, public controversy had centred on just one of its principal components - the abolition of compulsory licensing for the domestic manufacture of patented medicines - to the virtual exclusion of everything else, and the Government was obliged to respond to that matter of particular controversy. Indeed, the Federal Court of Appeal had described the protection of innovator pharmaceutical companies' rights as the purpose of Bill C-91. It had been widely believed that the repeal of the compulsory licensing provisions of the Patent Act would result in a dramatic increase in health care costs. Thus, when the effects of Bill C-91 were reviewed four years after its enactment, the background document prepared by the Government focused on pharmaceuticals, because of the intense public interest in determining whether the new system of enhanced protection for patents had in fact resulted in significant increases in the costs of pharmaceutical products.

Contrary to the EC's assertion, Canada had never implicitly confirmed that Section 55.2(1) applied only to pharmaceutical products. Section 55.2(1) made no mention of pharmaceutical products. It was not a measure that was "applied" by the Government, but was rather a defence that could be raised in a patent infringement action. There was no reason why it could not be raised as a defence in an infringement action arising in any field of technology. The issue respecting the applicability of Section 55.2(1) had nothing to do with its "drafting history" or what the Government might have said about it, but rather whether it could be raised as a defence in a patent infringement action.

The EC's argument was that Canada's approach strictly confined a patent owner's interest to the legal rights flowing from a patent while permitting third parties' interests to be

\footnotetext{
${ }^{297}$ See footnote 6 above.
} 
based on any kind of "economic, moral or other consideration". This argument, however, simply attempted to obscure the fact that a patentee possesses all of the exclusive rights under a patent during the term of protection, and that third parties possessed no rights at all until the expiry of the term. It was this imbalance which Article 30 allowed Members to address, where appropriate, by permitting other interests to be weighed against the patent rights.

While the EC contended that "the legitimate interests of third parties" could not be taken into account in determining whether there was "unreasonable conflict with a normal exploitation of a patent", it offered no standard by which the reasonableness of a conflict could be judged.

The EC appeared to have stopped short of submitting that a regulatory review exception like that in Section 55.2(1) of the Canadian Patent Act must be accompanied by either patent term extension or supplementary protection certificate systems in order to be permissible under Article 30. While the EC seemed to suggest that the presence of such systems might, in certain circumstances, be a relevant consideration under both Articles $27.1^{298}$ and 30 , its position on this point was not supported by any third party in the dispute. Indeed, the evidence was clear that at least four WTO Members - Argentina, Hungary, Poland and Thailand - had recently fulfilled or would soon be implementing their imminent TRIPS obligations by enacting regulatory review exceptions without any system of patent term extension.

Again, there was no nexus between Article 30 and patent term extension. Article 30 permitted limited exceptions to patent rights, but patent term extension was an augmentation of the enjoyment of a patent right, not an exception. Had the drafters of the TRIPS Agreement wished to make patent term extension a cognizable concept for the purposes of the Agreement, they would have done so in express terms, as had been done, for example, in Article 1709(12) of the North American Free Trade Agreement. Since patent term extension had clearly been raised as a subject for discussion during the Uruguay Round by both Switzerland and Austria, but had not been included in the text of the TRIPS Agreement, its omission was a matter of interpretative significance.

The absence of a nexus between a regulatory review exception and patent term extension was illustrated by the situation in the United States. The "Bolar exemption" in the US Patent Act (35 U.S.C. $\$ 271(\mathrm{e})$ ) made no reference to the provision of the Act creating patent term extensions (35 U.S.C. $§ 156$ ). The question of whether a particular patent could be extended, and for what term, was unrelated to whether anyone had taken advantage of the "Bolar exemption" with respect to that patent. Moreover, there were many other provisions of the US statute which advantaged either an innovator or a generic manufacturer. The scheme was very complex, and it was quite clear that Congress had not considered the matter to be a simple one of combining patent term extension with the 'Bolar exemption". That was one reason why the US Statement of Administrative Action for the Uruguay Round Agreements Act referred to the "Bolar exemption" alone when it spoke of permissible limited exceptions under the TRIPS Agreement. ${ }^{299}$ Further, it is significant that the United States did not, in its oral statement in these proceedings, suggest that there was any connection between its "Bolar exemption" and patent term extension.

298 The EC appeared to say that patent term extension was mere "differentiation", not discrimination, under Article 27.1. Equally, however, one could say that a regulatory review exception was mere differentiation, in that it addressed the distortion created by regulatory review systems. That was why, in its effort to maintain the argument that Canada's provision violated Article 27.1, the EC suggested that both "Bolar" exemptions and patent term extensions could be of significance for the purposes of Articles 27.1 and 30. However, that suggestion only implied that the EC's supplementary protection certificate system was unbalanced and thus discriminatory. Further, it was inconsistent with the negotiating history (see under the next indent).

${ }^{299}$ See footnote 100 above. 
The EC had argued that Section 55.2(1) of Canada's Patent Act unreasonably conflicted with a normal exploitation of a patent, because it excepted from infringement liability uses of a patented invention reasonably related to the development and submission of information required under a law of a country other than Canada. The United States as a third party in the dispute had also suggested that a "properly crafted exception" would not allow testing for purposes of "foreign regulatory approval". ${ }^{300}$ From this, it appeared that the EC sought to persuade the Panel that, even if the concept of "effective patent term" could not be used in order to restrain competition in Canada's domestic post-expiry markets, it could still operate at the international level, and prevent Canadian and foreign generic manufacturers from doing development work in Canada with a view to competing in foreign markets as soon as possible after patent expiry in those jurisdictions. The United States, while rejecting the EC's concept of "effective patent term" in the Canadian domestic context, nevertheless seemed to be seeking protection for its own generic manufacturers against foreign competition by preventing the foreign manufacturers from carrying out "pre-expiration testing" outside the United States. With respect to the United States position, the United States "Bolar exemption" expressly excepted from infringement liability the "import into the United States" of a patented invention "solely for uses reasonably related to the development and submission of information under a Federal law". The import exemption clearly assumed third party activity in other countries that would otherwise constitute an infringement of TRIPS requirements. In fact, the US Food and Drug Administration permitted the submission of foreign-generated clinical data in support of regulatory review applications made to it. ${ }^{301}$ Further, in its bilateral trade negotiations with other countries, the United States sought to ensure that foreign clinical test data were accepted for pharmaceutical products. ${ }^{302}$ The United States position in these proceedings thus sought to create an indirect ban - through foreign patent systems - on foreign "pre-expiration testing". However, that would only give rise to an inconsistency in United States domestic law, since the domestic law accepted foreign testing and samples for FDA purposes. The reason for adopting this position appeared to be a desire by the United States to protect its generic drug manufacturers against competition from generic manufacturers in countries with regulatory review laws similar to Canada's. Consequently, by attacking the "other country" aspect of Section 55.2(1), both the EC and the United States, in their own ways, sought to erect a non-tariff barrier to international trade, and to inhibit post-expiry competition in their domestic markets. In Canada's view, this attempt to interpret Article 30 of the TRIPS Agreement as not permitting an exception for foreign regulatory testing was inconsistent with the basic principle of the TRIPS Agreement, set out in its Preamble, "to reduce distortions and impediments to international trade".

In addition, by creating the equivalent of a technical regulation that distinguished between drug-testing services on the basis of the country in which they were tested, such an interpretation was contrary to the Agreement on Technical Barriers to Trade, which similarly aimed at the elimination of international trade barriers. ${ }^{303}$

${ }^{300}$ See under section V. below.

${ }^{301}$ Intermedics, Inc. v. Ventritex, Inc., 775 F.Supp. 1269 (N.D.Cal. 1991), p. 1284; affirmed 991 F.2d 808 (Fed.Cir. 1993)

${ }^{302}$ Letter from Richard W. Fisher, Deputy USTR, to Minister for Trade, Republic of Korea, June 4, 1999, reproduced in Inside US Trade, Vol. 17, No. 26, July 2, 1999, p. 36.

${ }^{303}$ Article 2.2 of the TBT Agreement provides that "Members shall ensure that technical regulations are not prepared, adopted or applied with a view to or with the effect of creating unnecessary obstacles to international trade [...]." Article 6.1 of the Agreement provides that "[...] Members shall ensure, whenever possible, that results of conformity assessment procedures in other Members are accepted, even when those procedures differ from their own, provided they are satisfied that those procedures offer an assurance of conformity with applicable technical regulations or standards equivalent to their own procedures $[\ldots] "$. 
- $\quad$ Reference was also made to what is reflected in this paragraph under (i), $4^{\text {th }}$ indent.

Canada wished to stress that many countries had no generic industries at all and must obtain generic (as well as brand name) products from other countries. The World Health Organization was sufficiently concerned about the lack of guaranteed access to essential medicines that it had recently adopted a resolution urging its member states "to explore and review their options under relevant international agreements, including trade agreements, to safeguard access to essential drugs". ${ }^{304}$

\section{ARGUMENTS PRESENTED BY THIRD PARTIES}

\section{AUSTRALIA}

5.1 Australia's approach to the present case was governed by three basic principles:

The TRIPS Agreement should be applied so as to foster trade and investment, technological innovation and the transfer of technology;

There should be no unreasonable diminution of intellectual property rights, including the legitimate interests of patent holders; and

- $\quad$ Governments, in implementing the TRIPS Agreement in accordance with its agreed objectives and principles, should have sufficient latitude to maintain the underlying balance of rights and obligations without diminishing the legitimate scope of intellectual property rights.

5.2 Australia identified the following points as what it saw as the key points to be made in the present case:

(1) A limited exception to patent rights solely for the purposes of obtaining regulatory approval for patented pharmaceuticals was consistent with TRIPS obligations:

rigorous, lengthy regulatory requirements specifically for pharmaceuticals were distinct from the normal processes undertaken when putting any new product on the market

- $\quad$ steps involved in obtaining regulatory approval were either not covered by patent rights under Article 28, or were allowable exceptions under Article 30, since any detriment to the patentee was reasonable and third party interests were acknowledged in a manner comparable with other accepted exceptions under Article 30.

(2) Responding to the consequences of technology-specific regulatory requirements was consistent with maintaining the fundamental balance of interests under the TRIPS Agreement and was not a discrimination on the basis of field of technology.

${ }^{304}$ World Health Assembly Resolution WHA52.19, "Revised Drug Strategy", 24 May 1999, adopted as proposed by the WHO Executive Board (see footnote 57 above). 


\section{SUMMARY OF LEGAL ISSUES}

5.3 Summarizing the legal issues in the present case, Australia advanced the following points:

Patent rights had been developed, enforced and bounded with the intention of serving the broader public interest through the provision of effective private rights. Exceptions to patent rights needed to be justified by reference to the overall public interest and should seek to maintain the fundamental balance of interests and mutual advantage at the core of the patent system, so as to serve the overall public benefit. The TRIPS Agreement set this balance of interests into an international trade context.

- $\quad$ Article 28 of the TRIPS Agreement specified the scope of patent rights that Members had to grant. Some activities relating to a patented invention were not within the scope of Article 28 and were thus permissible. Other activities could be permitted under Article 30 of the Agreement, or subject to the conditions for unauthorized use under its Article 31. The TRIPS Agreement distinguished Article 30 exceptions from the forms of unauthorized use considered under Article 31, such as government use and compulsory licences to redress competition concerns. Article 31 provided for compensation mechanisms through the provision of adequate remuneration.

The range of permissible Article 30 exceptions should be determined with reference to the overall objectives and balance of interests in the TRIPS Agreement and the availability of other forms of unauthorized use: this was the context in which the tests of 'reasonableness' in Article 30 should be considered. The cumulative test for an Article 30 exception essentially required that the patent owner should not be unreasonably deprived of the benefits of pursuing commercial exploitation during the patent term, with due regard for third party interests. Regulatory approval was particularly rigorous for pharmaceuticals and hence created a distinct burden for patentees and generic producers: legislatures and courts had recognized the need to respond to this exceptional situation, so as to maintain the fundamental balance of the patent system.

A capacity to restrain others from taking steps for regulatory approval was distinct from a capacity to restrain them from the normal preparatory steps for entry onto the market of a new product which were undertaken in any industry sector. The balance of interests in the patent system could be affected by allowing de facto exclusive rights over such extrinsic matters as government regulatory approval. A limited exception to allow steps to obtain regulatory approval conformed with Article 30, because if any such steps incidentally amounted to normal commercial exploitation of the invention, then the limited detriment to the patentee's interests could not be considered unreasonable.

Enjoyment of patent rights without discrimination as to field of technology under Article 27.1 of the Agreement did not require that identical rules should apply to patents in all technological fields. Patent administration could require differential treatment according to technological subject-matter. The key to non-discrimination was for the overall balance of rights and obligations to be maintained. Where legislatures or courts sought to sustain this balance by taking account of technology-specific factors (such as specific regulatory regimes for pharmaceuticals), this was legitimately characterized as seeking to ameliorate discrimination rather than as creating it.

\section{POLICY BACKGROUND}

5.4 Providing further background to the policy background related to the matter at issue, Australia drew attention to the following points: 
Reflecting a long line of development of national intellectual property (IP) laws, the TRIPS Agreement affirmed the 'balance of rights and obligations' that was a key objective of the 'protection and enforcement of intellectual property rights' (Article 7). The patent system was founded upon a complex interaction between private and public interests: a wellbalanced, TRIPS-consistent IP system worked to the 'mutual advantage of producers and users of technological knowledge', thus serving broader public policy goals. Any exceptions to the basic framework established by the TRIPS Agreement should be aimed at sustaining this mutually beneficial balance.

- In considering the balance of rights and obligations, one should not assume that the diverse interests engaged by the patent system were fundamentally divergent or in conflict. The acknowledged mutual advantage and common public benefits accruing from the very existence of adequate private patent rights should be kept in focus. Private patent rights in the pharmaceutical field did not merely benefit patentees, but also served the interests of the public, by promoting the development and preparation for marketing of new pharmaceuticals; of governments, by advancing public health objectives; and indeed of generic competitors, by providing them with a source of technological information and research data, new products and new commercial opportunities.

The present dispute between the European Communities and their Member States (EC) and Canada raised fundamental questions about the interaction of private IP rights and the public good. It concerned the way in which the broad objectives of the TRIPS Agreement were to be reflected in national intellectual property systems and how certain key provisions were to be implemented in individual jurisdictions.

Australia had a substantial trade interest in the protection of pharmaceutical inventions. In 1997, Australia had exported over A $\$ 979$ million of pharmaceutical goods; of this $\mathrm{A} \$ 173$ million had been exported to the EC and A\$ 17 million to Canada. Australia's research-based pharmaceutical industry was developing rapidly, and a number of important new pharmaceuticals coming onto the market under patent protection were the product of Australian research. More broadly, Australia had a fundamental interest in the integrity of the rules relating to trade-related intellectual property rights. Australia's approach to the present dispute was accordingly governed by these basic principles:

- $\quad$ the TRIPS Agreement should be applied so as to foster trade and investment, technological innovation and the transfer and dissemination of technology;

there should be no unreasonable diminution of intellectual property rights, including the legitimate interests of patent holders; and

governments, in implementing the TRIPS Agreement in accordance with its agreed objectives and principles, should have sufficient latitude to maintain the underlying balance of rights and obligations without diminishing the legitimate scope of IP rights.

The specific questions to be considered were whether exceptions to patent rights to allow for regulatory approval and pre-expiry manufacturing and stockpiling of pharmaceutical patents were allowable under Article 30 of the TRIPS Agreement, in conjunction with its Article 28; and whether this was inconsistent with the requirement of its Article 27.1 that patent rights be enjoyable without discrimination as to field of technology. Any specific factors affecting the exploitation of pharmaceutical patents needed to be reviewed in the light of the overall balance and policy objectives of the patent system reflected in the TRIPS Agreement. 


\section{THE DEVELOPMENT OF NATIONAL PATENT LAWS}

5.5 Australia also provided an overview of how it saw that national patent laws had developed over the years and, in doing so, advanced the following points:

Contemporary patent law, exemplified by the wide range of standards established and affirmed by the TRIPS Agreement, was the product of centuries of steady evolution of law at the national level. The patent system had always aimed to define, safeguard and bound private patent rights so as to promote common benefits and the mutual advantage of the state, innovators and entrepreneurs, and the general public. The TRIPS Agreement established international minimum standards in areas of substantive intellectual property law that had hitherto been largely the province of national law making. One of the key interpretive questions in applying the TRIPS Agreement to the present case was therefore how existing municipal patent law should be taken into consideration.

Obligations under the TRIPS Agreement should be interpreted according to the Vienna Convention on the Law of Treaties rather than by reference to any one national system, practice or tradition. However, given the absence of directly applicable international jurisprudence and any subsequent agreement between the relevant parties, it was appropriate to consider how patent law had developed at a national level and how it applied to the issues at stake, as this illustrated both the context of the provisions of the TRIPS Agreement in question, and the overall object and purpose of the TRIPS Agreement. The conferring of an exclusive private right, of fixed duration, in order to serve the broader public good, was a consistent feature of patent law, dating back, for example, to a 1474 statute prohibiting the manufacture in Venice ${ }^{305}$ of any 'new and ingenious device' other than by its originator, so that more would "apply their genius, discover and build devices of great utility and benefit"; similarly, the English Statute of Monopolies of 1623 allowed limited-term exclusive rights for the "sole working or making of any manner of new manufacture". ${ }^{306}$ Patents functioned, in effect, as a contract between the State and the inventor: "The right of the Crown to grant monopolies is now regulated by the Statute of Monopolies but it was always strictly limited at common law. A monopoly being a derogation from the common law right of freedom of trade could not be granted without consideration moving to the public. [...] In the case of new inventions the consideration was found either in the interest of the public to encourage inventive ingenuity or more probably in the disclosure made to the public of a new and useful article or process." ${ }^{1307}$

- $\quad$ The "balance of interests" noted in Article 7 of the TRIPS Agreement was found in this fundamental principle: an exclusive right to limit others' use of the invention was balanced by "consideration moving to the public", namely the making available of new technology for the benefit of the public and the full disclosure of the invention to the public. A new technology came into existence and was added to the common pool of knowledge; and the inventor, in exchange, had an exclusive limited opportunity to exploit the patent for financial reward. The TRIPS Agreement recognized that the need for this balance extended across borders, acknowledging the trade-distorting effects of insufficient or inappropriate protection of IP rights, and the impact of uneven or inconsistent forms of protection.

A further important element of the patent system was that it was broad and comprehensive in reach. The patent system functioned to promote innovation and investment in new technologies, and did not generally operate as a means of regulating the use of such technologies (which was the subject of specific regulations, such as those governing health,

\footnotetext{
${ }^{305}$ Patent statute of 1474, quoted in Mandich, Venetian Patents (1450-1550) (1948) 30 JPOS 166 at 1776-177

${ }^{306}$ Statute of Monopolies, 1623, 21 Jac. I c.3

${ }^{307}$ Lord Parker in Attorney General v Adelaide Steamship Co., House of Lords, (1913) AC 781
} 
safety and the environment). The patent system's overall public policy objectives would be compromised if the scope of patentable subject-matter were to be unduly restricted. These considerations were behind the general trend in patent law to define patentable inventions very broadly, and then to set out limited exceptions to this scope - such as exceptions based on ordre public or morality. ${ }^{308}$ This trend towards comprehensiveness of subject-matter was reflected in Article 27.1 of the TRIPS Agreement, which provided that patent rights be "enjoyable without discrimination as to [...] the field of technology".

\section{LIMITATIONS ON PATENT RIGHTS}

5.6 As to the issue of limitations on patent rights, Australia advanced the following points:

- Limitations applied to the grant and scope of patent rights in order to ensure the fairness of the exchange between the State and the innovator. For example, there were conditions on patentability to ensure a patented invention was genuinely a "manner of new manufacture" or the like, and there were limitations on the right of the patentee to restrain others' activities. However, the most important safeguard was the limitation on the duration of a patent. This guaranteed that the "contract" between the patentee and the State was to mutual advantage: the patentee could be confident that there would be a well-defined opportunity to exploit an invention, and the State could be certain that the public would, in time, have an unrestricted entitlement to use the patented invention (with full understanding about the invention and its practical implementation passing into the public domain at a very early stage, normally well before patent rights were granted).

- The nature and scope of a patent right were, therefore, shaped and circumscribed by the broader objectives of the patent system. These public policy purposes required clear boundaries to be set on a patent right, both in terms of the scope of the invention that could be validly claimed, and the scope of others' activities that could be restrained by the patent. These fundamental considerations were reflected in the substantive provisions of the TRIPS Agreement - the exclusive patent rights of Article 28 were set against restrictive criteria for the grant of patents, ensuring that patents were only granted for genuine inventions (Article 27.1) and further conditions such as full disclosure (Article 29), and reasonable and limited exceptions to those rights (Article 30), and other limitations on exclusive rights (Article 31).

A patent conferred a right to exclude others from certain acts in relation to the patented product or process. Two factors applied in determining the scope of this exclusive right - the actual scope of the claimed invention in individual patents (the "subject-matter" in Article 28); and the kind of activities that were considered infringing.

At a national level, certain acts had been considered non-infringing either as a result of explicit legislative provisions, or through case law. A good example was experimental use: the United Kingdom Patents Act specifically provided that an act which would otherwise infringe a patent was not an infringement if "it is done for experimental purposes" ${ }^{\prime 309}$; by contrast, in Australia, an experimental use exception did apply, but only to the extent that a court would find that specific experimental activities did not constitute infringing use, guided by case law on this point. Similarly, in assessing national patent law against the TRIPS Agreement, a permitted act - such as purely experimental use - could be justified as not falling within the scope of the original patent right under Article 28, and therefore as not being an infringing act; or it could be justified under Article 30 as a specific limited exception to the patent right.

\footnotetext{
${ }^{308}$ Article 27.2 of the TRIPS Agreement

${ }^{309}$ United Kingdom Patents Act 1977, Section 60(5)(b)
} 
- $\quad$ Existing patent law and international agreements provided for several uncontroversial exceptions to patent rights, which conformed with the scope of the exceptions permitted by Article 30 of the TRIPS Agreement and thus shed light on the intended application of that Article:

prior use exceptions, whereby a person who had been making or using a patented invention (or had taken definite steps to do so) prior to the patent's priority date could continue that activity without infringement ${ }^{310}$; and

use of a patented invention in foreign vessels, vehicles or aircraft passing temporarily or accidentally through a territory in which the patent applied (an obligation under the Paris Convention ${ }^{311}$ and hence the TRIPS Agreement).

A further class of permissible limitations on the patent right was the "other use without authorization of the right holder" considered by Article 31 of the TRIPS Agreement and Article 5A of the Paris Convention, often termed licences of right and compulsory licences, and government use. Such exceptions typically applied in cases of failure to work the patent, to respond to anti-competitive practices (as Article 31(c) and (k) indicated), or to respond to national emergencies. The exceptions sought to safeguard the fundamental balance of interests by ensuring that the benefits of the patented technology were available on reasonable terms to the public through "working" the patent. It was important, for the present case, to note that such measures were explicitly excluded from the scope of Article $30^{312}$ : hence, where such exceptions were allowed under national law, they would need to be subject to the specific limitations established by Article 31.

Within this general context, Australia considered how Articles 27, 28 and 30 of the TRIPS Agreement applied to the present dispute, in particular in relation to the provisions in the Canadian Patent Act which stipulated that it was not an infringement to make, construct, use or sell the patented invention firstly in relation to regulatory approval, and secondly in relation to pre-expiry manufacturing and stockpiling, in the case that these provisions had been applied solely to pharmaceutical patents.

\section{ARTICLE 28: THE NATURE OF PATENT RIGHTS}

5.7 Australia then provided its views as to the nature of the rights conferred by a patent on its owner:

Article 28 of the TRIPS Agreement provided that the holder of a product patent was granted the exclusive rights "to prevent third parties not having the owner's consent from the acts of: making, using, offering for sale, selling, or importing for these purposes that product" (with analogous rights in relation to process patents). Even before specific exceptions were considered, the rights conferred in accordance with Article 28 were limited to preventing others from performing certain acts, and conferred no corresponding right on the patentee to undertake those acts. In addition, in contrast to trade secret protection, a patent could not be used to prevent a third party from familiarizing itself with the patented invention and its practical implementation, because that was the very function of the patent document. Even this might require some practical verification or demonstration, entailing use of elements of the disclosed invention.

\footnotetext{
${ }^{310}$ See for example Australian Patents Act 1990, Section 119.

${ }^{311}$ Article 5ter of The Paris Convention for the Protection of Industrial Property (1967)

${ }^{312}$ Footnote to Article 31 of the TRIPS Agreement
} 


\begin{abstract}
The patent system aimed to make new technology public and to promote innovation: patents should advance the common store of knowledge and serve as the basis for further innovation; those affected by a patent should also be entitled to determine whether the invention functioned as claimed, and was indeed "capable of industrial application" or "useful". ${ }^{313}$ This had led to the recognition, by courts and legislatures, of the right of third parties to conduct trials and experimental use of a patented invention without infringing the patent. ${ }^{314}$
\end{abstract}

Courts in a range of jurisdictions had also repeatedly found that the purpose of the acts of "making" or "using" of the patent was critical in determining whether they infringed the rights of the patentee. In the common law tradition, the courts had held that the making or using of the patent by a third party would be an infringement if it had a clear commercial purpose. In British Motor Syndicate v John Taylor \& Sons (1900) 17 RPC 723 (CA), the court had found that, to infringe a patent, "making" had to be for a commercial purpose, and that any use which deprived patentees of the commercial benefit of their invention would infringe the patent. Similarly, in Union Carbide's (Culbertson's) Application (1971 RPC 81), the court had found that infringing use had to be for a commercial purpose.

In both statute and case law in many jurisdictions, the scope of exclusion related to commercial activities in a very general sense. Hence the TRIPS Agreement and national laws provided for exclusive rights of making, using, offering for sale, and not merely for sale. ${ }^{315}$ This had implications for the form of commercial interests that were relevant: "[For infringement to occur, t]he making must be for a commercial purpose. It is not necessary, however, that this be for actual sale: any use which deprives the patentee of the commercial benefit of his invention, even to a limited extent, will suffice." 316

- $\quad$ Article 31(b) and (c) discussed "public non-commercial use" as a potential exception to patent rights. The TRIPS Agreement therefore recognized that at least some forms of noncommercial use could be constrained by the exclusive rights established by Article 28 . Hence, in applying the TRIPS Agreement to national law, it appeared that some noncommercial use would be deemed infringing under Article 28, and would need to be justified with reference to Article 30 or Article 31.

Seeking regulatory approval for a generic image of a patented pharmaceutical entailed a range of activities in relation to the patented invention. Some activities were not covered by the exclusive rights established by Article 28 at all. Activities which were within the scope of Article 28 would need to be justified under Article 30. In some scenarios, activities related to seeking regulatory approval would be permitted within the terms of a compulsory licence, government use or the like under Article 31, but this was not directly at issue in the current case. Manufacturing and stockpiling had to be considered inherently commercial activities, and thus could fall within the scope of exclusive rights under Article 28.

\footnotetext{
${ }^{313}$ Article 27.1 of the TRIPS Agreement

${ }^{314}$ See Article 27(b) of the Community Patent Convention (1989), corresponding national legislation such as the UK Patents Act referred to above (see footnote 145), and case law in numerous jurisdictions: Frearson v Loe (1878) 9 Ch D 48, Proctor v Bailey \& Son (1889) 6 RPC 538 (CA); Smith Kline \& French v Micro Chemicals (1970) 60 CPR 193; Pharbita and Medicopharma v ICI Dutch Supreme Court 1992; Klinische Versuche II German Federal Supreme Court 1998 RPC 423; Wellcome Foundation Limited v Parexel International and Others, Paris Court of Appeal 1999; Otsuka Pharmaceutical Co. Ltd v Towa Yakuhin KK Japanese Supreme Court 1999 Case no. 1998.

${ }^{315}$ Under Section 13 of the Australian Patents Act 1990, a patent gives the patentee the exclusive rights, during the term of the patent, to exploit the invention and to authorize another person to exploit the invention. "Exploit" is defined, in relation to a product invention, as to "make, hire, sell or otherwise dispose of the product, offer to make, sell, hire or otherwise dispose of it, use or import it, or keep it for the purpose of doing any of those things", and analogously for a process patent.

${ }^{316}$ S. Ricketson, The Law of Intellectual Property, Sydney, 1984, p. 984
} 


\section{Regulatory Approval}

While they did not in themselves confer an active right to work an invention, patent rights were founded on the assumption that the patentee should have a reasonable opportunity to pursue fair commercial returns. This opportunity could be affected by the State's regulation of the use of certain technologies, and requirements for trial and approval on health, safety or environmental grounds. Given the nature of pharmaceuticals, this process was necessarily rigorous and time-consuming, especially when a new compound was involved (in contrast to an image product). This often led to extensive delays in reaching the marketplace for patentees of a new pharmaceutical and, to a lesser degree, delays for generic competitors seeking to place image products on the market; at the same time, as a class of product, new pharmaceuticals offered exceptional benefits to the public and entailed high levels of risk and investment.

- The steps required to obtain regulatory approval varied according to national laws, but some steps would not fall within the most generous reading of exclusive patent rights. A patent could not prevent a competitor from preparing supporting documentation and paying an application fee in relation to regulatory approval, activities beyond the scope of the rights established in Article 28. Hypothetically, a regulatory system could approve the proposed marketing of an image product solely through documentary cross-referencing and without any relevant use or manufacture of the patented pharmaceutical. There were also widely recognized rights, consistent with Articles 28 and 30 read together, to conduct trials as to the technical feasibility of the patent and as the basis of further research. The question of whether seeking regulatory approval could infringe the patent arose when the regulatory approval process required more extensive or dedicated tests and research and limited production of sample products.

- $\quad$ Recent German and Japanese Supreme Court decisions had found that the use of a patent to conduct trials and experiments in order to obtain regulatory approval for a pharmaceutical patent fell within the ambit of statutory exceptions to patent rights for research and experimental use. The German Supreme Court ${ }^{317}$ had found that the intention to use the results of experiments and trials for the purpose of obtaining regulatory approval was irrelevant to the determination of whether an act fell within the experimental use exception. The Japanese Supreme Court ${ }^{318}$ had commented that to refuse to permit, under the research exception, experimental use for the purpose of obtaining regulatory approval would extend the effective period of patent protection and therefore run counter to the guiding principles of the patent system, i.e. that society benefits as a result of any person being able to make use of an invention once the patent term expired.

- As these cases illustrated, the research exception (whether it was an a priori exception to the very definition of patent rights, or a specific exception under Article 30) could provide a legal basis for relevant use of a patent required for regulatory approval of an image product. However, further or distinct Article 30 exceptions, beyond a research exception, could be required for at least some of the steps taken in securing regulatory approval.

${ }^{317}$ Klinische Versuche II German Federal Supreme Court 1998 RPC 423

318 Otsuka Pharmaceutical Co., Ltd. v. Towa Yakuhin K.K., Tokyo High Court, Civil 6th Division, Case No. 3498(ne), 31 March 1998; affirmed by Second Petty Bench of the Supreme Court, Case No. 1998 (ju) 153, April 16, 1999 
WT/DS114/R

Page 102

\section{ARTICLE 30: LIMITED EXCEPTIONS}

5.8 Commenting more specifically on Article 30 of the TRIPS Agreement, Australia advanced the following points:

Article 30 gave WTO Members the discretion to create limited exceptions to the exclusive rights of patent holders conferred in Article 28 of the Agreement, provided that they:

- $\quad$ did not unreasonably conflict with the normal exploitation of a patent;

- $\quad$ did not unreasonably prejudice the legitimate interests of patent owners; and

took the legitimate interests of third parties into account.

This was a cumulative test, each element needing to be fulfilled.

Article 30 assumed that there were circumstances in which exceptions to patent rights would be justified, distinct from the set of limitations on patent rights contemplated by Article 31. For instance, some relevant exceptions were required by the Paris Convention (Article 5ter). Commentators on the TRIPS Agreement ${ }^{319}$ had illustrated the scope of the exceptions permitted by Article 30 by citing provisions allowing scientific research and experiment, simultaneous invention, and prior use. Other possible exceptions included implied licences for dealing with ${ }^{320}$ or repairing ${ }^{321}$ patented goods which had been legitimately purchased. In determining whether the provisions of Canadian law under dispute fell within the ambit of Article 30, it was necessary to have regard to both the scope of these provisions and their application to the pharmaceutical industry.

\section{Characteristics of the Pharmaceutical Industry}

- Before applying the provisions of Article 30, it was necessary to consider the distinctive characteristics of the pharmaceutical industry that formed the background to the present case. The stringent requirements for regulatory approval of new pharmaceuticals placed a burden on pharmaceutical producers: the approval process was lengthy (and, for the patentee, could exclude commercial exploitation for a substantial part of the patent term). This led, for the patentee, to a loss of revenue during the normal period of exclusive exploitation of the patent and a disincentive to invest in new pharmaceuticals and the research and clinical trials necessary for approval. For the generic producer, regulatory requirements could lead to a significant delay in introducing an image product on the market after patent expiry, distinct from normal commercial and industrial preparations to introduce an image product onto the market.

Courts and governments had recognized that the regulatory burden fell on both research-based and generic producers, and had sought to address this problem in different ways. For example, patent term extensions were available in a number of Members to redress the imbalance in rights caused by the inability to exploit a patent for extensive periods of the patent term. Similarly, limited "springboarding" exceptions to patent rights had been applied to redress the imbalance that could occur if a generic producer could only initiate regulatory preparations once a patent had expired. The underlying rationale for both such measures was

\footnotetext{
${ }^{319}$ See, for example, M. Blakeney, Trade-Related Aspects of Intellectual Property Rights: A Concise Guide to the TRIPS Agreement, London, 1996, p.87; and D. Gervais, The TRIPS Agreement: Drafting History and Analysis, London, 1998, p.159.

${ }^{320}$ See decisions noted by Ricketson, op. cit., p.988.

${ }^{321}$ Dunlop Pneumatic Tyre Company v Holborn Tyre Co. Ltd. (1901) 18 RPC 22
} 
to shift the balance back towards a reasonable effective period of exclusive commercial exploitation. These two complementary responses had the same purpose: to ameliorate the distorting commercial effects of the regulatory process, while ensuring that the public interest was still served by thorough testing of any new pharmaceutical.

A similar application of fundamental patent principles could be discerned in another widely-recognized exception permitted by Article 30 - the prior use exception discussed above. In this case, allowing a third party to continue use of the patented invention was a "reasonable" conflict with normal exploitation, because to prevent it would impair the balance of legitimate interests between patentee and the prior user. By contrast with these cases, the normal steps taken to exploit a pharmaceutical patent - technical and industrial preparations, manufacturing, distribution, offer for sale, etc. - were not subject to extrinsic, specific impediments or disproportionate disturbance of the fundamental balance of interests. For these steps, pharmaceutical products were essentially on par with any other technological field.

\section{"Unreasonable Conflict with the Normal Exploitation of a Patent"}

An exception to patent rights which conflicted with the normal exploitation of a patent could be allowable under Article 30, provided that the conflict was not unreasonable. "Normal exploitation" of a patent was broader in scope than the mere sale of patented products ${ }^{322}$ : it essentially amounted to the use of the patent for commercial purposes, or in a way which generated a return to the patent owner. This would include manufacturing the patented product on a commercial scale, offering the patented product for sale, licensing the use of the patent, and packaging and preparing the patented product for sale and its distribution.

Seeking technology-specific regulatory approval for a pharmaceutical could readily be distinguished from the regular process of taking a patented product to market. The balance of interests in a patent right did not extend to a right to exclude others from initiating regulatory approval for post-expiry use. Where seeking regulatory approval did incidentally require activities that overlapped with normal exploitation (for instance, a pilot-scale production run, or importation of samples), this would be a compelling instance of a reasonable conflict with normal exploitation: "unreasonably", in this context, could be defined with reference to the fundamental balance of interests in the patent system. Given that this balance was not disturbed by the secondary activity of seeking regulatory approval, this conflict could be considered reasonable. In cases where exceptions were granted to allow activities which did not correspond with specific impediments to post-expiry commercialization by competitors, the conflict with normal exploitation could be considered unreasonable.

\section{"Prejudicing the Legitimate Interests of Patent Owners"}

The legitimate interests of a patent owner were the interests acquired by virtue of the grant of a patent: the interests accruing from the right to exclusive exploitation of the patent, a right which expired with the patent term. Prejudice to these legitimate interests would entail injury, detriment or loss in relation to the exploitation of patent rights during the patent term. This could be caused by loss of sales, loss of licensing opportunities or diminished licensing returns, or loss of value in the assignment of rights. Unreasonable prejudice would be loss or damage that was inconsistent with the patent system's balance of rights and obligations; reasonable prejudice suggested that potential losses could be suffered, but that these losses

${ }^{322}$ See the definition of "exploit" in Australian law referred to above (footnote 315). 
did not deprive the patent owner of normal commercial returns, including the returns associated with licensing the patent for general commercial exploitation of the patent.

Patentees could derive commercial benefit from a range of forms of exercising their patents: some patentees derived their entire income from licensing fees. Licensing fees could relate to use of a patented invention for general commercial activities, and needed not be limited to a royalty on sales in the final marketplace. Legitimate interests should be interpreted in this broader context, and prejudice to those interests should be understood as more than simple loss of sales. But there were limits to legitimate interests: hypothetically, a patentee could seek to charge licence fees for a competitor's use of the patented pharmaceutical in preparing for and submitting material required for regulatory approval. However, in some circumstances, a patentee could have no legitimate interest in earning profit from a government regulatory process, distinct from the commercial exploitation of the patent. On the other hand, if it were considered that a patentee had, in general, a legitimate interest in deriving licensing fees from competitors preparing for the commercialization of a patented pharmaceutical, then the extent to which licensing revenue was lost as a result of an exception linked to regulatory approval, those interests would be prejudiced, but in a reasonable manner. This was again because the underlying balance of interests was not served by deriving benefit from the working of an invention solely in relation to extrinsic regulatory processes.

"Springboarding" provisions which allowed third parties to make limited use of the patent for the purpose of obtaining regulatory approval had the purpose and effect of facilitating the entry of competitors onto the market once the patent term had expired. Therefore they did not in any way interfere with the patent owner's commercial use of the patent or cause any loss or injury to the patent owner during the patent term. Any perceived losses - such as those complained of by the EC - were the effects of a change from a monopoly to a competitive market following the expiry of the patent term. Patent owners had no entitlement to compensation for a fall in profits as a result of fair competition once the patent term expired.

\section{"Taking into Account the Legitimate Interests of Third Parties"}

The third element of Article 30 was the requirement that the legitimate interests of third parties be taken into account. The determination of whether an exception "unreasonably conflicted" with the normal exploitation of a patent or "prejudices" the legitimate interests of a patent owner must therefore be moderated by the interests of third parties; this suggested that third parties' interests should be considered, but needed not prevail. This aspect of Article 30 reflected the objective, in Article 7, of contributing to a balance of rights and obligations. A clear instance of taking into account third parties' interests was the prior use exception: because of the strength of the third party interest (the entitlement flowing from having independently developed the invention prior to the filing date), the patentee had no right of action against that party.

Patent owners were not the only parties with an interest in the grant of patent protection for pharmaceutical products. The grant of patent protection was more complex than the simple unilateral grant of rights to a patent owner: it was a contract between the State and individual innovators in which the consideration for the grant of patent protection was the disclosure of the innovative knowledge and the public interest in promoting investment in the research and development of new pharmaceutical products. Parties with an interest therefore included private consumers of pharmaceutical products; governments which had responsibility for the protection of public health; and the generic producers of pharmaceutical products who wished to enter the market after the patent had expired. 


\begin{abstract}
The diverse interests of third parties did not necessarily conflict with the interests of patent owners. Australia believed that the interests of consumers, governments and even generic producers would not be served by the erosion of intellectual property protection for pharmaceutical patents, but that the legitimate interests of third parties lay in the appropriate balance between intellectual property protection and other issues of public interest, such as free and fair competition upon the expiry of the patent term, appropriate systems for pharmaceutical pricing, increased choice for consumers of pharmaceutical goods, and a continuing application of investment and risk-taking in the development of new pharmaceuticals.
\end{abstract}

- $\quad$ Third party interests were engaged by the fact that regulatory delays following a patent's expiry could exceptionally delay the introduction of image products onto the market, and thus diminish fair competition in the pharmaceutical market. Providing a limited exception to patent rights to allow for steps related to regulatory approval was, therefore, an appropriate means of taking these interests into account, while not unreasonably conflicting with the normal exploitation of a patent nor unreasonably prejudicing the legitimate interests of a patent owner.

\title{
ARTICLE 27.1: DISCRIMINATION AS TO THE FIELD OF TECHNOLOGY
}

5.9 Finally, Australia addressed the issues related to the non-discrimination clause of Article 27.1 of the TRIPS Agreement, putting forward the following points:

- $\quad$ Article 27.1 of the TRIPS Agreement provided that patents "shall be available and patent rights enjoyable without discrimination as to the field of technology". The EC claimed that "springboarding" provisions which only applied to the pharmaceutical industry created discrimination against that industry on the basis of the field of technology. It was submitted that this claim could not be sustained in relation to a limited "springboarding" provision which related solely to the obtaining of regulatory approval.

The principal form of discrimination on the grounds of the field of technology contemplated in Article 27.1 was that of denial of patent rights altogether - this was the subject of the specific exceptions to this rule in the subsequent paragraphs of Article 27. Lack of discrimination in relation to enjoyment of patent rights should be distinguished from the application of uniform rules in all areas of technology. It was not inconsistent with the TRIPS Agreement to provide for distinct patent rules that responded to practical consequences of differences between fields of technology: for instance, patent administration could require distinct rules for disclosure (such as obligations relating to the deposition of microorganisms in accordance with the Budapest Convention) in order to ensure that the basic balance of rights and obligations was maintained.

Hence, in some circumstances, some technology-specific rules could be implemented with the very intention of ensuring that patent rights could be enjoyed without discrimination. In this sense, differential treatment did not necessarily amount to discrimination. On the other hand, undifferentiated treatment, when applied across the board, could result in discrimination against those that face technology-specific circumstances. Governments, or in some instances courts, could elect to use such measures to respond to the special features and requirements of an industry sector. For instance, the need to respond to lengthy regulatory delays in the pharmaceutical domain had led to forms of term extension which were designed to restore the balance of interests. Similarly, limited exceptions to patent rights allowing generic competitors to seek regulatory approval for pharmaceuticals aimed to restore the balance of interests that applied immediately upon the expiry of the patent. 


\begin{abstract}
This balance of interests was achieved by ensuring that enjoyment of patent rights only restrained genuine commercial activities during the patent term, and these rights did not serve to limit the commercial activities a competitor could undertake after the patent expired. The lack of discrimination was maintained if the overall package of rights ensured that competitors were able to enter the market as soon as the patent had expired, as was the case in other industries, while legitimate patent rights during the course of the patent term were not unduly diluted. Hence, a balanced "springboarding" package ensured that the pharmaceutical industry was not indirectly discriminated against by the universal application of standard patent rights and conditions which would in practice result in the de facto extension of the monopoly rights of the patent owner beyond the expiration of the patent term.
\end{abstract}

BRAZIL

5.10 Brazil stated that its interest in the dispute stemmed from the fact that it involved a crucial debate on the relation between trade and public concerns. Whatever decision was taken on the matter, it would influence the manner in which the notion of balance, within the TRIPS Agreement, between public interest and trade commitments was perceived. In this sense, what motivated Brazil to intervene in this dispute was essentially a systemic interest. That was especially relevant in view of the dimension of the pharmaceutical market in Brazil, among the five largest in the world, with sales reaching US $\$ 9.6$ billion a year. The sector employed 47,100 people and accounted for investments, in 1996 alone, amounting to US\$200 million. Brazil's main concern was that the interpretation of the TRIPS Agreement sought by the European Communities and their member States might result in an undue advantage to the patent holder, in terms of a de facto extension of the patent term, to the detriment of the balance of rights and obligations carefully negotiated in the TRIPS Agreement.

5.11 Brazil could not agree with the reasoning of the European Communities and their member States that the subsections 55.2(1) and 55.2(2) of the Canadian Patent Act, laying down certain exceptions to the rights of patent holders, violated three provisions of the TRIPS Agreement, namely Article 27.1, Article 28.1 and Article 33, and that could not be justified under Article 30 of the Agreement. According to Brazil, Article 30 served the purpose of striking a balance between private and public concerns and Canada had made use of this provision without trespassing the limits established therein.

5.12 Brazil took the view that the notion of balance was of paramount importance in the TRIPS Agreement. On the one hand, there were the legitimate interests of the patent holders, the producers of technology who played an essential role in the process that led to economic development. The patent system could not be understood other than as a means of granting, for a limited period of time, adequate compensation for the investment made by inventors, as well as of providing an incentive for further research in the attempt to develop new creations. On the other hand, there was the consumer side, represented by the beneficiaries of these inventions, the society as a whole, whose interests were to be considered by governments. This relation was clearly depicted in Article 7 of the TRIPS Agreement. Brazil agreed with Canada that "intellectual property rights do not exist in a vacuum. They are granted taking into account other social and economic welfare policy interests and values". Along with Article 7, Article 8 of the TRIPS Agreement was also relevant as regards considerations of balancing rights and obligations of patent owners, when it mentioned the possibility that Members could adopt measures necessary to protect public health and promote public interest in sectors of vital importance to their socio-economic and technological development. In the opinion of the Brazilian Government, the general considerations of Articles 7 and 8 should be taken into account when applying the provisions of the TRIPS Agreement, since they were part of a whole that guaranteed the balance of rights and obligations of WTO Members. This was all the more so in respect of the subject-matter of the present case. 
5.13 According to Brazil, one possible way of achieving the balance in the case of patents could be to avoid that the period of protection extended beyond the 20 years prescribed in Article 33 of the TRIPS Agreement. As argued by the European Communities and their member States, in the absence of the measures provided for in the Canadian legislation, effective marketing would only be possible at the earliest two years after patent expiry. ${ }^{323}$ If it was true that there was no maximum term for patent protection prescribed in the TRIPS Agreement, it was also right to state that Members were not obliged to extend protection to patents beyond the 20-year time-limit. As a consequence, the Canadian legislation aimed at avoiding any de facto extension of the term of protection, thus allowing the market to establish new and lower price levels for generic drugs, immediately after the expiry of the 20-year period. Furthermore, the argument used by the EC when referring to economic losses incurred by right holders after expiry of the 20-year term of protection seemed to lack a sound legal basis, as no exclusive right - here translated into monopolistic revenue - could possibly be claimed under the TRIPS Agreement after the period of patent protection had expired. Legitimizing any such claim would necessarily create a spillover effect regarding the patent holder's rights, when this de facto extension of the term of protection was not compulsory under the TRIPS Agreement - right on the contrary, one could contend that Canada was providing a fair implementation of the TRIPS Agreement by building a legal wall around the rights of the patent holder so that they did not spill over beyond the 20 -year term. Conversely, the EC seemed to understand that Members had to apply, in practice, a minimum average period of 22 years of protection, from the filing date - or even a lengthier time-period (considering that Canada had referred to a period of three to six-and-a-half years instead of the minimum of two years referred to by the EC). ${ }^{324}$ Clearly, this represented neither the spirit nor the letter of the TRIPS Agreement. Canada had made use of the freedom to implement the provisions of the Agreement into its own legal system, in line with Article 1.1 thereof. The period of 20 years for the duration of a patent was long enough for the holders to prepare themselves for the situation that would emerge when their monopolistic right expired and free competition was allowed. In this respect, an analogy could be made with the tariff reductions negotiated in the WTO. Businesses prepared themselves for the moment the tariff phasing-out was completed and such preparation, which could take the form of increasing production capacity for example, was regarded as normal planning and not questioned by third parties.

5.14 Further, according to Brazil, Canada had correctly argued that the relevant provisions of its Patent Act were limited exceptions, of a non-discriminatory nature, which did not limit the minimum term of protection required under the TRIPS Agreement. Brazil emphasized that, regarding the use by Canada of the exceptions provided for in Article 30 of the TRIPS Agreement, the normal exploitation of a patent was guaranteed, as the allowed uses related to the development and submission of information, as well as those related to the manufacture and storage of articles, would not affect the rights of the patent holder until the term of protection had expired. Until that moment, no revenue would be generated, i.e. no commercial effect would be produced during the term of protection, for anyone but the right holder.

5.15 Finally, Brazil endorsed the Canadian analysis of Article 30, particularly with regard to the definition of third parties, whose legitimate interests were to be taken into account whenever exceptions to exclusive rights were established by Members. The concept of third parties had to include the society and, especially in the case of pharmaceutical products, the consumers whose legitimate interest was having access to drugs at lower prices.

\footnotetext{
${ }^{323}$ See paragraph 4.7 above.

${ }^{324}$ See paragraph 4.21 above under (c).
} 


\section{COLOMBIA}

5.16 Colombia submitted the view that the claim by the EC regarding a possible inconsistency between Section 55.2 of the Canadian Patent Act and Articles 27.1, 28 and 33 of the TRIPS Agreement required a careful analysis of the meaning of Article 30, which laid down a general exception applicable to the rights conferred by a patent and argued that the text of Article 30, taken together with the context of the provision and the object and purpose of the TRIPS Agreement, in particular as reflected in its Preamble and Article 7, indicated that the exclusive rights to a patent could be subject to exceptions, provided of course that the requirements contained in Article 30 were met. According to Colombia, the exception contained in Section 55.2 of the Act was in keeping with the requirements of Article 30 of the TRIPS Agreement in that:

- $\quad$ It was a "limited" exception within the meaning of Article 30, since it covered solely the technological sector and the rights of the patent owner that were necessary for the aim it was pursuing. This requirement of Article 30 permitted a derogation from the principle of non-discrimination in Article 27.1 of the Agreement when it arose from the very purpose of the exception;

- $\quad$ It did not "unreasonably conflict with a normal exploitation of the patent", since it protected the economic rights of the owner during the 20 years that the patent was in force; and

It did not "unreasonably prejudice the interests of the patent owner", since its sole effect was to prevent a de facto extension of the period of protection of the patent, beyond the 20 years provided for in Article 33 of the Agreement, which was not a legitimate interest of the patent owner.

5.17 In support of these conclusions, Colombia provided the following analysis of the conformity of Sections 55.2(1) and 55.2(2) of the Canadian Patent Act with Article 30 of the TRIPS Agreement, noting that, to establish the meaning of this general exception, the ordinary meaning of its terms must be determined in light of their context and relationship with the object and purpose of the Agreement, particularly its Preamble and Article 7.

Sections 55.2(1) and 55.2(2) permitted the use of a patent by a third party, without the consent of the owner, in order to: (a) develop a product and submit information to the regulatory authorities in order to fulfil requirements for the authorization of marketing of the product; and (b) manufacture and store the product with a view to its sale once the patent expired.

Article 30 of the TRIPS Agreement was a general exception which permitted Members to provide exceptions to the exclusive rights conferred by a patent, without any limitation regarding the sector, the circumstances or the methods of its application. ${ }^{325}$ The sole requirement for the application of this exception was the fulfilment of three conditions:

that it was limited;

that it did not unreasonably conflict with a normal exploitation of the patent; and

${ }^{325}$ The exception in Article 30 is a general exception which, by its nature, is different from other exceptions, particularly the exception contained in Article 13 of the TRIPS Agreement, which requires that the exception does not "conflict with a normal exploitation of the work". Article 30 does not merely concern "minor reservations", but forms an integral part of the balance of rights and obligations agreed to by all WTO Members. 
that it did not unreasonably prejudice the legitimate interests of the patent owner, taking account of the legitimate interests of third parties.

Article 7 concerning objectives of the TRIPS Agreement stated that protection of intellectual property rights must contribute to the promotion of technological innovation and should contribute to the transfer and dissemination of technology and favour the social and economic welfare of WTO Members. Consequently, if the three conditions of Article 30, as confirmed by Article 7, were met, the exception was compatible with the TRIPS Agreement and the question that the Panel had to answer was whether Section 55.2 of the Canadian Patent Act met these requirements.

\section{The Exception was Limited}

The mechanism established by Section 55.2 of the Patent Act was an exception which was limited in its scope of application, in the rights to which exception was made and in its duration in time. In all cases, the exception was limited to the aim pursued.

\section{The Scope of Application of the Exception was Limited by the Aim Pursued}

- $\quad$ The application of the exception was limited to pharmaceutical products, since its goal was to establish a balance between the ownership rights of the inventor and the social and economic welfare of society.

To protect intellectual property in a way that promoted invention, the mechanism retained the exclusive right of the patent owner to supply the market for 20 years.

To protect public health, it was necessary that both individuals and the public health system had access to generic drugs as a means of facilitating access to pharmaceutical products. The monopoly prices of pharmaceutical products protected by a patent necessarily limited the possibilities of consumer access. In this regard, reference was made to the explanations by Canada ${ }^{326}$ concerning the rising costs incurred for patented products and the price differential with generic products. The object of facilitating access to generic products, which was directly connected with the standard of living of the general public, was a legitimate objective recognized directly by the World Health Organization (Resolution of the Executive Board EB 103.R1 ${ }^{327}$ ) and indirectly by the TRIPS Agreement (Article 7).

The justification for applying this exceptional mechanism solely to pharmaceutical patents without extending it to the other technological sectors could not be regarded as a violation of the principle of non-discrimination in Article 27.1, not covered by Article 30. It was precisely Article 30 which required that the application of the exception be limited. In other words, Article 30 required by definition that the benefit should not be granted horizontally but exclusively where a justification existed for the exception. Granting this exception to all technological sectors would be contrary to the first requirement of Article 30 . Consequently, the condition in Article 30 was a derogation from the principle of nondiscrimination of Article 27.1 of the TRIPS Agreement.

In summary, the use of the Article 30 exception for pharmaceutical patents was justified by the need to protect a public good, namely health, through access to pharmaceutical products at competitive prices. This interest was combined with the interest in protecting intellectual property for a period that promoted invention, which was accepted as being 20 years. Consequently, access to pharmaceutical products at competitive prices was

\footnotetext{
${ }^{326}$ See paragraph 4.21 above under (c).

32726 January 1999
} 
permitted only immediately after the term of a patent had expired. The importance of pharmaceutical products for health and the necessary regulatory environment of the sector made it distinct from other sectors of technology and justified the exception in Canadian law.

\section{The Exception was Limited in Time and in the Rights it Covered}

- The exceptions contained in Section 55.2 of the Act covered only some of the rights of the patent owner. Section 55.2(1) referred exclusively to the use of the patent for the development of a product and the submission of information required by the regulatory authorities which authorized the production and sale of pharmaceutical products. Section 55.2(2) permitted a party that had made use of the exception in Section 55.2(1) to manufacture the product for storage during the six months prior to the expiry of the patent. The exception did not permit the sale or distribution of the product until the patent had expired.

$\underline{\text { The Exception did not Unreasonably Conflict with a Normal Exploitation of the Patent }}$

- $\quad$ The word "exploit" meant inter alia "to derive a profit from a business or industry for one's own benefit". ${ }^{328}$ This meant that the normal exploitation of the patent was an expression which referred to obtaining from it a profit, i.e. (an economic rent) for the time granted by this right (20 years). Section 55.2 of the Act did not affect the "normal exploitation" of the patent in that it preserved intact the possibility of obtaining a profit as the exclusive supplier of the market for 20 years. It did not affect either the other rights which formed part of the "normal exploitation" of the patent, such as the right to license the invention/patent or the possibility of transferring it.

What was more, in view of the fact that the exception was limited and did not permit the sale of the product until the patent expired, it was an exception which did not unreasonably conflict with the normal exploitation of the patent. For the exception to have an unreasonable impact on the right to exploitation of the patent, it would have to unjustifiably and substantially affect the rights derived by the patent owner. The word "unreasonable" meant "going beyond the limits of what is reasonable" ${ }^{329}$, as would be the case of: (i) an unjustified exception; (ii) an exception whose scope went beyond the rights directly connected with the aim pursued; or (iii) an exception applied in such a way as to damage substantially the economic right derived from the exploitation of the patent.

None of these situations was present in the application of Section 55.2 of the Act, since the exception had as its basis a legitimate public health policy. The exception protected the economic rights of a patent owner during the 20 years provided for in Article 33 of the TRIPS Agreement and created a balance between these rights and the needs of the social and economic welfare of the general public, which were met only after the 20 years of protection of the patent had passed.

\section{The Exception did not Unreasonably Prejudice the Legitimate Interests of the Patent Owner}

The legitimate interests of the patent owner were to use his invention to obtain an economic rent, either as a monopoly supplier or through the licensing of the patent for a period of 20 years, or through transfer of the right.

${ }^{328}$ Two other meanings are: (1) "to extract from mines the riches they contain"; and (2) "to take advantage for one's own ends, usually in an abusive way, of the qualities or sentiments of a person, or of any event or circumstance". (Diccionario de la Lengua Española, Real Academia de la Lengua, 1956).

${ }^{329}$ Oxford Dictionary 
The exception contained in Section 55.2 of the Act did not prejudice this interest. The sole effect of the exception was to avoid a de facto extension of the period of exploitation of the patent, since it enabled other suppliers to be in a position to enter the market and compete therein immediately after the expiration of the patent. ${ }^{330}$

Moreover, the attempt to secure a de facto extension of the period of exploitation of the patent was not a legitimate interest of its owner nor did it form part of the "normal exploitation" of the patent. It was, in a way, an abusive exploitation of the right granted by the patent.

\section{The Context of Article 30 and the Object and Purpose of the TRIPS Agreement}

The meaning of Article 30 was confirmed by the context of the provision. Article 7 of the TRIPS Agreement stated that the protection of intellectual property rights should contribute to the promotion of technological innovation and to the transfer and dissemination of technology in a manner conducive to the social and economic welfare of the Members of the WTO. In the light of Article 7, it was not possible to favour an interpretation of Article 30 which satisfied only the first of these objectives since, in such a case, Article 30 would be superfluous to Articles 27, 28 and 33.

- What was more, the Preamble to the TRIPS Agreement indicated that one of the objects of the Agreement was the adequate protection of intellectual property rights and ensuring that greater protection of these rights did not become a barrier to legitimate trade. This was a clear indication that the interpretation of the rights and obligations of the Agreement had to be such as to prevent abuse of the rights that the Agreement was designed to strengthen.

- $\quad$ Lastly, it should be noted that the Preamble recognized the developmental objectives that underlay the public policy objectives of national systems. This recognition in the Preamble was a clear indication that, by signing the TRIPS Agreement when becoming a Member of the WTO, WTO Members agreed to respect national legislation mechanisms which were designed to achieve a public policy objective.

\section{CUBA}

5.18 Cuba was of the view that the Canadian legal regime applied to patents for pharmaceutical products was wholly compatible with the provisions of the TRIPS Agreement and did not infringe any of its provisions. This position was based on the following considerations relating to the interpretation of the TRIPS Agreement.

\section{Section 5 of the TRIPS Agreement on Patents}

- $\quad$ Section 5 (Patents) of Part II (Standards Concerning the Availability, Scope and Use of Intellectual Property Rights) of the TRIPS Agreement dealt quite systematically with matters relating to the protection of inventions, to which all the standards included in Part I of the Agreement (General Provisions and Basic Principles) were inescapably applicable.

Thus, in Article 27 (Patentable Subject Matter) the Agreement defined the scope of patent protection, while in Article 28 (Rights Conferred) it established the specific scope of protection and in the following Articles (Article 29 - Conditions on Patent Applicants;

${ }^{330}$ Reference was made to the information provided by Canada that the time taken for product development, application preparation and the regulatory review process is three to six-and-a-half years (see paragraph 4.21 above under (c)). 
Article 30 - Exceptions to Rights Conferred; Article 31 - Other Use Without Authorization of the Right Holder; and Article 32 - Revocation/Forfeiture) it set out some material aspects of protection. Lastly, Article 33 (Term of Protection) established the term of protection to be applied for such rights. Article 34 (Process Patents: Burden of Proof) concerned a procedural instrument available to owners which applied solely to process patents.

In the view of Cuba, Section 5 of Part II of the TRIPS Agreement developed a systemic approach, which was more or less comprehensive as regards material requirements, to the question of patent protection for inventions. In other words, all the Articles included here were provisions of equal value and identical significance for the purposes of their implementation at national or regional level.

- $\quad$ It was worth stressing that, in general, the provisions of Part II (Standards Concerning the Availability, Scope and Use of Intellectual Property Rights) of the TRIPS Agreement, and in particular Section 5 (Patents), were subject to the regulations of Part I (General Provisions and Basic Principles). In this connection, the provisions of Article 7 (Objectives) and Article 8 (Principles) were particularly relevant for these purposes, together with the last sentence of Article 1.1 (Nature and Scope of Obligations), because they allowed WTO Members some flexibility in complying with the obligations stemming from the TRIPS Agreement.

It had been recognized that, notwithstanding its general features, the TRIPS Agreement had some specific features with regard to patent protection for pharmaceutical products. The standards in Article 70.8 and 70.9 (Protection of Existing Subject Matter) were an example. This was the finding of the Appellate Body set up in the case India - Patent Protection for Pharmaceutical Products and Agricultural Chemicals (complaint by the United States), which stated in its Report ${ }^{331}$ :

"30. Among the many provisions of the TRIPS Agreement are certain specific obligations relating to patent protection for pharmaceutical products [...]".

\section{$\underline{\text { Article } 27 \text { (Patentable Subject Matter) }}$}

As recognized by the Report of the Appellate Body in the case India - Patent Protection for Pharmaceutical and Agricultural Chemical Products (complaint by the United States) ${ }^{332}$, Article 27 (Patentable Subject Matter) was a general provision with respect to patentability. This was clear in the actual wording of the Article. Its first paragraph contained a general clause ("[...] patents shall be available for any inventions, whether products or processes, in all fields of technology, provided that they are new, involve an inventive step and are capable of industrial application [...] patents shall be available and patent rights enjoyable without discrimination as to the place of invention, the field of technology and whether products are imported or locally produced"), after which it went on, in paragraphs 2 and 3, to make certain exceptions to patentability which, in their turn, contained "exceptions to the exceptions", as in the case of plant varieties.

Article 27 should, nonetheless, always be read in the general context of the TRIPS Agreement, as part of a whole, which on the one hand established minimum requirements for the protection of intellectual property while on the other hand provided appropriate exceptions and limitations to the rights thus conferred. In other words, the purpose of Article 27 was clearly to extend the protection of inventions as far as possible in the Members of the WTO, but bearing in mind domestic needs in connection with the protection of public order,

${ }^{331}$ Document WT/DS50/AB/R of 19 December 1997

${ }^{332}$ See paragraph 30 of document WT/DS50/AB/R of 19 December 1997. 
morality, human and animal health and life, and the environment, and to serve as a support for scientific, technical and socio-economic development objectives. Pons de Val had written that "[i]n reality, the function of patent law itself is to foster technical and industrial progress, and hence it is necessary to design suitable mechanisms for attaining that objective. In other words, patent law is not designed merely as an instrument for the protection of the inventor, but also as an instrument in the interest of the community, which should be the ultimate beneficiary of technical progress". ${ }^{333}$

- However, merely because a particular technological sector - in this case pharmaceutical products - received a particular treatment under domestic law, it could not be inferred that there was discriminatory treatment, especially if the regime was applied without distinction, universally and in conformity with the principles of national treatment and mostfavoured-nation treatment.

- $\quad$ Moreover, even the TRIPS Agreement itself contained certain special provisions with respect to patents for pharmaceutical product inventions. Consequently, the general provision of Article 27 of the TRIPS Agreement in no way prohibited pharmaceutical product inventions from receiving special treatment. Referring to the Agreement in general, Casado Cerviño and Cerro Pradas had written that "[t]he ambitious content of this new international instrument is compensated, as it were, by a large dose of flexibility which contributes to the maintenance of a delicate balance between the different interests of the parties involved. Thus, the Agreement limits itself to setting minimum standards of protection which must be respected by all WTO Member States. In this respect, the Agreement is a treaty of minimums which will in any case favour a rapprochement among the various domestic legislations. On the other hand, the text contains different mechanisms which contribute to facilitating the balance between rights and obligations". ${ }^{334}$

- $\quad$ The subject of patent protection for pharmaceutical products had always warranted special attention from the legislative and doctrinal point of view, a fact easily attributable to the nature of the products involved and their social impact. In fact, the very action of protecting pharmaceuticals with patents had historically given rise to heated discussions. As observed by the panel in India - Patent Protection for Pharmaceutical and Agricultural Chemical Products (complaint by the United States), the TRIPS Agreement was no exception: "We note that in the negotiation of the TRIPS Agreement the question of patent protection for pharmaceutical and agricultural chemical products was a key issue, which was negotiated as part of a complex of related issues concerning the scope of the protection to be accorded to patents and some related rights and the timing of the economic impact of such protection. [...]". ${ }^{335}$ Similarly, Correa had stated "[t]he importance of patent protection for pharmaceutical and agricultural chemical products is clearly reflected in specific transitional provisions establishing rights that are not granted to patent holders in other fields of technology". ${ }^{336}$ Taking up the same reasoning as the panel referred to above, the panel that had examined the complaint by the European Communities and their member States against India in India - Patent Protection for Pharmaceutical and Agricultural Chemical Products had also stated ${ }^{337}:$ "[...] A critical part of the deal struck was that developing countries that

${ }^{333}$ Pons de Val, Marta - Las licencias obligatorias por falta de explotación de la patent: hacia un nuevo concepto de explotación, in "Comunidad Europea Aranzadi", XXII, Number 10, October 1996, p. 41

Bulletin, p. 111

${ }^{334}$ Casado Cerviño, Alberto y Cerro Prada, Begoña - La propiedad intelectual, special issue of the ICE Economic

${ }^{335}$ Paragraph 7.29 of document WT/DS50/R of 5 September 1997 and restated by the panel in India - Patent Protection for Pharmaceutical and Agricultural Chemical Products (complaint by the EC) in its report (document WT/DS79/R, paragraph 7.40)

${ }^{336}$ Correa Carlos M. Acuerdo TRIPS. Régimen internacional de la propiedad intelectual. Ediciones Ciudad Argentina, Buenos Aires, 1996, p. 234

${ }^{337}$ See footnote 335 above. 
did not provide product patent protection for pharmaceuticals and agricultural chemicals were permitted to delay the introduction thereof for a period of ten years from the entry into force of the WTO Agreement. However, if they chose to do so, they were required to put in place a means by which patent applications for such inventions could be filed so as to allow the preservation of their novelty and priority for the purposes of determining their eligibility for protection by a patent after the expiry of the transitional period. In addition, they were required to provide also for exclusive marketing rights in respect of the products in question if those products obtained marketing approval during the transitional period, subject to a number of conditions."

- It should be borne in mind that there were other extremely important factors connected with patentability of pharmaceutical inventions which had led to the recognition of the "particularity" of this sector. In this connection, Otero Lastres ${ }^{338}$ had written that "[...] this industrial sector presents a number of peculiar characteristics which differentiated it from the others. Among the most important of these characteristics are the following:

(a) Firstly, it is a sector in which research plays a fundamental role, and this research, in its turn, has its own specific features worth mentioning. The first of these derives from the actual purpose of the research and the nature of the field involved. [...] The second lies in the organization of the scientific and technical research [...] The third of these features is the enormous human and economic effort that goes into obtaining a new drug. [...]. And the fourth and last feature is closely related to the others: pharmaceutical research requires a certain entrepreneurial scale. Indeed, this accounts for the clear trend towards concentration of enterprises in the countries in which pharmaceutical research takes place (see De Haas, p. 452). [...]

(b) Secondly, this sector is characterized by the "vulnerability" of chemical and pharmaceutical inventions to imitation. Once they are marketed, most of the new drugs may be copied at minimum cost by any enterprise with a certain amount of experience in the sector. This is due to the very nature of chemical or pharmaceutical products which, once they have been synthesized and their constituents established, tend to be easy to reproduce, as well as to the fact that the research companies themselves tend to publish their experiments and results in detail in order to improve the degree of acceptance of the product (see Gasoliba, pp. 52-53).

(c) Thirdly, the chemical and pharmaceutical sector has to operate in a market which presents certain peculiarities affecting the actual configuration of competition as well as the sales practices and product distribution circuits. Unlike in other sectors of the market, in which competition is based on price, in this sector competition revolves around innovation and product substitution: competition depends almost exclusively on the quality of the product. Thus, there is a causal relationship between investment in research and market leadership in the sector. To promote their sales, pharmaceutical companies depend on highly expensive advertising. Although pharmaceutical products are consumed by the general public, the advertising essentially targets doctors. This implies, on the one hand, that the advertising must be very technical, well-documented and highly specialized. At the same time, in order to inform specialists as precisely as possible of the qualities of the new product, the companies resort not only to technical publications, but also to medical visitors. And finally, the distribution circuits are unusual in that most pharmaceutical products are paid for by social security, which either purchases them for direct use in hospitals or finances the totality or a large part of the price of products acquired by its members.

${ }^{338}$ Otero Lastres, José Manuel. La patentabilidad de los productos químico-farmacéuticos, in "Hacia un nuevo sistema de patentes", Editorial Montecorvo, S.A., Madrid, 1982, pp. 147-152 
A very small portion of these products is purchased without any kind of financing by the general public. Now, the fact that social security is the main "customer" of pharmaceutical companies has a double impact on the price of pharmaceutical products: firstly, social security is involved in the formation of the selling price, and secondly it obtains a form of discount owing to the large volume of its purchases (see De Haas, pp. 9 and 10).

(d) The final particularity of the chemical and pharmaceutical sector is that it is subject to strict control by the public authorities. This control pursues two fundamental objectives and is determined by the importance of what is at stake: public health.

Since it is public health that is at stake, the authorities exercise strict control over the products. Only once a product has undergone a rigorous examination in which its properties are verified and it is shown not to have any harmful effects on health do the public authorities allow it onto the market. For the same reason, the price of the product is fixed by the authorities, who tend to be reluctant to raise it. This "blockage" effect on the price of the product while manufacturing costs continue to increase (raw materials and labour in particular) causes profits gradually to decline, sometimes disappearing altogether. In order to avoid this, pharmaceutical laboratories are obliged to replace old products with new products, many of which are of little real interest from the therapeutic point of view (see De Haas, p. 14)." On the same subject, Professor Fernández Novoa ${ }^{339}$ had written that "[t]he relationship between industrial property (essentially patents and trademarks) and the chemical and pharmaceutical sector has traditionally been complex, because the administrative system of sanitary authorizations interferes - to a greater or lesser extent - with the actual problems of industrial property. In the field of trademark law, the slow pace and the complexity of the administrative authorization procedure has an impact on the legal burden of using the trademark. In the field of patent law, the slow pace and complexity of the administrative authorization procedure for drugs has resulted in a significant shortening of the effective legal life span of the exclusive right to chemical and pharmaceutical inventions". In his text Brevet et Médicament en droit français et en droit européen, De Haas ${ }^{340}$ had written that "[t]he peculiarity [of the pharmaceutical industry] essentially lies in the organization of the pharmaceutical industry's scientific and technical research and in the organization of the distribution of its products". ${ }^{341}$ Further on, he had written that "[a]n examination of the procedural and substantive conditions governing the patentability of a drug invention leads us to the conclusion that if the drug presents, beyond any possible doubt, a peculiarity due to research and pharmaceutical use, there is no distinction between the law applicable to it and ordinary patent law, even if certain provisions have been taken to avoid errors of interpretation and to safeguard the interests of public health". ${ }^{342}$

As could be seen, the "peculiarity" of the pharmaceutical industry began with the actual process of research and development of new products and procedures, and extended through to the patent protection of its results and the exercise of the rights thus conferred. In particular, approval for marketing, although common to other products, was particularly

\footnotetext{
${ }^{339}$ Fernández Novoa, Carlos - Las tendencias actuales del derecho comunitario de patentes, in Jornadas CEFI, "Reflexiones sobre la protección de la investigación en el umbral del 2000" (28 April 1993), published by the Centro de Estudios para el Fomento de la Investigación (CEFI), Barcelona, 1993 Paris, 1981

${ }^{340}$ De Haas, Michel - Brevet et Médicament en droit français en droit européen, Librairies Techniques (LITEC),

${ }^{341}$ Ibid, pp. 4 and 5

${ }^{342}$ Ibid, p. 235
} 
different for pharmaceutical products, and directly influenced the rights of the holder in terms of their content, scope and exercise. ${ }^{33}$

\section{Article 28 (Rights Conferred)}

Article 28 was one of the key provisions as regards patent protection. It defined the rights conferred by a patent on its owner. Legal doctrine as well as most domestic legislations, in regulating the exercise of industrial property rights in general and the rights of the patent holder in particular, had always insisted on the negative nature of those rights in the sense that the ius prohibendi of the holder of the exclusive right was reflected first and foremost in the prohibition of third parties from using the protected subject-matter during the term of the patent. The TRIPS Agreement took this same approach when it stipulated that the right holder should have the exclusive right "[...] to prevent third parties without the owner's consent from the acts of: [...]". The actual legal logic underlying private rights ${ }^{344}$ implied the delimitation of legal action within the framework of civil law in the broad sense of the term.

Another distinctive characteristic of industrial property rights which was clearly recognized in the TRIPS Agreement was that, owing to the very nature of the intangibles that they covered, their legal effectiveness depended on their enforcement. Thus, Part III of the TRIPS Agreement (Enforcement of Intellectual Property Rights) was devoted to regulating the requirements to be included in the legislations of WTO Members to that end. But the notion of infringement (and risk of infringement) of intellectual property rights was closely linked to use in economic transactions (or genuine attempt at introduction into the market), with the non-bona fide intention of making a profit, of the subject-matter of the patent during its term. Without providing an exhaustive list, Cuba cited Article 44.1 (Injunctions), Article 45 (Damages) and Article 46 (Other Remedies) in support of its view.

According to Section 55.2 of the Canadian Patent Act, no one could, during the term of the patent, sell the subject-matter of the patent without being considered an infringer. What both subsections (1) and (2) sought was to ensure rapid competition in the market once the term of the patent had expired. One could not speak of economic injury or of payment of royalties in connection with acts that were not considered to be infringing, since the simple manufacture and storage of the product during the final part of the last year of the term of the patent did not in itself provide any direct guarantee, at that moment, for future competitors. They amounted to no more than preparation for introduction into the market, but did not involve, for example, advertising or acts of distribution which were decisive and essential to the building up of sales, and hence profits.

In further examining the Canadian laws currently in force, one could see that they even went beyond the TRIPS Agreement by protecting, in addition, the rights of pharmaceutical patent holders through the Patented Medicines (Notice of Compliance) Regulations, which ensured and enhanced the realization of the exclusive rights during the term of the patent.

- $\quad$ In the light of Articles 7 and 8.1 of the TRIPS Agreement, it was important to stress that the interpretation of the TRIPS Agreement could not be broken down into isolated elements. In particular, Articles 7 and 8 formed a framework for the implementation of the entire TRIPS Agreement which, although it appeared as a single text, was contained in the legislations of countries with differing economic and social realities and whose legal systems were obviously not identical either. This had clearly been recognized by the drafters of the

${ }^{343}$ Reference was made in this regard to the point made by the European Communities and their member States and reflected in paragraph 4.4 above, under the $3^{\text {rd }}$ indent.

344 "Recognizing that intellectual property rights are private rights" (Preamble of the TRIPS Agreement) 
Agreement, who had included, in Article 1.1, a sentence which was the key to any attempt to understand the implementation of the TRIPS Agreement: "Members shall be free to determine the appropriate method of implementing the provisions of this Agreement within their own legal system and practice."

Any provision which, while ensuring the full and exclusive enjoyment of the rights of the patent holder during the entire term of the patent, at the same time favoured the dissemination of knowledge and the free use of subject-matter which, although previously protected, had fallen into the public domain, was, in the view of the Cuban Government, consistent with the provisions of the TRIPS Agreement, the more so if it favoured rapid access to drugs which could be vital to public health in conditions which guaranteed the end user the best possible price, presentation, composition or dosage. This seemed to be the case of Canadian patent law, since the rights of the patent holder were nowhere affected. This clearly emerged from the information contained in the information package prepared jointly by Industry Canada and Health Canada to provide factual background information for the review of the Patent Act Amendment Act, 1992 (Bill C-91) by the House of Commons Committee on Industry, Government of Canada, issued in February 1997. ${ }^{345}$ This document stated that "Canada's drug patent policy has three key objectives:

- $\quad$ to support the development of the pharmaceutical industry in Canada;

- $\quad$ to ensure patented drugs are available at non-excessive prices; and

- $\quad$ to ensure conformity with Canada's international obligations."

- $\quad$ All of these objectives were consistent with the TRIPS Agreement. Any other interpretation of Article 28 of the TRIPS Agreement would in fact involve an unjustified extension of the life of the patent with consequent effects on public health, and would affect the necessary balance between the right holders and the users of the knowledge.

\section{Article 30 (Exceptions to Rights Conferred)}

Article 30 authorized WTO Members to provide, in their domestic law, exceptions to the exclusive rights conferred by a patent. The Article did not state or give any example of what such exceptions could be, which was left within the discretionary power of Members. It only confined itself to stating that such exceptions had to be limited, in the sense that:

- $\quad$ they did not unreasonably conflict with a normal exploitation of the patent;

- $\quad$ they did not unreasonably prejudice the legitimate interests of the patent owner;

- $\quad$ they took account of the legitimate interests of third parties.

While, as the European Communities and their member States asserted, a violation of Article 27.1 of the TRIPS Agreement - or of any other Article - could not be justified under Article 30 of the TRIPS Agreement, it was clear that the drafting of this Article introduced elements that allowed considerable freedom to national law in the regulation of what these exceptions were to be and what their scope should be. Thus, for example, the TRIPS Agreement did not indicate when an exception conflicted with a normal exploitation of the patent, nor when it prejudiced the legitimate interests of the patent owner, but merely stated that it should not do so unreasonably, which meant that exceptions were legitimate if they were considered "reasonable". However, the qualification of "reasonable" was given by the 
national law, within its own framework, in accordance with Article 1.1 of the TRIPS Agreement.

When analysing this issue, Correa ${ }^{346}$ had stated that "[b]ased on comparative law and other proposals, the following exceptions may be provided for within the scope of Article 30:

acts done privately and on a non-commercial scale, or for a non-commercial purpose;

use of the invention for research;

experimentation on the invention to test it or to improve on it;

use of the invention for teaching purposes;

preparation of medicines under individual prescriptions;

prior use (use of the invention by a third party before the date of application for the patent);

experiments made for the purposes of seeking regulatory approval for marketing of a product after the expiration of a patent."

He cited the following example in a footnote: "[...] the US Drug Price competition and Patent Term Restoration Act permits to carry out testing to establish the bioequivalency of generic products before the expiration of the relevant patent. Its purpose is to help generic drug producers to place their products on the market as soon as the patent expires". ${ }^{34}$

- $\quad$ All this led Cuba to the views that, although Article 30 of the TRIPS Agreement sought to limit the exceptions to the rights conferred which it authorized for Members by imposing requirements of a legal nature to avoid undue prejudice, the lawfulness of such exceptions could only be judged in relation to the domestic law taking the broad view, and not in relation to the text of the Agreement itself. This did not in any way mean that Members did not have to comply strictly with the obligations stemming from the TRIPS Agreement, but it did allow great flexibility in the implementation of a proper balance between the interests of owners and those of third parties. One of the bases of the TRIPS Agreement, set out in its Preamble, stated:

"[...] Recognizing the underlying public policy objectives of national systems for the protection of intellectual property, including developmental and technological objectives $[\ldots] "$.

\section{Article 33 (Term of Protection)}

Article 33 of the TRIPS Agreement was quite clear in its wording, and did not in any way impose an obligation to extend the effects of a patent beyond its term of validity. The measures inferred from the Canadian patent legislation did not in any way affect the validity of the patent, which retained a term of protection that was in keeping with the TRIPS Agreement. The information provided by Canada concerning the patent linkage in its regulatory review process ${ }^{348}$ was good evidence of this, within a framework of mutual

${ }^{346}$ Correa, C.M. - Patent Rights. Offprint from "Intellectual Property and International Trade: The TRIPS Agreement". Kluwer Law International, 1998. Page 208.

${ }^{347}$ Op. Cit., page 208, footnote 46

${ }^{348}$ See paragraph 4.21 above, under (c), in combination with paragraphs 2.2 and following above. 
compensation and flexibility in the balance between the rights of owners and the general interest. The assertion that Canada only provided protection to pharmaceutical patents for a term of 19 years and six months was not strictly in keeping with what Canada's law stipulated, as it was based on certain acts that were not considered infringing in accordance with the domestic law. There was no evidence that patent owners were prevented from bringing actions against persons who infringed their rights throughout the term of validity of the patent.

5.19 In conclusion, Cuba stated that the provisions of Section 55 of the Canadian Patent Act were in keeping with the spirit and the letter of the TRIPS Agreement and were in no way discriminatory, nor nullified or impaired, directly or indirectly, any benefit accruing from the application of the WTO TRIPS Agreement. The TRIPS Agreement had, at all times, to be read and interpreted in such a way that the important objectives and principles it contained were not relegated to the background by the overriding application of any of its other provisions. Cuba therefore considered that all of Section 5 (Patents) of Part II (Standards Concerning the Availability, Scope and Use of Intellectual Property Rights) of the TRIPS Agreement, and in particular Article 27 (Patentable Subject Matter), in connection with Article 28 (Rights Conferred) under Article 30 (Exceptions to Rights Conferred), had to form a single interpretative concept in the light of the provisions of Article 1 (Nature and Scope of Obligations), Article 7 (Objectives) and Article 8 (Principles) of Part I (General Provisions and Basic Principles) of the TRIPS Agreement.

\section{INDIA}

5.20 India pointed out that, while its trade interest in the matter before the Panel was limited, it had substantial systemic interest in the case at hand. It would be wrong to assume that the matter before the Panel involved just the trade interests of the European Communities and their member States. The matter related to the more fundamental issue of the appropriate balance between private intellectual property rights and public policy objectives. The crux of this systemic issue was the balance in the TRIPS Agreement between the rights and obligations of the producers of technical knowledge on the one hand and the users of that knowledge on the other. Indeed the TRIPS Agreement was full of textual language that aimed to reconcile these two, sometimes conflicting, objectives. Thus, the Preamble of the TRIPS Agreement stressed the need to promote effective and adequate protection of intellectual property rights while, at the same time, underlining the need to ensure that measures and procedures to enforce intellectual property rights did not themselves become barriers to legitimate trade. Similarly, the Preamble also recognized the underlying public policy objectives of national systems for the protection of intellectual property rights including developmental and technological objectives. Again Article 7 of the TRIPS Agreement said: "The protection and enforcement of intellectual property rights should contribute to the promotion of technological innovation and to the transfer and dissemination of technology, to the mutual advantage of producers and users of technological knowledge and in a manner conducive to social and economic welfare, and to a balance of rights and obligations."

5.21 According to India, the central question before the Panel was therefore whether the provisions of Section 55.2(1) and 55.2(2) of the Canadian Patent Act were limited exceptions to the exclusive rights conferred by a patent within the meaning of Article 30 of the TRIPS Agreement. At issue was the question of balance in the TRIPS Agreement between exclusive rights conferred on the owner of a patent and recognized exceptions to those rights. Any tilting to the balance one way or the other would be a gross misinterpretation of the TRIPS Agreement and its objectives. This balance was of a fundamental, systemic importance for several countries including, in particular, developing countries.

5.22 It was India's view that the exceptions in the Canadian Patent Act were legitimate exceptions within the meaning of Article 30. Any other interpretation of Article 30 would alter the delicate balance in the TRIPS Agreement between the rights conferred on the owner of the patent and the legitimate interests of all those other than the patent owner. India therefore urged the Panel to find 
that the disputed measures in this case fully conformed with Canada's obligations under the TRIPS Agreement. In doing so, the measures at issue should be examined in the light of Article 30 of the TRIPS Agreement as well as in the light of societal interests and public policy objectives. It advanced the following arguments in support of its view:

Artic les 27 and 28 of the TRIPS Agreement conferred rights on the owner of a patent. Article 28 in particular, spelled out those rights as preventing third parties, not having the owner's consent, from the acts of making, using, offering for sale, selling, or importing the product, both in cases where the subject-matter of a patent was the product and, where the subject-matter of a patent was a process, the product obtained directly by that process. However, Article 30 provided exceptions to the exclusive rights conferred by Article 28 of the TRIPS Agreement. In effect, Article 30 clearly stated that "Members may provide limited exceptions to the exclusive rights conferred by a patent, provided that such exceptions do not unreasonably conflict with a normal exploitation of the patent and do not unreasonably prejudice the legitimate interests of the patent owner, taking account of the legitimate interests of third parties".

The question therefore was to ask whether the two provisions of Canada's Patent Act were exceptions to rights conferred within the meaning of Article 30 of the TRIPS Agreement. India understood subsection 55.2(1) of the Canadian Patent Act as an exception which was solely for uses reasonably related to the development and submission of information required under Canadian law for regulatory approval. Similarly, subsection 55.2(2) of the Canadian Patent Act was a stockpiling exception for articles intended for sale after the patent expired. Since the two exceptions were related it could be useful to take them in conjunction.

The language in Article 30 basically set out the following criteria if the exceptions to rights conferred were to be considered consistent with the TRIPS Agreement:

- $\quad$ the exception must be limited;

- $\quad$ the exception must not unreasonably conflict with a normal exploitation of the patent;

- $\quad$ the exception must not unreasonably prejudice the legitimate interests of the patent owner; and

- $\quad$ the exception must take into account the legitimate interests of third parties.

- $\quad$ Regarding the first criterion, it was India's view that both the regulatory review exception and the stockpiling exception by Canada were limited. In the case of the first exception, it was solely for uses reasonably related to regulatory approval. In the case of the second exception, it was limited to manufacture and stockpiling only and was confined to six months before the expiry of the patent period. Both the Canadian exceptions therefore were limited exceptions within the meaning of Article 30 of the TRIPS Agreement.

The second criterion provided that the exceptions must not unreasonably conflict with a normal exploitation of the patent. This necessitated two questions to be posed. First, did the two Canadian exceptions conflict at all with the normal exploitation of the patent? Secondly, if there was a conflict, was it unreasonable? But there was simply no doubt that by restricting them solely for uses reasonably related to the regulatory approval, Canada had made sure that there was no conflict with the normal exploitation of the patent, i.e. working it for commercial gain. Again, the fact that the stockpiling exception was limited to six months prior to the expiry of the patent was made in such a way that there was no conflict at all with 
the normal exploitation of the patent. As Canada argued correctly in its submission, where there was no conflict, the question of "unreasonableness" did not arise.

The next question was whether the two Canadian exceptions unreasonably prejudiced the legitimate interests of the patent owner. Once again, the two Canadian exceptions, in India's view, did not in any way unreasonably prejudice the legitimate interests of the patent owner. The legitimate interests of the patent owner, defined through commercial gain and protected during the term of patent protection, were fully safeguarded. It was true that the six month stockpiling exception could conflict with Article 33, but it was India's view that the legitimate interests of the patent owner were not prejudiced at all making it a valid exception under Article 30.

- The last criterion, that of taking into account the legitimate interests of third parties, was crucial from India's perspective. The term "third parties" referred to the society at large, consumers and others whose interests could be different from those of the patent owner. Article 30 explicitly provided that the interests of third parties had to be taken into account. If the Canadian exceptions were not there, it was obvious that the patent term would go well beyond the term of protection and the interests of third parties would be seriously prejudiced. In fact, the argument by the European Communities and their member States that their alleged losses had been calculated by taking into account the fact that, if there were no measures by Canada then the patent protection would virtually continue for two more years, was the best argument why the two provisions by Canada were fully valid. Patent protection was valid only for 20 years and not for 22 years. In fact, it could be argued that the Canadian measures were imperative if the interests of third parties were to be fully safeguarded. If the third parties' interests were not safeguarded, it would have serious repercussions on societal interests such as keeping drug costs down and strengthening competition - all of which was recognized in various provisions of the TRIPS Agreement, such as in Articles 7, 8, 40 and the Preamble. Indeed, as Canada had rightly pointed out, controlling the cost of drugs was a key developmental objective which was vigorously pursued in developing countries.

The European Communities and their member States had expressed the view that the exceptions in the Canadian Patent Act at issue applied exclusively to pharmaceutical products and might therefore be in violation of Article 27.1 of the TRIPS Agreement. The EC had hinted that the Canadian exceptions must therefore be extended to all fields in order to be in compliance with Article 27.1. India found it strange that exceptions, which under Article 30 must be limited in scope, were being criticized for being too limited in scope. India believed that, by being limited, the exceptions in question met both the spirit and the letter of the criteria set out in Article 30 of the TRIPS Agreement.

\section{ISRAEL}

5.23 Israel supported Canada's basic position in the dispute. Its view was that the provisions of the Canadian law at issue were essentially in compliance with the TRIPS Agreement and in particular with the Preamble and Articles 7, 8, 27, 28 and 30. The following arguments were put forward in this regard:

The Preamble of the TRIPS Agreement underlined the need to promote effective protection of intellectual property rights while at the same time ensuring that the measures found in the Agreement did not become barriers to legitimate trade. Additionally, the Preamble recognized the public policy objectives of national systems, including developmental and technological objectives. The spirit of the TRIPS Agreement, effectively codifying the delicate balance of the rights and interests achieved throughout the multilateral negotiations, was found in its Article 7. It included achieving a balance of the rights and 
obligations which were conducive to promoting technological innovation, provided it was in a manner which was also conducive to social and economic welfare. Article 8 embodied the principle of the Agreement and stated, inter alia, that, in formulating their laws, Members could adopt laws to protect health and nutrition, provided that such measures were consistent with the Agreement. The fact that the objectives and principles set forth in Articles 7 and 8 appeared in the body of the Agreement, rather than having them set forth in the more general language of the Preamble, emphasized their importance and status for purposes of resolving disputes and should serve as primary tools for interpretation of the Agreement.

The central issue at the heart of this dispute was whether the challenged provisions of the Canadian Patent Law were limited exceptions to the exclusive rights conferred by a patent within the meaning of Article 30 of the Agreement. It was submitted that the high costs of a comprehensive health care system, due in large part to expenditures on therapeutic drugs, had motivated a large number of Members to include the principle regarding health and nutrition as set out in Article 8 of the Agreement. Without the exceptions found in the Agreement, patent owners would be able to charge monopoly prices for their drugs and hence raise the drug costs for additional years causing strain on already strained health budgets. Encouraging and promoting the sale of generic drugs following the expiry of the patent monopoly, as evidenced in a number of countries, including those found in the European Union, was consistent with the objectives of the Agreement.

Without wishing to take a detailed position on the "stockpiling" provision found in subsection 55.2(2) of the Canadian Patent Act at this time, it was asserted by Israel that the basic legislative balance found in the Canadian patent law qualified as limited exceptions within the meaning of Article 30.

In conjunction with the principles found in Article 8, Article 30 of the Agreement granted Members the discretion to limit the full application of patent rights in light of the particular circumstances that prevailed in their respective jurisdictions, when social and economic welfare had to be considered. The provisions of the Canadian Patent Act at issue allowed patent owners complete freedom to exploit their rights throughout the full term of patent protection, leaving the monopoly of commercial exploitation and the exclusivity of economic benefits unimpaired for the life of the patent. The limited exceptions only affected the patent owner's commercial exploitation after the patent had expired. A situation whereby the patent owner's ability to, de facto, exploit his patent monopoly beyond the expiration of the monopoly, as intimated by the European Communities and their member States, would be disregarding the public policy principles inherent in Articles 29 and 33 of the Agreement, which encouraged free and open competition with the patent owner immediately upon expiry of the patent. Therefore, the Agreement did not require such greater protection beyond the patent term.

The scope of the patent monopoly required by the Agreement was defined by the interaction of Articles 27, 28 and 30 thereof. Articles 27 and 28, taken together, set forth the maximum borders of the exclusive rights of patentees, which might, however be reduced pursuant to Article 30, which empowered national legislatures to set limited exceptions to the maximum borders of exclusive rights, provided that such exceptions did not unreasonably conflict with a normal exploitation of a patent and did not unreasonably prejudice the legitimate interest of patentees and third parties.

The Canadian law preserved the patentee's exclusive rights subject to reasonable limited exceptions as permitted by Article 30 of the Agreement. The limited exception of making preparations for the post-expiration period did not unreasonably prejudice the patentee's legitimate interests, taking into account the legitimate interests of third parties, and did not interfere with the patentee's exclusive right to commercialization of the invention 
during the full patent term. Thus, these limited exceptions did not interfere with the exclusive right to commercialize the invention during the entire patent term, including the exclusive right to sell or license the patented invention. Indeed, these exceptions did not allow for competitors to commercially exploit the patented invention during the life of the patent. The exceptions were limited and took into account the countervailing legitimate interests of patentees and society as a whole and related to activities which would have commercial value only after expiration of the entire patent term.

Therefore, it was reasonable for Canada to recognize that delays inherent in regulatory approval processes could delay the availability of less expensive and more widely distributed generic drugs for the health and welfare of the Canadian public. Consequently, it was reasonable for Canada to permit limited pre-expiry use of patented drugs solely to allow generic drugs to be distributed immediately after patent expiry, as was expressed in Section 55.2(1) of the Canadian Patent Act.

\section{JAPAN}

5.24 Japan's position was that one of the contested Canadian measures, i.e. Section 55.2(1) of the Patent Act, was justified under Article 30 of the TRIPS Agreement, even if it came into conflict with the provisions of Articles 27, 28 and 33 thereof. Section 55.2(1) permitted activities solely for uses reasonably related to the development of information required for obtaining marketing approval for pharmaceutical products without consent of the patent owner during the patent term. However, Japan believed that the other Canadian measure, i.e. Section 55.2(2), was not justified under Article 30. Section 55.2(2) permitted activities aimed at the manufacture and storage of patented products without the consent of the patent owner within six months before the expiry of the patent. To illustrate the reasons for this position, Japan presented the following arguments on the interpretation of Article 30, without prejudice to its position on the interpretation of Articles 27, 28 and 33:

\section{Experiments or Research Aimed at Technological Development}

Members were allowed to provide exceptions to the exclusive rights conferred by a patent in respect of experiments or research regarding patented products under Article 30 of the TRIPS Agreement, if those activities were aimed at technological development. No problem would arise, in terms of the TRIPS Agreement, even if the effect of a patent were not extended to such cases.

Following the rules of treaty interpretation under Article 31 of the Vienna Convention on the Law of Treaties, it was necessary to analyse the ordinary meaning of the terms of Article 30 as applied to experiments or research aimed at technological development. By definition, such exceptions were "limited" in scope. They did not conflict with a normal exploitation of the patent. Nor did they unreasonably prejudice the legitimate interests of the patent owner.

As Canada had correctly argued, this interpretation was confirmed by the context of the TRIPS Agreement, which included its Preamble. In Japan's view, however, the fifth recital in the Preamble was the more pertinent to this case, reading: "Recognizing the underlying public policy objectives of national systems for the protection of intellectual property, including developmental and technological objectives."

- $\quad$ This point became clearer when one turned to the object and purpose of the TRIPS Agreement, which appeared in its Article 7. The patent system encouraged inventions by granting an exclusive right for a certain period to those who had disclosed their inventions to the public. At the same time, the patent system was aimed at contributing to industrial growth by giving third parties the opportunity to study freely the disclosed inventions. In other 
words, if a patent was extended not only to the prohibition of activities for the production, use or assignment of the products relating to the patent, but also to the prohibition of studying them through, inter alia, experiments/research aimed at developing new technology, the development of new technology would be strongly impeded.

Thus, the analysis of the object and purpose of the TRIPS Agreement confirmed that these experiments/research should be excluded from the subject to be covered by the effect of a patent, taking into account the legitimate interests of third parties. Such exclusions did not unreasonably conflict with a normal exploitation of the patent and did not unreasonably prejudice the legitimate interests of patent owners.

\section{Tests Aimed at Development of Information Required to Obtain Marketing Approval}

For similar reasons, tests aimed at the development of information required to obtain marketing approval should also be justified under Article 30 of the TRIPS Agreement.

The same analysis of the text and context as employed above applied to tests aimed at the development of information required to obtain marketing approval.

As regards the object and purpose of the TRIPS Agreement, one of the fundamental principles of the patent system was that any person was free to use the technology relating to a patent after the patent term had expired, resulting in benefits for the society as a whole. However, in some fields, including, inter alia, the field of pharmaceutical products, manufacturers were required to satisfy certain requirements prescribed in the relevant laws and regulations to put their products onto the market. In order to ascertain whether the requirements were fulfilled, the manufacturers needed to carry out certain tests. Therefore, if these tests were to be prohibited during the term of patent, such a prohibition would lead to an unexpected substantial extension of the patent term, upsetting the fundamental principle mentioned above.

Consideration of these factors confirmed the correctness of the interpretation that these tests should be excluded from the subject covered by the effect of a patent, taking into account the legitimate interests of third parties. In addition, such exclusion did not unreasonably conflict with a normal exploitation of the patent and did not unreasonably prejudice the legitimate interests of patent owners.

A recent decision by the Supreme Court of Japan was consistent with this interpretation of Article 30. What had been at issue was the provision of Article 69 of the Japanese Patent Law, which provided that "[t]he effects of the patent right shall not extend to the working of the patent right for the purposes of experiment or research". The Supreme Court had affirmed the judgement of the Osaka High Court that the use of a patented invention aimed at the development of information required to obtain marketing approval for pharmaceutical products, which could be carried out without the consent of the patent owner during the patent term, should be deemed to constitute "the working of a patented invention for the purposes of experiment or research" as specified in the provision referred to above.

The Manufacture and Storage of the Patented Products Without the Consent of the Patent Owner

- Unlike the two instances cited above, the manufacture and storage of patented products without the consent of the patent owner could not be justified under Article 30 of the TRIPS Agreement. 
- It went against the ordinary meaning of the terms of Article 30. If a third party was allowed, during the patent term, to manufacture or store the patented products to be put on the market immediately after the expiry of the patent, i.e. beyond the scope and quantity reasonably required for the tests referred to above, the legitimate interests of the patent owner would be seriously prejudiced without enhancing any public interest.

In other words, the manufacture and storage of the patented products without the consent of the patent owner for the purpose of putting the products on the market immediately after expiry of the patent term should be interpreted as prejudicing the legitimate interests of the patent owner and thus was not covered by the exceptions stipulated in Article 30 of the TRIPS Agreement.

\begin{abstract}
This reading was supported by a contextual analysis. In this regard, Canada had correctly referred to recital in the Preamble of the TRIPS Agreement indicating "the need to promote effective and adequate protection of intellectual property rights". Permitting unauthorized manufacture and storage would not serve this purpose. Unlike Canada, Japan did not believe that the object and purpose of the TRIPS Agreement supported justification under Article 30 of the manufacture and storage of patented products without the consent of the patent owner. On the contrary, the interpretation adopted by Canada would create a serious loophole in the patent regime, upsetting the carefully negotiated balance of interests between the patent owner and his/her competitors.
\end{abstract}

5.25 In conclusion, Japan stated that activities solely for uses reasonably related to the development of information required to obtain marketing approval for pharmaceutical products, carried out without the consent of the patent owner during the patent term, could be excluded from the subjects to be covered by the effect of a patent. Such activities as subsection 55.2(1) of the Canadian Patent Act excluded from the effect of a patent should be regarded as being justified under Article 30 of the TRIPS Agreement as amounting to an exception which was taking into account the legitimate interests of third parties properly and should not be regarded as amounting to an exception which unreasonably conflicted with a normal exploitation of the patent and unreasonably prejudiced the interests of the patent owner. However, activities, carried out without the consent of the patent owner within six months before the expiry of the patent, to manufacture/store the patented products for the purpose of marketing the products immediately after the expiry of the patent could not be justified under Article 30 of the TRIPS Agreement, because they should be considered beyond the appropriate scope of the conditions stipulated in Article 30 of the TRIPS Agreement.

5.26 Japan wished to emphasize that it attached great importance to reducing distortions and impediments to international trade through ensuring appropriate protection of intellectual property in WTO Members in accordance with the TRIPS Agreement. Japan's trade interests, as well as the systemic interests it had in the WTO regime, would be seriously affected if any measure in violation of the TRIPS Agreement were to remain unchecked. As this Panel was to address issues regarding the appropriate intellectual property protection in respect of pharmaceutical products in one of its major trading partners, Japan had a substantial interest in the proceedings and their outcome.

\title{
POLAND
}

5.27 Poland informed the Panel that it had accepted the TRIPS Agreement as part of the WTO Agreement on the understanding that Article 30 of the TRIPS Agreement allowed the so-called "Bolar exemption", as a justifiable exception to the rights conferred by a patent. Consequently, Poland's new draft Law on Industrial Property, which was under consideration in Parliament, included provisions allowing for such a "Bolar exemption" and Poland would expect the Panel to confirm the consistency of this approach with the provisions of the TRIPS Agreement. In Poland's view, to meet their obligation to protect public health, WTO Members could provide limited exceptions to the exclusive 
rights conferred by a patent. The so-called "Bolar exemption" was an exception to exclusive rights conferred by a patent and fell within the scope of Article 30. Even if it was in conflict with a normal exploitation of the patent and prejudiced the patent owner's legitimate interest, it did not do so in an unreasonable manner. Poland put forward the following points in support of its view:

The objectives which were taken into account during the negotiations of the TRIPS Agreement were included in the final text of the TRIPS Agreement. The first recital in the Preamble of the Agreement stated: "Desiring to reduce distortions and impediments to international trade, and taking into account the need to promote effective and adequate protection of intellectual property rights $[\ldots] "$. Another recital stated: "Recognizing the underlying public policy objectives of national systems for protection of intellectual property [...]". These recitals underscored the need to achieve a balance between the effective and adequate protection of intellectual property rights on the one hand and the objectives of public policy on the other.

It was the proper role of every Member to find a trade-off between these two competing goals. Social welfare and especially protection of public health had always been at the top of many Members' policy agenda. The importance of these two social concerns had been confirmed in the provisions of the TRIPS Agreement. Article 7, which laid down the main objectives of the TRIPS Agreement, explicitly referred to the societal and economic welfare: "The protection and enforcement of intellectual property rights should contribute to the promotion of technological innovation and to the transfer and dissemination of technology, to the mutual advantage of producers and users of technological knowledge and in a manner conducive to social and economic welfare, and to a balance of rights and obligations." On a proper reading of this provision, one could infer that reaching the aforementioned objectives in a manner which would be obstructive to the attainment of social and economic welfare could hardly be reconciled with the letter and spirit of the Agreement.

This conclusion could easily be corroborated by another provision of the Agreement, namely Article 8.1: "Members may, in formulating or amending their laws and regulations, adopt measures necessary to protect public health and nutrition, and to promote the public interest in sectors of vital importance to their socio-economic and technological development, provided that such measures are consistent with the provisions of this Agreement." Under this provision, in Poland's view, Members, acting in the pursuance of the above-mentioned goals, could, in full conformity with the Agreement, restrict exclusive rights of patent holders, provided that any restrictions so introduced respected the requirements set out in Article 30 of the Agreement. Another interpretation, disallowing the restrictions in question, would make this provision redundant and, hence, should be rejected.

The protection of public health was especially important in the context of patent protection for pharmaceutical products. Members should take it into account while providing for the protection of intellectual property rights. One of the priorities of the Polish Government was to ensure a proper level of public health protection. To achieve this aim, it was a vital necessity for Poland to protect the generic drug market from collapsing.

Members could promote the use of generic drug products by setting up conditions which allowed free competition among drug producers as soon after patent expiry as possible. As Poland's experience indicated, a monopoly was rarely conducive to the efficient allocation of economic resources. That was why the TRIPS Agreement provided for a time-limited, although generous, protection for exclusive rights of a patent owner. The meaning of this limitation was to pave the way for free competition to prevail in the marketplace in as short a period of time as possible. 


\begin{abstract}
This, in turn, should lead to a significant drop in prices of drug products at issue and, thus, to lower public health budget expenditures and/or a larger portion of the general public being covered by health programmes at the same level of budget outlays. Generic drugs were several times less expensive than patented ones. A replacement of such drugs by patented ones would lead to either the lowering of a proper level of public health protection or to reallocation of funds within the budget at the cost of other equally justified objectives. An alternative to that might be the increase of the budgetary deficit or an increase of taxation. These were both unacceptable in view of Poland's intention to join the single currency area the EURO area - of the European Union and of the generally approved tax reduction policy in Poland.
\end{abstract}

\begin{abstract}
Generic drug producers had to carry out experiments and tests required to obtain marketing approval for their products. It took several years to carry out these experiments and tests. If these tests were not allowed during the patent term, the term of effective patent protection of a drug would be much longer and, thus, would extend the period of restricted competition beyond the point at which two equally justified policy objectives met in a wellbalanced manner, i.e. the internalization of positive externality and the cost-effective protection of public health.
\end{abstract}

These views were in full consonance with the Resolution of the EU Parliament of 16 April 1996, which provided as follows: "Measures should be introduced which enable pharmaceutical companies to begin, in advance of patent or supplementary protection certificate expiry, such laboratory experiments and regulatory preparations as may be required only for the registration of the generic pharmaceuticals developed in the EU to be available on the market immediately, but only after the expiry of a patent or supplementary protection certificate for a proprietary product."

Finally, Poland stressed that the Panel Report in the present case would be one of the first reports concerning the patent provisions of the TRIPS Agreement and would be of great importance to all Members, both as a guidance to ensure international cohesion within a body of WTO-oriented national laws and regulations and as an attempt to resolve an issue of utmost economic significance, especially for countries with a strong generic sector.

\title{
SWITZERLAND
}

5.28 Switzerland agreed with the European Communities and their member States that Section 55.2 of the Canadian Patent Act and its implementing regulations were inconsistent with Articles 27.1, 28.1 and 33 of the TRIPS Agreement and could not be justified under Article 30 of the Agreement. It advanced the following arguments in support:

\section{General remarks on the patent system and the regulatory marketing system}

According to Article 33 of the TRIPS Agreement, countries must provide for a 20year term for patent protection from the date of application for a patent. Neither the patent application nor the grant of the patent meant, however, that the invention would be immediately used by the patent applicant, or respectively the patent owner, for commercial purposes.

The commercial use of the patented invention was delayed, in particular, when the product was subject to a mandatory governmental market approval. The actual duration for exploiting the patented invention was shortened due to the period elapsing from the date of the patent application and the market approval. If this period was too long, the result was a 
considerable inequality of treatment between inventions which were subject to a marketing approval and those which were not.

This problem was more evident in the field of pharmaceuticals. In the last decades, requirements for marketing approval had become more stringent with regard to clinical, toxicological and pharmacological tests. This had resulted in increasing the delay for the exploitation of the invention. The average duration for obtaining marketing approval could be eight to 12 years. The actual term of protection for the patent owner was therefore from eight to 12 years only.

The shortening of the actual period of protection not only represented a situation of inequality of treatment of pharmaceuticals vis-à-vis other products, but also had a disincentive effect on research activities. It was unchallenged that regulatory measures, based on objectives of health protection, penalized the patent owner, even more so if, in addition to high costs for the patent owner, they resulted in long waiting periods for compliance approval. In other fields of technology, not subject to long and complex regulatory approval, the patent owner could expect to fully enjoy the 20-year term of protection. It was therefore important that, in the field of pharmaceuticals - or any other field subject to analogous regulatory rules - the patent owner could fully enjoy the exclusive rights conferred during the rest of the protection term. This meant that, during the remaining time-period, he had to be able to enjoy his exclusive right to prevent others from using his invention without his consent.

- However, even this possibility was not fully satisfactory due to the fact that the research cost for a new drug was very high - some hundred millions of Swiss francs - and could not, in such a case, be recouped by the actual term of protection. For these reasons, a number of countries had provided for an extension of the 20-year patent term. In doing so, those countries had paid due attention to the various interests at stake, in particular the health costs containment considerations - i.e., drug prices and possible price increases - on the one hand and the R\&D objectives on the other hand. It should be said though that, even with an extension of the patent term, the actual total period of protection might range from 12 to 15 years, depending on the country. It did not fully cover the 20 -year period, whereas products not subject to market approval enjoyed a full term of protection. Nevertheless, this extension was generally considered as striking a fair balance. It helped the patent owner to recoup his $R \& D$ investments and, hence, gave him incentives for developing other new drugs, to the benefit of the advancement of science, of health protection and of social welfare.

\section{The Provisions of the TRIPS Agreement Invoked by the Parties to the Dispute}

\section{Article 27.1 of the TRIPS Agreement}

In order to fully grasp the meaning of the obligation under Article 27.1 that "patents shall be available and patent rights enjoyable without discrimination as to the field of technology", an analysis of all parts of Article 27.1 was useful.

\section{Meaning of the First Sentence of Article 27.1}

Under this provision, Members were obliged to provide patent protection for products and processes, provided they fulfilled three basic conditions: novelty, inventive activity (non-obviousness) and industrial application (usefulness).

- In meeting this obligation, Members were obliged not to discriminate as to fields of technology. In other words, in technological fields like pharmaceuticals, patents for both product and process inventions had to be available. 
The only exceptions foreseen were those contained in Article 27.2 and 27.3.

\section{Meaning of the Second Sentence of Article 27.1}

Under this provision, Members were obliged to provide for full availability and enjoyment of rights without any discrimination as to the place of invention. In other words, the fact that evidence of inventive activity originated in one WTO Member had to be accepted in the proceedings in another WTO Member.

- Secondly, Members were obliged to provide for full availability and enjoyment of rights without any discrimination as to whether products were imported or locally produced. This provision meant that importation of products covered by the patent to satisfy the needs of a local market amounted to exploitation of the invention.

And, thirdly, Members were obliged to provide for full availability and enjoyment of rights without any discrimination as to the field of technology. This requirement was a logical consequence of the obligation contained in the first sentence of Article 27.1 - i.e. the obligation to provide product and process patents in all fields of technology, as referred to above.

For all three obligations contained in the second sentence of Article 27.1, the only restriction or exception foreseen by that sentence was the transitional period during which developing countries and countries in transition could defer patent protection for products in certain technological fields, as well as the exclusions contained in Article 27.3 of the Agreement.

It appeared that Article 27.1 was drafted in a very clear way. The obligations contained therein were "absolute" - i.e. absolues in French - and the restrictions, if any, would have been expressly written down. For example, another wording would have been used, such as "Subject to the provisions of this Section (or Article 30) [...]" or "Without prejudice to the provisions of this Section (or Article 30) [...]". According to GATT/WTO practice regarding dispute settlement, "one of the corollaries of the 'general rule of interpretation' in the Vienna Convention is that interpretation must give meaning and effect to all the terms of a treaty. An interpreter is not free to adopt a reading that would result in reducing whole clauses or paragraphs of a treaty to redundancy or inutility". ${ }^{349}$ In the case before the Panel, it was not unreasonable to say that the wording was clear enough for Members to construe the obligations under Article 27.1 as being "absolute". Consequently, they applied to all the provisions of Section 5 of Part II of the TRIPS Agreement and were not limited to Article 27.1 itself, nor subordinated to the interpretation of another provision of Section 5. For example, the principle of non-discrimination applied also to Article 29 (obligation to disclose the invention): in other words, as an illustration, Members could not provide for more - or less - stringent rules on disclosure for patent applications in the field of foodstuffs or aircraft only (i.e. greater or lesser disclosure).

Rights available were those contained in Article 28.1 (Rights Conferred), Article 33 (Term of Protection) and other rights, such as the right to judicial review (e.g., in Articles 31, $32,41,62)$ and the right to be heard (e.g., Article 41). 


\section{Article 28 of the TRIPS Agreement}

Under Article 28.1, a patent shall confer on its owner exclusive rights, namely, where the subject-matter of the patent was a product, to prevent third parties not having the owner's consent from the acts of making, using, offering for sale, selling, or importing for these purposes that product. Where the subject-matter of the patent was a process, the patent owner shall have similar rights to prevent acts of using the process and of using, offering for sale, selling, or importing for these purposes at least the product obtained directly by that process. The acts enumerated in these provisions were self-explanatory.

In spite of its non-binding character, the WIPO Model Law for Developing Countries on Inventions could shed some light on the various situations covered by "exclusive rights". Article 135 of this Model Law defined "exploitation" as making, importing, offering for sale and use of the product as well as detaining the product for purposes of offering for sale, sale or use. ${ }^{350}$

To say that these exclusive rights conferred a monopoly on the patent owner was misleading. A patent was not, accurately speaking, a monopoly because it did not deprive the public of anything to which it was formally entitled.

\section{Article 33 of the TRIPS Agreement}

Article 33 of the TRIPS Agreement was self-explanatory. Reference was made to the comments above concerning the obligation to treat all fields of technology in a nondiscriminatory way. Article 33 appeared to be an "absolute" obligation for Members as well. Nothing in the wording allowed for a de jure curtailment or nullification of the 20-year term.

\section{Article 30 of the TRIPS Agreement}

Article 30 of the TRIPS Agreement was similar - not identical - to Article 13 of the Agreement regarding copyright, which reproduced the wording of Article 9(2) of the Berne Convention, and to Article 17 of the Agreement regarding trademarks. The three provisions contained variations as to the wording. As with the other provisions, Article 30 dealt with "minor reservations" where third parties had legitimate interests. Four requisites had been laid down in Article 30. In the course of the analysis of Article 30, it would be helpful to look at Article 13 - and hence to Article 9(2) of the Berne Convention.

First, the exceptions had to be limited, which corresponded to the wording "in certain special cases" in Article 13 (and Article 9(2) of the Berne Convention). In the field of copyright, one used to refer to private use or to exceptions for limited categories of users (e.g. blind people). It was quite interesting that the WIPO Guide to the Berne Convention ${ }^{351}$, while citing the criterion of personal and private use, specifically referred, in an example, to the absence of profit purposes. In the field of patents, WIPO's publications might be of some help as well. In spite of its non-binding character, the WIPO Model Law for Developing Countries on Inventions offered some thoughts on exceptions or limitations on exclusive rights. One exception which seemed to be not at all controversial was the research exemption. Article 136(1) of that Model Law read as follows: "The rights under the patent shall extend only to acts done for industrial or commercial purposes and in particular not to acts done only for scientific research. ${ }^{.352}$

\footnotetext{
${ }^{350}$ WIPO publication $\mathrm{N}^{\circ} 840,1979$, page 27

${ }^{351}$ WIPO publication $\mathrm{N}^{\circ} 615,1978$, paragraph 9.10

${ }^{352}$ Op. cit., page 28
} 
- $\quad$ It was interesting to note that the Model Law Commentary cited educational purposes and purely private purposes as exceptions. However, as noted, any industrial or commercial application of a scientific, educational or personal use violated the patent right. Indeed, the Model Law used the words "in particular". ${ }^{353}$ There were other exceptions possible, such as prior use; however, it sufficed, for the purposes of this analysis, that the provision mentioned the specific case of non-commercial use. This line of thinking was further confirmed by WIPO's "Intellectual Property Reading Material": "There are, in most laws, five exceptions to infringement of exclusive rights to use a patented product, namely: - where the use of the patented product is solely for purposes of scientific research and experiment; [...]". ${ }^{354}$

- $\quad$ Second, the exception must not unreasonably conflict with the normal exploitation of the patent. As explained above, normal exploitation included the exclusive right for the patent owner, inter alia, to prevent the infringement during the patent term. This right was at the core of the patent system; further, it was the justification of the legal obligation for innovators to disclose their inventions to the benefit of society instead of keeping them secret by having, as some sort of compensation, the right to prevent others from using their inventions for commercial purposes. The question arose as to when the normal exploitation of a patent was "unreasonably" limited. One could say that, in the case of products, the life of which was already curtailed for reasons other than the patent owner's will, permitting use of the patent without the latter's consent - e.g. in cases other than compulsory licences, dependent licensing and government use, or in very specific cases such as private or nonprofit research - constituted an "unreasonable" - i.e. unjustifiable - limitation of his rights.

- $\quad$ Third, the exception must not unreasonably prejudice the legitimate interests of the patent owner. Again, the explanations regarding Article 9(2) of the Berne Convention could be of some help. In sum, it was said therein that any use without the consent of the author was prejudicial per se, but the most important and difficult question was to determine whether it was unjustified. From the comments made in WIPO's Guide to the Berne Convention on the loss of opportunity to do business, for example, it was possible to draw the conclusion that such loss could be considered as unjustified and measures should be taken to compensate the copyright owner. ${ }^{355}$

Fourth, the legitimate interests of third parties must be taken into account. This condition could seem redundant, since it was quite obvious that Members had the obligation to take into account all interests at stake when they adopted a piece of legislation. This was the very purpose of the system of exceptions in the field of intellectual property. The main issue was whether there was a proper balance between the interests of the patent owner and those of third parties. This could only be answered in light of all circumstances of a situation and of all the instruments - legal, administrative and others - available to government authorities when adopting a measure.

\section{$\underline{\text { Relationship between Articles 27.1, } 28.1 \text { and } 30 \text { of the TRIPS Agreement }}$}

A literal reading of Article 30 - "exceptions to the exclusive rights conferred" allowed for limiting the linkage of this Article to Article 28.1 of the TRIPS Agreement only. The fact that Article 31 - as a limitation to the exclusive right - stood on its own also demonstrated that Article 30 was purported to deal with minor reservations and not with an overall exception. In most laws, provisions concerning exceptions immediately followed the provisions relating to "rights conferred by the patent" - or in provisions dealing with "infringements". The fact that its location in the TRIPS Agreement was not immediately next

\footnotetext{
${ }^{353}$ Op. cit., page 28, Section 136(1)

${ }^{354}$ WIPO Publication $\mathrm{N}^{\circ}$ 476, page 27, paragraph 2.104

${ }^{355}$ Op. cit., paragraph 9.3
} 
to Article 28 - i.e. it was separated by Article 29 - was coincidental. During the Uruguay Round, the concepts of "rights and obligations" had frequently been referred to when participants had discussed the content of the exclusive rights conferred on the patentee. In order to take into account the concerns and the political context, the location of Article 29 seemed logical. With regard to the systemic and legal structure, Article 30 should normally be located next to the provision on exclusive rights. These comments would confirm the "absolute" character of the non-discrimination obligation contained in Article 27.1 of the TRIPS Agreement; Article 30 could not be invoked to justify exceptions to the nondiscrimination principle under Article 27.1.

\section{Section 55.2 of Canada's Patent Act in the Light of Articles 27.1, 28, 33 and 30}

\section{Article 27.1}

In light of the analysis made above, in particular with regard to Article 27.1 of the TRIPS Agreement, Section 55.2 of the Canadian Patent Act and its implementing regulations were inconsistent with the second sentence of Article 27.1.

Canada had offered an interesting argument, according to which a strict respect of Article 27.1 would result in an incongruous situation: Canada would have to extend the same system - i.e. providing for the exceptions and allowing a six-month "immunity" period to third parties - to all other fields of technology. This reasoning was opposed and had to be reversed: if there were other fields the treatment of which was consistent with the letter and spirit of Article 27.1, then this treatment should be applied to the field of pharmaceuticals.

\section{Article 33}

Under Section 55.2(1), the permissible acts - with the exception of the act of stockpiling dealt with in Article 55.2(2) - were not limited in time. They could be performed without the consent of the right holder at any point in time during the 20 -year patent term. One might wonder whether all the benefits expected by the patent owner of the minimal term of protection were not nullified with such an exception based on regulatory procedures.

Section 55.2(2), which allowed for stockpiling, curtailed the mandatory minimum term of protection under Article 33. It clearly resulted in $191 / 2$ years of protection for pharmaceuticals compared to other products and was below the level required.

Following the comments made above regarding the inconsistency of the Canadian Patent Act with Article 27.1, one could also contend that Section 55.2 was inconsistent with the principle of non-discrimination as to fields of technology. If other fields were better "treated", that treatment should also apply to pharmaceuticals. Otherwise, the wording of Article 33 would have been different; it would have contained some reservation formulation. The patent term was one of the key issues during the negotiations; it was noteworthy that the negotiators did not concretize any such reservation in the provision. No other interpretation which resulted in lessening or circumventing that minimal level was possible.

Article 1.1 of the TRIPS Agreement allowed for more protection ("more extensive"), provided that such protection did not contravene the provisions of this Agreement. That provision did not say that Members could grant less protection where the provisions were clearly minimum mandatory standards. The patent term under Section 55.2 was below the required minimum level. 
- The Preamble of the TRIPS Agreement, cited by Canada, should be read in a different way: the phrase "measures and procedures to enforce intellectual property rights do not themselves become barriers to legitimate trade; [...]" referred to enforcement measures and procedures. The so-called "substantive norms" (as opposed - incorrectly from a systemic legal point of view but used as such by negotiators - to enforcement) were covered by the preceding phrase "effective and adequate protection of intellectual property rights". During the Uruguay Round negotiations, it had, indeed, been a well-founded fear that enforcement rules might be used to create barriers vis-à-vis the owners of intellectual property rights as well as third parties. ${ }^{356}$ Article 30 was a "substantive" norm and the enforcement argument was not relevant. What was at stake was more a matter of implementation of a TRIPS obligation by Members than an "enforcement" question.

\section{Articles 28.1 and 30}

- $\quad$ The comments made above in relation to Articles 27.1 and 33 of the Agreement should be sufficient to demonstrate the inconsistency of the Canadian Patent Act with the TRIPS Agreement. However, Canada's arguments in relation to Articles 28 and 30 should also be examined, in particular the health and competition concerns expressed.

Under the Canadian legislation, a third party was de jure allowed not only to use the patent owner's invention for experimentation - notably, for commercial purposes - but also to make the product and to stockpile it in any quantity. According to many laws and as described above, experimental use with commercial intent constituted a violation of the exclusive rights, not to mention the acts of making and stockpiling. However, the main question that had arisen was whether exceptions to the exclusive rights under Article 28.1 of the TRIPS Agreement like those in the Canadian Patent Act could be justified under Article 30 of the Agreement.

Canada had explained that "[i]t is not uncommon for the product development, application preparation and regulatory review process to take, in the case of an innovative drug, eight to 12 years and, in the case of a generic drug, three to six-and-a-half years". It had further affirmed that "[w]ithout the limited exceptions (particularly the regulatory review exception), patentees would benefit from an additional gratuitous and often lengthy period of de facto protection - equal to the time required for a competitor manufacturer to prosecute its application for regulatory approval - which is neither contemplated by domestic law nor required by TRIPS." This argument called for the following provisional comments: the patent owner was already penalized by the delay caused by authorization requirements (eight to 12 years). The generic competitor had to go through a procedure which could also be lengthy, although to a lesser degree (three to six-and-a-half years). If the practice in Canada was as described, the "additional gratuitous and often lengthy period of de facto protection" ranged from 15 to $191 / 2$ years of "de facto" protection. If one took the best-case scenario, 15 years of protection out of the minimal "absolute" requirement of 20 years was well below the expectations the patent owner could have vis-à-vis the protection granted by the TRIPS Agreement. However, these were mainly practical considerations. More important was, from a legal point of view, whether it was justified that the patent owner was again de jure or de facto penalized by having his exclusive rights cut out or curtailed during the patent term. It was therefore stressed that, as far as the patent owner was concerned, the penalty occurred twice.

356 This fear stemmed, inter alia, from the so-called "Section 337" case opposing the EC and the USA, which dealt, inter alia, with enforcement problems (BISD 36S/386). 
- $\quad$ With regard to Section 55.2(1), the European Communities and their member States were right in their analysis that the "interplay and cumulation of all these possibilities leads to a situation that very significant quantities of the products protected by a patent can be manufactured, imported and sold without the consent of the patent holder at any time during the patent term". One could wonder if it would not result in a measure equivalent to expropriation.

With regard to Section 55.2(2), the European Communities and their member States had also pertinently pointed out that "[t]he faculty is entirely unqualified in terms of the extent and volume of the use and [...] nor does the latter have any right to be informed of such unauthorized use of his invention [...]."

- Moreover, the six-month period chosen could be considered as arbitrary, although the argument put forward had been that it was purported to take into account the interests of the patent owner and third parties. Why not one month or five days before the expiry of the patent term? Other avenues could have been considered such as a facilitated or abridged procedure of authorization for the generic product. One should envisage a better and stricter application of competition rules if market access on fair terms by third parties was refused arbitrarily by the patent owner. The solution chosen for Section 55.2 appeared to be disproportionate in light of the obligations under the TRIPS Agreement.

An additional consideration was that the solution ignored the fact that the TRIPS Agreement had a wide gamut of legal measures for ensuring access to the use of the patented invention during its term of protection. Without considering that compulsory licensing was the adequate solution in terms of efficiency, one could cite Article 31 of the TRIPS Agreement as containing possibilities for a fair competitor to enter the market on fair terms: for example, by a request for voluntary licences on "reasonable commercial terms and conditions and $[\ldots]$ within a reasonable period of time"; by a request for licences in case of anti-competitive business practices.

5.29 Switzerland further pointed out that, as a country active in trade and R\&D activities, Switzerland had serious concerns that its trade and systemic interests in the WTO multilateral system would be seriously affected if any measure inconsistent with the letter and spirit of the TRIPS Agreement were to remain unchecked. Research-based industry as well as generic industry were both important in Switzerland. It paid particular attention not only to innovative activities but also to health problems. As in all countries of the world, Switzerland was faced with the quest for new molecules to more efficiently combat new and existing diseases and for new strategies to contain health costs. For example, the need to give proper balance between $R \& D$ objectives on the one hand and health costs containment objectives on the other hand had been debated at the national level when the Supplementary Protection Certificate (that is to say a limited extension of the patent term) had been introduced.

\section{THAILAND}

5.30 In Thailand's view, the main issue of systemic concern in the present dispute was the preservation of the balance achieved at the conclusion of the Uruguay Round between the rights and obligations of patent owners on the one hand and those of third parties and the general public on the other, a balance that had been duly reflected in the text of the TRIPS Agreement. According to Thailand, the points at issue in this case were:

(a) whether Sections 55.2(1) and 55.2(2) of the Patent Act were "limited exceptions to the exclusive rights conferred by a patent" within the meaning of TRIPS Article 30; 
whether theses measures were consistent with the requirement of TRIPS Article 27.1 that patent rights be "enjoyable without discrimination as to the field of technology"; and TRIPS Article 33.

5.31 Thailand limited itself in its comments to addressing Section 55.2(1) of the Canadian Patent Act and argued that this provision was, in essence, a national measure permitting application for marketing approval for patented pharmaceutical products by a third party, during patent term, with the intent to commercially exploit the products after the expiry of the protection period, which amounted to a limited exception to the exclusive rights conferred by a patent within the meaning of Article 30 of the TRIPS Agreement and consistent with Article 33 of the Agreement. It advanced the following arguments in support:

Pharmaceutical products were, in their availability to the public, different from other products eligible for patent protection. Marketing approval for pharmaceutical products in a given country was usually a time-consuming and lengthy administrative process involving intensive research and development activities. It was therefore in the interest of the general public to allow this process to be initiated some time during the 20 -year protection period, so as to ensure that at the expiry of the said period any competing products could immediately enter the market. The increased number of competitors in the market would benefit the general public not only in bringing a drug's price down to an affordable level, but also in providing an incentive for competition conducive to quality products.

- $\quad$ The application for marketing approval - or the Drug Registration Application as termed by the relevant Thai legislation - could involve activities that affected the exclusive rights conferred by a patent to its owner under Article 28.1 of the TRIPS Agreement. National measures allowing such activities, however, were consistent with the TRIPS Agreement, if they fell within the exceptions provided for by Article 30 of the Agreement.

The exclusive rights conferred by a patent to its owner under Article 28.1 of the TRIPS Agreement were therefore subject to exceptions provided for by Article 30 of the Agreement. These exceptions could be provided by Members on the condition that they were limited, did not unreasonably conflict with a normal exploitation of the patent, did not unreasonably prejudice the legitimate interests of the patent owner, and took into account the legitimate interests of third parties.

In accordance with customary rules of public international law on treaty interpretation $^{357}$, Article 30 of the TRIPS Agreement was to be construed in accordance with the ordinary meaning to be given to its terms in their context. The context included, inter alia, the Preamble and Part I of the Agreement.

During the Uruguay Round negotiations, Thailand had made clear its understanding that protection of intellectual property rights must not undermine relevant legitimate trade, and that proper protection of public interest must also be ensured. Thailand had stated, in particular, that:

"[..] the enforcement procedures should lead to further liberalisation. They should not themselves become barriers or harassment to legitimate trade [...];"

\footnotetext{
${ }^{357}$ Article 31 of the Vienna Convention on the Law of Treaties
} 
and that:

"[...] the two fundamental goals pursued by Governments when granting intellectual property protection are the stimulation or encouragement of intellectual creation and the accord of proper and legitimate protection for public interest. It goes without saying that the former must not put undue burden on or adversely affect the latter." ${ }^{358}$

Thailand's thinking had been duly reflected in both the Preamble and Part I of the TRIPS Agreement. The Preamble provided, inter alia, "Desiring (...) to ensure that measures and procedures to enforce intellectual property rights do not themselves become barriers to legitimate trade;" and Article 7 described the objectives of the Agreement as follows:

"The protection and enforcement of intellectual property rights should contribute to the promotion of technological innovation and to the transfer and dissemination of technology, to the mutual advantage of producers and users of technological knowledge and in a manner conducive to social and economic welfare, and to a balance of rights and obligations."

Article 8 stipulated:

"Members may, in formulating or amending their laws and regulations, adopt measures necessary to protect public health and nutrition, and to promote the public interest in sectors of vital importance to their socio-economic and technological development, provided that such measures are consistent with the provisions of this Agreement."

It was in this context that Article 30 was to be read and construed.

In this context, Members could therefore introduce, as an exception under Article 30, a national measure permitting, during the patent term, activities related to an application for marketing approval for a patented pharmaceutical product with the intent to produce, sell or import the product after the expiry of the protection period. Only in this way could legitimate trade be ensured, public interest as well as social and economic welfare protected, and a balance of rights and obligations of all concerned - patent owners, competitors and consumers - achieved.

Such a national measure was also consistent with the requirements of Article 30:

(a) It was "limited" because restricted to a partic ular circumstance where a third party conducted activities in view of obtaining marketing approval from the relevant national authority.

(b) It did not "unreasonably conflict with a normal exploitation of the patent", and did not "unreasonably prejudice the legitimate interests of the patent owner", because the relevant applicant intended to commercially exploit the product only after expiry of the period of protection. It did not in any way derogate from the patent owner's ability to exploit his invention for the full term of patent protection. The patent owner could still enjoy the exclusive rights to produce, sell or import the patented products for a full period of 20 years regardless of the measure. 
(c) It took account of the legitimate interests of third parties, which in this case included consumers and the general public.

Under the TRIPS Agreement, a patent owner was granted a monopoly in return for his/her contribution to the development of technology by his/her creation or invention. The monopoly was granted by way of a patent and should last for a finite period. After such a period, the creation or invention should enter the public domain and be free for everybody to exploit. In cases such as that of pharmaceutical products, if application for marketing approval was to be initiated only after the expiry of the protection period, the entry of competing products on the market would then be delayed for a considerable amount of time. This went against public interest in any given country to have adequate supply of up-to-date pharmaceutical products at competitive prices and within a reasonable period of time after the relevant patent expired.

Consequently, not only was such a national measure consistent with Article 33 of the TRIPS Agreement, but also, and above all, to defer the beginning of the application process until after the expiry of the protection period would amount to extending the monopoly of the patent owner beyond the 20-year protection term, and therefore violate Article 33 itself.

\section{UNITED STATES}

5.32 According to the United States, the present dispute presented extremely important issues regarding core provisions of the TRIPS Agreement. The United States had chosen to participate as a third party in the dispute, because it had a substantial trade interest in the Canadian pharmaceutical market affected by the patent legislation challenged by the European Communities and their member States. In 1998, the United States had exported to Canada over US $\$ 1.3$ billion in pharmaceutical products, and imported products worth US $\$ 648$ million. The United States also had a broad systemic interest in the proper interpretation of the TRIPS provisions at issue.

5.33 In the view of the United States, the Panel should, in considering the two distinct exceptions under Canadian patent law to the exclusive rights conferred by a patent - both of which fell under Section 55.2 of the Canadian Patent Act - challenged by the European Communities and their member States, keep in mind the basic purposes of the patent system and the background of the regulated pharmaceutical industry. The United States identified these purposes and background as follows:

Patent systems encouraged innovation by granting inventors certain exclusive rights for a limited period of time in exchange for disclosure of the invention. They provided incentives to invest in research and development by preventing competitors from free-riding off such investments, and thereby ensuring that inventors had an opportunity to recoup their investments. They also enlarged public knowledge through disclosure, which facilitated further improvements in the technology and public use of the invention after the patent expired.

The pharmaceutical industry operated in a highly regulated market in which the interaction of stringent regulatory requirements, such as obtaining pre-market approval, with the patent system was complex and had important consequences. Regulatory authorities generally required that new pharmaceutical products be proven safe and effective before they could be commercially marketed. It commonly took many years for innovative pharmaceutical companies to satisfy these regulatory requirements for new drugs. The result was that an innovator company often suffered a significant reduction in the effective period of exclusive rights provided by the patent due to the inability of the company to market the product prior to its approval. On the other hand, the regulatory process for generic 
pharmaceuticals also took time to complete, and could delay effective competition with a pharmaceutical product coming off patent significantly beyond the time that it would normally take for a competitor to begin manufacturing and distribution. Governments maintaining these regulatory regimes for pharmaceuticals could seek to ensure that the regimes did not interfere with the incentives provided by the patent system for the creation of new pharmaceuticals, or with effective generic competition after the term of patent protection had ended.

5.34 The United States expressed the view that a properly crafted "pre-expiration testing"1359 exception was a reasonable exception to the exclusive rights that WTO Members were required to provide under Article 28 of the TRIPS Agreement, and was justified under Article 30 of the Agreement. By contrast, the United States did not believe that an exception to patent rights for "stockpiling" ${ }^{1360}$ could be similarly justified.

5.35 As a preliminary matter, the United States observed that, as the complaining party alleging a violation of the TRIPS Agreement, the European Communities and their member States had the burden of proving the inconsistency of Canadian law with Articles 28, 33 and 27. By contrast, the burden of proving the applicability of an exception under Article 30 should fall on the party invoking the exception - in this case, Canada. This standard was in accord with the Appellate Body reports in United States - Standards for Reformulated and Conventional Gasoline ${ }^{361}$, and United States Measures Affecting Woven Wool Shirts and Blouses from India. ${ }^{362}$

5.36 The United States advanced the following arguments in support of its views on the substantive issues before the Panel: ${ }^{363}$

\section{(1) ARTICLES 28 AND 30 OF THE TRIPS AGREEMENT}

Article 28 of the TRIPS Agreement was relatively straightforward; it required that product patents conferred on their owners five exclusive rights, i.e. the exclusive right to prevent third parties from making, using, offering for sale, selling or importing the patented product without the owner's consent. In addition, patent owners must have the right to assign the patent, or transfer it by succession, and to conclude licensing contracts. The primary issue in the dispute, however, was the applicability of Article 30, as Section 55.2(1) and (2) of the Canadian Patent Act clearly represented exceptions to the exclusive rights of patent holders.

- $\quad$ Article 30 set out several criteria that defined the scope of permissible exceptions. The application of these criteria required a fact-intensive analysis that took into account all the circumstances of each case. The plain text allowed exceptions to exclusive patent rights only where they were:

limited;

359 The United States used the term "pre-expiration testing" as shorthand for activities designed to develop information required for domestic regulatory purposes.

360 The United States used the term "stockpiling" as shorthand for the manufacture and storage of patented products for sale after the patent expired.

${ }^{361}$ WT/DS2/AB/R, p.22

${ }^{362}$ WT/DS33/AB/R, p.16

${ }^{363}$ The United States referred to the Appellate Body's decision in India - Patent Protection for Pharmaceutical and Agricultural Chemical Products (WT/DS50/AB/R, p. 17) and Article 31 of the Vienna Convention and said that its arguments were based on the text, context, object and purpose of each of the provisions invoked by the parties, namely Articles 27, 28, 30 and 33 of the TRIPS Agreement. Article 31 of the Vienna Convention provided in part that "[a] treaty shall be interpreted in good faith in accordance with the ordinary meaning to be given to the terms of the treaty in their context and in the light of its object and purpose". See also United States - Standards for Reformulated and Conventional Gasoline (WT/DS2/AB/R, pp. 16-17). 
Article 30 also required that the legitimate interests of third parties had to be taken into account in determining whether these criteria were met. To take these third party interests into account in the analysis, the relevant third parties and their interests had to be identified, and the relationship between those interests and the limitation in question had to be examined.

The context of Article 30 included other exceptions in the TRIPS Agreement that provided WTO Members a certain amount of flexibility in implementing the relevant provisions of the Agreement. For example, Article 31 in the patent section of the Agreement represented another limitation on the exclusive rights of patent holders. Article 1.1 also emphasized flexibility, and provided that "Members shall be free to determine the appropriate method of implementing the provisions of this Agreement within their own legal system and practice".

The object and purpose of Article 30, as reflected in its text, was to allow certain exceptions to the exclusive rights conferred by a patent. The specific reference to the "legitimate interests of third parties" in Article 30 echoed another provision of the Agreement, which could be found in Part I, namely Article 7 and provided that the provisions of the Agreement were designed to result in mutual advantages to producers and users, and contribute to a balance of rights and obligations. The Agreement also envisioned that Members could adopt measures to serve a variety of public policy objectives, provided that, as stipulated in Article 8, such measures were consistent with the Agreement. It should be noted, however, that while Articles 7 and 8 could afford some insight into the object and purpose of Article 30, neither diminished the substantive obligations of the Agreement.

(a)

\section{"Pre-expiration Testing"}

\section{(i) Limited exceptions}

Under Article 30, WTO Members could provide only "limited" exceptions to the exclusive rights conferred by a patent. Article 30, thus, did not excuse a Member from providing all five exclusive rights, but merely permitted limited exceptions to be made to any one (or all) of those rights. The requirement that exceptions be limited precluded a Member from deciding, for example, that one of the exclusive rights was relatively unimportant, and therefore from providing only the other four exclusive rights. Moreover, the mere imposition of any kind of condition on the availability or scope of an exception did not convert it, automatically, into a "limited" one within the meaning of Article 30.

Properly crafted, a "pre-expiration testing" provision represented a limited exception to the exclusive rights of patent holders, if it was restricted to certain specific and welldefined activities linked directly to the stated purpose of the exception - to permit the development and submission of information required by domestic regulatory authorities.

Canada's "pre-expiration testing" exception limited, to a certain extent, three exclusive rights - the right to make, use and sell. It permitted third parties to engage in such activities without the authorization of the patent owner if, and only if, the purpose of the activity was to provide information required by regulatory authorities. It should be noted, however, that Canada's "pre-expiration testing" exception was not limited to acts by third parties to meet requirements imposed by Canadian regulatory authorities, but also shielded infringing acts that were done to satisfy the requirements of regulatory authorities of any country. 
The second criterion in Article 30 was the requirement that exceptions must not unreasonably conflict with a normal exploitation of the patent. Examining this factor required consideration of both the meaning of "normal exploitation", as well as "unreasonable conflicts".

Patent owners normally exploited their patents by taking those actions that they believed would most effectively generate economic value from their inventions. Such actions could range from prohibiting third parties from any use of the patented invention to exclusive licensing of the patent rights to one entity or to non-exclusive licensing to many entities.

Normal exploitation, however, was not unfettered exploitation. Exceptions and restrictions normally applied to the exploitation of patent rights. For example, an exception for experimental use was a part of many WTO Member's patent laws, and an early draft of the TRIPS Agreement had specifically listed "acts done for experimental purposes" as an example of the limited exceptions permitted to the exclusive rights conferred by a patent. ${ }^{364}$ The fact that patent owners' rights were normally limited in this fashion was significant, and courts in several WTO Members had concluded that "pre-expiration testing" activities performed by third parties to satisfy specific requirements imposed by that Member's regulatory authority fell within the experimental use exception. ${ }^{365}$

- Normal exploitation of a patent also took place during the patent term, and was unrelated to the governmental regulatory process. There was no provision in the TRIPS Agreement or the Paris Convention that would justify a claim for the enjoyment of patent rights beyond the term of the patent. Indeed, patent systems were designed to provide a limited term of exclusive rights in exchange for public disclosure of the invention. The disclosure of the invention ensured that the public would be able to fully exploit the patented invention after the term of exclusive rights ended. In many countries, actions by a patent owner to attempt to extend contractually the term of exclusive rights of a patent ranged from being inconsistent with patent policy to a violation of competition rules. ${ }^{366}$

For these reasons, the United States believed that a properly crafted "pre-expiration testing" exception was consistent with a normal exploitation of the patent. Thus, such an exception would not unreasonably conflict with the normal exploitation of the patent.

\section{(iii) Unreasonable prejudice to the legitimate interests of the patent owner}

- An analysis of the third criterion of Article 30 - "unreasonable prejudice to the legitimate interests of the patent owner" - first required the identification of such legitimate interests, and then consideration of whether any prejudice was unreasonable.

The grant of a patent conferred no legitimate interest in a period of market exclusivity that resulted solely from the operation of the government regulatory system. Government regulatory regimes imposing pre-market approval requirements for innovative and generic

\footnotetext{
${ }^{364}$ Status of Work in the Negotiating Group (MTN.GNG/NG11/W/76, p. 32)

${ }^{365}$ See, e.g., Klinische Versuche II, 1998 R.P.C. 423 (Germany); Otsuka Pharmaceutical Co., Ltd. v. Towa Yakuhin K.K., Case No. 1998(ju)12 (Supreme Court, Apr. 16, 1999) (Japan). But cf. Roche Prod. Inc. v. Bolar Pharmaceutical Co., 733 F.2d 858 (Fed. Cir.), cert. denied, 469 U.S. 856 (1984) (United States)

${ }^{366}$ See Scott Paper Co. v. Marcalus Co., 326 U.S. 249, 256 (1964) ("[A]ny attempted reservation or continuation in the patentee $[\ldots]$ of the patent monopoly, after the patent expires, whatever the legal device employed, runs counter to the policy and purpose of the patent laws."); Brulotte v. Thys Co., 379 US 29 (1964); Patent Licensing Transactions, Matthew Bender \& Co., ch. 5.05 (1998) (citing prohibitions in the European Communities, Japan and Korea)
} 
drugs were enacted to protect the health and safety of the public, and not for the purpose of altering the effective term of protection provided by a patent (e.g., by delaying the onset of competition after the expiration of the patent term). A delay in competition after expiration of the patent, which occurred purely as an unintended consequence of government health and safety regulation, was not a right or benefit granted by the patent law or the TRIPS Agreement.

Given that patent holders had an interest in maintaining exclusivity of their rights to preclude third parties from making, using, offering for sale, selling and importing their invention, any exception at all to exclusive rights would technically "prejudice" some interest of the patent holder. For this reason, the key inquiry was whether the prejudice was unreasonable. The reasonableness analysis should begin by evaluating the extent to which the limitation interfered with the economic benefits that ordinarily would be realized by the patent holder during the patent term.

The European Communities and their member States did not argue that their right holders suffered any economic harm during the patent term. All of the damages referred to stemmed from the loss of market exclusivity that would otherwise result from operation of the regulatory process after the patent expired. The damage calculation performed by the EC was based on losses during a two-year period after expiration of the patent term during which - in the absence of a "pre-expiration testing" exception - the interaction of the patent and regulatory processes would keep competitors from marketing their products.

\section{(iv) Legitimate interests of third parties}

Article 30 specifically mandated that, in determining the scope of permissible exceptions, the Panel had to consider the legitimate interests of third parties. A close analysis of the text of the provision indicated that the interests of third parties were to be weighed in determining both whether any conflict with a normal exploitation of the patent was unreasonable, and whether the prejudice to the legitimate interests of the patent owner was unreasonable. In addition, the evaluation of reasonableness should incorporate some determination of whether the limitation addressed the identified third party interests.

Generic pharmaceutical companies had a significant third party interest in competing in the post-expiration pharmaceutical market, and thus had an interest in a "pre-expiration testing" exception. Such companies' interest was not limited to post-expiration competition, however, as they relied on the research-based pharmaceutical companies for a continuing supply of new products, and therefore also had a stake in an effective patent regime that fostered innovation.

- $\quad$ Similarly, consumers of patented medicines in a country allowing "pre-expiration testing" were also important third parties. They had interests not only in encouraging innovation and the development of new medicines, but also in encouraging competition in the domestic pharmaceutical market so as to take advantage of the best products at the lowest prices. A balanced "pre-expiration testing" exception for activities aimed at obtaining domestic regulatory approval (rather than foreign regulatory approval) addressed this legitimate interest.

WTO Member governments themselves were important third parties with similar priorities. They had a legitimate interest in the prices that they (and ultimately their taxpayers) paid as a consumer of pharmaceutical products through their national health and welfare programmes. Governments also had a legitimate interest in making sure that their regulatory processes did not unnecessarily increase the costs and impede the availability of safe medicines (whether pioneer or generic). This interest was limited to their own regulatory 
processes, however, as such governments had no interest in mitigating the impact on foreign consumers of foreign regulatory processes.

Fully taking into account the legitimate interests of these third parties in "preexpiration testing" required more than simply identifying those parties and their legitimate interests. It was also important to consider the magnitude of the effect on these parties if "pre-expiration testing" were not permitted. As mentioned above, the marketing of pharmaceutical products was tightly regulated in WTO Members for health and safety reasons, and pre-market approval requirements generally applied to the marketing of both innovative and generic pharmaceuticals. Even in countries such as the United States where abbreviated approval requirements applied to generic drugs, the process of obtaining regulatory approval to market a generic product could still take years. The process of formulating a generic product and conducting required bioequivalence and stability studies generally took at least one or two years. Then, after a generic company had completed these steps necessary to submit an application for marketing approval to the regulatory authorities, the regulatory approval process itself could take significant additional time.

If "pre-expiration testing" of generic drugs were not permitted to begin until after expiration of the patent on an innovative drug, the result would likely be a delay in market entry of the generic drug, and de facto extension of the exclusive rights conferred by the patent of at least two-and-a-half to three years and possibly longer. During this time, the legitimate interests of generic pharmaceutical manufacturers, consumers and governments in encouraging competition in the pharmaceutical market after expiration of a patent would be thwarted, even though the patent holder had no legitimate interest in continued enjoyment of its exclusive rights.

For all of these reasons, the United States believed that, in appropriate circumstances, Article 30 of the TRIPS Agreement permitted exceptions for "pre-expiration testing" of patented pharmaceuticals. Properly crafted, the exception was a limited one that, taking into account the legitimate interests of third parties, did not unreasonably conflict with the normal exploitation of patent rights, nor caused unreasonable prejudice to the legitimate interests of patent owners.

\section{"Stockpiling"}

In contrast to "pre-expiration testing", an exception allowing "stockpiling" raised distinct issues under Articles 28 and 30 of the TRIPS Agreement, and did not appear justified under the latter provision.

- $\quad$ First, a "stockpiling" exception was less limited than "pre-expiration testing". For the period during which it applied, it resulted in the abrogation of two of the five exclusive rights conferred by a patent (the exclusive rights to make and use). The only limitation imposed by Canada during the "stockpiling" period was the requirement that the "stockpiling" be done by the same person that took advantage of the "pre-expiration testing" exception - in other words, the patent holder's competitors. In reality, this limitation had little meaning, as it applied to the entire universe of parties that would be in a position to use the patented invention after the term expired.

There were other significant differences between "pre-expiration testing" and "stockpiling". "Pre-expiration testing" was necessary to mitigate the effect on post-expiration competition caused by government health and safety requirements. A "stockpiling" exception, however, did not address the time delay caused by the regulatory process, and was not limited to uses related to the regulatory process. Here, Canada's "stockpiling" exception allowed activity during the patent term merely to facilitate the avoidance by generic 
manufacturers of the normal manufacturing and distribution start-up time after patent expiration that was faced by all competitors of producers of all patented products.

Furthermore, a "stockpiling" exception was not necessary to ensure immediate market entry of generic drugs, and thus was not necessary to protect the interests of third parties. The United States was aware of no empirical evidence suggesting that the absence of the "stockpiling" authority would result in any significant delay in market entry for generic drugs. On the contrary, the United States understanding was that generic manufacturers that had obtained regulatory approval generally had the ability to manufacture and distribute large quantities of drugs very quickly after patent expiration.

Finally, on this point, the United States informed the Panel that it considered that the statements advanced by Canada regarding US FDA requirements and "stockpiling" were factually inaccurate and legally irrelevant. ${ }^{367}$ Canada had correctly acknowledged that United States law and Canadian law differed on this point, and the United States agreed notwithstanding Canada's citation of one US court decision, from a district court, which in turn cited only to the affirmations of the parties for its description of FDA requirements. Beyond noting the difference, the United States did not intend to address this point further or speculate on irrelevant and varied industry practices in the United States.

\section{ARTICLE 33 OF THE TRIPS AGREEMENT}

The United States believed that the EC's claim that Canada's "pre-expiration testing" and "stockpiling" exceptions violated Article 33 of the TRIPS Agreement was not wellfounded. Article 33 required WTO Members to ensure that the term of patent protection available should be no less than 20 years counted from the date of filing of the underlying patent application. Canada's patent law made available, for patents filed after 1 October 1989, a patent term of 20 years from the date of filing. Whether the rights conferred by the patent during that term were sufficient under the Agreement was a separate issue controlled by the provisions of Articles 28 and 30. Thus - although other provisions of Canada's patent law could raise concerns regarding Article 33 - the provisions at issue in this dispute did not.

\section{ARTICLE 27.1 OF THE TRIPS AGREEMENT}

The United States had two concerns in connection with Article 27.1 of the TRIPS Agreement, in particular concerning its requirement that patents be available and patent rights enjoyable without discrimination as to the field of technology.

(i) Canada's interpretation of the legal relationship between Article 27.1 and Article 30 of the TRIPS Agreement

The United States could not agree with Canada's interpretation of the legal relationship between Article 27.1 and Article 30 of the TRIPS Agreement. Nothing in the text of Article 27.1 or Article 30 implied that a WTO Member could apply exceptions to patent rights in a discriminatory fashion. Canada's interpretation was also at odds with the context, object and purpose of Article 27.1. Article 30 on its face permitted Members to provide "limited exceptions to the exclusive rights conferred by a patent". This provision was a derogation to Article 28, which also referred specifically to "exclusive rights". Canada had asked the question whether the term "patent rights" in Article 27.1 referred to the exclusive rights set out in Article 28, or to the rights provided in Article 28 as modified by Article 30. ${ }^{368}$

\footnotetext{
${ }^{367}$ See paragraph 4.21 above, under (b), $6^{\text {th }}$ indent.

${ }^{368}$ See paragraph 4.16 above.
} 
The choice presented by Canada was a false one - the "patent rights" referred to in Article 27.1 were the rights provided under a WTO Member's patent law.

Moreover, Canada's interpretation left a glaring question unanswered. If Article 27.1 applied to the rights in Article 28 as modified by Article 30, then why would it not also apply to the rights in Article 28 as modified by Article 31 concerning compulsory licensing? The text of Article 27.1 permitted no distinction between the exceptions to exclusive rights allowed under Article 30 and the exceptions allowed under Article 31. And as Canada had acknowledged $^{369}$, there was little doubt that the negotiators of Article 27.1 had intended to eliminate the practice of discriminatory compulsory licensing.

- Canada's interpretation of Article 27.1 would also violate fundamental precepts of treaty interpretation. With respect to exceptions to exclusive rights, it would make Article 27.1 redundant of Articles 28 and 30. No exception would violate Article 27.1 without also violating Article 28 and not being justified by Article 30 .

Canada had argued that it would be absurd and inconsistent with the context and object of Article 27.1 to require that exceptions to patent rights be applicable in a nondiscriminatory manner. While the United States did not agree that such an interpretation would be absurd, it was also not the case that every exception to patent rights had to apply to all fields of technology. In some circumstances, differential treatment could actually restore parity in the enjoyment of patent rights rather than resulting in discrimination.

(ii) The United States views on the interpretation of Article 27.1 of the TRIPS Agreement

Article 27.1 prohibited discrimination in the enjoyment of patent rights between fields of technology. The term "enjoyment" was not defined in the TRIPS Agreement or any other international intellectual property convention. The dictionary defined the term as to "have the use or benefit of (something pleasant or advantageous)". ${ }^{370}$ The benefits that flowed from a patent were affected not only by the exceptions allowed to patent rights, but also by other factors, such as the procedures concerning the acquisition, maintenance and enforceability of the rights. In short, the prohibition in Article 27.1 on the discrimination in the enjoyment of patent rights required consideration not only of the de jure exclusive rights provided under the law, but also the effective protection provided to the patent holder as a result of the patent.

- $\quad$ The analysis of "national treatment" in the panel report on Section $337^{371}$, provided guidance in approaching the discrimination analysis under Article 27.1. Based on the panel's analysis in that case, differential treatment was not necessarily treatment that was inconsistent with TRIPS requirements. Indeed, as the Section 337 report recognized, formally identical treatment of products could constitute discrimination, and in such a situation a WTO Member might be required to apply formally different treatment to ensure that there was no discrimination.

In the present dispute, the Panel should assess whether the aspects of the Canadian regime that applied differentially to pharmaceuticals effectively and consistently accorded less favourable treatment in the enjoyment of rights to pharmaceutical inventions, as compared to inventions in other fields of technology. In undertaking this analysis, the Panel should take into account the significant impact of the regulatory process on the enjoyment of

\footnotetext{
${ }^{369}$ See paragraph 4.17 above.

${ }^{370}$ The New Shorter Oxford English Dictionary, Lesley Brown (ed), v.1, 823 (1993)

${ }^{371}$ United States - Section 337 of the Tariff Act of 1930, BISD 36S/386, para 5.11
} 
patent rights in the pharmaceutical market, and the need to ensure that the regulatory process itself did not cause discrimination in the effective enjoyment of patent rights for pharmaceuticals.

Finally, it should be noted that a "stockpiling" exception could raise more serious issues under Article 27.1, because there was no connection between the special pharmaceutical regulatory process and "stockpiling". Every firm that sought to begin manufacturing a product to compete with an innovative product that was going off patent faced the same dilemma - the difficulty of selling competing products the instant that the patent expired because of the need to manufacture the products, which was not possible until after expiration of the patent term.

\section{INTERIM REVIEW}

6.1 The Panel's interim report was sent to the parties on 21 January 2000. On 28 January 2000 both the European Communities and Canada requested the Panel to review precise aspects of the interim report, in accordance with Article 15.2 of the Dispute Settlement Understanding. Neither the EC nor Canada requested a further meeting with the Panel. Canada, however, requested an opportunity to comment on the comments submitted by the EC. The Panel decided that both parties should be given an opportunity to submit further comments strictly limited to each other's comments, to be submitted no later than 3 February 2000. On 2 February, both the EC and Canada submitted further comments.

6.2 The following is a description of the comments made at the interim review stage, and the Panel's responses, as required by Article 15.3 of the DSU.

6.3 The EC made four comments in its first submission. First, in what is now footnote 434 to what is now paragraph 7.97, the EC pointed out that the text of the footnote attributed to it a position concerning the meaning of Section 55.2(1) of Canada's Patent Act that it had never taken. The Panel revised the text of the footnote to remove the erroneous attribution and made a similar revision to what is now paragraph 7.95 .

6.4 Second, in what is now paragraph 7.103, the EC pointed out that the Panel's description of the EC's characterization of the legislative proceedings leading to the enactment of Section 55.2(1) and 55.2(2) contained a qualification that was not part of the EC's characterization. The Panel revised the text to remove the qualification.

6.5 Third, the EC asked for clarification of several paragraphs of the interim report, but the paragraphs themselves were subsequently removed by the Panel in light of a clarification submitted by Canada, as described in paragraph 6.8 below. Removal of the paragraphs rendered the EC's question moot.

6.6 Fourth, the EC pointed out that the meaning of the final sentence of what is now paragraph 7.99 was unclear, and suggested a clearer form of expression. In its further comment responding to the EC comments, Canada objected to the wording of the correction suggested by the EC, which would have described Canada's representations about the meaning of the Canadian statute in question as an "undertaking". Canada pointed out that its Government was in no position to give undertakings about the eventual judicial interpretation of the statute, since it had no control over them. The Panel accepted the EC suggestion to clarify the sentence, and amended the paragraph accordingly, without describing Canada's representations as an "undertaking". 
6.7 Canada submitted two comments in its first submission. First, in what is now paragraph 7.1, Canada objected to a paraphrase of Article 33 of the TRIPS Agreement which it believed might have unwanted legal significance. The Panel agreed to substitute a text tracking the exact words of Article 33.

6.8 Second, Canada called attention to the Panel's interpretation of a statement made by Canada to the Panel explaining the meaning of Section 55.2(1) with regard to commercial disposition of patented goods manufactured during the term of the patent in order to meet testing requirements of the regulatory review process. Canada clarified the intended meaning of its statement in a way that made the Panel's initial interpretation of that statement incorrect. In its further comment responding to Canada's comments, the EC disputed the interpretation of Section 55.2(1) represented by Canada in its corrected statement. The Panel found Canada's interpretation of Section 55.2(1) more persuasive than the EC's interpretation. Accordingly, the Panel withdrew from the Report its discussion of the issue of consistency with the TRIPS Agreement raised by its original interpretation of the Canadian statement, and substituted footnote 404 to paragraph 7.45 below explaining how the issue had arisen and why the Panel had concluded that the Canadian law did not in fact present an issue of consistency with the TRIPS Agreement.

\section{FINDINGS}

\section{A. MEASURES AT ISSUE}

7.1 At issue in this dispute is the conformity of two provisions of Canada's Patent Act with Canada's obligations under the Agreement on Trade-Related Aspects of Intellectual Property Rights ("the TRIPS Agreement"). The two provisions in dispute, Sections 55.2(1) and 55.2(2) of the Patent Act, create exceptions to the exclusive rights of patent owners. Under Article 28.1 of the TRIPS Agreement, patent owners shall have the right to exclude others from making, using, selling, offering for sale or importing the patented product during the term of the patent. According to Article 33 of the TRIPS Agreement, the term of protection available shall not end before the expiration of a period of 20 years counted from the filing date of the application against which the patent was granted. Sections 55.2(1) and 55.2(2) allow third parties to make, use or sell the patented product during the term of the patent without the consent of the patent owner in certain defined circumstances.

\section{SECTION 55.2(1): THE REGULATORY REVIEW EXCEPTION}

7.2 Section 55.2(1) provides as follows:

"It is not an infringement of a patent for any person to make, construct, use or sell the patented invention solely for uses reasonably related to the development and submission of information required under any law of Canada, a province or a country other than Canada that regulates the manufacture, construction, use or sale of any product."

Section 55.2(1) is known as the "regulatory review exception". It applies to patented products such as pharmaceuticals whose marketing is subject to government regulation in order to assure their safety or effectiveness. The purpose of the regulatory review exception is to permit potential competitors of the patent owner to obtain government marketing approval during the term of the patent, so that they will have regulatory permission to sell in competition with the patent owner by the date on which the patent expires. Without the regulatory review exception, the patent owner might be able to prevent potential competitors from using the patented product during the term of the patent to comply with testing requirements, so that competitors would have to wait until the patent expires before they could begin the process of obtaining marketing approval. This, in turn, would prevent potential competitors from entering the market for the additional time required to complete the regulatory approval process, 
in effect extending the patent owner's period of market exclusivity beyond the end of the term of the patent.

7.3 Because of the regulatory review exception's importance to the pharmaceutical industry, the operation of the exception with regard to new pharmaceuticals was explained in some detail by the parties. Information supplied by Canada in the proceedings before the Panel on the process of regulatory approval in Canada for patented and generic drugs can be found in paragraphs 2.2 to 2.7 above and Annexes 3 and 4 to this Report. The information has not been contested by the European Communities. Since patent applications are generally filed as quickly as possible after the invention has been made, actual marketing of the patented product is frequently delayed for a certain period of time because time is required for development of the product in commercial form, after which additional time is required to complete the testing required for government approval. According to the information supplied by Canada, the process of development of the drug and regulatory approval for new patented pharmaceuticals normally takes approximately eight to 12 years. The long development and approval process means that, for most patented pharmaceuticals, the 20-year patent term results in an actual period of market exclusivity of only some 12 to eight years. After a pharmaceutical patent expires, it is common for other producers to enter the market supplying copies of the patented product at lower prices. These lower-priced copies, known as "generic" pharmaceuticals, often constitute a large part of the supply of pharmaceuticals in national markets. Generic pharmaceuticals must also comply with the government approval process. According to Canada's information, for generic producers the process of developing their version of the drug and obtaining regulatory approval takes approximately three to six-and-a-half years, with development taking some two to four years and the regulatory process itself one to two-and-a-half years. If none of the development process could be performed during the term of the patent, generic producers could be forced to wait the full three to six-and-a-half years after the patent expires before being able to enter the market in competition with the patent owner. To the extent that some development activity might be permitted, consistently with Article 30 of the TRIPS Agreement, under other exceptions such as the traditional exception for experimental use of the patented product, the delay in entering the market would be correspondingly less. The regulatory review exception in Section 55.2(1) would allow generic producers to complete both development and regulatory approval during the term of the patent, thus allowing them to enter the market as soon as the patent expires.

7.4 The structure of the generic pharmaceutical industry illustrates the actual operation of the regulatory review exception. Production of generic pharmaceuticals often involves a two-tier production arrangement. The firm that assembles and markets the final generic product often does not have the technological capacity/expertise or the commercial motivation to produce the so-called "active ingredient" - the chemical product that generates the desired medicinal effect. The active ingredient is thus often manufactured by a specialized producer of fine chemicals, and then sold to the generic producer which assembles the active ingredient with other agents to create the final product in a form that can be used by the ultimate consumer. In such cases, both producers must engage in conduct that, in the absence of a regulatory review exception, would be potentially infringing, if they are to satisfy the requirements of the regulatory review process - the fine chemical producer in developing, making and selling the necessary amounts of the active ingredient to the generic producer, and the generic producer in combining the various elements to make the final product and then demonstrating its safety, stability and effectiveness by appropriate tests. ${ }^{372}$ The regulatory review exception applies to these activities of both producers.

7.5 To qualify for exemption under Section 55.2(1), such activities by either fine chemical producers or generic producers must be "solely for uses reasonably related to the development and submission of information required" by any law, Canadian or non-Canadian, that "regulates the manufacture, construction, use or sale of any product". In answer to a question from the Panel,

372 The active ingredient may also be imported, for example from a producer located in a country where the product in question is not covered by patent protection. 
Canada stated that, although Canadian marketing regulations for generic producers did not require production runs to demonstrate the applicant's ability to maintain quality production in commercial volumes $^{373}$, the statute would allow either fine chemical manufacturers or generic producers to undertake such production runs if they were required by regulations in other countries.

7.6 With regard to the enforcement of these conditions, Canada explained that these exceptions were part of the general law of infringement, under which it is up to the patent owner to enforce his patent rights in a civil action for infringement. ${ }^{374}$ Patent owners who believed that actions by generic producers did not comply with the requirements of Section 55.2(1) would have to bring an infringement action against such conduct. ${ }^{375}$ Patent owners would merely be required to prove conduct inconsistent with the owner's exclusive patent rights, after which persons claiming the benefit of the Section 55.2(1) exemptions would then be required to prove their compliance with the conditions of that provision as a defence.

\section{SECTION 55.2(2): THE STOCKPILING EXCEPTION}

7.7 Section 55.2(2) of the Patent Act, which is referred to as "the stockpiling exception", reads as follows:

"It is not an infringement of a patent for any person who makes, constructs, uses or sells a patented invention in accordance with subsection (1) to make, construct or use the invention, during the applicable period provided for by the regulations, for the manufacture and storage of articles intended for sale after the date on which the term of the patent expires."

The provision allows competitors to manufacture and stockpile patented goods during a certain period before the patent expires, but the goods cannot be sold until the patent expires. Without this exception, the patent owner's right to exclude any person from "making" or "using" the patented good would enable the patent owner to prevent all such stockpiling.

7.8 The exception created by Section 55.2(2) does not become effective until implementing regulations are issued. The only regulations issued to date under the stockpiling exception have been regulations making the exception operative with regard to pharmaceutical products. The period during which pharmaceutical products can be made and stockpiled is six months immediately prior to the expiration of the patent.

7.9 The text of Section 55.2(2) gives permission only to "make, construct or use" the patented product for purposes of stockpiling. In answer to a question from the Panel, however, Canada has taken the position that the exception will be construed also to allow the "sale" of patented ingredients that have been ordered by a producer who is stockpiling the final patented product - for example, with regard to pharmaceuticals, sales by fine chemical producers of active ingredients ordered by the generic producer. ${ }^{376}$

${ }^{373}$ For the requirements under the Canadian marketing regulations, see Part C.08 of the Food and Drug Regulations, which Canada made available in the proceedings and which can be found in Annex 2 to this Report.

${ }^{374}$ See paragraph 4.20 above.

${ }^{375}$ Canada also called attention to the provisions of Section 55.2(4) of the Patent Act and the Patented Medicines (Notice of Compliance) Regulations, which establish a summary procedure that owners of a patent for a drug can use to prevent competitors seeking regulatory approval for a drug while comparing that drug with the patented drug from marketing their approved drug before the patent in question expires, if their drug infringes the patent or is covered by the patent claims but meets the conditions of Section 55.2(1).

${ }^{376}$ See footnote 49 above. 
7.10 The stockpiling exception is available only to persons who have invoked the regulatory review exception in Section 55.2(1). This limitation has the effect of limiting the exception to products that are subject to the kind of government marketing regulations referred to in Section 55.2(1). As a practical matter, only persons who have actually obtained regulatory permission to market such regulated products would be able to benefit from the stockpiling exception, because there would be no commercial advantage in having a stock of goods on hand when the patent expires unless one also has regulatory permission to sell those goods as of that date. Conversely, the stockpiling exception does complement the competitive effects of the regulatory review exception. Without the additional permission to stockpile during the term of the patent, competitors who obtain regulatory permission to sell on the day the patent expires would still not be able to enter the market on that day, because they would first have to manufacture a sufficient stock of goods.

B. CLAIMS OF THE PARTIES

7.11 The EC asked the Panel to find that Sections 55.2(1) and 55.2(2) of Canada's Patent Act are inconsistent with Canada's obligations under Articles 27.1 and 28.1 of the TRIPS Agreement and, to the extent that Section 55.2(2) violates Article 28.1, it is also inconsistent with Article 33 of the TRIPS Agreement. ${ }^{377}$

7.12 Canada argued that neither Section 55.2(1) nor Section 55.2(2) violate any of the three TRIPS provisions cited. With regard to the claimed violation of Article 28.1 of the TRIPS Agreement, Canada acknowledged that Sections 55.2(1) and 55.2(2) permit conduct that conflicts with the patent rights granted in accordance with Article 28.1, but Canada claimed that each of these two provisions is an exception authorized by Article 30 of the Agreement. With regard to the claimed violation of Article 27.1, Canada presented two defences: first, that Article 27.1 does not apply to measures authorized by Article 30 of the Agreement and second, that, even if Article 27.1 does apply to measures authorized by Article 30, the two provisions of the Patent Act in question do not discriminate in violation of Article 27.1. With regard to the claimed violation of Article 33, Canada maintained that Section 55.2(2) does not violate Article 33.

\section{PRINCIPLES OF INTERPRETATION}

7.13 The legal issues in this dispute primarily involve differences over interpretation of the key TRIPS provisions invoked by the parties, chiefly Articles 27.1, 30 and 33. The rules that govern the interpretation of WTO agreements are the rules of treaty interpretation stated in Articles 31 and 32 of the Vienna Convention. ${ }^{378}$ The starting point is the rule of Article 31(1) which states:

"A treaty is to be interpreted in good faith in accordance with the ordinary meaning to be given to the terms of the treaty in their context and in the light of its object and purpose."

The parties have submitted arguments on each of these elements, as well as further arguments based on subsequent practice by certain WTO Members, thus relying on Article 31(3)(b), which reads in relevant part as follows:

"There shall be taken into account, together with the context: (a) [...]; (b) any subsequent practice in the application of the treaty which establishes the agreement of the parties regarding its interpretation."

377 On each occasion that the EC refers to its claim that Section 55.2(2) violates Article 28.1 of the TRIPS Agreement, the EC describes the violation as a violation of "Article 28.1 together with Article 33". The precise meaning of this linking terminology was not explained. The Panel concluded that it was required to deal with the claimed violation of Article 28.1 as a separate issue, and that it should defer considering the Article $33 \mathrm{claim}$, and the exact meaning of the "together with" linkage until that issue actually presented itself.

${ }^{378}$ Vienna Convention on the Law of Treaties 1969, entered into force on 27 January 1980 
The parties have also advanced arguments based on the negotiating history of the TRIPS provisions in dispute. Negotiating history falls within the category of "Supplementary Means of Interpretation" and is governed by the rule of Article 32 of the Vienna Convention, which provides as follows:

"Recourse may be had to supplementary means of interpretation, including the preparatory work of the treaty and the circumstances of its conclusion, in order to confirm the meaning resulting from the application of Article 31, or to determine the meaning when the interpretation according to Article 31:

(a) leaves the meaning ambiguous or obscure; or

(b) leads to a result which is manifestly absurd or unreasonable."

7.14 The Panel noted that, in the framework of the TRIPS Agreement, which incorporates certain provisions of the major pre-existing international instruments on intellectual property, the context to which the Panel may have recourse for purposes of interpretation of specific TRIPS provisions, in this case Articles 27 and 28, is not restricted to the text, Preamble and Annexes of the TRIPS Agreement itself, but also includes the provisions of the international instruments on intellectual property incorporated into the TRIPS Agreement, as well as any agreement between the parties relating to these agreements within the meaning of Article 31(2) of the Vienna Convention on the Law of Treaties. Thus, as the Panel will have occasion to elaborate further below, Article 9(2) of the Berne Convention for the Protection of Literary and Artistic Works (1971) (hereinafter referred to as the Berne Convention) is an important contextual element for the interpretation of Article 30 of the TRIPS Agreement.

7.15 As a consequence of the extended context that has to be taken into account when interpreting provisions of the TRIPS Agreement, the Panel, in considering the negotiating history of the TRIPS Agreement, concluded that interpretation may go beyond the negotiating history of the TRIPS Agreement proper and also inquire into that of the incorporated international instruments on intellectual property.

D.

\section{BURDEN OF PROOF}

7.16 The legal issues in the present dispute turn primarily on questions of legal interpretation - the meaning of the TRIPS provisions under which the two provisions of Canada's Patent Act have been challenged. The basic facts pertaining to these issues of interpretation are essentially undisputed. However, a small number of factual issues have been raised with regard to the meaning of certain aspects of the Canadian law, and about the actual impact of that law in practice. Moreover, application of legal standards frequently involves mixed questions of law and fact, and disagreements over the application of such standards sometimes therefore involve disagreement over factual premises. To the extent that such factual disagreements do exist, rules pertaining to burden of proof are potentially relevant whenever the weight of the evidence does not permit conclusive judgements. As the Appellate Body put it in United States - Measure Affecting Imports of Woven Wool Shirts and Blouses from India ${ }^{379}$ :

"[...] it was up to India to present evidence and argument sufficient to establish a presumption that the transitional safeguard determination made by the United States was inconsistent with its obligations [...]. With this presumption thus established, it was then up to the United States to bring evidence and argument to rebut that presumption". 380

${ }^{379}$ Document WT/DS33/AB/R, pp. 13-16 (adopted 23 May 1997).

${ }^{380}$ In other contexts the Appellate Body has used the terms "prima facie case" instead of "presumption" (see EC Measures Concerning Meat and Meat Products (Hormones), WT/DS26/AB/R, paragraph 104). 
Similarly in the present case, it was the Panel's view that the EC bears the burden to present evidence and argument sufficient to establish a prima facie case that Canada has violated Articles 27.1, 28.1 and 33 of the TRIPS Agreement. It would be up to Canada to advance sufficient argument and evidence to rebut such a prima facie case. Canada has, for all practical purposes, conceded the violation of Article 28, because it has resorted to the exception of Article 30 of the TRIPS Agreement in this case. Since Article 30 is an exception to the obligations of the TRIPS Agreement, it would be up to Canada to demonstrate that the provisions of Sections 55.2(1) and 55.2(2) comply with the criteria laid down in Article 30. It is on this basis that the Panel approached the analysis of the claims submitted to it.

E. SECTION 55.2(2) (THE STOCKPILING EXCEPTION)

(1) APPLICATION OF ARTICLE 28.1 AND ARTICLE 30 OF THE TRIPS AGREEMENT

\section{(a) Introduction}

7.17 The Panel began by considering the claims of violation concerning Section 55.2(2), the socalled stockpiling provision. It began by considering the EC claim that this measure was in violation of Article 28.1 of the TRIPS Agreement, and Canada's defence that the measure was an exception authorized by Article 30 of the Agreement.

7.18 Article 28.1 provides:

\section{"Rights Conferred}

1. A patent shall confer on its owner the following exclusive rights:

(a) Where the subject-matter of a patent is a product, to prevent third parties not having the owner's consent from the acts of making, using, offering for sale, selling, or importing for these purposes that product;"

There was no dispute as to the meaning of Article 28.1 exclusive rights as they pertain to Section 55.2(2) of Canada's Patent Act. Canada acknowledged that the provisions of Section 55.2(2) permitting third parties to "make", "construct" or "use" the patented product during the term of the patent, without the patent owner's permission, would be a violation of Article 28.1 if not excused under Article 30 of the Agreement. The dispute on the claim of violation of Article 28.1 involved whether Section 55.2.(2) of the Patent Act complies with the conditions of Article 30.

7.19 The TRIPS Agreement contains two provisions authorizing exceptions to the exclusionary patent rights laid down in Article 28 - Articles 30 and 31. ${ }^{381}$ Of these two, Article 30 - the so-called limited exceptions provision - has been invoked by Canada in the present case. It reads as follows:

${ }^{381}$ The text of Article 31 reads as follows:

Article 31 - Other Use Without Authorization of the Right Holder: "Where the law of a Member allows for other use (footnote: "other use" refers to use other than that allowed under Article 30) of the subject matter of a patent without the authorization of the right holder, including use by the government or third parties authorized by the government, the following provisions shall be respected:

(a) authorization of such use shall be considered on its individual merits;

(b) such use may only be permitted if, prior to such use, the proposed user has made efforts to obtain authorization from the right holder on reasonable commercial terms and conditions and that such efforts have not been successful within a reasonable period of time. This requirement may be waived by a Member in the case of a national emergency or other circumstances of extreme urgency or in cases of public non-commercial use. In situations of national emergency or other circumstances of extreme urgency, the right holder shall, nevertheless, be notified as soon as reasonably practicable. In the case of public noncommercial use, where the government or contractor, without making a patent search, knows or has 


\section{"Exceptions to Rights Conferred}

Members may provide limited exceptions to the exclusive rights conferred by a patent, provided that such exceptions do not unreasonably conflict with the normal exploitation of the patent and do not unreasonably prejudice the legitimate interests of the patent owner, taking account of the legitimate interests of third parties."

7.20 Both parties agreed upon the basic structure of Article 30. Article 30 establishes three criteria that must be met in order to qualify for an exception: (1) the exception must be "limited"; (2) the exception must not "unreasonably conflict with normal exploitation of the patent" ${ }^{\text {"82 }}$; (3) the exception must not "unreasonably prejudice the legitimate interests of the patent owner, taking account of the legitimate interests of third parties". The three conditions are cumulative, each being a separate and independent requirement that must be satisfied. Failure to comply with any one of the three conditions results in the Article 30 exception being disallowed.

7.21 The three conditions must, of course, be interpreted in relation to each other. Each of the three must be presumed to mean something different from the other two, or else there would be redundancy. ${ }^{383}$ Normally, the order of listing can be read to suggest that an exception that complies with the first condition can nevertheless violate the second or third, and that one which complies with the first and second can still violate the third. The syntax of Article 30 supports the conclusion that an exception may be "limited" and yet fail to satisfy one or both of the other two conditions. The

demonstrable grounds to know that a valid patent is or will be used by or for the government, the right holder shall be informed promptly;

(c) the scope and duration of such use shall be limited to the purpose for which it was authorized, and in the case of semi-conductor technology shall only be for public non-commercial use or to remedy a practice determined after judicial or administrative process to be anti-competitive;

(d) such use shall be non-exclusive;

(e) such use shall be non-assignable, except with that part of the enterprise or goodwill which enjoys such use;

(f) any such use shall be authorized predominantly for the supply of the domestic market of the Member authorizing such use;

(g) authorization for such use shall be liable, subject to adequate protection of the legitimate interests of the persons so authorized, to be terminated if and when the circumstances which led to it cease to exist and are unlikely to recur. The competent authority shall have the authority to review, upon motivated request, the continued existence of these circumstances;

(h) the right holder shall be paid adequate remuneration in the circumstances of each case, taking into account the economic value of the authorization;

(i) the legal validity of any decision relating to the authorization of such use shall be subject to judicial review or other independent review by a distinct higher authority in that Member;

(j) any decision relating to the remuneration provided in respect of such use shall be subject to judicial review or other independent review by a distinct higher authority in that Member;

(k) Members are not obliged to apply the conditions set forth in subparagraphs (b) and (f) where such use is permitted to remedy a practice determined after judicial or administrative process to be anti-competitive. The need to correct anti-competitive practices may be taken into account in determining the amount of remuneration in such cases. Competent authorities shall have the authority to refuse termination of authorization if and when the conditions which led to such authorization are likely to recur;

(1) where such use is authorized to permit the exploitation of a patent ("the second patent") which cannot be exploited without infringing another patent ("the first patent"), the following additional conditions shall apply:

(i) the invention claimed in the second patent shall involve an important technical advance of considerable economic significance in relation to the invention claimed in the first patent;

(ii) the owner of the first patent shall be entitled to a cross-licence on reasonable terms to use the invention claimed in the second patent; and

(iii) the use authorized in respect of the first patent shall be non-assignable except with the assignment of the second patent.

382 The parties disagreed over whether this second condition also includes the final phrase of Article 30 - "taking account of the legitimate interests of third parties". For reasons explained below, the Panel found it unnecessary to resolve this disagreement.

${ }^{383}$ See United States - Standards for Reformulated and Conventional Gasoline, WT/DS2/AB/R, p. 23 (adopted 20 May 1996). 
ordering further suggests that an exception that does not "unreasonably conflict with normal exploitation" could nonetheless "unreasonably prejudice the legitimate interests of the patent owner". ${ }^{384}$

7.22 Canada argued that Section 55.2(2) complies with each of the three conditions of Article 30. The European Communities argued that Section 55.2(2) fails to comply with any of the three conditions. Both parties introduced their arguments with an analysis of the object and purpose of the TRIPS Agreement in this area, and then presented interpretations of the three Article 30 conditions in support of their positions.

\section{(b) Object and Purpose}

7.23 Canada called attention to a number of other provisions of the TRIPS Agreement as relevant to the purpose and objective of Article 30. Primary attention ${ }^{385}$ was given to Articles 7 and 8.1, which provide:

\section{"Article 7}

\section{Objectives}

The protection and enforcement of intellectual property rights should contribute to the promotion of technological innovation and to the transfer and dissemination of technology, to the mutual advantage of producers and users of technological knowledge and in a manner conducive to social and economic welfare, and to a balance of rights and obligations." (Italics added)

\section{"Article 8}

\section{Principles}

1. Members may, in formulating or amending their laws and regulations, adopt measures necessary to protect health and nutrition, and to promote the public interest in sectors of vital importance to their socio-economic and technological development, provided that such measures are consistent with the provisions of this Agreement."

7.24 In the view of Canada, the italicized text of Article 7 above declares that one of the key goals of the TRIPS Agreement was a balance between the intellectual property rights created by the Agreement and other important socio-economic policies of WTO Member governments. Article 8 elaborates the socio-economic policies in question, with particular attention to health and nutritional policies. With respect to patent rights, Canada argued, these purposes call for a liberal interpretation of the three conditions stated in Article 30 of the Agreement, so that governments would have the

\footnotetext{
384 The report of the drafting committee for Article 9(2) of the Berne Convention, from which this text was derived, concluded that measures not in conflict with "normal exploitation" could nonetheless prejudice the "legitimate interests" of the copyright owner. The report is quoted in paragraph 7.72 below.

${ }^{385}$ Attention was also called to the text of the first recital in the Preamble to the TRIPS Agreement and to part of the text of Article 1.1. The Preamble text in question reads:
}

"Desiring to reduce distortions and impediments to international trade, and taking into account the need to promote effective and adequate protection of intellectual property rights, and to ensure that measures and procedures to enforce intellectual property rights do not themselves become barriers to legitimate trade;" (emphasis added by Canada)

Part of the Article 1.1 text referred to reads:

"Members shall be free to determine the appropriate method of implementing the provisions of this Agreement within their own legal systems and practice." 
necessary flexibility to adjust patent rights to maintain the desired balance with other important national policies.

7.25 The EC did not dispute the stated goal of achieving a balance within the intellectual property rights system between important national policies. But, in the view of the EC, Articles 7 and 8 are statements that describe the balancing of goals that had already taken place in negotiating the final texts of the TRIPS Agreement. According to the EC, to view Article 30 as an authorization for governments to "renegotiate" the overall balance of the Agreement would involve a double counting of such socio-economic policies. In particular, the EC pointed to the last phrase of Article 8.1 requiring that government measures to protect important socio-economic policies be consistent with the obligations of the TRIPS Agreement. The EC also referred to the provisions of first consideration of the Preamble and Article 1.1 as demonstrating that the basic purpose of the TRIPS Agreement was to lay down minimum requirements for the protection and enforcement of intellectual property rights.

7.26 In the Panel's view, Article 30's very existence amounts to a recognition that the definition of patent rights contained in Article 28 would need certain adjustments. On the other hand, the three limiting conditions attached to Article 30 testify strongly that the negotiators of the Agreement did not intend Article 30 to bring about what would be equivalent to a renegotiation of the basic balance of the Agreement. Obviously, the exact scope of Article 30's authority will depend on the specific meaning given to its limiting conditions. The words of those conditions must be examined with particular care on this point. Both the goals and the limitations stated in Articles 7 and 8.1 must obviously be borne in mind when doing so as well as those of other provisions of the TRIPS Agreement which indicate its object and purposes.

\section{(c) "Limited Exceptions"}

7.27 Canada asserted that the word "limited" should be interpreted according to the conventional dictionary definition, such as "confined within definite limits", or "restricted in scope, extent, amount". Canada argued that the stockpiling exception in Section 55.2(2) is restricted in scope because it has only a limited impact on a patent owner's rights. The stockpiling exception, Canada noted, does not affect the patent owner's right to an exclusive market for "commercial" sales during the patent term, since the product that is manufactured and stockpiled during the final six months of the term cannot be sold in competition with the patent owner until the patent expires. By "commercial sales", Canada clearly meant sales to the ultimate consumer, because it acknowledged that sales of patented ingredients to producers engaged in authorized stockpiling is permitted. Thus, Canada was arguing that an exception is "limited" as long as the exclusive right to sell to the ultimate consumer ${ }^{386}$ during the term of the patent is preserved. In addition, Canada also claimed that the exception is further limited by the six-month duration of the exception, and by the fact that it can be used only by persons that have made, constructed or used the invention under Section 55.2(1).

7.28 The EC interpreted the word "limited" to connote a narrow exception, one that could be described by words such as "narrow, small, minor, insignificant or restricted". ${ }^{387}$ The EC measured the "limited" quality of the proposed exception by reference to its impact on the exclusionary rights granted to the patent owner under Article 28.1. Applying that measure, the EC contended that the stockpiling exception is not "limited" because it takes away three of the five Article 28.1 rights - the rights to exclude "making", "using" and "importing". ${ }^{388}$ The EC argued that the impairment of three out of five basic rights is in itself extensive enough to be considered "not limited". The EC further contended that limitation of the exception to the last six months of the patent term does not constitute a limited impairment of rights when six months is taken as a percentage of the 20-year patent term, and especially not when taken as a percentage of the actual eight to 12-year period of effective market

\footnotetext{
${ }^{386}$ The term is used here to include purchasers in the distribution chain to the ultimate consumer.

${ }^{387}$ EC Oral Statement at First Meeting, paragraph 52

${ }^{388}$ EC Rebuttal, paragraph 59
} 
exclusivity enjoyed by most patented pharmaceuticals. ${ }^{389}$ In addition, the EC noted, there was no limitation on the quantities that could be produced during this period, nor any limitation on the markets in which such products could be sold. Finally, the EC pointed out that no royalty fees are due for such production, and that the patent holder does not even have a right to be informed of the use of the patent. ${ }^{390}$

7.29 In considering how to approach the parties' conflicting positions regarding the meaning of the term "limited exceptions", the Panel was aware that the text of Article 30 has antecedents in the text of Article 9(2) of the Berne Convention. However, the words "limited exceptions" in Article 30 of the TRIPS Agreement are different from the corresponding words in Article 9(2) of the Berne Convention, which reads "in certain special cases". ${ }^{391}$ The Panel examined the documented negotiating history of TRIPS Article 30 with respect to the reasons why negotiators may have chosen to use the term "limited exceptions" in place of "in special circumstances". The negotiating records show only that the term "limited exceptions" was employed very early in the drafting process, well before the decision to adopt a text modelled on Berne Article 9(2), but do not indicate why it was retained in the later draft texts modelled on Berne Article 9(2). ${ }^{392}$

7.30 The Panel agreed with the EC that, as used in this context, the word "limited" has a narrower connotation than the rather broad definitions cited by Canada. Although the word itself can have both broad and narrow definitions, the narrower being indicated by examples such as "a mail train taking only a limited number of passengers ${ }^{1393}$, the narrower definition is the more appropriate when the word "limited" is used as part of the phrase "limited exception". The word "exception" by itself connotes a limited derogation, one that does not undercut the body of rules from which it is made. When a treaty uses the term "limited exception", the word "limited" must be given a meaning separate from the limitation implicit in the word "exception" itself. The term "limited exception" must therefore be read to connote a narrow exception - one which makes only a small diminution of the rights in question.

7.31 The Panel agreed with the EC interpretation that "limited" is to be measured by the extent to which the exclusive rights of the patent owner have been curtailed. The full text of Article 30 refers to "limited exceptions to the exclusive rights conferred by a patent". In the absence of other indications, the Panel concluded that it would be justified in reading the text literally, focusing on the extent to which legal rights have been curtailed, rather than the size or extent of the economic impact. In support of this conclusion, the Panel noted that the following two conditions of Article 30 ask more particularly about the economic impact of the exception, and provide two sets of standards by which such impact may be judged. ${ }^{394}$ The term "limited exceptions" is the only one of the three conditions in Article 30 under which the extent of the curtailment of rights as such is dealt with.

7.32 The Panel does not agree, however, with the EC's position that the curtailment of legal rights can be measured by simply counting the number of legal rights impaired by an exception. A very small act could well violate all five rights provided by Article 28.1 and yet leave each of the patent owner's rights intact for all useful purposes. To determine whether a particular exception constitutes a limited exception, the extent to which the patent owner's rights have been curtailed must be measured.

\footnotetext{
${ }^{389}$ Ibid, paragraph 60

${ }^{390}$ First Submission of the European Communities, paragraph 23

${ }^{391}$ Article 9(2) of the Berne Convention reads: "It shall be a matter for legislation in the countries of the Union to permit the reproduction of [literary and artistic] works in certain special cases, provided that such reproduction does not conflict with a normal exploitation of the work and does not unreasonably prejudice the legitimate interests of the author."

${ }^{392}$ See Annex 6 to this Report for the various drafts of what became Article 30 discussed in the Uruguay Round Negotiating Group on TRIPS.

${ }^{393}$ The Shorter Oxford English Dictionary at p. 1216

${ }^{394}$ The interpretation of the second and third conditions of Article 30 are explained under $F(1)(b)$ and (c) below.
} 
7.33 The Panel could not accept Canada's argument that the curtailment of the patent owner's legal rights is "limited" just so long as the exception preserves the exclusive right to sell to the ultimate consumer during the patent term. Implicit in the Canadian argument is a notion that the right to exclude sales to consumers during the patent term is the essential right conveyed by a patent, and that the rights to exclude "making" and "using" the patented product during the term of the patent are in some way secondary. The Panel does not find any support for creating such a hierarchy of patent rights within the TRIPS Agreement. If the right to exclude sales were all that really mattered, there would be no reason to add other rights to exclude "making" and "using". The fact that such rights were included in the TRIPS Agreement, as they are in most national patent laws, is strong evidence that they are considered a meaningful and independent part of the patent owner's rights.

7.34 In the Panel's view, the question of whether the stockpiling exception is a "limited" exception turns on the extent to which the patent owner's rights to exclude "making" and "using" the patented product have been curtailed. The right to exclude "making" and "using" provides protection, additional to that provided by the right to exclude sale, during the entire term of the patent by cutting off the supply of competing goods at the source and by preventing use of such products however obtained. With no limitations at all upon the quantity of production, the stockpiling exception removes that protection entirely during the last six months of the patent term, without regard to what other, subsequent, consequences it might have. By this effect alone, the stockpiling exception can be said to abrogate such rights entirely during the time it is in effect.

7.35 In view of Canada's emphasis on preserving commercial benefits before the expiration of the patent, the Panel also considered whether the market advantage gained by the patent owner in the months after expiration of the patent could also be considered a purpose of the patent owner's rights to exclude "making" and "using" during the term of the patent. In both theory and practice, the Panel concluded that such additional market benefits were within the purpose of these rights. In theory, the rights of the patent owner are generally viewed as a right to prevent competitive commercial activity by others, and manufacturing for commercial sale is a quintessential competitive commercial activity, whose character is not altered by a mere delay in the commercial reward. In practical terms, it must be recognized that enforcement of the right to exclude "making" and "using" during the patent term will necessarily give all patent owners, for all products, a short period of extended market exclusivity after the patent expires. The repeated enactment of such exclusionary rights with knowledge of their universal market effects can only be understood as an affirmation of the purpose to produce those market effects.

7.36 For both these reasons, the Panel concluded that the stockpiling exception of Section 55.2(2) constitutes a substantial curtailment of the exclusionary rights required to be granted to patent owners under Article 28.1 of the TRIPS Agreement. Without seeking to define exactly what level of curtailment would be disqualifying, it was clear to the Panel that an exception which results in a substantial curtailment of this dimension cannot be considered a "limited exception" within the meaning of Article 30 of the Agreement.

7.37 Neither of the two "limitations" upon the scope of the measure are sufficient to alter this conclusion. First, the fact that the exception can only be used by those persons who have utilized the regulatory review exception of Section 55.2(1) does limit the scope of the exception both to those persons and to products requiring regulatory approval. In regard to the limitation to such persons, the Panel considered this was not a real limitation since only persons who satisfy regulatory requirements would be entitled to market the product. In regard to the limitation to such products, the Panel considered that the fact that an exception does not apply at all to other products in no way changes its effect with regard to the criteria of Article 30. Each exception must be evaluated with regard to its impact on each affected patent, independently. Second, the fact that the exception applied only to the last six months of the patent term obviously does reduce its impact on all affected patented products, but the Panel agreed with the EC that six months was a commercially significant period of time, 
especially since there were no limits at all on the volume of production allowed, or the market destination of such production.

7.38 Having concluded that the exception in Section 55.2(2) of the Canadian Patent Act does not satisfy the first condition of Article 30 of the TRIPS Agreement, the Panel therefore concluded that Section 55.2(2) is inconsistent with Canada's obligations under Article 28.1 of the Agreement. This conclusion, in turn, made it unnecessary to consider any of the other claims of inconsistency raised by the European Communities. Accordingly, the Panel did not consider the claims of inconsistency under the second and third conditions of Article 30, the claim of inconsistency with TRIPS Article 27.1, and the claim of inconsistency with Article 33.

\section{F. $\quad$ SECTION 55.2(1) (THE REGULATORY REVIEW EXCEPTION)}

\section{(1) APPLICATION OF ARTICLE 28.1 AND ARTICLE 30 OF THE TRIPS AGREEMENT}

7.39 Both parties agreed that, if the regulatory review exception of Section 55.2(1) met the conditions of Article 30 of the TRIPS Agreement, the acts permitted by that Section would not be in violation of Article 28.1 of the TRIPS Agreement. Canada argued that Section 55.2(1) complies with each of the three conditions of Article 30. The European Communities argued that Section 55.2(1) fails to comply with any of the three conditions. We now turn to the respective arguments for applying these three Article 30 conditions to Section 55.2(1).

\section{(a) "Limited Exceptions"}

7.40 Canada's arguments pertaining to the "limited" character of the regulatory review exception of Section 55.2(1) started from the same premises as its arguments with regard to the "limited" character of the stockpiling exception of Section 55.2(2). Canada again asserted that the regulatory review exception of Section 55.2(1) can be regarded as "limited" because the rights given to third parties do not deprive the patent holder of his right to exclude all other "commercial sales" of the patented product during the term of the patent. As noted above when discussing this argument in relation to Section 55.2(2), Canada evidently intended the term "commercial sales" to refer to sales to the ultimate consumer, rather than sales by suppliers of ingredients. As before, Canada was taking the position that an exception is "limited" as long as the exclusive right to sell to the ultimate consumer during the term of the patent is preserved.

7.41 In the case of the regulatory review exception, however, Canada added two further arguments based on the negotiating history of Article 30 and on the subsequent practices of certain WTO Members. Canada pointed out that in 1984 the United States had enacted a regulatory review exception similar to Section 55.2(1) of Canada's Patent Act, known as the Bolar exemption". ${ }^{395}$ Canada asserted that the United States "Bolar exemption" was well known during the negotiation of Article 30, and that governments were aware that the United States intended to secure an exception that would permit it to retain its "Bolar exemption". Canada further asserts that it was known that the United States agreed to the general language of Article 30 on the understanding that the provision would do so. Canada called attention to subsequent statements by United States officials stating that "[O]ur negotiators ensured that the TRIPS Agreement permits the Bolar exemption to be maintained."1396

395 First Submission of Canada, paragraph 25. The US statute in question is 35 United States Code, Section 271(e). The statute was passed to reverse a federal court decision ruling that infringing conduct for the purpose of making submissions for regulatory approval was not excused by the "scientific use" exemption in US patent law, and could thus be prohibited by the patent holder (Roche Products Inc. v Bolar Pharmaceutical Co., Inc, 733 F.2d 858 (C.A.F.C. 1984)).

${ }^{396}$ First Submission of Canada, paragraph 105 and Exhibit 41, quoting letter of US Trade Representative Michael Kantor to Alfred B. Engelberg, 1 February 1996 
7.42 With regard to subsequent practice, Canada pointed out that after the conclusion of the TRIPS Agreement four other WTO Members (Argentina, Australia, Hungary and Israel) adopted legislation containing similar regulatory review exceptions, and that both Japan and Portugal adopted interpretations of existing patent law which confirmed exemptions for regulatory review submissions. ${ }^{397}$ Canada argued that these actions are subsequent practices by parties to the agreement, within the meaning of Article 31(3)(b) of the Vienna Convention, that confirm its interpretation that regulatory review exceptions are authorized by TRIPS Article $30 .{ }^{398}$

7.43 In arguing that the regulatory review exception was not "limited", the EC again focused on the extent to which that exception diminishes the patent owner's rights of exclusivity required by Article 28.1 of the TRIPS Agreement. The EC pointed out that Section 55.2(1) permits third parties to perform all five of the activities which the patent owner may otherwise exclude under Article 28.1. ${ }^{399}$ The EC acknowledged that the permission to conduct these activities was subject to the condition that the final purchaser of the patented product has the intention to use the product for supplying information to regulatory authorities, but the EC argued that the terms of Section 55.2(1) allowed "wide-ranging activities by a wide range of operators" and "infringing acts of a significant extent". ${ }^{400}$ The EC called particular attention to the fact that Section 55.2(1) authorizes the commercial sale of ingredients by fine chemical producers who often supply generic drug manufacturers with the ingredients needed to make test products. ${ }^{401}$ The EC also noted that regulatory requirements often require applicants or their suppliers to produce commercial quantities of drugs in order to demonstrate their ability to maintain the required level of quality at such production levels. ${ }^{402}$ The EC also stressed the fact that infringing activities are authorized at any time during the 20-year term of the patent. And finally, the EC called particular attention to the fact that Section 55.2(1) applied to regulatory submissions anywhere in the world, suggesting that the number and variety of such foreign regulatory procedures, as well as Canada's inability to supervise or influence them, would further enlarge the range of excluded activities permitted by this exception. ${ }^{403}$

7.44 In the previous part of this Report dealing with the stockpiling exception of Section 55.2(2), the Panel concluded that the words "limited exception" express a requirement that the exception make only a narrow curtailment of the legal rights which Article 28.1 requires to be granted to patent owners, and that the measure of that curtailment was the extent to which the affected legal rights themselves had been impaired. As was made clear by our conclusions regarding the stockpiling exception, the Panel could not accept Canada's contention that an exception can be regarded as "limited" just so long as it preserves the patent owner's exclusive right to sell to the ultimate consumer during the patent term.

7.45 In the Panel's view, however, Canada's regulatory review exception is a "limited exception" within the meaning of TRIPS Article 30. It is "limited" because of the narrow scope of its curtailment of Article 28.1 rights. As long as the exception is confined to conduct needed to comply with the requirements of the regulatory approval process, the extent of the acts unauthorized by the right holder that are permitted by it will be small and narrowly bounded. Even though regulatory approval processes may require substantial amounts of test production to demonstrate reliable manufacturing, the patent owner's rights themselves are not impaired any further by the size of such production runs, as long as they are solely for regulatory purposes and no commercial use is made of resulting final products. $^{404}$

\footnotetext{
${ }^{397}$ First Submission of Canada, paragraphs 109-117

${ }^{398}$ See paragraph 7.13 above.

${ }^{399}$ First Submission of the European Communities at paragraphs 30 and 54

${ }^{400}$ Oral Statement at First Meeting, paragraphs 67 and 68

${ }^{401}$ Ibid. at paragraph 32

${ }^{402}$ First Submission of the EC, paragraph 30

${ }^{403}$ EC Oral Statement at First Meeting, paragraphs 64-69

${ }^{404}$ In responding to a question asked by the Panel after the first meeting with the parties, Canada submitted an answer that indicated to the Panel that Section 55.2(1) would be interpreted by Canada to authorize the commercial
} 
7.46 The Panel found no basis for believing that activities seeking product approvals under foreign regulatory procedures would be any less subject to these limitations. There is no a priori basis to assume that the requirements of foreign regulatory procedures will require activities unrelated to legitimate objectives of product quality and safety, nor has the EC provided any evidence to that effect. Nor is there any reason to assume that Canadian law would apply the exception in cases where foreign requirements clearly had no regulatory purpose. Nor, finally, is there any reason to assume that it will be any more difficult to enforce the requirements of Canadian law when Canadian producers claim exceptions under foreign procedures. With regard to the latter point, the Panel concurred with Canada's point that the government is not normally expected to regulate the actual conduct of third parties in such cases. The enforcement of these conditions, as with other enforcement of patent rights, occurs by means of private infringement actions brought by the patent owner. The patent owner merely has to prove that the challenged conduct is inconsistent with the basic patent rights created by national law. Once that initial case is made, the burden will be on the party accused of infringement to prove its defence by establishing that its conduct with respect to foreign regulatory procedures was in compliance with the conditions of Section 55.2(1).

7.47 In reaching this conclusion, the Panel also considered Canada's additional arguments that both the negotiating history of Article 30 of the TRIPS Agreement and the subsequent practices of certain WTO Member governments supported the view that Article 30 was understood to permit regulatory review exceptions similar to Section 55.2(1). The Panel did not accord any weight to either of those arguments, however, because there was no documented evidence of the claimed negotiating understanding, and because the subsequent acts by individual countries did not constitute "practice in the application of the treaty which establishes the agreement of the parties regarding its interpretation" within the meaning of Article 31.3(b) of the Vienna Convention. ${ }^{405}$

7.48 A final objection to the Panel's general conclusion remains to be addressed. Although the point was raised only briefly in the parties' legal arguments, the Panel was compelled to acknowledge that the economic impact of the regulatory review exception could be considerable. According to information supplied by Canada itself, in the case of patented pharmaceutical products approximately three to six-and-a-half years are required for generic drug producers to develop and obtain regulatory approval for their products. If there were no regulatory review exception allowing competitors to apply for regulatory approval during the term of the patent, therefore, the patent owner would be able to extend its period of market exclusivity, de facto, for some part of that three to six-and-half year period, depending on how much, if any, of the development process could be performed during the term of the patent under other exceptions, such as the scientific or experimental use exception. The Panel believed it was necessary to ask whether measures having such a significant impact on the economic interests of patent owners could be called a "limited" exception to patent rights.

disposition of patented products, manufactured during the term of the patent to meet regulatory review requirements, provided that they were sold after the patent in question had expired (see footnote 101 above). Although the parties themselves had not raised the issue of commercial disposition in such circumstances, this possible interpretation of Section 55.2(1) raised for the Panel the question whether a regulatory review exception authorizing such post-expiry commercial disposal could be considered "limited" within the meaning of Article 30 of the TRIPS Agreement. In its initial comments to the Panel's interim report, however, Canada corrected the Panel's interpretation of its earlier answer (see paragraph 6.8 above). Canada explicitly represented to the Panel that Section 55.2(1) did not permit commercial disposition of such products, even after the patent had expired, whether for export or domestic sales. Canada assured the Panel that all such commercial disposition would be considered an infringement of the patent on the ground that it would not be "reasonably related to the development or submission of information" required by regulatory review authorities. In its further comment responding to this Canadian comment (see paragraph 6.8 above), the EC disputed Canada's interpretation on the ground that actions taken after expiry of the patent "are perfectly free because the exclusive rights granted by the patent have ceased to exist". The Panel did not accept the EC position, finding no reason why a statute granting immunity from infringement liability could not make that immunity contingent on subsequent conduct. Moreover, given that the text of Section 55.2(1) does not deal explicitly with the issue of post-expiry sales, the Panel found Canada's interpretation of the statute's general language on this point to be the more likely interpretation. Accordingly, having found that Section 55.2(1) did not in fact present an issue of consistency with Article 30, the Panel did not pursue the issue further.

${ }^{405}$ See paragraph 7.13 above. 
WT/DS114/R

Page 160

7.49 After analysing all three conditions stated in Article 30 of the TRIPS Agreement, the Panel was satisfied that Article 30 does in fact address the issue of economic impact, but only in the other two conditions contained in that Article. As will be seen in the analysis of these other conditions below, the other two conditions deal with the issue of economic impact, according to criteria that relate specifically to that issue. Viewing all three conditions as a whole, it is apparent that the first condition ("limited exception") is neither designed nor intended to address the issue of economic impact directly.

7.50 In sum, the Panel found that the regulatory review exception of Section 55.2(1) is a "limited exception" within the meaning of Article 30 of the TRIPS Agreement.

\section{(b) "Normal Exploitation"}

7.51 The second condition of Article 30 prohibits exceptions that "unreasonably conflict with a normal exploitation of the patent". Canada took the position that "exploitation" of the patent involves the extraction of commercial value from the patent by "working" the patent, either by selling the product in a market from which competitors are excluded, or by licensing others to do so, or by selling the patent rights outright. ${ }^{406}$ The European Communities also defined "exploitation" by referring to the same three ways of "working" a patent. ${ }^{407}$ The parties differed primarily on their interpretation of the term "normal".

7.52 Canada's view of "normal exploitation" was implicit in its primary argument. Canada considered that the regulatory review exception of Section 55.2(1) does not conflict with "normal exploitation" because it does not conflict at all with the patent owner's exclusive marketing rights throughout the term of the patent. ${ }^{408}$ To be sure, the value derived from the exercise of exclusive marketing rights during the term of the patent is the key ingredient in the exploitation of a patent. The issue in dispute, however, was whether the concept of "normal exploitation" also includes the additional period of market exclusivity that would be obtained, after the term of the patent, if patent rights could be used to prevent competitors from obtaining, or taking steps to obtain, marketing authorization during the term of the patent. By inference, Canada's assertion that "normal exploitation" is sufficiently safeguarded by protecting market exclusivity during the term of the patent amounted to an assertion that these post-expiration forms of market exclusivity should not be considered as normal exploitation. Although Canada did not explain this conclusion further in its arguments pertaining to the "normal exploitation" test, that same conclusion was also implicit in Canada's repeated assertion, in other contexts, that it had never been the intent of either the patent laws or the marketing authorization requirements, to permit themselves to be used by patent owners to create a period of de facto market exclusivity after the patent expires. ${ }^{409}$ In other words, Canada argued, such patent extension had never been part of the bargain between patent owners and society, and consequently patent owners had no "legitimate interest" in such an extension.

7.53 The EC reply to Canada's definition of "normal exploitation" argued that Canada's focus on commercial sales during the term of the patent mistakenly treats a patent as establishing a right to sell, whereas in fact patent rights are rights to exclude several different kinds of behaviour. According to the EC's argument, Canada's definition of "normal exploitation" only took account of the patent owner's right to exclude sales by third parties during the term of the patent, and so failed to address the patent owner's other rights to exclude third parties from "making" or "using" the patented product

\footnotetext{
${ }^{406}$ Canada's First Submission, paragraph 78

${ }^{407}$ EC Oral Statement at First Meeting, paragraph 70

${ }^{408}$ Canada's First Submission, paragraphs 78-79

${ }^{409}$ Canada, First Submission, paragraphs 81-86
} 
during the term of the patent. ${ }^{410}$ The EC's argument implied that "normal exploitation" should be defined in terms of the market exclusivity that arises from the exercise of all exclusionary rights, regardless of whether that market exclusivity arises during the patent term or after it. Since the rights to exclude "making" or "using" often lead to periods of de facto market exclusivity in the period after the patent expires, due respect for these particular patent rights must lead, in the EC's view, to the conclusion that post-expiration market exclusivity created by the exercise of such exclusionary rights must be part of the "normal exploitation" of a patent."

7.54 The Panel considered that "exploitation" refers to the commercial activity by which patent owners employ their exclusive patent rights to extract economic value from their patent. The term "normal" defines the kind of commercial activity Article 30 seeks to protect. The ordinary meaning of the word "normal" is found in the dictionary definition: "regular, usual, typical, ordinary, conventional". ${ }^{411}$ As so defined, the term can be understood to refer either to an empirical conclusion about what is common within a relevant community, or to a normative standard of entitlement. The Panel concluded that the word "normal" was being used in Article 30 in a sense that combined the two meanings.

7.55 The normal practice of exploitation by patent owners, as with owners of any other intellectual property right, is to exclude all forms of competition that could detract significantly from the economic returns anticipated from a patent's grant of market exclusivity. The specific forms of patent exploitation are not static, of course, for to be effective exploitation must adapt to changing forms of competition due to technological development and the evolution of marketing practices. Protection of all normal exploitation practices is a key element of the policy reflected in all patent laws. Patent laws establish a carefully defined period of market exclusivity as an inducement to innovation, and the policy of those laws cannot be achieved unless patent owners are permitted to take effective advantage of that inducement once it has been defined.

7.56 Canada has raised the argument that market exclusivity occurring after the 20-year patent term expires should not be regarded as "normal". The Panel was unable to accept that as a categorical proposition. Some of the basic rights granted to all patent owners, and routinely exercised by all patent owners, will typically produce a certain period of market exclusivity after the expiration of a patent. For example, the separate right to prevent "making" the patented product during the term of the patent often prevents competitors from building an inventory needed to enter the market immediately upon expiration of a patent. There is nothing abnormal about that more or less brief period of market exclusivity after the patent has expired.

7.57 The Panel considered that Canada was on firmer ground, however, in arguing that the additional period of de facto market exclusivity created by using patent rights to preclude submissions for regulatory authorization should not be considered "normal". The additional period of market exclusivity in this situation is not a natural or normal consequence of enforcing patent rights. It is an unintended consequence of the conjunction of the patent laws with product regulatory laws, where the combination of patent rights with the time demands of the regulatory process gives a greater than normal period of market exclusivity to the enforcement of certain patent rights. It is likewise a form of exploitation that most patent owners do not in fact employ. For the vast majority of patented products, there is no marketing regulation of the kind covered by Section 55.2(1), and thus there is no possibility to extend patent exclusivity by delaying the marketing approval process for competitors.

7.58 The Panel could not agree with the EC's assertion that the mere existence of the patent owner's rights to exclude was a sufficient reason, by itself, for treating all gains derived from such rights as flowing from "normal exploitation". In the Panel's view, the EC's argument contained no evidence or analysis addressed to the various meanings of "normal" - neither a demonstration that

${ }^{410}$ EC Second (Rebuttal) Submission, paragraphs 62-64, 80-81

${ }^{411}$ The New Shorter Oxford English Dictionary, p.1940 
most patent owners extract the value of their patents in the manner barred by Section 55.2(1), nor an argument that the prohibited manner of exploitation was "normal" in the sense of being essential to the achievement of the goals of patent policy. To the contrary, the EC's focus on the exclusionary rights themselves merely restated the concern to protect Article 28 exclusionary rights as such. This is a concern already dealt with by the first condition of Article 30 ("limited exception") and the Panel found the ultimate EC arguments here impossible to distinguish from the arguments it had made under that first condition. ${ }^{412}$

7.59 In sum, the Panel found that the regulatory review exception of Section 55.2(1) does not conflict with a normal exploitation of patents, within the meaning of the second condition of Article 30 of the TRIPS Agreement. The fact that no conflict has been found makes it unnecessary to consider the question of whether, if a conflict were found, the conflict would be "unreasonable". Accordingly, it is also unnecessary to determine whether or not the final phrase of Article 30, calling for consideration of the legitimate interests of third parties, does or does not apply to the determination of "unreasonable conflict" under the second condition of Article 30.

\section{(c) "Legitimate Interests"}

7.60 The third condition of Article 30 is the requirement that the proposed exception must not "unreasonably prejudice the legitimate interests of the patent owner, taking into account the legitimate interests of third parties". Although Canada, as the party asserting the exception provided for in Article 30, bears the burden of proving compliance with the conditions of that exception, the order of proof is complicated by the fact that the condition involves proving a negative. One cannot demonstrate that no legitimate interest of the patent owner has been prejudiced until one knows what claims of legitimate interest can be made. Likewise, the weight of legitimate third party interests cannot be fully appraised until the legitimacy and weight of the patent owner's legitimate interests, if any, are defined. Accordingly, without disturbing the ultimate burden of proof, the Panel chose to analyse the issues presented by the third condition of Article 30 according to the logical sequence in which those issues became defined.

7.61 The ultimate issue with regard to the regulatory review exception's compliance with the third condition of Article 30 involved similar considerations to those arising under the second condition ("normal exploitation") - the fact that the exception would remove the additional period of de facto market exclusivity that patent owners could achieve if they were permitted to employ their rights to exclude "making" and "using" (and "selling") the patented product during the term of the patent to prevent potential competitors from preparing and/or applying for regulatory approval during the term of the patent. The issue was whether patent owners could claim a "legitimate interest" in the economic benefits that could be derived from such an additional period of de facto market exclusivity and, if so, whether the regulatory review exception "unreasonably prejudiced" that interest.

\section{(i) Primary EC claim of legitimate interest}

7.62 The European Communities argued that the regulatory review exception in Section 55.2(1) fails to satisfy the third condition of Article 30. The primary EC argument on this point rested on an interpretation that identified "legitimate interests" with legal interests. The EC asserted that the "legitimate interests" of the patent owner can only be the full enjoyment of his patent rights during the

\footnotetext{
${ }^{412}$ Paragraph 82 of the EC's Second (Rebuttal) Submission argues as follows:
}

\footnotetext{
"By disregarding all patent rights stipulated by Article 28.1 of the TRIPS Agreement during the entire patent term for a wide range of beneficiaries and for activities which are of a significant extent if performed for Canadian regulatory requirements and perfectly outside the control and largely outside the knowledge of the Canadian authorities if performed to meet regulatory requirements in any other country, Section 55.2(1) of the Patent Act has to be considered to unreasonably conflict with a normal exploitation of the patent." (boldface in original)
} 
entire term of the patent. ${ }^{413}$ Given that starting point, it followed that any exception to Article 28.1 rights would constitute "prejudice" to the legitimate interests of a patent owner. Consequently, the remainder of the EC's argument concentrated on whether the prejudice was "unreasonable", an issue which in turn focused on whether the "legitimate interests of third parties" outweighed the patent owner's interests in full enjoyment of his legal rights. The EC first argued that the only relevant "third parties" for the purpose of Article 30 are the patent owner's competitors - in the case of pharmaceutical patents the generic drug producers, because they were the only parties with interests adverse to those of patent owners. According to the EC's view, the TRIPS Agreement constitutes a recognition that patent systems serve the interest of the society, including the multiple interests of its health policy. That being so, the patent rights granted by that Agreement, being a part of the balance of rights and obligations that governments have agreed to as beneficial, cannot be found to be adverse to, or in conflict with, the interests represented by general social welfare policy. And that, in turn, means that the only adverse third party interests to patent owners are the interests of those firms with whom they compete.

7.63 Then, following its position that "legitimate interests" are essentially legal interests, the EC went on to argue that the legitimate interests of competing producers are essentially the same as those of patent owners - that is, the full enjoyment of their legal rights. The legal rights of the patent owner's competitors, the EC argues, are the rights to make, use or sell the patented product on the day after the patent expires. ${ }^{414}$ Such competitors, therefore, could have no "legitimate" interest in the rights granted by the regulatory review exception of Section 55.2(1), because they could have no legal right to "make" or "use" (or "sell") the patented product during the term of the patent.

7.64 Given these interpretations of the third condition of Article 30, the EC concluded: (1) that the impairment of the patent owner's Article 28 legal rights by the regulatory review exception amounts to "prejudice" to the patent owner's legitimate interests; and (2) that in the absence of any legitimate third party interest to the contrary, the abrogation of rights authorized by Section 55.2(1) is substantial enough to be characterized as "unreasonable".

7.65 Canada contested the two key parts of this EC argument - the EC's interpretation of the term "legitimate interests", and the EC's interpretation of the term "third parties".

7.66 Canada's interpretation of patent owners' "legitimate interests" departed from a base similar to the EC's focus on the patent owner's legal rights. Citing definitions of the word "legitimate" as "conformable to law, lawful, proper", Canada asserted that legitimate interests are those that "relate to the rights and duties that the patent laws confer or impose", and which "arise from the status of being a patent holder, not from the more general status of being a business person or manufacturer". ${ }^{415}$ But the words "relate to" and "arise from" indicate that Canada was referring to something beyond the legal rights themselves. In explaining why the patent holder has no "legitimate interest" in the de facto extension of market exclusivity created by the regulatory review process, Canada's explanation rested not on an analysis of the legal rights of the patent owner, but on the norms (or policies) that Canada deduced from the patent laws that create those rights. Canada stated:

"[N]otwithstanding the private economic advantage that would be obtained by doing so, a patentee can have no legitimate interest deriving from patent law in exercising its exclusive use and enforcement rights within the term of protection to achieve, through exploitation of regulatory review laws, a de facto extension of that term of protection beyond the prescribed period, thereby unilaterally altering the bargain between the patentee and society. In this

\footnotetext{
${ }^{413}$ EC Oral Statement, First Meeting, paragraph 59; EC Second (Rebuttal) Submission, paragraph 67

${ }^{414}$ EC Oral Statement, First Meeting, paragraphs 72-74; EC Second (Rebuttal) Submission, paragraphs 68-70

${ }^{415}$ Canada, First Submission, paragraph 81
} 
respect, the interests of a patentee of a pharmaceutical invention can be no different from those of patentees in other fields of technology. ${ }^{.416}$

Canada's conclusion as to the "bargain" contained in the patent laws was a conclusion as to the underlying norms or policies of the patent laws. It tests the legitimacy of claims by their conformity to these norms - to be sure, norms based on the patent laws, but nonetheless a normative rather than legal definition of "legitimate". Thus, for Canada it is possible that the exercise of some legal rights in some circumstances are contrary to the policy norms of patent law, and that in such cases the patent owner has no "legitimate interest" in exercising those rights in those circumstances.

7.67 With regard to the EC's definition of the "third party interests" referred to in the last phrase of Article 30, Canada took the position that general societal interests, and particularly interests connected with health policy, were within the ambit of the term "third parties" and thus were entitled to consideration. In support of this position, Canada, together with several of the third party participants in this proceeding ${ }^{417}$, relied most heavily on the statements of objectives and principles stated in Articles 7 and 8.1 of the TRIPS Agreement.

\section{(ii) Definition of "legitimate interests"}

7.68 The word "legitimate" is commonly defined as follows:

(a) Conformable to, sanctioned or authorized by, law or principle: lawful; justifiable; proper;

(b) Normal, regular, conformable to a recognized standard type. ${ }^{418}$

Although the European Communities' definition equating "legitimate interests" with a full respect of legal interests pursuant to Article 28.1 is within at least some of these definitions, the EC definition makes it difficult to make sense of the rest of the third condition of Article 30, in at least three respects. First, since by that definition every exception under Article 30 will be causing "prejudice" to some legal rights provided by Article 28 of the Agreement, that definition would reduce the first part of the third condition to a simple requirement that the proposed exception must not be "unreasonable". Such a requirement could certainly have been expressed more directly if that was what was meant. Second, a definition equating "legitimate interests" with legal interests makes no sense at all when applied to the final phrase of Article 30 referring to the "legitimate interests" of third parties. Third parties are by definition parties who have no legal right at all in being able to perform the tasks excluded by Article 28 patent rights. An exceptions clause permitting governments to take account of such third party legal interests would be permitting them to take account of nothing. And third, reading the third condition as a further protection of legal rights would render it essentially redundant in light of the very similar protection of legal rights in the first condition of Article 30 ("limited exception").

7.69 To make sense of the term "legitimate interests" in this context, that term must be defined in the way that it is often used in legal discourse - as a normative claim calling for protection of interests that are "justifiable" in the sense that they are supported by relevant public policies or other social norms. This is the sense of the word that often appears in statements such as "X has no legitimate interest in being able to do Y". We may take as an illustration one of the most widely adopted Article 30-type exceptions in national patent laws - the exception under which use of the patented product for scientific experimentation, during the term of the patent and without consent, is not an

\footnotetext{
${ }^{416}$ Canada, First Submission, paragraph 86

417 The Panel uses the term "third party" here in the sense defined in Article 10 of the DSU, in contrast to the sense employed in Article 30 of the TRIPS Agreement, or the sense employed in Article 28 of that Agreement.

${ }^{418}$ New Shorter Oxford Dictionary, page 1563
} 
infringement. It is often argued that this exception is based on the notion that a key public policy purpose underlying patent laws is to facilitate the dissemination and advancement of technical knowledge and that allowing the patent owner to prevent experimental use during the term of the patent would frustrate part of the purpose of the requirement that the nature of the invention be disclosed to the public. To the contrary, the argument concludes, under the policy of the patent laws, both society and the scientist have a "legitimate interest" in using the patent disclosure to support the advance of science and technology. While the Panel draws no conclusion about the correctness of any such national exceptions in terms of Article 30 of the TRIPS Agreement, it does adopt the general meaning of the term "legitimate interests" contained in legal analysis of this type.

7.70 The negotiating history of the TRIPS Agreement itself casts no further illumination on the meaning of the term "legitimate interests", but the negotiating history of Article 9(2) of the Berne Convention, from which the text of the third condition was clearly drawn, does tend to affirm the Panel's interpretation of that term. With regard to the TRIPS negotiations themselves, the meaning of several important drafting changes turns out to be equivocal upon closer examination. The negotiating records of the TRIPS Agreement itself show that the first drafts of the provision that was to become Article 30 contemplated authorizing "limited exceptions" that would be defined by an illustrative list of exceptions - private use, scientific use, prior use, a traditional exception for pharmacists, and the like. ${ }^{419}$ Eventually, this illustrative list approach was abandoned in favour of a more general authorization following the outlines of the present Article 30. The negotiating records of the TRIPS Agreement give no explanation of the reason for this decision.

7.71 The text of the present, more general version of Article 30 of the TRIPS Agreement was obviously based on the text of Article 9(2) of the Berne Convention. Berne Article 9(2) deals with exceptions to the copyright holder's right to exclude reproduction of its copyrighted work without permission. The text of Article 9(2) is as follows:

"It shall be a matter for legislation in the countries of the Union to permit the reproduction of [literary and artistic] works in certain special cases, provided that such reproduction does not conflict with a normal exploitation of the work and does not unreasonably prejudice the legitimate interests of the author." 420

The text of Berne Article 9(2) was not adopted into Article 30 of the TRIPS Agreement without change. Whereas the final condition in Berne Article 9(2) ("legitimate interests") simply refers to the legitimate interests of the author, the TRIPS negotiators added in Article 30 the instruction that account must be taken of "the legitimate interests of third parties". Absent further explanation in the records of the TRIPS negotiations, however, the Panel was not able to attach a substantive meaning to this change other than what is already obvious in the text itself, namely that the reference to the "legitimate interests of third parties" makes sense only if the term "legitimate interests" is construed as a concept broader than legal interests.

7.72 With regard to the meaning of Berne Article 9(2) itself, the Panel examined the drafting committee report that is usually cited as the most authoritative explanation of what Article $9(2)$ means. The drafting committee report states:

"If it is considered that reproduction conflicts with the normal exploitation of the work, reproduction is not permitted at all. If it is considered that reproduction does not conflict with

${ }^{419}$ See document MTN.GNG/NG11/W/76 of 23 July 1990 - Status of Work in the Negotiating Group: Chairman's Report to the Group of Negotiations on Goods, Part III, Section 5, paragraph 2.2. The relevant text is quoted in Annex 6 to the present report.

${ }_{420}$ The text of Berne Article 9(2) also served as the model for three other exceptions clauses in the TRIPS Agreement - Articles 13, 17 and 26.2, providing respectively for similar exceptions from obligations on copyright, trademarks and industrial designs. Article 13 is a nearly identical copy of Berne Article 9(2). Like Article 30, both Articles 17 and 26.2 made small changes to the text of Berne Article 9(2). 
the normal exploitation of the work, the next step would be to consider whether it does not unreasonably prejudice the legitimate interests of the author. Only if such is not the case would it be possible in certain special cases to introduce a compulsory license, or to provide for use without payment. A practical example may be photocopying for various purposes. If it consists of producing a very large number of copies, it may not be permitted, as it conflicts with a normal exploitation of the work. If it implies a rather large number of copies for use in industrial undertakings, it may not unreasonably prejudice the legitimate interests of the author, provided that, according to national legislation, an equitable remuneration is paid. If a small number of copies is made, photocopying may be permitted without payment, particularly for individual or scientific use. ${ }^{421}$

The Panel recognized that the drafting committee's examples concern the area of copyright as opposed to patents, and that, even further, they deal with the situation as it was in 1967, and accordingly the Panel was reluctant to read too much into these examples as guides to the meaning of Article 30 . But the Panel did find that the concepts of "normal exploitation" and "legitimate interests" underlying the three examples used by the drafting committee were consistent with the Panel's definitions of these concepts and of the differences between them.

7.73 In sum, after consideration of the ordinary meaning of the term "legitimate interests", as it is used in Article 30, the Panel was unable to accept the EC's interpretation of that term as referring to legal interests pursuant to Article 28.1. Accordingly, the Panel was unable to accept the primary EC argument with regard to the third condition of Article 30. It found that the EC argument based solely on the patent owner's legal rights pursuant to Article 28.1, without reference to any more particular normative claims of interest, did not raise a relevant claim of non-compliance with the third condition of Article 30.

\section{(iii) Second claim of "legitimate interest"}

7.74 After reaching the previous conclusion concerning the EC's primary argument under the "legitimate interests" condition of Article 30, the Panel then directed its attention to another line of argument raised in statements made by the EC and by one third party. This second line of argument called attention to the fact that patent owners whose innovative products are subject to marketing approval requirements suffer a loss of economic benefits to the extent that delays in obtaining government approval prevent them from marketing their product during a substantial part of the patent term. According to information supplied by Canada, regulatory approval of new pharmaceuticals usually does not occur until approximately eight to 12 years after the patent application has been filed, due to the time needed to complete development of the product and the time needed to comply with the regulatory procedure itself. ${ }^{422}$ The result in the case of pharmaceuticals, therefore, is that the innovative producer is in fact able to market its patented product in only the remaining eight to 12 years of the 20 -year patent term, thus receiving an effective period of market exclusivity that is only 40-60 per cent of the period of exclusivity normally envisaged in a 20-year patent term. The EC argued that patent owners who suffer a reduction of effective market exclusivity from such delays should be entitled to impose the same type of delay in connection with corresponding regulatory requirements upon the market entry of competing products. According to the EC,

"[T]here exists no reason why the research based pharmaceutical enterprise is obliged to accept the economic consequence of patent term erosion because of marketing approval requirements which reduce their effective term of protection to $12-8$ years while the copy

${ }^{421}$ Report on the Work of Main Committee I (Substantive Provisions of the Berne Convention: Articles 1 to 20), paragraph 85, in "Records of the Intellectual Property Conference of Stockholm, June 11-July 14, 1967", World Intellectual Property Organization (WIPO), Geneva, 1971, Vol. II, pp. 1145-1146.

${ }^{422}$ See paragraph 2.5 above. 
producer should be entirely compensated for the economic consequence of the need of marketing approval for his generic product, and at the expense of the inventor and patent holder". ${ }^{423}$

Applied to the regulatory review exception, this argument called for the removal of such exceptions so that patent owners may use their exclusionary patent rights to prevent competitors from engaging in product development and initiating the regulatory review process until the patent has expired. The result of removing the exception would be to allow patent owners to create a period of further, de facto market exclusivity after the expiration of the patent, for the length of time it would take competing producers to complete product development and obtain marketing approval. ${ }^{424}$

7.75 The normative claim being made in this second argument ultimately rested on a claim of equal treatment for all patent owners. The policy of the patent laws, the argument would run, is to give innovative producers the advantage of market exclusivity during the 20 -year term of the patent. Although patent laws do not guarantee that patent owners will obtain economic benefits from this opportunity, most patent owners have at least the legal opportunity to market the patented product during all or virtually all this 20 -year period of market exclusivity. Producers whose products are subject to regulatory approval requirements may be deprived of this opportunity for a substantial part of the 20 -year period.

7.76 Under the Panel's interpretation of Article 30, this argument could be characterized as a claim of "legitimate interest" under the third condition of Article 30. It was distinct from the claim made under the second condition of Article 30 ("normal exploitation"), because it did not rest on a claim of interest in the "normal" means of extracting commercial benefits from a patent. Instead, it was a distinctive claim of interest, resting on a distinctive situation applicable only to patent owners affected by marketing approval requirements, asking for an additional means of exploitation, above and beyond "normal exploitation," to compensate for the distinctive disadvantage claimed to be suffered by this particular group of claimants.

7.77 The Panel therefore examined whether the claimed interest should be considered a "legitimate interest" within the meaning of Article 30. The primary issue was whether the normative basis of that claim rested on a widely recognized policy norm.

7.78 The type of normative claim put forward by the EC has been affirmed by a number of governments that have enacted de jure extensions of the patent term, primarily in the case of pharmaceutical products, to compensate for the de facto diminution of the normal period of market exclusivity due to delays in obtaining marketing approval. According to the information submitted to the Panel, such extensions have been enacted by the European Communities, Switzerland, the United States, Japan, Australia and Israel. ${ }^{425}$ The EC and Switzerland have done so while at the same time allowing patent owners to continue to use their exclusionary rights to gain an additional, de facto extension of market exclusivity by preventing competitors from applying for regulatory approval during the term of the patent. The other countries that have enacted de jure patent term extensions have also, either by legislation or by judicial decision, created a regulatory review exception similar to

${ }^{423}$ Oral Statement, First Meeting, paragraph 74. See also EC Written Rebuttal, paragraphs 84-85. For a similar point made by Switzerland, see Third Party Submission by Switzerland, paragraph 37.

${ }^{424}$ The actual length of the additional period of de facto market exclusivity would depend on the time it would take competitors to complete the regulatory approval process from the day the patent expired. This would vary depending on whether and to what extent competitors would have been able to perform some of the development process during the patent term, which in turn would depend on the scope of other exceptions permitting use of the patented product without the consent of the patent owner, such as exceptions for scientific or experimental use of the product.

${ }^{425}$ The data on patent term extensions and regulatory review exceptions for the countries listed were supplied in replies to questions posed by the Panel to the parties and third parties in the proceeding. The questions posed by the Panel and the replies received can be found in Annex 5 to this report. 
Section 55.2(1), thereby eliminating the possibility of an additional de facto extension of market exclusivity.

7.79 This positive response to the claim for compensatory adjustment has not been universal, however. In addition to Canada, several countries have adopted, or are in the process of adopting, regulatory review exceptions similar to Section 55.2(1) of the Canadian Patent Act, thereby removing the de facto extension of market exclusivity, but these countries have not enacted, and are not planning to enact, any de jure extensions of the patent term for producers adversely affected by delayed marketing approval. ${ }^{426}$ When regulatory review exceptions are enacted in this manner, they represent a decision not to restore any of the period of market exclusivity due to lost delays in obtaining marketing approval. Taken as a whole, these government decisions may represent either disagreement with the normative claim made by the EC in this proceeding, or they may simply represent a conclusion that such claims are outweighed by other equally legitimate interests.

7.80 In the present proceeding, Canada explicitly disputed the legitimacy of the claimed interest. As noted above, Canada appeared to interpret the term "legitimate interests" in accordance with the Panel's view of that term as a widely recognized normative standard. Canada asserted:

"[N]otwithstanding the private economic advantage that would be obtained by doing so, a patentee can have no legitimate interest deriving from patent law in exercising its exclusive use and enforcement rights within the term of protection to achieve, through exploitation of regulatory review laws, a de facto extension of that term of protection beyond the prescribed period, thereby unilaterally altering the bargain between the patentee and society. In this respect, the interests of a patentee of a pharmaceutical invention can be no different from those of patentees in other fields of technology." ${ }^{1427}$

7.81 Canada's argument that all fields of technology must be treated the same implicitly rejected the EC's argument that those fields of technology affected by marketing approval requirements should be given certain additional marketing advantages in compensation. Canada was asked by the Panel to explain the distinction between its decision in Section 55.2(1) to remove the delay in obtaining marketing approval for competitive producers seeking to enter the market after the patent expires and its decision not to correct or compensate for the similar delay encountered by the patent owner himself. Canada responded that the de facto diminution of the market exclusivity for patent owners was an unavoidable consequence of the time required to ensure and to demonstrate the safety and efficacy of the product, whereas the delay imposed on competitors by use of the patent rights to block product development and initiation of the regulatory review process during the term of the patent was neither necessary to product safety nor otherwise an appropriate use of patent rights. ${ }^{428}$ Canada's answer implied a further question as to the extent to which the marketing delays experienced by patent owners were in fact the result of government regulatory action, as opposed to the normal consequence of the necessary course of product development for products of this kind.

7.82 On balance, the Panel concluded that the interest claimed on behalf of patent owners whose effective period of market exclusivity had been reduced by delays in marketing approval was neither so compelling nor so widely recognized that it could be regarded as a "legitimate interest" within the meaning of Article 30 of the TRIPS Agreement. Notwithstanding the number of governments that had responded positively to that claimed interest by granting compensatory patent term extensions, the issue itself was of relatively recent standing, and the community of governments was obviously still divided over the merits of such claims. Moreover, the Panel believed that it was significant that concerns about regulatory review exceptions in general, although well known at the time of the

${ }^{426}$ See replies of Poland and Thailand to questions asked by the Panel to third parties. See First Submission of Canada, paragraphs 115, 116 (Hungary, Argentina).

${ }_{427}$ Canada, First Submission, paragraph 86

${ }^{428}$ Canada, Responses to Questions from the Panel to the Parties (at the first meeting), Question 14 
TRIPS negotiations, were apparently not clear enough, or compelling enough, to make their way explicitly into the recorded agenda of the TRIPS negotiations. The Panel believed that Article 30's "legitimate interests" concept should not be used to decide, through adjudication, a normative policy issue that is still obviously a matter of unresolved political debate.

7.83 Consequently, having considered the two claims of "legitimate interest" put forward by the $\mathrm{EC}$, and having found that neither of these claimed interests can be considered "legitimate interests" within the meaning of the third condition of Article 30 of the TRIPS Agreement, the Panel concluded that Canada had demonstrated to the Panel's satisfaction that Section 55.2(1) of Canada's Patent Act did not prejudice "legitimate interests" of affected patent owners within the meaning of Article 30.

(iv) Conclusion with regard to compliance of Section 55.2(1) with Article 30

7.84 Having reviewed the conformity of Section 55.2(1) with each of the three conditions for an exception under Article 30 of the TRIPS Agreement, the Panel concluded that Section 55.2(1) does satisfy all three conditions of Article 30, and thus is not inconsistent with Canada's obligations under Article 28.1 of the TRIPS Agreement.

\section{APPLICATION OF ARTICLE 27.1 OF THE TRIPS AGREEMENT}

7.85 The EC claimed that Section 55.2(1) of the Canada Patent Act is also in conflict with the obligations under Article 27.1 of the TRIPS Agreement. Article 27.1 provides:

\section{"Article 27 \\ Patentable Subject Matter}

1. Subject to the provisions of paragraphs 2 and 3, patents shall be available for any inventions, whether products or processes, in all fields of technology, provided that they are new, involve an inventive step and are capable of industrial application. Subject to paragraph 4 of Article 65, paragraph 8 of Article 70 and paragraph 3 of this Article, patents shall be available and patent rights enjoyable without discrimination as to the place of invention, the field of technology and whether products are imported or locally produced." (emphasis added)

7.86 The EC argued that the anti-discrimination rule stated in the italicized language in the text of Article 27.1 above not only requires that the core patent rights made available under Article 28 be non-discriminatory, but also requires that any exceptions to those basic rights made under Articles 30 and 31 must be non-discriminatory as well. Thus, the EC concluded, Article 27.1 requires that the exception made by Section 55.2(1) must be non-discriminatory. The EC contended that Section 55.2(1) does not comply with the obligations of Article 27.1, because it is limited, both de jure and de facto, to pharmaceutical products alone, and thus discriminates by field of technology.

7.87 Canada advanced two defences to the EC's claim of an Article 27.1 violation. First, Canada argued that the non-discrimination rule of Article 27.1 does not apply to exceptions taken under Article 30. Second, Canada argued that Section 55.2(1) does not discriminate against pharmaceutical products. The Panel examined these two defences in order.

Applicability of Article 27.1 to Article 30 Exceptions

7.88 Canada took the position that Article 27.1's reference to "patent rights" that must be enjoyable without discrimination as to field of technology refers to the basic rights enumerated in Article 28.1 subject to any exceptions that might be made under Article 30. In other words, governments may discriminate when making the "limited" exceptions allowed under Article 30, but they may not discriminate as to patent rights as modified by such exceptions. 
7.89 In support of this position, Canada argued that the scope of Article 30 would be reduced to insignificance if governments were required to treat all fields of technology the same, for if all exceptions had to apply to every product it would be far more difficult to meet the requirement that Article 30 exceptions be "limited". It would also be more difficult to target particular social problems, as are anticipated, according to Canada, by Articles 7 and 8 of the TRIPS Agreement. Conversely, Canada argued, requiring that exceptions be applied to all products would cause needless deprivation of patent rights for those products as to which full enforcement of patent rights causes no problem.

7.90 Canada acknowledged that there are certain textual difficulties with this position. It acknowledged that two of the primary purposes of Article 27.1 were to eliminate two types of discrimination that had been practised against pharmaceuticals and certain other products - either a denial of patentability for such products, or, if patents were granted, automatic compulsory licences permitting others to manufacture such products for a fee. Canada acknowledged that, in order to preclude discrimination as to compulsory licences, the non-discrimination rule of Article 27 was made applicable to Article 31 of the TRIPS Agreement, which grants a limited exception for compulsory licences under specified conditions. To defend its position, therefore, Canada was required to explain how Article 27.1 could apply to exceptions made under Article 31, but not to exceptions made under its neighbouring exception provision in Article 30. Canada argued that Article 31 was "mandatory" in character while Article 30 was "permissive," and that this distinction made it appropriate to apply the non-discrimination provision to the former but not the latter.

7.91 The Panel was unable to agree with Canada's contention that Article 27.1 did not apply to exceptions granted under Article 30. The text of the TRIPS Agreement offers no support for such an interpretation. Article 27.1 prohibits discrimination as to enjoyment of "patent rights" without qualifying that term. Article 30 exceptions are explicitly described as "exceptions to the exclusive rights conferred by a patent" and contain no indication that any exemption from non-discrimination rules is intended. A discriminatory exception that takes away enjoyment of a patent right is discrimination as much as is discrimination in the basic rights themselves. The acknowledged fact that the Article 31 exception for compulsory licences and government use is understood to be subject to the non-discrimination rule of Article 27.1, without the need for any textual provision so providing, further strengthens the case for treating the non-discrimination rules as applicable to Article 30 . Articles 30 and 31 are linked together by the opening words of Article 31 which define the scope of Article 31 in terms of exceptions not covered by Article 30. ${ }^{429}$ Finally, the Panel could not agree with Canada's attempt to distinguish between Articles 30 and 31 on the basis of their mandatory/permissive character; both provisions permit exceptions to patent rights subject to certain mandatory conditions. Nor could the Panel understand how such a "mandatory/permissive" distinction, even if present, would logically support making the kind of distinction Canada was arguing. In the Panel's view, what was important was that in the rights available under national law, that is to say those resulting from the basic rights and any permissible exceptions to them, the forms of discrimination referred to in Article 27.1 should not be present.

7.92 Nor was the Panel able to agree with the policy arguments in support of Canada's interpretation of Article 27. To begin with, it is not true that being able to discriminate against particular patents will make it possible to meet Article 30's requirement that the exception be "limited". An Article 30 exception cannot be made "limited" by limiting it to one field of technology, because the effects of each exception must be found to be "limited" when measured against each affected patent. Beyond that, it is not true that Article 27 requires all Article 30 exceptions to be applied to all products. Article 27 prohibits only discrimination as to the place of invention, the field of technology, and whether products are imported or produced locally. Article 27 does not prohibit

${ }^{429}$ Article 31 is titled "Other Use Without Authorization of the Rights Holder", and footnote 7 to Article 31 defines "other use" as "use" (derogations from exclusive patent rights) other than that allowed by Article 30. 
bona fide exceptions to deal with problems that may exist only in certain product areas. Moreover, to the extent the prohibition of discrimination does limit the ability to target certain products in dealing with certain of the important national policies referred to in Articles 7 and 8.1, that fact may well constitute a deliberate limitation rather than a frustration of purpose. It is quite plausible, as the EC argued, that the TRIPS Agreement would want to require governments to apply exceptions in a nondiscriminatory manner, in order to ensure that governments do not succumb to domestic pressures to limit exceptions to areas where right holders tend to be foreign producers.

7.93 The Panel concluded, therefore, that the anti-discrimination rule of Article 27.1 does apply to exceptions of the kind authorized by Article 30. We turn, accordingly, to the question of whether Section 55.2(1) of the Canadian Patent Act discriminates as to fields of technology.

\section{(b) Discrimination as to the Field of Technology}

7.94 The primary TRIPS provisions that deal with discrimination, such as the national treatment and most-favoured-nation provisions of Articles 3 and 4, do not use the term "discrimination". They speak in more precise terms. The ordinary meaning of the word "discriminate" is potentially broader than these more specific definitions. It certainly extends beyond the concept of differential treatment. It is a normative term, pejorative in connotation, referring to results of the unjustified imposition of differentially disadvantageous treatment. Discrimination may arise from explicitly different treatment, sometimes called "de jure discrimination", but it may also arise from ostensibly identical treatment which, due to differences in circumstances, produces differentially disadvantageous effects, sometimes called "de facto discrimination". The standards by which the justification for differential treatment is measured are a subject of infinite complexity. "Discrimination" is a term to be avoided whenever more precise standards are available, and, when employed, it is a term to be interpreted with caution, and with care to add no more precision than the concept contains.

7.95 The European Communities acknowledged that the words of the regulatory review exception of Section 55.2(1) do not limit its application to pharmaceutical products. The terms of the exception protect potentially infringing conduct:

"solely for uses reasonably related to the development and submission of information required under any law $[\ldots]$ that regulates the manufacture, construction, use or sale of any product".

Applied literally, these words apply to any of a wide range of products that require regulatory approval for marketing. The EC itself mentioned agricultural chemicals, foodstuffs, cosmetics, automobiles, vessels and aircraft as products that often require regulatory approval. ${ }^{430}$

7.96 The EC pointed out, however, that pharmaceuticals were the only products mentioned in Canada's 1991 legislative debates on the enactment of Sections 55.2(1). ${ }^{431}$ It also asserted that Section 55.2(1) was "in effect applied only to pharmaceuticals products". ${ }^{432}$ These assertions led to two distinct allegations of discrimination. The first claim of discrimination was the claim that the legislative history's concentration on pharmaceuticals actually governs the legal scope of the measure, so that, as a matter of law, Section 55.2(1) applied only to pharmaceuticals. If that is so, it could be said that Section 55.2(1) imposes de jure discrimination against pharmaceuticals. The second claim of discrimination was the claim that, whatever the de jure scope of Section 55.2(1), the actual effects of Section 55.2(1) are limited to pharmaceutical producers, and these differential effects amount to a case of de facto discrimination. ${ }^{433}$

\footnotetext{
${ }^{430}$ EC First Submission, paragraph 58

${ }^{431}$ EC First Submission, paragraph 51

${ }^{432}$ EC First Submission, paragraph 57

${ }^{433}$ EC Answers to Questions Asked by the Panel after the First Substantive Meeting, Answer to Question 16
} 
7.97 Canada denied that the de jure scope of Section 55.2(1) is limited to pharmaceuticals. ${ }^{434}$ It pointed to the words of that provision making the exception available to "any product" for which marketing approval was needed. Canada did inform the Panel of a lower court decision, involving invocation of Section 55.2(1) by a producer of a medical device, holding that the legislative history of Section 55.2(1) limits its legal scope to patented pharmaceutical products. ${ }^{435}$ That decision itself was reversed on appeal, however, but only on the ground that such a holding could not be made by summary procedure, reserving decision on the legal scope of the statute for determination at trial. No further developments in that case, or other relevant judicial interpretations of Section 55.2(1) were brought to the Panel's attention. With regard to the claim that the actual effects of Section 55.2(1) were limited to pharmaceutical producers, Canada pointed out that the legal decision referred to above did involve a producer of medical devices who had employed Section 55.2(1) as a defence to a claim of infringement.

7.98 In considering how to address these conflicting claims of discrimination, the Panel recalled that various claims of discrimination, de jure and de facto, have been the subject of legal rulings under GATT or the WTO. ${ }^{436}$ These rulings have addressed the question whether measures were in conflict with various GATT or WTO provisions prohibiting variously defined forms of discrimination. As the Appellate Body has repeatedly made clear, each of these rulings has necessarily been based on the precise legal text in issue, so that it is not possible to treat them as applications of a general concept of discrimination. Given the very broad range of issues that might be involved in defining the word "discrimination" in Article 27.1 of the TRIPS Agreement, the Panel decided that it would be better to defer attempting to define that term at the outset, but instead to determine which issues were raised by the record before the Panel, and to define the concept of discrimination to the extent necessary to resolve those issues.

7.99 With regard to the issue of de jure discrimination, the Panel concluded that the European Communities had not presented sufficient evidence to raise the issue in the face of Canada's formal declaration that the exception of Section 55.2(1) was not limited to pharmaceutical products. Absent other evidence, the words of the statute compelled the Panel to accept Canada's assurance that the exception was legally available to every product that was subject to marketing approval requirements. In reaching this conclusion, the Panel took note that its legal finding of conformity on this point was based on a finding as to the meaning of the Canadian law that was in turn based on Canada's representations as to the meaning of that law, and that this finding of conformity would no longer be warranted if, and to the extent that, Canada's representations as to the meaning of that law were to prove wrong.

7.100 The Panel then turned to the question of de facto discrimination. Although the EC's response to the Panel's questions indicated that it did intend to raise the issue of de facto discrimination ${ }^{437}$ the EC did not propose a formal definition of de facto discrimination, nor did it submit a systematic exposition of the evidence satisfying the elements of such a concept. Australia and the United States, third parties in the proceedings, referred to previous GATT and WTO legal rulings treating de facto discrimination, but primarily for the purpose of suggesting the mirror image principle - that not all

${ }^{434}$ Initially, the EC took the position that, while a wide list of other products from foodstuffs to aircraft were subject to regulatory review requirements in Canada and other countries, the legal scope of Section 55.2(1) was confined only to pharmaceuticals (EC First Submission, paragraph 58). Canada, however, has explicitly denied having conceded that point, and has reaffirmed without qualification that the legal scope of the statute is as broad as the words indicate (Canada, First Submission, paragraph 131; Oral Statement at Second Meeting, paragraph 30).

${ }^{435}$ Visx, Inc. v. Nidek Co. et al. (1997) 77 C.P.R. (3d) 286 (Fed.Ct. T.D.), appeal allowed, Nidek Co. v. Visx, Inc., (1998) 77 C.P.R. (3d) 289 (Fed.Ct.App.) [Canada, Exhibit 59]

${ }^{436}$ See, e.g., Japan - Taxes on Alcoholic Beverages, WT/DS8/AB/R, WT/DS10/AB/R, WT/DS11/AB/R (adopted 1 November 1996); European Communities - Regime for the Importation, Sale and Distribution of Bananas, WT/DS27/AB/R (adopted 17 November 1997); EC Measures Concerning Meat and Meat Products (Hormones), WT/DS26/AB/R, WT/DS48/AB/R (adopted 15 February 1998); United States - Import Prohibition of Certain Shrimp and Shrimp Products, WT/DS58/AB/R (adopted 6 November 1998)

${ }^{437}$ EC Answers to Questions Asked by the Panel after the First Substantive Meeting, Answer to Question 16 
differential treatment is "discrimination". Canada did not associate itself with the Australian and United States positions. Notwithstanding the limited development of the arguments on the issue of de facto discrimination, the Panel concluded that its terms of reference required it to pursue that issue once raised, and accordingly the Panel proceeded to examine the claim of a de facto discrimination violation on the basis of its own examination of the record in the light of the concepts usually associated with claims of de facto discrimination.

7.101 As noted above, de facto discrimination is a general term describing the legal conclusion that an ostensibly neutral measure transgresses a non-discrimination norm because its actual effect is to impose differentially disadvantageous consequences on certain parties, and because those differential effects are found to be wrong or unjustifiable. Two main issues figure in the application of that general concept in most legal systems. One is the question of de facto discriminatory effect - whether the actual effect of the measure is to impose differentially disadvantageous consequences on certain parties. The other, related to the justification for the disadvantageous effects, is the issue of purpose not an inquiry into the subjective purposes of the officials responsible for the measure, but an inquiry into the objective characteristics of the measure from which one can infer the existence or nonexistence of discriminatory objectives.

7.102 With regard to the first issue - the actual effects of the measure -, the EC had argued that, despite its potentially broad coverage of many industries, the exception created by Section 55.2(1) had "in effect" applied only to pharmaceutical patents. The Panel received no systematic information on the range of industries that have actually made use of Section 55.2(1). In the absence of such information, the critical question was whether there was some practical reason why the regulatory review exception would in reality work only to the disadvantage of producers of patented pharmaceutical products. The Panel asked the parties for an explanation of any practical considerations that would limit the scope of application of Section 55.2(1) to pharmaceutical products $^{438}$, but no such explanation was provided. Nor was the Panel able to find such a practical reason from the information before it. The Panel concluded that the EC had not demonstrated that Section 55.2(1) had had a discriminatory effect limited to patented pharmaceutical products.

7.103 On the issue of discriminatory purpose, the EC had stressed on several occasions that, in the public discussion of Section 55.2(1), all relevant participants had been exclusively concerned with the impact of the measure on pharmaceutical products, with both support and opposition to the measure being argued in terms of that one dimension. Canada did not contest this characterization of the public debates.

7.104 The Panel did not find this evidence from the debates on Section 55.2(1) to be persuasive evidence of a discriminatory purpose. To be sure, such evidence makes it clear that the primary reason for passing the measure was its effect on promoting competition in the pharmaceutical sector. This is also evident from Canada's justification for the measure presented in this dispute settlement proceeding. But preoccupation with the effects of a statute in one area does not necessarily mean that the provisions applicable to other areas are a sham, or of no actual or potential importance. Individual problems are frequently the driving force behind legislative actions of broader scope. The broader scope of the measure usually reflects an important legal principle that rules being applied in the area of primary interest should also be applied to other areas where the same problem occurs. Indeed, it is a common desideratum in many legal systems that legislation apply its underlying principles as broadly as possible. So long as the broader application is not a sham, the legislation cannot be considered discriminatory. In the absence of any proof that the broader scope was a sham, it must be found that the evident concentration of public attention upon the effects of Section 55.2(1) on the pharmaceutical industry is not, by itself, evidence of a discriminatory purpose.

${ }^{438}$ Questions Asked by the Panel after the First Substantive Meeting, Question 16 
7.105 In sum, the Panel found that the evidence in record before it did not raise a plausible claim of discrimination under Article 27.1 of the TRIPS Agreement. It was not proved that the legal scope of Section 55.2(1) was limited to pharmaceutical products, as would normally be required to raise a claim of de jure discrimination. Likewise, it was not proved that the adverse effects of Section 55.2(1) were limited to the pharmaceutical industry, or that the objective indications of purpose demonstrated a purpose to impose disadvantages on pharmaceutical patents in particular, as is often required to raise a claim of de facto discrimination. Having found that the record did not raise any of these basic elements of a discrimination claim, the Panel was able to find that Section 55.2(1) is not inconsistent with Canada's obligations under Article 27.1 of the TRIPS Agreement. Because the record did not present issues requiring any more precise interpretation of the term "discrimination" in Article 27.1, none was made. ${ }^{439}$

\section{CONCLUSIONS}

8.1 In light of the findings above, the Panel has concluded as follows:

(1) Section 55.2(1) of Canada's Patent Act is not inconsistent with Canada's obligations under Article 27.1 and Article 28.1 of the TRIPS Agreement.

(2) Section 55.2(2) of Canada's Patent Act is not consistent with the requirements of Article 28.1 of the TRIPS Agreement.

Accordingly, the Panel recommends that the Dispute Settlement Body request that Canada bring Section 55.2(2) into conformity with Canada's obligations under the TRIPS Agreement.

${ }^{439}$ On the record before the Panel, there was no occasion to consider the question raised by certain third parties -whether measures that are limited to a particular area of technology - de jure or de facto - are necessarily "discriminatory" by virtue of that fact alone, or whether under certain circumstances they may be justified as special measures needed to restore equality of treatment to the area of technology in question. The Panel's decision regarding Section 55.2(1) did not touch upon that issue. 


\section{ANNEX 1}

\section{WORLD TRADE}

\section{ORGANIZATION}

WT/DS114/5

12 November 1998

(98-4503)

Original: English

\section{CANADA - PATENT PROTECTION OF PHARMACEUTICAL PRODUCTS}

\section{$\underline{\text { Request for the Establishment of a Panel by the European Communities }}$}

The following communication, dated 11 November 1998, from the Permanent Delegation of the European Commission to the Chairman of the Dispute Settlement Body, is circulated pursuant to Article 6.2 of the DSU.

My authorities have asked me to submit the following request on behalf of the Communities and their Member States for consideration at the next meeting of the Dispute Settlement Body.

The Agreement on Trade-Related Aspects of Intellectual Property Rights contained in Annex 1C to the Agreement Establishing the World Trade Organization (hereafter the "TRIPS Agreement") obliges those Members of the World Trade Organization (hereafter the "WTO"), which apply the Agreement since 1 January 1996 (Article 65.1 of the TRIPS Agreement), to grant patent protection for the subject matter specified in Article 27 of the TRIPS Agreement for a defined period of time. More precisely, the TRIPS Agreement provides in its:

Article 27.1 that "[...] patents shall be available and patent rights enjoyable without discrimination as to the place of invention, the field of technology and whether products are imported or locally produced";

- $\quad$ Article 28 that a patent shall confer on its owner the exclusive right to prevent third parties not having the owner's consent from the acts of making, using, offering for sale, selling or importing the patented product;

Article 33 that the "term of protection available shall not end before the expiration of a period of twenty years counted from the filing date".

However, the legal regime currently in force in Canada does allow with respect to pharmaceutical patents only that a third party may, without the consent of the patent holder, use the patented invention to: 
carry out experiments and tests required (proof of safety and bioequivalency) to obtain marketing approval of the copy of an innovative medicine before the expiration of the relevant patent in order to ensure market access immediately following the patent expiry (in particular, Section 55.2 (1) of the Patent Act);

manufacture and stockpile patented products for a period of up to six months before patent expiry for sale after expiry (in particular, Section 55.2 (2) of the Patent Act in conjunction with the "manufacturing and Storage of Patented Medicines Regulation").

As a consequence of the above, Canada's legal regime appears to be inconsistent with its obligations under the TRIPS Agreement, including but not limited to Articles 27, 28, and 33 of the TRIPS Agreement.

In a communication, dated 19 December 1997 (WT/DS114/1), the European Communities and their Member States requested consultations with Canada pursuant to Article 4 of the Understanding on Rules and Procedures Governing the Settlement of Disputes (hereafter the "DSU"), contained in Annex 2 of the WTO Agreement and Article 64 of the TRIPS Agreement in conjunction with Article XXII of the General Agreement on Tariffs and Trade 1994 (GATT 1994). Consultations were held on 13 February and 12 June 1998, but did not result in a satisfactory solution of the dispute.

Accordingly, the European Communities and their Member States request the establishment of a panel to examine the matter in the light of the relevant provisions of the TRIPS Agreement and to find that Canada fails to conform to the obligations contained in Articles 27, 28, and 33 of the TRIPS Agreement and thereby nullifies or impairs benefits accruing directly or indirectly to the European Communities and their Member States under the TRIPS Agreement.

The European Communities and their Member States ask that the panel be established with the standard terms of reference as provided for in Article 7 of the DSU. 


\section{ANNEX 2 \\ FOOD AND DRUG REGULATIONS \\ - PART C.08}

C.08.001. For the purposes of the Act and this Division, "new drug" means

(a) a drug that contains or consists of a substance, whether as an active or inactive ingredient, carrier, coating, excipient, menstruum or other component, that has not been sold as a drug in Canada for sufficient time and in sufficient quantity to establish in Canada the safety and effectiveness of that substance for use as a drug;

(b) a drug that is a combination of two or more drugs, with or without other ingredients, and that has not been sold in that combination or in the proportion in which those drugs are combined in that drug, for sufficient time and in sufficient quantity to establish in Canada the safety and effectiveness of that combination and proportion for use as a drug; or

(c) a drug, with respect to which the manufacturer prescribes, recommends, proposes or claims a use as a drug, or a condition of use as a drug, including dosage, route of administration, or duration of action and that has not been sold for that use or condition of use in Canada, for sufficient time and in sufficient quantity to establish in Canada the safety and effectiveness of that use or condition of use of that drug. SOR/95-172, s. 2.

C.08.001.1. For the purposes of this Division,

"Canadian reference product" means

(a) a drug in respect of which a notice of compliance is issued pursuant to section C.08.004 and which is marketed in Canada by the innovator of the drug,

(b) a drug, acceptable to the Minister, that can be used for the purpose of demonstrating bioequivalence on the basis of pharmaceutical and, where applicable, bioavailability characteristics, where a drug in respect of which a notice of compliance has been issued pursuant to section C.08.004 cannot be used for that purpose because it is no longer marketed in Canada, or

(c) a drug, acceptable to the Minister, that can be used for the purpose of demonstrating bioequivalence on the basis of pharmaceutical and, where applicable, bioavailability characteristics, in comparison to a drug referred to in paragraph (a); (produit de référence canadien)

"pharmaceutical equivalent" means a new drug that, in comparison with another drug, contains identical amounts of the identical medicinal ingredients, in comparable dosage forms, but that does not necessarily contain the same non-medicinal ingredients; (équivalent pharmaceutique)

"specifications" means a detailed description of a new drug and of its ingredients and includes

(a) a statement of all properties and qualities of the ingredients that are relevant to the manufacture and use of the new drug, including the identity, potency and purity of the ingredients,

(b) a detailed description of the methods used for testing and examining the ingredients, and

(c) a statement of the tolerances associated with the properties and qualities of the ingredients.

(spécifications) SOR/95-411, s. 3.

C.08.002. (1) No person shall sell or advertise a new drug unless

(a) the manufacturer of the new drug has filed with the Minister a new drug submission or an abbreviated new drug submission relating to the new drug that is satisfactory to the Minister;

(b) the Minister has issued, pursuant to section C.08.004, a notice of compliance to the manufacturer of the new drug in respect of the new drug submission or abbreviated new drug submission;

(c) the notice of compliance in respect of the submission has not been suspended pursuant to section C.08.006; and 
(d) the manufacturer of the new drug has submitted to the Minister specimens of the final version of any labels, including package inserts, product brochures and file cards, intended for use in connection with that new drug, and a statement setting out the proposed date on which those labels will first be used.

(2) A new drug submission shall contain sufficient information and material to enable the Minister to assess the safety and effectiveness of the new drug, including the following:

(a) a description of the new drug and a statement of its proper name or its common name if there is no proper name;

(b) a statement of the brand name of the new drug or the identifying name or code proposed for the new drug;

(c) a list of the ingredients of the new drug, stated quantitatively, and the specifications for each of those ingredients;

(d) a description of the plant and equipment to be used in the manufacture, preparation and packaging of the new drug;

(e) details of the method of manufacture and the controls to be used in the manufacture, preparation and packaging of the new drug;

$(f)$ details of the tests to be applied to control the potency, purity, stability and safety of the new drug;

$(g)$ detailed reports of the tests made to establish the safety of the new drug for the purpose and under the conditions of use recommended;

(h) substantial evidence of the clinical effectiveness of the new drug for the purpose and under the conditions of use recommended;

(i) a statement of the names and qualifications of all the investigators to whom the new drug has been sold;

$(j)$ a draft of every label to be used in conjunction with the new drug;

(k) a statement of all the representations to be made for the promotion of the new drug respecting

(i) the recommended route of administration of the new drug,

(ii) the proposed dosage of the new drug,

(iii) the claims to be made for the new drug, and

(iv) the contra-indications and side effects of the new drug;

(l) a description of the dosage form in which it is proposed that the new drug be sold;

$(m)$ evidence that all test batches of the new drug used in any studies conducted in connection with the submission were manufactured and controlled in a manner that is representative of market production; and

$(n)$ for a drug intended for administration to food-producing animals, the withdrawal period of the new drug.

(3) The manufacturer of a new drug shall, at the request of the Minister, provide the Minister, where for the purposes of a new drug submission the Minister considers it necessary to assess the safety and effectiveness of the new drug, with the following information and material:

(a) the names and addresses of the manufacturers of each of the ingredients of the new drug and the names and addresses of the manufacturers of the new drug in the dosage form in which it is proposed that the new drug be sold;

(b) samples of the ingredients of the new drug;

(c) samples of the new drug in the dosage form in which it is proposed that the new drug be sold; and

(d) any additional information or material respecting the safety and effectiveness of the new drug. SOR/85-143. s. 1; SOR/93-202, s. 24; SOR/95-411, s. 4.

C.08.002.1. (1) A manufacturer of a new drug may file an abbreviated new drug submission for the new drug where, in comparison with a Canadian reference product,

(a) the new drug is the pharmaceutical equivalent of the Canadian reference product; 
(b) the new drug is bioequivalent with the Canadian reference product, based on the pharmaceutical and, where the Minister considers it necessary, bioavailability characteristics;

(c) the route of administration of the new drug is the same as that of the Canadian reference product; and

(d) the conditions of use for the new drug fall within the conditions of use for the Canadian reference product.

(2) An abbreviated new drug submission shall contain sufficient information and material to enable the Minister to assess the safety and effectiveness of the new drug, including the following:

(a) the information and material described in paragraphs C.08.002(2)(a) to (f) and (j) to (1);

(b) information identifying the Canadian reference product used in any comparative studies conducted in connection with the submission;

(c) evidence from the comparative studies conducted in connection with the submission that the new drug is

(i) the pharmaceutical equivalent of the Canadian reference product, and

(ii) where the Minister considers it necessary on the basis of the pharmaceutical and, where applicable, bioavailability characteristics of the new drug, bioequivalent with the Canadian reference product as demonstrated using bioavailability studies, pharmacodynamic studies or clinical studies;

(d) evidence that all test batches of the new drug used in any studies conducted in connection with the submission were manufactured and controlled in a manner that is representative of market production; and

(e) for a drug intended for administration to food-producing animals, sufficie nt information to confirm that the withdrawal period is identical to that of the Canadian reference product.

(3) The manufacturer of a new drug shall, at the request of the Minister, provide the Minister, where for the purposes of an abbreviated new drug submission the Minister considers it necessary to assess the safety and effectiveness of the new drug, with the following information and material:

(a) the names and addresses of the manufacturers of each of the ingredients of the new drug and the names and addresses of the manufacturers of the new drug in the dosage form in which it is proposed that the new drug be sold;

(b) samples of the ingredients of the new drug;

(c) samples of the new drug in the dosage form in which it is proposed that the new drug be sold; and

(d) any additional information or material respecting the safety and effectiveness of the new drug. SOR/95-41 1, s. 5.

C.08.003. (1) Notwithstanding section C.08.002, no person shall sell a new drug in respect of which a notice of compliance has been issued to the manufacturer of that new drug and has not been suspended pursuant to section C.08.006, if any of the matters specified in subsection (2) are significantly different from the information or material contained in the new drug submission or abbreviated new drug submission, unless

(a) the manufacturer of the new drug has filed with the Minister

(i) a supplement to that new drug submission, or

(ii) a supplement to that abbreviated new drug submission;

(b) the Minister has issued a notice of compliance to the manufacturer of the new drug in respect of the supplement;

(c) the notice of compliance in respect of the supplement has not been suspended pursuant to section C.08.006; and

(d) the manufacturer of the new drug has submitted to the Minister specimens of the final version of any label, including any package insert, product brochure and file card, intended for use in connection with the new drug, where a change with respect to any of the matters specified in subsection (2) is made that would require a change to the label. 
(2) The matters specified for the purposes of subsection (1), in relation to the new drug, are the following:

(a) the description of the new drug;

(b) the brand name of the new drug or the identifying name or code proposed for the new drug;

(c) the specifications of the ingredients of the new drug;

(d) the plant and equipment used in manufacturing, preparation and packaging the new drug;

(e) the method of manufacture and the controls used in manufacturing, preparation and packaging the new drug;

$(f)$ the tests applied to control the potency, purity, stability and safety of the new drug;

$(g)$ the labels used in connection with the new drug;

(h) the representations made with regard to the new drug respecting

(i) the recommended route of administration of the new drug,

(ii) the dosage of the new drug,

(iii) the claims made for the new drug,

(iv) the contra-indications and side effects of the new drug, and

(v) the withdrawal period of the new drug; and

(i) the dosage form in which it is proposed that the new drug be sold.

(3) A supplement to a new drug submission or to an abbreviated new drug submission, with respect to the matters that are significantly different from those contained in the submission, shall contain sufficient information and material to enable the Minister to assess the safety and effectiveness of the new drug in relation to those matters. SOR/85-143, s. 2; SOR/93-202, s. 25; SOR/95-411, s. 6.

C.08.003.1. In the examination of a new drug submission, an abbreviated new drug submission, a supplement to a new drug submission, a supplement to an abbreviated new drug submission or a preclinical new drug submission, the Minister may examine any information or material filed with the Minister by any manufacturer, pursuant to section C.08.002, C.08.002. 1, C.08.003, C.08.005 or C.08.005. 1, to establish the safety and effectiveness of the new drug for which the submission or supplement has been filed. SOR/95-411, s. 6 .

C.08.004. (1) Subject to section C.08.004. 1, the Minister shall, after completing an examination of a new drug submission or abbreviated new drug submission or a supplement to either submission

(a) if that submission or supplement complies with section C.08.002, C.08.002.1 or C.08.003, as the case may be, and section C.08.005. 1, issue a notice of compliance; or

(b) if that submission or supplement does not comply with section C.08.002, C.08.002.1 or C.08.003, as the case may be, or section C.08.005.1, notify the manufacturer that the submission or supplement does not so comply.

(2) Where a new drug submission or abbreviated new drug submission or a supplement to either submission does not comply with section C.08.002, C.08.002.1 or C.08.003, as the case may be, or section C. 08.005. 1, the manufacturer who filed the submission or supplement may amend the submission or supplement by filing additional information or material.

(3) Subject to section C.08.004. 1, the Minister shall, after completing an examination of any additional information or material filed in respect of a new drug submission or an abbreviated new drug submission or a supplement to either submission,

(a) if that submission or supplement complies with section C.08.002, C.08.002.1 or C.08.003, as the case may be, and section C.08.005. 1, issue a notice of compliance; or

(b) if that submission or supplement does not comply with the requirements of section C.08.002, C.08.002.1 or C.08.003, as the case may be, or section C.08.005.1, notify the manufacturer that the submission or supplement does not so comply. 
(4) A notice of compliance issued in respect of a new drug on the basis of information and material contained in a submission filed pursuant to section C.08.002.1 shall state the name of the Canadian reference product referred to in the submission and shall constitute a declaration of equivalence for that new drug. SOR/84-267, ss. 1 to 3; SOR/85-143, s. 3; SOR/86-1009, s. 1; SOR/86-1101, s. 1; SOR/88-42, s. 1; SOR/88-257, s. 1; SOR/95-411, s. 6.

C.08.004.1. (1) Where a manufacturer files a new drug submission, an abbreviated new drug submission, a supplement to a new drug submission or a supplement to an abbreviated new drug submission for the purpose of establishing the safety and effectiveness of the new drug for which the submission or supplement is filed, and the Minister examines any information or material filed with the Minister, in a new drug submission, by the innovator of a drug that contains a chemical or biological substance not previously approved for sale in Canada as a drug, and the Minister, in support of the manufacturer's submission or supplement, relies on data contained in the information or material filed by the innovator, the Minister shall not issue a notice of compliance in respect of that submission or supplement earlier than five years after the date of issuance to the innovator of the notice of compliance or approval to market that drug, as the case may be, issued on the basis of the information or material filed by the innovator for that drug.

(2) Subsection (1) does not apply where the manufacturer of a new drug for which a notice of compliance was issued pursuant to section C. 08.004 gives written permission to another manufacturer to rely on the test or other data filed in respect of that new drug.

(3) Subsection (1) does not apply where the data relied upon by the Minister was contained in information or material filed by the innovator before January 1, 1994. SOR/95-411, s. 6.

C.08.005. (1) Notwithstanding sections C.08.002 and C.08.003, a manufacturer of a new drug may sell the new drug to an investigator qualified to use it (hereinafter referred to as a "qualified investigator") for use by the investigator solely for the purpose of clinical testing to obtain evidence with respect to the safety, dosage and effectiveness of that new drug, if

(a) before the sale, the manufacturer has filed with the Minister, in compliance with section

C.08.005.1, a preclinical submission containing information and material respecting

(i) the brand name of the new drug or the identifying name or code proposed for the new drug,

(ii) the chemical structure or other specific identification of the composition of the new drug,

(iii) the source of the new drug,

(iv) a detailed protocol of the clinical testing,

(v) the results of investigations made to support the clinical use of the new drug,

(vi) the contra-indications and precautions known in respect of the new drug and the suggested treatment of overdosage of the new drug,

(vii) all ingredients of the new drug, stated quantitatively,

(viii) the methods, equipment, plant and controls used in the manufacture, processing and packaging of the new drug,

(ix) the tests applied to control the potency, purity and safety of the new drug, and

(x) the names and qualifications of all investigators to whom the drug is to be sold and the names of all institutions in which the clinical testing is to be carried out;

(b) the Director has not, within 60 days after the date of receipt of the preclinical submission, sent by registered mail to the manufacturer a notice in respect of that new drug indicating that the preclinical submission is not satisfactory;

(c) all inner labels and outer labels used in conjunction with the sale of the new drug to qualified investigators carry the statements

(i) "Investigational Drug" or "Drogue de recherche", and

(ii) "To Be Used By Qualified Investigators Only" or 'Réservée uniquement i l'usage de chercheurs compétents"; 
(d) before the sale, the manufacturer ascertains that every qualified investigator to whom the new drug is to be sold

(i) has the facilities for the clinical testing to be conducted by the investigator, and

(ii) has received the information and material referred to in subparagraphs (a)(i) to (vi); and

(e) every qualified investigator to whom the new drug is to be sold has agreed in writing with the manufacturer that the investigator will

(i) not use the new drug or permit it to be used other than for clinical testing,

(ii) not permit the new drug to be used by any person other than the investigator except under the investigator's direction,

(iii) report immediately to that manufacturer and, if so required by the Director, report to the Director all serious adverse reactions encountered during the clinical testing, and

(iv) account to the manufacturer for all quantities of the new drug received, where so requested by the manufacturer.

(2) Notwithstanding subsection (1), no manufacturer shall sell a new drug to a qualified investigator unless that manufacturer has, in respect of all previous sales of that new drug to any qualified investigator,

(a) kept accurate records of the distribution of that new drug and of the results of the clinical testing and has made those records available to the Director for inspection on the request of the Director; and

(b) immediately reported to the Director all information he has obtained with respect to serious adverse reactions.

(3) The Minister may notify the manufacturer of a new drug that sales of that new drug to qualified investigators are prohibited if, in the opinion of the Minister, it is in the interest of public health to do so.

(4) Notwithstanding subsection (1), no manufacturer shall sell a new drug to a qualified investigator if the Minister has notified the manufacturer of that drug that such sales are prohibited.

(5) Paragraph (1)(c) does not apply to a radiopharmaceutical as defined in section C.03.201 or to a component or kit as defined in section C.03.205. SOR/79-236, s. 5; SOR/85-143, s. 4; SOR/87-511, s. 1; SOR/93-202, s. 26; SOR/95-411, s. 7.

C.08.005.1. (1) Every manufacturer who files a new drug submission, an abbreviated new drug submission, a supplement to a new drug submission, a supplement to an abbreviated new drug submission or a preclinical new drug submission shall, in addition to such information and material as is required under sections C.08.002, C.08.003 and C.08.005, include in the submission or supplement

(a) a copy of all clinical case reports respecting any subject of a study included in the submission or supplement if that subject has died, suffered a serious adverse reaction or an unexpected adverse reaction, or the study, insofar as it relates to this subject, has not been completed;

(b) a sectional report in respect of each human, animal and in vitro study included in the submission or supplement;

(c) a comprehensive summary of each human, animal and in vitro study referred to or included in the submission or supplement; and

(d) a submission certificate in respect of all information and material contained in the submission or supplement and any additional information or material filed to amend the submission or supplement. ,

(2) A sectional report referred to in paragraph (1)(b) shall include

(a) a summary of each study included in the submission or supplement; 
(b) a summary of any additional information or material filed to amend the submission or supplement; and

(c) where raw data is available to the manufacturer in respect of a study,

(i) a summary of the data,

(ii) a cross-referencing of the data to the relevant portions of the sectional report,

(iii) a description of the conditions under which the experiments from which the data were obtained were conducted,

(iv) the details of the data treatment process, and

(v) the results and conclusions of the study.

(3) The comprehensive summary referred to in paragraph (1)(c) shall include a summary of the methods used, results obtained and conclusions arrived at in respect of all studies referred to or included in the submission or supplement and shall be cross-referenced to the relevant portions of the sectional reports.

(4) The submission certificate referred to in paragraph (1)(a) shall

(a) certify that all information and material included in the submission or supplement and any additional information or material filed to amend the subn-dssion or supplement are accurate and complete, and that the sectional reports and the comprehensive summary correctly represent the information and material referred to or included in the submission or supplement; and

(b) be signed and dated by

(i) the senior executive officer in Canada of the manufacturer filing the submission or supplement, and

(ii) the senior medical or scientific officer of the manufacturer.

(5) No person shall sign a submission certificate if a sectional report, comprehensive summary or any information or material included in the submission or supplement, or any additional information and material filed to amend the submission or supplement,

(a) is false or misleading; or

(b) contains omissions that may affect its accuracy and completeness.

(6) Every manufacturer who has any clinical case reports or raw data that relate to a new drug submission, an abbreviated new drug submission, a supplement to a new drug submission, a supplement to an abbreviated new drug submission or a preclinical new drug submission filed by the manufacturer, and that were not included therein, shall keep those reports or data and shall, within 30 days after receiving a written request from the Minister, submit them to the Minister. SOR/85-143, s. 5; SOR/92-543, s. 1; SOR/94-689, s. 2(F); SOR/95-411, s. 8.

C.08.006. (1) For the purposes of this section, evidence or new information obtained by the Minister includes any information or material filed by any manufacturer pursuant to section C.08.002, C.08.002. 1, C.08.003, C.08.005 or C.08.005. 1.

(2) The Minister may, by notice to a manufacturer, suspend, for a definite or indefinite period, a notice of compliance issued to that manufacturer in respect of a new drug submission or an abbreviated new drug submission or a supplement to either submission if the Minister considers

(a) that the drug is not safe for the use represented in the submission or supplement, as shown by evidence obtained from

(i) clinical or other experience not reported in the submission or supplement or not available to the Minister at the time the notice of compliance was issued, or

(ii) tests by new methods or tests by methods not reasonably applicable at the time the notice of compliance was issued;

(b) that, upon the basis of new information obtained after the issuance of the notice of compliance, there is lack of substantial evidence that the drug will have the effect it is 
represented to have under the conditions of use prescribed, recommended or proposed by the manufacturer;

(c) that the submission or supplement contained an untrue statement of material fact;

(d) that the manufacturer has failed to establish a system for maintaining required records or has repeatedly or deliberately failed to maintain such records;

(e) that, on the basis of new information obtained after the issuance of the notice of compliance, the methods, equipment, plant and controls used in the manufacturing, processing and packaging of the drug are inadequate to assure and preserve the identity, strength, quality or purity of the new drug; or

(f) that, on the basis of new information obtained after the issuance of the notice of compliance, the labelling of the drug is false or misleading or incomplete in any particular and that this defect was not corrected by the manufacturer upon receipt of a written notice from the Director specifying the respect in which the labelling is false or misleading or incomplete. SOL/95-411, s. 9.

C.08.007. Where a manufacturer has received a notice of compliance issued in respect of a new drug submission or abbreviated new drug submission or a supplement to either submission, the manufacturer shall establish and maintain records, in a manner that enables an audit to be made, respecting

(a) animal or clinical experience, studies, investigations and tests conducted by the manufacturer or reported to him by any person concerning that new drug;

(b) reports from the scientific literature or the bibliography therefrom that are available to him concerning that new drug;

(c) experience, investigations, studies and tests involving the chemical or physical properties or any other properties of that new drug;

(d) any substitution of another substance for that new drug or any mixing of another substance with that new drug;

(e) any error in the labelling of that new drug or in the use of the labels designed for that new drug;

$(f)$ any bacteriological or any significant chemical or physical or other change or deterioration in any lot of that new drug;

$(\mathrm{g})$ any failure of one or more distributed lots of the new drug to meet the specifications established for that new drug in the submission or supplement; and

(h) any unusual failure in efficacy of that new drug. SOR/95-41 1, s. 10; SOR/95-52 1, s. 3.

(i) [Repealed, SOR/95-521, s. 31

C.08.008. No manufacturer shall sell a new drug unless the manufacturer has, with respect to all the manufacturer's previous sales of that new drug, furnished to the Minister

(a) on request, reports of all records respecting the information described in paragraphs C.08.007(a) to (c);

(b) immediately on receipt by the manufacturer, reports of all records respecting the information described in paragraphs C.08.007(d) to (1); and

(c) within 15 days after the receipt by the manufacturer of information referred to in paragraphs C.08.007(g) and (h), a report on the information received. SOR/95-411, s. 11; SOR/95-521, s. 4.

C.08.009. (1) Where the Minister has decided

(a) to notify the manufacturer of a new drug that sales of that new drug to qualified investigators are prohibited, or

(b) to suspend a notice of compliance issued in respect of a new drug submission or an abbreviated new drug submission or a supplement to either submission,

the manufacturer, if dissatisfied with that decision, may require the Minister to provide him with the reasons for the decision. 
(2) Where the manufacturer has received the reasons for a decision of the Minister pursuant to subsection (1), he may require the Minister to refer that decision to a New Drug Committee and thereupon shall provide the Minister with a statement of the reasons for his dissatisfaction and any information and material upon which he relies in support of those reasons.

(3) Where the Minister has been required to refer a decision to a New Drug Committee pursuant to subsection (2), he shall appoint a member of the New Drug Committee, the dissatisfied manufacturer shall appoint a member of the New Drug Committee and the two members so appointed shall appoint a third member of the New Drug Committee who shall be chairman, or, if they are unable to do so within a reasonable time, the Minister shall appoint a third member of the New Drug Committee who shall be chairman.

(4) Any person who is in the full-time employment of the Department or in the full-time employment of the dissatisfied manufacturer shall not be appointed a member of a New Drug Committee.

(4.1) A member of a New Drug Committee shall, on appointment, sign an undertaking not to disclose or use any information, material, data, evidence or representations considered pursuant to subsection (6).

(5) The Minister shall pay the reasonable fees and costs incurred by the member of the New Drug Committee appointed by the Minister, and the dissatisfied manufacturer shall pay the reasonable fees and costs incurred by the member appointed by the dissatisfied manufacturer, and the Minister and the dissatisfied manufacturer shall each pay half of the reasonable fees and costs incurred by the chairman.

(6) The New Drug Committee formed pursuant to subsection (3) shall consider the reasons for the decision of the Minister, the reasons for the dissatisfaction of the dissatisfied manufacturer and any information or material in support of the reasons of the Minister or the dissatisfied manufacturer and may consider other evidence, material, information or representations.

(7) The New Drug Committee formed pursuant to subsection (3) shall report its findings and recommendations to the Minister.

(7.1) No member of a New Drug Committee shall disclose or use any information, material, data, evidence or representations considered pursuant to subsection (6).

(8) Where the Minister has received the findings and recommendations of a New Drug Committee, he may reconsider the decision to which those findings and recommendations relate. SOR/95-411, s. 12.

\section{Sale of New Drug for Emergency Treatment}

C.08.010. (1) The Director may issue a letter of authorization authorizing the sale of a quantity of a new drug for human or veterinary use to a practitioner named in the letter of authorization for use in the emergency treatment of a patient under the care of that practitioner, if

(a) the practitioner has supplied to the Director information concerning

(i) the medical emergency for which the drug is required,

(ii) the data in the possession of the practitioner with respect to the use, safety and efficacy of that drug,

(iii) the names of all institutions in which the drug is to be used, and

(iv) such other data as the Director may require; and

(b) the practitioner has agreed to

(i) report to the manufacturer of the new drug and to the Director on the results of the use of the drug in the medical emergency, including information respecting any adverse reactions encountered, and 
(ii) account to the Director on request for all quantities of the drug received by him.

(2) The Director shall, in any letter of authorization issued pursuant to subsection (1), state

(a) the name of the practitioner to whom the new drug may be sold;

(b) the medical emergency in respect of which the new drug may be sold; and

(c) the quantity of the new drug that may be sold to that practitioner for that emergency.

C.08.011. (1) Notwithstanding section C.08.002, a manufacturer may sell to a practitioner named in a letter of authorization issued pursuant to section C.08.010, a quantity of the new drug named in that letter that does not exceed the quantity specified in the letter.

(2) A sale of a new drug made in accordance with subsection (1) is exempt from the provisions of the Act and these Regulations.

\section{Sale of Medicated Feeds}

C.08.012. (1) Notwithstanding anything in this Division, a person may sell, pursuant to a written prescription of a veterinary practitioner, a medicated feed if

(a) as regards the drug or drugs used as the medicating ingredient of the medicated feed,

(i) the Director has assigned a drug identification number pursuant to section C.01.014.2,

(ii) the sale is permitted by section C.08.005, C.08.01 1 or C.08.013;

(b) the medicated feed is for the treatment of animals under the direct care of the veterinary practitioner who signed the prescription;

(c) the medicated feed is for therapeutic purposes only; and

(d) the written prescription contains the following information:

(i) the name and address of the person named on the prescription as the person for whom the medicated feed is to be mixed,

(ii) the species, production type and age or weight of the animals to be treated with the medicated feed,

(iii) the type and amount of medicated feed to be mixed,

(iv) the proper name, or the common name if there is no proper name, of the drug or each of the drugs, as the case may be, to be used as medicating ingredients in the preparation of the medicated feed, and the dosage levels of those medicating ingredients,

(v) any special mixing instructions, and

(vi) labelling instructions including

(A) feeding instructions,

(B) a warning statement respecting the withdrawal period to be observed following the use of the medicated feed, and

(C) where applicable, cautions with respect to animal health or to the handling or storage of the medicated feed.

(2) For the purpose of this section, "medicated feed" has the same meaning as in the Feeds Regulations. SOR/80-741, s. 1; SOR/92-130, s. 1; SOR/93-202, s. 27.

\section{Experimental Studies}

\section{Conditions of Sale}

C.08.013. (1) Notwithstanding anything in this Division, a person may sell a new drug proposed for use in animals to an experimental studies investigator in a quantity specified by the Director for the purpose of conducting an experimental study in animals if 
(a) the experimental studies investigator has been issued an experimental studies certificate pursuant to subsection C.08.015(1) and the certificate has not been suspended or cancelled pursuant to section C.08.018; and

(b) the drug is labelled in accordance with subsection C.08.016(1).

(2) For the purposes of this section and sections C.08.014 to C.08.018,

"experimental studies certificate" means a certificate issued pursuant to subsection C.08.015(1); (certificat d'études expérimentales)

"experimental studies investigator" means a person named as the investigator in an experimental studies certificate; (expert en études expérimentales)

"experimental study" means a limited test of a new drug in animals carried out by an experimental studies investigator. (étude expérimentale) SOR/81-333, s. 1.

\section{Experimental Studies Certificate}

C.08.014. (1) For the purpose of obtaining an experimental studies certificate, an applicant shall submit to the Director, in writing, the following information and material:

(a) the brand name of the new drug or the identifying name or code proposed for the new drug;

(b) the objectives and an outline of the proposed experimental study of the new drug;

(c) the species, number and production type of animals in respect of which the new drug is to be administered;

(d) the name and address of the manufacturer of the new drug;

(e) the address of the premises in which the experimental study is to be conducted;

$(f)$ a description of the facilities to be used to conduct the experimental study;

$(g)$ the name, address and qualifications of the proposed experimental studies investigator;

(h) the chemical structure, if known, and the relevant compositional characteristics of the new drug;

(i) the proposed quantity of the new drug to be used for the experimental study;

$(j)$ the results of any toxicological or pharmacological studies that may have been conducted with the new drug;

$(k)$ the written agreement referred to in subsection (2); and

(1) such other information and material as the Director may require.

(2) Where a food-producing animal is involved in an experimental study, the applicant referred to in subsection (1) shall, for the purposes of obtaining an experimental studies certificate, obtain from the owner of the animals, or from a person authorized by the owner, a written agreement not to sell the animal or any products from it without prior authorization from the experimental studies investigator.

(3) The Director may request the manufacturer of a new drug to submit to him samples o f the new drug or of any ingredient of the drug and, in satisfactory form and manner, any other information that the Director requests and where such samples or information are not submitted, the Director may refuse to issue an experimental studies certificate. SUR/81-333, s. 1; SOR/93-202, s. 28.

C.08.015. (1) Where, on receipt of the information and material submitted pursuant to section C.08.014, the Director is satisfied that

(a) the applicant is qualified as an experimental studies investigator for the purposes of the proposed experimental study,

(b) the facilities for the conduct of the experimental study are adequate for the purposes of the proposed experimental study, and

(c) the proposed experimental study can be conducted without undue foreseeable risk to humans or animals, 
the Director shall issue an experimental studies certificate for the purposes of the proposed experimental study and shall specify therein the quantity of the new drug that may be sold to the experimental studies investigator.

(2) Where, on receipt of the information and material submitted pursuant to section C.08.014, the Director is not satisfied that the requirements of paragraphs (1)(a), (b) and (c) have been met, he shall refuse to issue an experimental studies certificate. SOR/81-333, s. 1.

\section{Labelling}

C.08.016. (1) The label of a new drug that is sold pursuant to section C. 08.013 shall show

(a) the brand name of the new drug or the identifying name or code proposed for the new drug;

(b) a warning statement to the effect that the drug is for use only in an experimental study in animals;

(c) the lot number of the drug;

(d) the name and address of the manufacturer of the drug; and

(e) the name of the person to whom the drug has been supplied.

(2) Sections C.01.004, C.01.005 and C.01.014 do not apply to a drug that is sold pursuant to section C.08.013 and labelled in accordance with subsection (1). SOR/81-333, s. 1; SOR/88-378, s. 2; SOR/93-202, s. 29.

\section{Conditions of Experimental Study}

C.08.017. An experimental studies investigator shall

(a) use the new drug only in accordance with the outline of the experimental study;

(b) report immediately to the Director 0 serious adverse reactions associated with the use of the new drug, drug,

(c) report promptly to the Director, on request, the results of the experimental study;

(d) return to the manufacturer, on request, all quantities of the new drug not used in the experimental study;

(e) maintain all records of the experimental study for a period of at least two years after the conclusion of the study and, on request, make such records available to the Director;

$(f)$ report promptly to the Director any known disposition of animals involved in the study or of any products from the animals that is contrary to the terms of the agreement referred to in subsection C.08.014(2); and

$(\mathrm{g})$ account to the Director, on request, for all quantities of the new drug received by him. SOR/81-333, s. 1.

\section{Suspension or Cancellation of Experimental Studies Certificate}

C.08.018. (1) Where the Director is of the opinion that it is necessary in order to safeguard animal health or public health or to promote public safety, he may suspend for a definite or indefinite period or cancel an experimental studies certificate.

(2) Without limiting the generality of subsection (1), the Director may suspend or cancel an experimental studies certificate if

(a) the information and material submitted pursuant to section C.08.014 contains an untrue statement or contains any omission concerning the properties of the drug that were known or ought reasonably to have been known to the manufacturer or the experimental studies investigator,

(b) the labelling of the new drug is, at any time, false, misleading, deceptive or incomplete;

(c) the qualifications of the experimental studies investigator prove to be inadequate; 
(d) there is evidence that the experimental studies investigator has not complied with the conditions referred to in section C.08.017; or

(e) an action of the manufacturer in respect of the new drug has resulted in his conviction for a violation of section C.08.002. SOR/81-333, s. 1 . 
WT/DS114/R

Page 190

\section{ANNEX 3}

$\underline{\text { Letter from Jim Keon, Canadian Drug Manufacturers }}$

Association to Reagan Walker

Canadian Drug Manufacturers Association

L'Association Canadienne des

Fabricants de Produits Pharmaceutiques

May 13, 1999

Mr. Reagan Walker

Legal Counsel

Foreign Affairs \& International Trade

Trade Law Division/JLT

Fax: 613-944-0027

125 Sussex Drive

Ottawa, Ontario

K1A OG2

Re: Timing for Development of new Generic Drugs

Dear Mr. Walker,

The following information is provided in response to your question regarding the average time taken up in pre-submission activities for the development of a generic drug.

To answer the question accurately, we conducted a telephone survey of our member companies who are final dosage manufacturers.

The results of our survey indicate that the total pre-submission time necessary to develop a generic drug is 2-4 years. This includes 1 to 3 years to develop and test the proper formulation in addition to one year (approximately) needed for development of the raw material.

The CDMA would be please to provide further information as required.

Yours truly,

Jim Keon

President

$\mathrm{JK} / \mathrm{lp}$ 


\title{
ANNEX 4 \\ Patented Medicines (Notice of Compliance) Regulations
}

SOR/93-133

Registration 12 March, 1993

\author{
PATENT ACT
}

\section{Patented Medicines (Notice of Compliance) Regulations}

P.C. 1993-502 12 March, 1993

His Excellency the Governor General in Council, on the recommendation of the Minister of Consumer and Corporate Affairs, pursuant to subsection 55.2(4)* of the Patent Act, is pleased hereby to make the annexed Regulations respecting a notice of compliance pertaining to patented medicines.

*S.C. 1993 , c. 2 , s. 4

\section{REGULATIONS RESPECTING A NOTICE OF COMPLIANCE PERTAINING TO PATENTED MEDICINES}

\section{SHORT TITLE}

1. These Regulations may be cited as the Patented Medicines (Notice of Compliance) Regulations.

\section{INTERPRETATION}

2. In these Regulations,

"claim for the medicine itself" includes a claim in the patent for the medicine itself when prepared or produced by the methods or processes of manufacture particularly described and claimed or by their obvious chemical equivalents; (revendication pour le médicament en soi)

"claim for the use of the medicine" means a claim for the use of the medicine for the diagnosis, treatment, mitigation or prevention of a disease, disorder or abnormal physical state, or the symptoms thereof; (revendication pour l'utilisation du médicament)

"court" means the Federal Court of Canada or any other superior court of competent jurisdiction; (tribunal)

"expire" means, in relation to a patent, expire, lapse or terminate by operation of law; (expiré)

"first person" means the person referred to in subsection 4(1); (première personne) 
"medicine" means a substance intended or capable of being used for the diagnosis, treatment, mitigation or prevention of a disease, disorder or abnormal physical state, or the symptoms thereof; (médicament)

"Minister" means the Minister of National Health and Welfare; (ministre)

"notice of compliance" means a notice issued under section C.08.004 of the Food and Drug Regulations; (avis de conformité)

"patent list" means a list of all patents that is submitted pursuant to section 4; (iste de brevets)

"register" means the register maintained by the Minister under section 3; (registre)

"second person" means the person referred to in subsection 5(1). (seconde personne) SOR/98-166, s. 1.

\section{REGISTER}

3. (1) The Minister shall maintain a register of any information submitted pursuant to section 4. To maintain it, the Minister may refuse to add or may delete any information that does not meet the requirements of that section.

(2) The register shall be open to public inspection during business hours.

(3) No information submitted pursuant to section 4 shall be included on the register until after the issuance of the notice of compliance in respect of which the information was submitted.

(4) For the purpose of deciding whether information submitted under section 4 should be added to or deleted from the register, the Minister may consult with officers or employees of the Patent Office. SOR/98-166, s. 2.1

\section{PATENT LIST}

4. (1) A person who files or has filed a submission for, or has been issued, a notice of compliance in respect of a drug that contains a medicine may submit to the Minister a patent list certified in accordance with subsection (7) in respect of the drug.

(2) A patent list submitted in respect of a drug must

(a) indicate the dosage form, strength and route of administration of the drug;

(b) set out any Canadian patent that is owned by the person, or in respect of which the person has an exclusive licence or has obtained the consent of the owner of the patent for the inclusion of the patent on the patent list, that contains a claim for the medicine itself or a claim for the use of the medicine and that the person wishes to have included on the register; 
(c) contain a statement that, in respect of each patent, the person applying for a notice of compliance is the owner, has an exclusive licence or has obtained the consent of the owner of the patent for the inclusion of the patent on the patent list;

(d) set out the date on which the term limited for the duration of each patent will expire pursuant to section 44 or 45 of the Patent Act; and

(e) set out the address in Canada for service on the person of any notice of an allegation referred to in paragraph $5(3)(b)$ or $(c)$, or the name and address in Canada of another person on whom service may be made, with the same effect as if service had been made on the person.

(3) Subject to subsection (4), a person who submits a patent list must do so at the time the person files a submission for a notice of compliance.

(4) A first person may, after the date of filing of a submission for a notice of compliance and within 30 days after the issuance of a patent that was issued on the basis of an application that has a filing date that precedes the date of filing of the submission, submit a patent list, or an amendment to an existing patent list, that includes the information referred to in subsection(2).

(5) When a first person submits a patent list or an amendment to an existing patent list in accordance with subsection (4), the first person must identify the submission to which the patent list or the amendment relates, including the date on which the submission was filed.

(6) A person who submits a patent list must keep the list up to date but may not add a patent to an existing patent list except in accordance with subsection (4).

(7) A person who submits a patent list or an amendment to an existing patent list under subsection (1) or (4) must certify that

(a) the information submitted is accurate; and

(b) the patents set out on the patent list or in the amendment are eligible for inclusion on the register and are relevant to the dosage form, strength and route of administration of the drug in respect of which the submission for a notice of compliance has been filed. SOR/98166 , s. 3.

5. (1) Where a person files or has filed a submission for a notice of compliance in respect of a drug and wishes to compare that drug with, or make a reference to, another drug that has been marketed in Canada pursuant to a notice of compliance issued to a first person in respect of which a patent list has been submitted, the person shall, in the submission, with respect to each patent on register in respect of the other drug,

(a) state that the person accepts that the notice of compliance will not issue until the patent expires; or

(b) allege that 
(i) the statement made by the first person pursuant to paragraph $4(2)(b)$ is false,

(ii) the patent has expired,

(iii) the patent is not valid, or

(iv) no claim for the medicine itself and no claim for the use of the medicine would be infringed by the making, constructing, using or selling by that person of the drug for which the submission for the notice of compliance is filed.

(2) Where, after a second person files a submission for a notice of compliance, but before the notice of compliance is issued, a patent list or an amendment to a patent list is submitted in respect of a patent pursuant to subsection 4(4), the second person shall amend the submission to include, in respect of that patent, the statement or allegation that is required by subsection(1).

(3) Where a person makes an allegation pursuant to paragraph (1)(b) or subsection (2) the person shall

(a) provide a detailed statement of the legal and factual basis for the allegation;

(b) if the allegation is made under any of subparagraphs $(1)(b)(\mathrm{i})$ to (iii), serve a notice of the allegation on the first person;

(c) if the allegation is made under subparagraph (1)(b)(iv),

(i) serve on the first person a notice of the allegation relating to the submission filed under subsection (1) at the time that the person files the submission or at any time thereafter, and

(ii) include in the notice of allegation a description of the dosage form, strength and route of administration of the drug in respect of which the submission has been filed; and

(d) serve proof of service of the information referred to in paragraph $(b)$ or $(c)$ on the Minister. SOR/98-166, ss. 4, 9(T).

\section{RIGHT OF ACTION}

6. (1) A first person may, within 45 days after being served with a notice of an allegation pursuant to paragraph $5(3)(b)$ or $(c)$, apply to a court for an order prohibiting the Minister from issuing a notice of compliance until after the expiration of a patent that is the subject of an allegation.

(2) The court shall make an order pursuant to subsection (1) in respect of a patent that is the subject of one or more allegations if it finds that none of those allegations is justified.

(3) The first person shall, within the 45 days referred to in subsection (1), serve the Minister with proof that an application referred to in that subsection has been made.

(4) Where the first person is not the owner of each patent that is the subject of an application referred to in subsection (1), the owner of each such patent shall be made a party to the application. 
(5) In a proceeding in respect of an application under subsection (1), the court may, on the motion of a second person, dismiss the application

(a) if the court is satisfied that the patents at issue are not eligible for inclusion on the register or are irrelevant to the dosage form, strength and route of administration of the drug for which the second person has filed a submission for a notice of compliance; or

(b) on the ground that the application is redundant, scandalous, frivolous or vexatious or is otherwise an abuse of process.

(6) For the purposes of an application referred to in subsection (1), where a second person has made an allegation under subparagraph $5(1)(b)(i v)$ in respect of a patent and where that patent was granted for the medicine itself when prepared or produced by the methods or processes of manufacture particularly described and claimed or by their obvious chemical equivalents, it shall be considered that the drug proposed to be produced by the second person is, in the absence of proof to the contrary, prepared or produced by those methods or processes.

(7) On the motion of a first person, the court may, at any time during a proceeding,

(a) order a second person to produce any portion of the submission for a notice of compliance filed by the second person relevant to the disposition of the issues in the proceeding and may order that any change made to the portion during the proceeding be produced by the second person as it is made; and

(b) order the Minister to verify that any portion produced corresponds fully to the information in the submission.

(8) A document produced under subsection (7) shall be treated confidentially.

(9) In a proceeding in respect of an application under subsection (1), a court may make any order in respect of costs, including on a solicitor-and-client basis, in accordance with the rules of the court.

(10) In addition to any other matter that the court may take into account in making an order as to costs, it may consider the following factors:

(a) the diligence with which the parties have pursued the application;

(b) the inclusion on the certified patent list of a patent that should not have been included under section 4; and

(c) the failure of the first person to keep the patent list up to date in accordance with subsection 4(6). SOR/98-166, ss. 5, 9(T).

\section{NOTICE OF COMPLIANCE}

7. (1) The Minister shall not issue a notice of compliance to a second person before the latest of 
(a) [Repealed, SOR/98-166, s. 6]

(b) the day on which the second person complies with section 5,

(c) subject to subsection (3), the expiration of any patent on the patent list that is not the subject of an allegation,

(d) subject to subsection (3), the expiration of 45 days after the receipt of proof of service of a notice of any allegation pursuant to paragraph $5(3)(b)$ or $(c)$ in respect of any patent on the register,

(e) subject to subsections (2), (3) and (4), the expiration of 24 months after the receipt of proof of the making of any application referred to in subsection 6(1), and

(f) the expiration of any patent that is the subject of an order pursuant to subsection 6(1).

(2) Paragraph (1)(e) does not apply if at any time, in respect of each patent that is the subject of an application pursuant to subsection 6(1),

(a) the patent has expired; or

(b) the court has declared that the patent is not valid or that no claim for the medicine itself and no claim for the use of the medicine would be infringed.

(3) Paragraphs (1) $(c),(d)$ and $(e)$ do not apply in respect of a patent if the owner of the patent has consented to the making, constructing, using or selling of the drug in Canada by the second person.

(4) Paragraph (1)(e) ceases to apply in respect of an application referred to in subsection 6(1) if the application is withdrawn or discontinued by the first person or is dismissed by the court hearing the application.

(5) If the court has not yet made an order under subsection 6(1) in respect of an application, the court may

(a) shorten the time limit referred to in paragraph (1)(e) on consent of the first and second persons or if the court finds that the first person has failed, at any time during the proceeding, to reasonably cooperate in expediting the application; or

(b) extend the time-limit referred to paragraph 1(e) on consent of the first and second persons or, if the court finds that the second person has failed, at any time during the proceeding, to reasonably cooperate in expediting the application. SOR/98-166, ss. 6, 9(T). 


\section{REMEDIES}

[Repealed, SOR/98-166, s. 7]

8. (1) If an application made under subsection 6(1) is withdrawn or discontinued by the first person or is dismissed by the court hearing the application or if an order preventing the Minister from issuing a notice of compliance, made pursuant to that subsection, is reversed on appeal, the first person is liable to the second person for any loss suffered during the period

(a) beginning on the date, as certified by the Minister, on which a notice of compliance would have been issued in the absence of these Regulations, unless the court is satisfied on the evidence that another date is more appropriate; and

(b) ending on the date of the withdrawal, the discontinuance, the dismissal or the reversal.

(2) A second person may, by action against a first person, apply to the court for an order requiring the first person to compensate the second person for the loss referred to in subsection (1).

(3) The court may make an order under this section without regard to whether the first person has commenced an action for the infringement of a patent that is the subject-matter of the application.

(4) The court may make such order for relief by way of damages or profits as the circumstances require in respect of any damage referred to in subsection (1).

(5) In assessing the amount of compensation the court shall take into account all matters that it considers relevant to the assessment of the amount, including any conduct of the first or second person which contributed to delay the disposition of the application under subsection 6(1).

SOR/98-166, ss 8, 9(T).

\section{SERVICE}

9. (1) Service of any document referred to in these Regulations shall be effected personally or by registered mail.

(2) Service by registered mail shall be deemed to be effected on the addressee five days after mailing.

\section{[ TRANSITIONAL PROVISIONS: SOR/98-166:}

9. (1) Subsection 4(4) does not apply to an allegation if, before the coming into force of these Regulations, it was served on the first person, if proof of that service was served on the Minister and if the first person has commenced a proceeding under subsection $6(1)$. 
(2) Subsections 6(5) and (9) and paragraphs 6(10)(a) and (b) of the Regulations, as enacted by section 5, apply to an application pending on the coming into force of these Regulations.

(3) Subsections 6(6) to (8) and paragraph 6(10)(c) of the Regulations, as enacted by section 5, apply to an application commenced on or after the coming into force of these Regulations.

(4) Paragraph 7(1)(e) of the Regulations, as enacted by subsection 6(2), applies to an application made on or after the coming into force of these Regulations. Paragraph $7(1)(e)$ of the Regulations as it read before the coming into force of these Regulations, continues to apply to an application pending at the time of that coming into force.

(5) Subsection 7(5) of the Regulations, as enacted by subsection 6(3), applies to an application pending on the coming into force of these Regulations.

(6) Section 8 of the Regulations, as enacted by section 8, applies to an application pending on the coming into force of these Regulations.] 


\begin{abstract}
ANNEX 5
Questions Posed by the Panel and Replies Received from the Parties and Third Parties on the Practice in Countries Other Than Canada as Regards Regulatory Review Exceptions and Patent Term Extension or Supplementary Protection Certificate Systems
\end{abstract}

Questions from the Panel to the EC and Canada after the First Substantive Meeting

The European Communities and their member States (EC/MS) have argued that all countries other than Canada with regulatory review/approval-type exceptions also have patent term extension or supplementary protection certificate (SPC) systems in place for the benefit of innovative drug producers or are countries benefiting from a transitional period under the TRIPS Agreement.

(a) Can you confirm this assertion?

(b) What is its legal significance with respect to the application of Article 30 in regard of such a regulatory review/approval-type exception?

(c) Does it imply that a regulatory review/approval exception for the benefit of producers of generic drugs would be permissible under Article 30 if accompanied by patent term extension or supplementary protection certificate systems for the benefit of innovative drug producers? Please explain fully.

\title{
$\underline{\text { Reply from the EC }}$
}

1. The EC/MS have pointed out under point 24 of their oral statement to the first meeting of the Panel that "[...] all industrialised countries which have been mentioned by Canada in its first written submission [...] all these countries have a system of patent term extension [...]." This has been fully confirmed by the replies by the third parties. The more complete picture appears to be this:

United States: patent term extension and regulatory review/approval-type exception;

Japan: patent term extension and regulatory review/approval-type exception;

Australia: patent term extension and regulatory review/approval exception;

Switzerland: special protection certificate without regulatory review/approval exception;

EC/MS: special protection certificate without regulatory review/approval exception;

Canada: no patent term extension, but regulatory review/approval and manufacturing and stockpiling exception.

A number of countries mentioned by Canada and a number of third parties continue to benefit from transitional periods up to 1 January 2000, and in some instances even up to 1 January 2005 under TRIPS. These countries are Argentina, Brazil, Columbia, Cuba, Hungary, India, Israel, Poland and Thailand.

2. The existence of a patent term extension or SPC system may make Article 30 TRIPS redundant or may influence the balance of interests to be struck between the patent holder and the would-be copy producer under Article 30 TRIPS. 
3. This question is highly speculative and it is very difficult if not impossible to give a meaningful reply in the absence of precise features of the individual system. But as pointed out in the reply to question No. 17 the existence of a patent term extension or special protection certificate can influence the finding of discrimination in Article 27.1 TRIPS. As far as Article 30 TRIPS is concerned depending on the way in which the protection after the expiry of the original patent is granted and how the "Bolar-style" exception operates one could imagine a case where Article 30 TRIPS might be redundant, because there would be no violation of Article 28.1 TRIPS in the first place.

\section{Reply from Canada}

1. Although the EU's statement - in isolation - is technically correct, it is very misleading. Countries that currently enjoy a transitional period - other than less-developed countries - are nearing the end of that period, which terminates on January 1, 2000 (see TRIPS, Articles 65.2 and 65.3). Thus, within six months from now, those countries will be obligated to the full level of protection required by the TRIPS Agreement. The purpose of recent legislation in such countries, such as Argentina ${ }^{40}$, must be taken to implement, not ignore, TRIPS obligations. Moreover, in its oral statement on June 10, 1999, Thailand confirmed that legislation that is due to be enacted in September, 1999, will not alter Subsection 36(5) of its Patent Act, which - like Argentina's recent legislation - contains a regulatory approval exception but does not require patent term extension. Similarly, according to Poland's written answer dated June 18, $19 \overline{99}$, its draft law will also contain a regulatory approval exception with no patent term extension, similar to Hungary's current law. ${ }^{441}$ These developing countries and transitional economies, that are on the eve of being bound by the TRIPS Agreement, must be taken as having enacted their patent legislation in this respect in contemplation of their obligations. Moreover, none of the third parties that intervened in this dispute have argued that a regulatory approval exception had to be accompanied by patent term extension.

2. There is no nexus between Article 30 and patent term extension. Article 30 permits limited exceptions from the exclusive rights granted under Article 28. A patent term extension is an augmentation of the enjoyment of a right and not an exception, and for this reason has no relevance to the application of Article 30 .

Article 7 requires a balance of rights and obligations, and Article 30 provides the substantive means of providing that balance in the case of patents. However, as mentioned, Article 30 permits exceptions only, not amplification of rights. As there is no counterpart to Article 30 dealing with amplification of rights, it must be concluded that the balance required by Article 7 is to be achieved through limited exceptions only.

It was open to the TRIPS negotiators to make special provision for augmenting the enjoyment of patent rights in the case of products requiring time-consuming regulatory approval. By way of comparison, Article 1709(12) of the North American Free Trade Agreement, which was similarly based on the Dunkel text, expressly does so:

"Each Party shall provide a term of protection for patents of at least 20 years from the date of filing or 17 years from the date of grant. A party may extend the term of patent protection, in appropriate cases, to compensate for delays caused by regulatory approval." [Emphasis added]

Had the drafters of the TRIPS Agreement wished to provide for increased protection, they would have done so by including a provision similar to the above NAFTA provision. However, under

${ }^{440}$ December 1996. See paragraph 116 of Canada's First Written Submission.

${ }^{441}$ See paragraph 115 of Canada's First Written Submission. 
the final wording of the Agreement, term limits were as prescribed in Article 33, which does not contemplate patent term extension. Moreover, providing patent term extension for some products but not others would be contrary to Article 27.1.

In addition, patent term extension was squarely before the parties during the negotiations. Both Switzerland ${ }^{42}$ and Austria ${ }^{443}$ had made proposals for it. The fact that it was clearly raised during negotiations, but not agreed to, also indicates that the intent of the TRIPS Agreement was that such a level of protection was not required.

It is significant that four WTO Members have implemented their imminent obligations in such a way that a regulatory approval exception is not coupled with patent term extension. This indicates that, in the opinion of those Members, such an extension of patent rights was not required. Rather, in balancing private and public rights under Articles 7 and 8 - through an exception under Article 30 - there is no requirement to exceed the minimum patent term required by Article 33.

3. Please see answers to (1) and (2) above, as well as the answer to question $14 .{ }^{444}$

\section{Questions from the Panel to the Third Parties at the Third Party Meeting ${ }^{445}$}

The Panel believes that it might be important for it to take account of existing laws in other countries concerning the issues dealt with in Section 55.2(1) and (2) of the Canadian Patent Act, although it has not reached any conclusions as yet as to the relevance of such provisions to the legal questions before it. You are, therefore, kindly requested to:

${ }^{442}$ Standards and Principles Concerning the Availability, Scope and Use of Trade-Related Intellectual Property Rights: Communication from Switzerland (11 July 1989), MTN.GNG/NG11/W/38, p. 3 (reproduced as Exhibit 81).

443 Trade-Related Intellectual Property Rights: Submission by Austria (8 December 1989), MTN.GNG/NG11/W/55, paragraph 5.3 (reproduced as Exhibit 82).

${ }^{444}$ Question 14 and Canada's reply to it read as follows:

"Question 14: Canada refers to the regulatory review/approval process for drugs as an "economic distortion" (paragraphs 36 and 37 of its first written submission). Is the distortion for the innovative drug producer different in kind from the distortion for the producer of generic drugs? Please explain why or why not and the nature of the difference, if any. To the extent that Section 55.2(1) and (2) of the Canadian Patent Act address one distortion but not the other, what is the specific justification for such distinction?

Reply Canada: The circumstances facing innovators are different from those facing generic drug manufacturers. The difference is that the only factor which delays an innovator's market entry is society's requirement that it establish, to the satisfaction of the regulatory authorities, that its product is safe and effective for the use claimed. Given the potential harm that chemical substances may cause, it is difficult to characterize the delay associated with this process as being a distortion. In contrast to the innovator's position, there are two factors that delay a generic manufacturer's market entry. The first is its parallel need to demonstrate the safety and efficacy of its product to the satisfaction of the regulatory authorities. As in the case of the innovator, this delay factor is not by itself fairly described as a "distortion". The second factor which delays generic entry is the presence of an innovator's patent. In order to obtain regulatory approval, a generic manufacturer must make and use a product that will, during its term of protection, infringe an innovator's patent. Absent provisions such as those here in issue, patent owners may exercise their exclusive rights to prevent the commencement of a generic manufacturer's application for regulatory review until the relevant patent has expired. The capacity to prevent such use gives rise to distortions in the legal system which both grants those rights and imposes the relevant regulatory review requirements. The distortion arises because the rights accorded by the patent laws, which are by law supposed to expire on the conclusion of a specified term, can be exercised during their currency before their expiry to convert the requirements of the regulatory review laws, which are designed to protect public health not private commercial interests, into a de facto extension of patent rights which, under the patent law, have ceased to have any de jure existence. For obvious reasons relating to this prolongation of private commercial rights, the economic distortion referred to follows from the distortion of the legal framework defining patent rights and regulatory review requirements. Where, as explained in the foregoing, the distortion referred to only affects one side of the market, there is no distinction in policy approach that invites specific justification.

${ }^{445}$ The Panel did not receive a reply from India to these questions. 
- $\quad$ correct any inaccurate information provided, or assertions made, in the proceedings so far about provisions of your country's law;

inform the Panel of any provisions in your country's law dealing with issues comparable to those dealt with in Section 55.2(1) and (2) of the Canadian Patent Act;

inform the Panel of any provisions in your country's law establishing patent term extension or some other form of supplementary protection for inventions beyond the normal patent term.

\section{Reply from Australia}

In response to the questions posed by the Panel on 10 June 1999, while noting that third parties' laws are not at issue in the present case, we provide as background information the following material concerning Australia's legislative regime for pharmaceutical patents:

A. Extracts drawn from the Explanatory Memorandum to the Intellectual Property Laws Amendment Act 1998.

"The Intellectual Property Laws Amendment Act 1998 amended the Patents Act 1990 to give effect to the government's decision to provide for an extension of term scheme for pharmaceutical patents. The amendments entered into force on 27 January 1999 and provide that an extension of up to five years will be available for a standard patent relating to a pharmaceutical substance that is the subject of first inclusion on the Australian Register of Therapeutic Goods. The scheme will apply to all existing 20 year patents, as well as those patents granted after the commencement date.

The new arrangements also make provision for 'spring-boarding' activities. This allows manufacturers of generic drugs to undertake certain activities at any time after the extension is granted solely for the purposes of meeting pre-marketing regulatory approval requirements."

"The amended Patents Act 1990 provides an extension of term scheme for pharmaceutical patents with the following features:

- extensions of up to five years for standard patents in relation to a pharmaceutical substance that is the subject of the first registration as a therapeutic good on the Therapeutic Goods Act 1989;

- extensions being in relation to product claims for substances and for product by process claims when produced by recombinant DNA technology;

- exclusive rights during extensions limited to the use of the substances for therapeutic purposes in humans;

- allowing producers of generic drugs to engage in spring-boarding only after the extension is granted; and

- to be applied to all standard 20 year patents, as well as to patents granted on applications made on or after the commencement of the scheme." 
B. Extracts from the Patents Act 1990 as amended by the Intellectual Property Laws Amendment Act 1998.

70. Applications for extension of patent

(1) The patentee of a standard patent may apply to the Commissioner for an extension of the term of the patent if the requirements set out in subsections (2), (3) and (4) are satisfied.

(2) Either or both of the following conditions must be satisfied:

(a) one or more pharmaceutical substances per se must in substance be disclosed in the complete specification of the patent and in substance fall within the scope of the claim or claims of that specification;

(b) one or more pharmaceutical substances when produced by a process that involves the use of recombinant DNA technology, must in substance be disclosed in the complete specification of the patent and in substance fall within the scope of the claim or claims of that specification.

(3) Both of the following conditions must be satisfied in relation to at least one of those pharmaceutical substances:

(a) goods containing, or consisting of, the substance must be included in the Australian Register of Therapeutic Goods;

(b) the period beginning on the date of the patent and ending on the first regulatory approval date for the substance must be at least 5 years.

Note: Section 65 sets out the date of a patent.

(4) The term of the patent must not have been previously extended under this Division.

(5) For the purposes of this section, the first regulatory approval date, in relation to a pharmaceutical substance, is:

(a) if no pre-TGA marketing approval was given in relation to the substance- the date of commencement of the first inclusion in the Australian Register of Therapeutic Goods of goods that contain, or consist of, the substance; or

(b) if pre-TGA marketing approval was given in relation to the substance-the date of the first approval.

(6) For the purposes of this section, pre-TGA marketing approval, in relation to a pharmaceutical substance, is an approval (however described) by a Minister, or a Secretary to a Department, to:

(a) market the substance, or a product containing the substance, in Australia; or

(b) import into Australia, for general marketing, the substance or a product containing the substance.

\section{Form and timing of an application}

\section{Form of application}

(1) An application for an extension of the term of a standard patent must:

(a) be in the approved form; and

(b) be accompanied by such documents (if any) as are ascertained in accordance with the regulations; and 
(c) be accompanied by such information (if any) as is ascertained in accordance with the regulations.

For this purpose, document includes a copy of a document.

Timing of application

(2) An application for an extension of the term of a standard patent must be made during the term of the patent and within 6 months after the latest of the following dates:

(a) the date the patent was granted;

(b) the date of commencement of the first inclusion in the Australian Register of Therapeutic Goods of goods that contain, or consist of, any of the pharmaceutical substances referred to in subsection 70(3);

(c) the date of commencement of this section.

72. Notification and public inspection of application

If a patentee makes an application for an extension of the term of a standard patent, the Commissioner must publish in the Official Journal a notice that the application has been made and is open to public inspection.

73. Withdrawal of application

(1) A patentee who has applied for an extension of the term of a standard patent may, by notice in writing to the Commissioner, withdraw the application.

(2) If an application for an extension of the term of a standard patent is withdrawn, the Commissioner must publish in the Official Journal a notice stating that the application has been withdrawn.

74. Acceptance or refusal of application

Acceptance

(1) If a patentee of a standard patent makes an application for an extension of the term of the patent, the Commissioner must accept the application if the Commissioner is satisfied that the requirements of sections 70 and 71 are satisfied in relation to the application.

(2) If the Commissioner accepts the application, the Commissioner must:

(a) notify the applicant in writing of the acceptance; and

(b) publish a notice of the acceptance in the Official Journal.

Refusal

(3) The Commissioner must refuse to accept the application if the Commissioner is not satisfied that the requirements of sections 70 and 71 are satisfied in relation to the application.

(4) If the Commissioner refuses to accept the application, the Commissioner must:

(a) notify the applicant in writing of the reasons for the refusal; and 
(b) publish a notice of the refusal in the Official Journal.

75 .

Opposition to grant of extension

(1) The Minister or any other person may, in accordance with the regulations, oppose the grant of an extension of the term of a standard patent on the ground that one or more of the requirements of sections 70 and 71 are not satisfied in relation to the application for the extension. The Minister or other person may not oppose the grant of the extension on any other ground.

(2) If the grant of an extension of the term of a standard patent is opposed, the Commissioner must decide the case in accordance with the regulations.

(3) The Commissioner must give the applicant and the opponent a reasonable opportunity to be heard before deciding a case.

(4) The applicant, and any opponent, may appeal to the Federal Court against a decision of the Commissioner under this section.

\section{Grant of extension}

(1) The Commissioner must grant an extension of the term of a standard patent if:

(a) there is no opposition to the grant; or

(b) in spite of opposition, the Commissioner's decision, or the decision on appeal, is that the extension should be granted.

(2) If the Commissioner grants an extension, the Commissioner must notify the applicant in writing of the grant and publish a notice of the grant in the Official Journal.

\section{A. Notification of extension to the Secretary, Health and Family Services}

In respect of each application for an extension approved by the Commissioner under section 76 in a financial year, the patent holder must lodge with the Secretary of the Department, before the end of the following financial year, a return setting out the following information:

(a) details of the amount and origin of any Commonwealth funds spent in the research and development of the drug which was the subject of the application; and

(b) the name of any body:

(i) with which the applicant has a contractual agreement; and

(ii) which is in receipt of Commonwealth funds; and

(c) the total amount spent on each type of research and development, including preclinical research and clinical trials, in respect of the drug which was the subject of the application.

\section{Calculation of term of extension}

(1) If the Commissioner grants an extension of the term of a standard patent, the term of the extension is equal to: 
(a) the period beginning on the date of the patent and ending on the earliest first regulatory approval date (as defined by section 70) in relation to any of the pharmaceutical substances referred to in subsection 70(2);

reduced (but not below zero) by:

(b) 5 years.

Note: Section 65 sets out the date of a patent.

(2) However, the term of the extension cannot be longer than 5 years.

\section{Exclusive rights of patentee are limited if extension granted}

(1) If the Commissioner grants an extension of the term of a standard patent, the exclusive rights of the patentee during the term of the extension are not infringed:

(a) by a person exploiting:

(i) a pharmaceutical substance per se that is in substance disclosed in the complete specification of the patent and in substance falls within the scope of the claim or claims of that specification; or

(ii) a pharmaceutical substance when produced by a process that involves the use of recombinant DNA technology, that is in substance disclosed in the complete specification of the patent and in substance falls within the scope of the claim or claims of that specification;

for a purpose other than therapeutic use; or

(b) by a person exploiting any form of the invention other than:

(i) a pharmaceutical substance per se that is in substance disclosed in the complete specification of the patent and in substance falls within the scope of the claim or claims of that specification; or

(ii) a pharmaceutical substance when produced by a process that involves the use of recombinant DNA technology, that is in substance disclosed in the complete specification of the patent and in substance falls within the scope of the claim or claims of that specification.

(2) If the Commissioner grants an extension of the term of a standard patent, the exclusive rights of the patentee after the grant of the extension are not infringed by a person exploiting:

(a) a pharmaceutical substance per se that is in substance disclosed in the complete specification of the patent and in substance falls within the scope of the claim or claims of that specification; or

(b) a pharmaceutical substance when produced by a process that involves the use of recombinant DNA technology, that is in substance disclosed in the complete specification of the patent and in substance falls within the scope of the claim or claims of that specification;

solely for purposes in connection with:

(c) having goods included in the Australian Register of Therapeutic Goods, where the goods are intended for therapeutic use; or

(d) obtaining similar regulatory approval under a law of a foreign country or of a part of a foreign country. 
If:

(a) a patentee applies for an extension of the term of a standard patent; and

(b) the term of the patent expires before the application is determined; and

(c) the extension is granted;

the patentee has, after the extension is granted, the same rights to start proceedings in respect of the doing of an act during the period:

(d) commencing on the expiration of the term of the patent; and

(e) ending on the day on which the extension was granted;

as if the extension had been granted at the time when the act was done.

\section{$\underline{\text { Reply from Brazil }}$}

The Brazilian legislation has no provisions related to issues comparable to those dealt with in Section 55.2(1) and (2) of the Canadian Patent Act.

The Brazilian legislation has no provisions related to patent term extension beyond the normal patent term.

$\underline{\text { Reply from Colombia }}$

See the information from Colombia contained in part $\mathrm{V}$ of this report.

\section{$\underline{\text { Reply from Cuba }}$}

Permítame referirme a la pregunta formulada por la presidencia del Grupo Especial durante la sesión oral con las terceras partes el día 10 de junio.

Mi país desea responder, que de acuerdo a las disposiciones del Acuerdo sobre los ADPIC, se encuentra en el proceso de transición previsto para los países en desarrollo y regulado en el párrafo 2 del artículo 65, por lo cual la legislación cubana aún no cumple con todos los requerimientos de este texto de la OMC.

\section{$\underline{\text { Reply from Israel }}$}

1. The information provided by Canada is generally accurate.

2. The Isaeli Patent Law 1967 as amended to date allows pre-patent expiration activities pursuant to certain conditions. Israel does not permit stockpiling and reference to that is Section 54A(2) of the Law which is described below.

3. Israel permits patent term extension subject to certain conditions for up to five years to compensate for lost marketing time with a maximum patent term of 14 years.

The following is an unofficial translation of the relevant sections:

Exclusive rights of the patentee are set forth in Section 49(a) of the Law: "A patent holder is entitled to prevent any other person from exploiting the invention for which the patent has been granted without his permission or unlawfully, either in the manner defined in the claims or in a similar manner which - in the light of what is defined by those claims - involves the essence of the invention which is the subject-matter of the patent (hereafter "infringement"). 
Chapter One, Section 1 defines the term "exploitation of an invention", be it a product or process, as follows: "(1) in respect of an invention that is a product - any act that is one of the following: production, use, offer for sale, sale, or import for purposes of one of the said acts; (2) in respect of an invention that is a process - use of the process, and in respect of a product directly derived from the process - any act that is one of the following : production, use, offer for sale, sale, or import for purposes of one of the said acts."

Exceptions to the exclusive rights are also found in Section 1 (1-3): "(1) an act that is not on a commercial scale and is not commercial in character; (2) an experimental act in connection with the invention, the objective of which is to improve the invention or to develop another invention; (3) an act performed under the provisions of Section 54A."

Section 54A of the Law refers to experimental acts which are defined: "An experimental act, which is part of an effort to obtain a licence to market the product after the patent has lapsed, does not constitute "exploitation of an invention", if the following two conditions are met: (1) the effort to obtain a licence is made in order to obtain a licence in Israel or in a country, in which an experimental act on a patent protected invention for the purpose of obtaining a licence is permitted before the patent lapses; (2) any product produced under the terms of this Section is not used - both while the patent is in effect or thereafter - for any purpose other than obtaining a licence as aforesaid."

\section{$\underline{\text { Reply from Japan }}$}

\section{Subsection 55.2(1) and (2) of Canadian Patent Act}

Japanese Patent Law has provisions corresponding to Subsection 55.2(1) of Canadian patent Act, but has no provision corresponding to Subsection 55.2(2) thereof. Relevant provisions are Article 68 (Effects of patent right) and Article 69 (Limits of patent right). See Annex.

As our submission to the Panel, dated 10 June, 1999, says, tests aimed at development of information required to obtain marketing approval (as provided by Subsection 55.2(1) of Canadian patent Act) shall be excluded from the extent of the patent right under Article 69(1) of Japanese Patent Law. On the other hand, the manufacture and storage of the patented products without a consent of patent owner (as provided by Subsection 55.2(2) of Canadian Patent Act) does not fall within the Article 69 of Japanese Patent Law.

\section{2. $\quad$ Patent-term-extension-system}

Since 1988, Japan has the patent-term-extension-system. Relevant provision is Article 67(2) of Japanese Patent Law. See Annex.

Pursuant to Cabinet Order, patentee of pharmaceutical products and agricultural chemicals are allowed to enjoy this system.

\section{(Term of patent right)}

67(1). The term of the patent right shall be 20 years from the filing date of the patent application.

67(2). The term of the patent right may be extended, upon application for registration of an extension, by a period not exceeding five years if, because of the necessity of obtaining an approval or other disposition which is governed by provisions in laws intended to ensure safety, etc. in the working of the patented invention, and which is provided for in Cabinet Order as 
being such that, in view of the object of the relevant disposition, proceedings, etc., a considerable period of time is required for the proper action for the disposition, it was not possible to work the patented invention for two years or more.

\section{(Effects of patent right)}

68. A patentee shall have an exclusive right to commercially work the patented invention. However, where the patent right is the subject of an exclusive license, this provision shall not apply to the extent that the exclusive licensee exclusively possesses the right to work the patented invention.

\section{(Limits of patent right)}

69(1). The effects of the patent right shall not extend to the working of the patent right for the purposes of experiment or research.

69(2). The effects of the patent right shall not extend to the following:

(i) vessels or aircraft merely passing through Japan or machines, instruments, equipment or other accessories used therein;

(ii) products existing in Japan prior to the filing of the patent application.

69(3). The effects of the patent right for inventions of medicines (namely, products used for the diagnosis, cure, medical treatment or prevention of human diseases - hereinafter referred to as "medicines" in this subsection) to be manufactured by mixing two or more medicines or for inventions of processes for manufacturing medicines by mixing two or more medicines shall not extend to acts of preparing medicines in accordance with the prescriptions of physicians or dentists or to medicines prepared in accordance with the prescriptions of physicians or dentists.

\section{$\underline{\text { Reply from Poland }}$}

The provisions of the Polish Patent Law do not deal with issues comparable to those dealt with in Section 55.2(1) and (2) of the Canadian Patent Act. Neither does it provide for patent term extension or some other form of supplementary protection for inventions beyond the normal patent term (there is no "Bolar" exemption nor are there any SPC provisions under now-in-force Polish law).

As for the draft Law on Industrial Property, there is a provision providing that the following acts do not infringe a patent:

application of an invention for research and experimental purposes for its evaluation or research purposes;

using an invention, in a necessary scope, to perform acts required by the law for registration or approval being a condition for allowing some products for trade in regard to their designation, in particular pharmaceutical products.

No "stockpiling" exception is foreseen under the draft Law.

\section{$\underline{\text { Reply from Switzerland }}$}

See the information from Switzerland contained in part V of this report. 
WT/DS114/R

Page 210

\section{Reply from Thailand}

The legislation concerned is Thailand's Patent Act B.E. 2522 (1979), as amended by the Patent Act (Number 2) of B.E. 2535 (1992). Section 36(5) thereof stipulates that any act in respect of applications for drug registration with the intent to produce, sell or import patented pharmaceutical products after the patent has expired shall not constitute an act of infringement. Under this legislation, there is no provision for extending the patent protection term beyond the normal term, which under Section 35 shall be 20 years.

\section{$\underline{\text { Reply from the United States }}$}

1. Canada's description of United States law in its First Written Submission is inaccurate. The US FDA does not require the production of three commercial-scale batches as a precondition for obtaining marketing approval. See Third Party Oral Statement of the United States, p. 13 (June 10, 1999).

2. United States law contains a balanced pre-expiration testing exception: 35 U.S.C. § 271(e). Certain aspects of Section 271(e) differ from Section 55.2(1) of the Canadian Patent Act. U.S. law contains no exception to patent rights for stockpiling. In other words, there is no exception comparable to Section 55.2(2) of the Canadian law.

3. United States law provides for patent term restoration: 35 U.S.C. $\S 156$. Both Sections 156 and 271(e) of Title 35 were enacted in 1984 in the Drug Price Competition and Patent Term Restoration Act. 98 Stat. 1585. 


\title{
ANNEX 6 \\ EXCEPTIONS TO RIGHTS CONFERRED BY A PATENT: SUCCESSIVE URUGUAY ROUND NEGOTIATING DRAFTS
}

\author{
Note prepared by the Secretariat for the Panel
}

The negotiation of the TRIPS Agreement on the basis of draft legal texts was initiated in the spring of 1990 on the basis of five draft legal texts submitted to the Uruguay Round Negotiating Group on TRIPS - by the European Communities, the United States, Japan, Switzerland, and 15 developing countries. These texts were first put by the Secretariat into a composite draft text, dated 12 June 1990. Following intensive consultations, the Chair issued a revised text on 23 July 1990 (MTN.GNG/NG11/W/76). Successive revised Chairman's texts were issued thereafter following successive rounds of consultations. The various formulations appearing in these texts for what subsequently became Article 30 of the TRIPS Agreement are reproduced below.

\section{COMPOSITE DRAFT TEXT}

(Informal Note No. 1404 of 12 June 1990) $)^{446}$

\section{$\underline{\text { Paragraph III.5.3.2 }}$}

\section{"(Exceptions to Rights Conferred)}

"Limited exceptions to the exclusive rights conferred by a patent may be made for certain acts, such as rights based on prior use, acts done privately and for non-commercial purposes and acts done for experimental purposes, provided that they take account of the legitimate interests of the proprietor of the patent and of third parties." ${ }^{447}$

\section{CHAIRMAN'S TEXT OF 23 JULY 1990}

(Document MTN.GNG/NG11/W/76 of 23 July 1990)

\section{Section III.5.2.2}

\section{"Exceptions to Rights Conferred}

"2.2 [Provided that legitimate interests of the proprietor of the patent and of third parties are taken into account,] limited exceptions to the exclusive rights conferred by a patent may be made for certain acts, such as:

2.2.1 Rights based on prior use.

2.2.2 Acts done privately and for non-commercial purposes.

2.2.3 Acts done for experimental purposes.

2.2.4 Preparation in a pharmacy in individual cases of a medicine in accordance with a prescription, or acts carried out with a medicine so prepared.

${ }^{446}$ See the Appendix to this Annex.

${ }^{447}$ This language was drawn from the draft TRIPS Agreement proposed by the European Communities (MTN.GNG/NG11/W/68). None of the other draft legal texts contained a corresponding provision. 
WT/DS114/R

Page 212

2.2.5A Acts done in reliance upon them not being prohibited by a valid claim present in a patent as initially granted, but subsequently becoming prohibited by a valid claim of that patent changed in accordance with procedures for effecting changes to patents after grant.

2.2.6B Acts done by a government for purposes merely of its own use."

CHAIRMAN'S TEXT OF 1 OCTOBER 1990

(Informal Note No. 2341 of 1 October 1990)

\section{Section III.5.4}

"Exceptions to Rights Conferred

"4.1 PARTIES may provide limited exceptions to the exclusive rights conferred by a patent, provided that such exceptions do not conflict with a normal exploitation of the patent and do not unreasonably prejudice the legitimate interests of the patent owner."

CHAIRMAN'S TEXT OF 25 OCTOBER 1990

(Informal Note No. 2613 of 25 October 1990)

\section{"Article 31: Exceptions to Rights Conferred}

"PARTIES may provide limited exceptions to the exclusive rights conferred by a patent, provided that such exceptions do not unreasonably conflict with a normal exploitation of the patent and do not unreasonably prejudice the legitimate interests of the patent owner and of third parties."

\section{CHAIRMAN'S TEXT OF 13 NOVEMBER 1990}

(Informal Note No. 2814 of 13 November 1990)

"PARTIES may provide limited exceptions to the exclusive rights conferred by a patent, provided that such exceptions do not unreasonably conflict with a normal exploitation of the patent and do not unreasonably prejudice the legitimate interests of the patent owner, taking account of the legitimate interests of third parties."

The text remained the same in the Chairman's texts of 20 November 1990 (No. 2870) and 22 November 1990 (No. 2909) as well as in the text that was forwarded to the Brussels Ministerial Conference (document MTN.TNC/W/35/Rev.1 of 3 December 1990). It is also the text contained in the Draft Final Act Embodying the Results of the Uruguay Round of Multilateral Trade Negotiations of 20 December 1991 (MTN.TNC/W/FA) and, apart from referring to "Members" instead of "PARTIES", that contained in the TRIPS Agreement. 


\section{$\underline{\text { APPENDIX }}$}

In parallel with the 1990 negotiations in the Uruguay Round Negotiating Group on TRIPS, work was taking place in WIPO in a Committee of Experts on the Harmonization of Certain Provisions in Laws for the Protection of Inventions by way of preparation for a draft patent law harmonization treaty. While the texts being developed in WIPO were not circulated officially in the Negotiating Group on TRIPS, the Negotiating Group was kept informed by the WIPO representative of developments in that work. The draft text dealing with exceptions to patent rights that was under consideration in the WIPO work at that time was contained in Articles 19 and 20 of a draft prepared by the International Bureau of WIPO (HL/CE/VIII/3) dated 15 February 1990. The texts in question read as follows:

"[...]

"Article 19(3)(a). Notwithstanding paragraphs (1) and (2), any Contracting Party shall be free to provide that the owner of a patent has no right to prevent third parties from performing, without his authorization, the acts referred to in paragraphs (1) and (2) in the following circumstances:

(i) where the act concerns a product which has been put on the market by the owner of the patent, or with his express consent, insofar as such an act is performed after that product has been so put on the market in the territory of that Contracting Party, or, in the case of a group of States constituting a regional market, in the territory of one of the member States of such group;

(ii) where the act is done privately and on a non-commercial scale, provided that it does not significantly prejudice the economic interests of the owner of the patent;

(iii) where the act consists of making or using for exclusively experimental purposes, provided that it does not significantly prejudice the economic interests of the owner of the patent;

(iv) where the act consists of the preparation for individual cases, in a pharmacy or by a medical doctor, of a medicine in accordance with a medical prescription or acts concerning the medicine so prepared.

"Article 19(3)(b). The provisions of paragraphs (1) and (2) shall not be interpreted as affecting the freedom that Contracting Parties have under the Paris Convention for the Protection of Industrial Property to allow, under certain circumstances, the performance of acts without the authorization of the owner of the patent.

"[...]

"Article 20(1). Any Contracting Party may provide that a patent shall, notwithstanding Article 19, have no effect against any person (hereinafter referred to as "the prior user") who in good faith before the filing date or, where priority is claimed, the priority date of the application on which the patent is granted and within the territory where the patent produces its effect was using the invention or was making effective and serious preparations for such use; any such person shall have the right, for the purposes of his business, to continue such use or to use the invention as envisaged in such preparations. 
WT/DS114/R

Page 214

"Article 20(2). The right of the prior user may only be transferred or devolve together with his enterprise or business in which the use or preparations for use have been made." 